

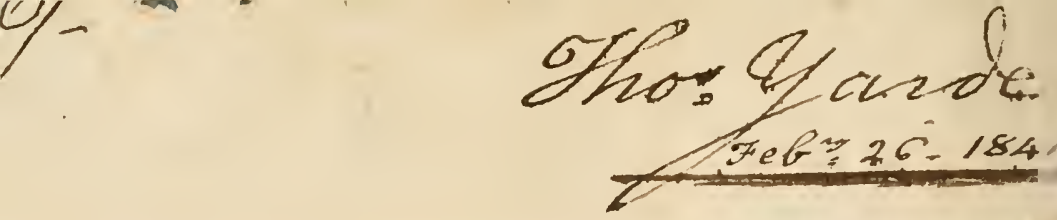

+QK45

. 55

1809

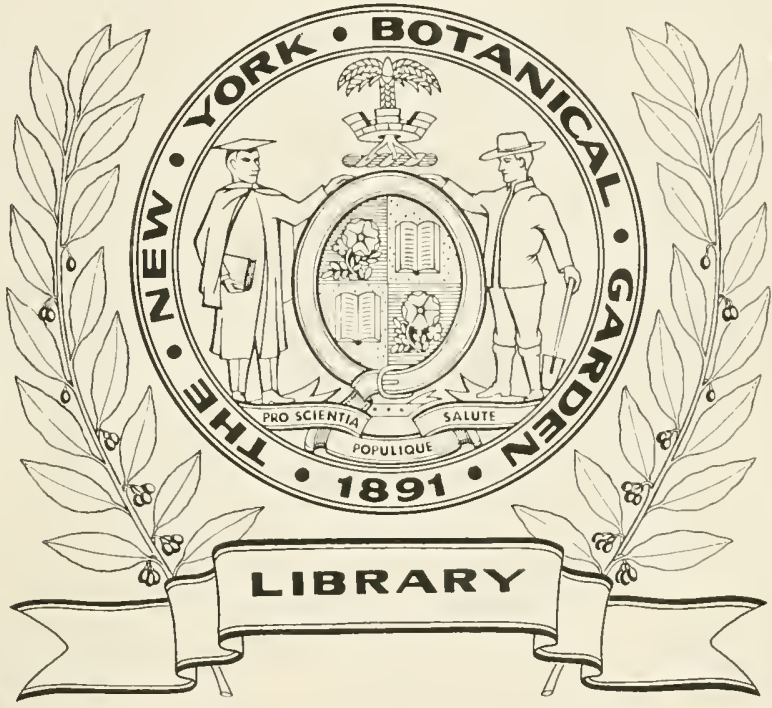





\section{$A \mathrm{~N}$ \\ INTRODUCTION}

To

\section{PHYSIOLOGICAL AND SYSTEMATICAL}

\section{BOTANY.}

BY

JAMES EDWARD SMITH, M.D. F.R.S.

\&c. \&c.

PRESIDENT OF THE LINNAAN SOCIETY.

"CONSIDER THE LILIES OF THE FIELD, HOW THEY GROW."

SECOND EDITION.

\section{LIBRARY}

NEW YONK

POTANBCAL

\section{Zlondon: LARUEN.}

PRINTED FOR

LONGMAN, HURST, REES, AND ORME, PATERNOSTER ROW; AND J. WHITE, FLEET-STRELT. 
Printed by fichard Taylor and Co. Shoe-Lane. 
TIE HONOURABLE AND RIGHT REVEREND

\section{S II U'T E,}

\section{LORD BISHOP OF DURHAM.}

\section{My Lord,}

THE circunstances which induce me to solicit your Lordship's protection for the following pages are such, that I trust they will ensure pardon for myself, and more indulgence for my performance than I might expect, even from your Lordship's usual goodness towards me.

The contents of these pages were, in a very unfinished state, honoured with the approbation and encouragement of an excellent and lamented lady, to whom they were destined to be offered in their present less unworthy condition. I should have been proud to have

- sheitered them under her patronage, because I have always found the most intelligent critics the most indulgent. Their general tendency at least, as calculated to render an 
interesting and useful science accessible, and in every point eligible, to the more accomplished and refined of her own sex, could not fail to have been approved by her, who knew and exemplified so well the value and importance of such pursuits, and their inestimable effects upon the mind. These hopes, which my late hanoured friend and patroness had, with her usual benignity, encouraged, are now most unhappily defeated, and I have no resource but in your Lordship, who is no stranger to my pretensions, nor to my sentiments, and in whom I have not now for the first time to seek an able and enlightened patron. I remain,

with the profoundest respect,

$$
\text { my Lord, }
$$

your Lordship's most obliged and obedient servant,

$$
\text { J. E. SMITH. }
$$

Norwich, Nov. 15, 1807. 


\section{PREFA C E.}

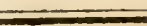

After the many elementary works on Botany which have appeared in various languages, any new attempt of the same kind may, at first sight, seem unnecessary. But when we consider the rapid progress of the science within a few years, in the acquisition and determination of new plants, and especially the discoveries and in provements in regetable physiology: when we reflect on the views with which those fundamental works of Linnæus, the basis of all following ones, were composed, and to whom they were addressed, we must be aware of their unfitness for purposes of general and popular utility, 
and that something else is wanting. If we examine the mass of introductory books on botany in this light, we shall find them in some cases too elaborate and intricate, in others too obscure and imperfect: they are also deficient in that very pleasing and instructive part of botany the anatomy and physiology of plants. There are indecd works, such as Rose's Elcments of Botamy, and Darwin's Phytologia, with which no such faults can be found. The former is a compendium of Limnæan learning, the latter a store of ingenious philosophy; but they were designed for philosophers, and are not calculated for every reader. Linnæus and his scholars have generally written in Latin. They addressed themselves to physicians, to anatomists, to philosophers, little thinking that their science would ever be the amusing pursuit of the young, the elegant and the refined, or they would 
have treated the subject differently. It appears to me, therefore, that an introductory publication is still desirable in this country, on an original plan, easy, comprehensive, and fit for general use, and such were the reasons which first prompted me to the undertaking.

When, however, I had proceeded a considerable way in its execution, I found that such a work might not only serve to teach the first outlines of the science, but that it might prove a vehicle for many observations, criticisms, and communications, scarcely to be brought together on any other plan; nor did it appear any objection to the general use of the book, that, besides its primary intention, it might be capable of leading into the depths of botanical philosophy, whether physiological, systematical, or critical, any student who should be desirous of proceeding so far. A volume of this size can indeed be but 
elementary on subjects so extensive; but if it be clear and intelligible as far as it goes, serving to indicate the scope of the science of botany, and how any of its branches may be cultivated further, my purpose is answered. 'The subject has naturally led me to a particular criticism of the Linnæan system of arrangement, which the public, it seems, has expected from me. Without wasting any words on those speculative and fanciful changes, which the most ignorant may easily make, in an artificial system; and without entering into controversy with the very few competent writers who have proposed any alterations; I have simply stated the result of my own practical observations, wishing by the light of experience to correct and to confirm what has been found useful, rather than rashly to overthrow what perbaps cannot on the whole be improved. 
As the discriminating characters of the Linnæan system are founded in nature and fact, and depend upon parts essential to every species of plant when in perfection; and as the application of them to practice is, above all other systems, easy and intelligible; I conceive nothing more useful can be done than to perfect, upon its own principles, any parts of this systcin that experience may show to have been originally defective. This is all I presume to do. Speculative alterations in an artificial system are endless, and scarcely answer any more useful purpose than changing the order of letters in an alphabet. 'Ihe philosophy of botanical arrangement, or the study of the natural affinities of plants, is quite another matter. But it would be as idle, while we pursue this last-mentioned subject, so deep and so intricate that its most able cultivators are only learners, to lay aside 
the continual use of the Linnæan system, as it would be for philologists and logicians to slight the convenience, and indeed necessity, of the alphabet, and to substitute the Chinese character in its stead. If the following pages be found to elucidate and to confirm this comparison, I wish the student to keep it ever in view.

The illustration of the Linnæan system of classification, though essential to my purpose, is however but a small part of my aim. 'T'o explain and apply to practice those beautiful principles of method, arrangement and discrimination, which render botany not merely an amusement, a motive for taking air and exercise, or an assistance to many other arts and sciences; but a school for the mental powers, an alluring incitement for the young mind to try its growing strength, and a confirmation of the most enlightened understand- 
ing in some of its sublimest most important truths. That every path tending to ends so desirable may be accessible, I have not confined myself to systematical subjects, wide and various as they are, but I have introduced the anatony and physiology of plants to the botanical student, wishing to combine all these several objects; so far at least that those who do not cultivate them all, may be sensible of the value of each in itself, and that no disgraceful rivalship or contempt, the offspring of ignorance, may be felt by the pursuers of any to the prejudice of the rest.

I have treated of physiological and anatomical subjects in the first place, because a true knowledge of the structure and parts of plants seems necessary to the right understanding of botanical arrangement; and I trust the most superficial reader will bere find enough for that pur- 
pose, even though he should not be led to pursue these subjects further by himself. I have every where aimed at familiar illustrations and examples, referring, as much as possible, to plants of easy acquisition. In the explanation of botanical terms and characters, I have, besides furnishing a new set of plates with references to the body of the work, always cited a plant for my purpose by its scientific name, with a reference to some good and sufficient figure. For this end I have generally' used either my own works English and Exotic Botany, all the plates of which, as well as of the present volume, are the performance of the same excellent botanist as well as artist; or Curtis's Magazine, much of which also was drawn by Mr. Sowerby. I have chosen these as the most comprehensive and popular books, quoting others only when these failed me, or when I had some 
particular end in view. If this treatise should be adopted for general use in schools or families, the teacher at least will probably be furnished with those works, and will accommodate their contents to the use of the pupils. I am aware of the want of a systematical English description of British plants, on the principles of this Introduction; but that deficiency I hope as soon as possible to supply. In the mean while Dr. Withering's work may serve the desired purpose, attention being paid only to his original descriptions, or to those quoted from English writers. His index will atone for the changes I cannot approve in his system. Wherever my book may be found deficient in the explanation of his or any other terms, as I profess to retain only what are necessary, or in some shape useful, the Language of Botany, by Pro- 
fessor Martyn, will prove extremely serviceable.

Having thus explained the use and intention of the present work, perhaps a few remarks on the recommendations of the study of Botany, besides what have already been suggested, may not here be misplaced.

I shall not labour to prove how delightful and instructive it is to

"Look through Nature up to Nature's God."

Neither, surely, need I demonstrate, that if any judicious or improved use is to be made of the natural bodies around us, it must be expected from those who discriminate their kinds and study their properties. Of the benefits of natural science in the improvement of many arts, no one doubts. Our food, our physic, our luxuries are improved by it. By the inquiries of the curious new acquisitions 
are made in remote countries, and our resources of various kinds are augmented. 'The skill of Linnaus by the most simple observation, founded lowever on scientific principles, taught his countrymen to destroy an insect, the Cantharis navalis, which had cost the Swedish goverument many thousand pounds a year by its ravages on the timber of onc dockyard only. After its metamorphoses, and the season when the fly laid its egrgs, were known, all its ravages were stopped by immersing the timber in water during that period. The same great observer, by his botanical knowledge, detected the cause of a dreadful discase among the lorned cattle of the north of Lapland, which had previously been thought equally unaccountable and irrensediable, and of which he has given an cxquisite account in his Lapland tour, as well as under Cicuta virosa, Engl. Bot. t. 479, in his Flora Lapponica. One man 
in our days, by his scientific skill alone, has given the bread-fruit to the WestIndies, and his country justly honours his character and pursuits. All this is acknowledged. We are no longer in the infancy of science, in which its utility, not having been proved, might be doubted, nor is it for this that I contend. I would recommend botany for its own sake. I have often alluded to its benefits as a mental exercise, nor can any study exceed it in raising curiosity, gratifying a taste for beauty and ingenuity of contrivance, or sharpening the powers of discrimination. What then can be better adapted for young persons? The chief use of a great part of our education is no other than what I have just mentioned. The languages and the mathematics, however valuable in themselves when acquired, are even more so as they train the youthful mind to thought and observation. In 
Sweden Natural History is the study of the schools, by which men rise to prefermerit; and there are no people with more acute or better regulated minds than the Sivedes.

T'o those whose minds and understandings are already formed, this study nuy be recommended, independently of all other considerations, as a rich source cí innocent pleasure. Some people are ever inquiring "what is the use" of any particular plant, by which they mean "what food or physic, or what materials for the painter or dyer does it afford?" 'They look on a beautiful flowery neadow with admiration, only in proportion as it aflords nauseous drugs or salves. Others consider a botanist with respect only as he may be able to teach them some profitable improvement in tanning, or dyeing, by which they may quickly grow rich, and be then perhaps no longer of any use to 
mankind or to themselves. They would permit their children to study botany, only because it might possibly lead to professorships, or other lucrative preferment.

These viers are not blameable, but they are not the sole end of human existence. Is it not desirable to call the soul from the feverish agitation of worldly pursuits, to the contemplation of Divine Wisdom in the beautiful cconony of Nature? Is it not a privilege to walk with God in the garden of creation, and hold converse with his providence? If such elevated feelings do not lead to the study of Nature, it cannot far be pursued without rewarding the student by exciting them.

Rousseau, a great judge of the human heart and observer of human manners, has remarked, that "when science is transplanted from the mountains' and woods into cities and worldly society, it 
loses its genuine charms, and becones a source of cnvy, jealousy and rivalship." 'This is still more true if it be cultivated as a mere source of emolument. 13ut the man who loves botany for its own sake knows no such feelings, nor is he dependent for happiness on situations or scenes that farour their growth. He would fird himself neither solitary nor desolate, had he no other companion than a " mountain claisy," that "modest crimson-tipped flower," so sweetly sung by one of $\mathrm{Na}$ ture's own poets. The humblest weed or moss will ever afford him something to examine or to illustrate, and a great deal to adinire. Introduce lim to the magnificence of a tropical forest, the enamelled meadows of the Alps, or the wonders of New Holland, and his thoughts will not dwell much upon riches or literary honours, things that

5. Play round the head, but come not near the heart." 
One idea is indeed worthy to mix in the pure contemplation of Nature, the anticipation of the pleasure we may have to bestow on kindred minds with our own, in sharing with them our discoveries and our acquisitions. This is truly an object worthy of a good man, the pleasure of communicating virtuous disinterested placasure to those who have the same tastes with oursclres; or of guiding young ingenuous minds to worthy pursuits, and facilitating their acquisition of what we have already obtained. If honours and respectfinl consideration reward such motives, they flow from a pure source. 'The giver and the receiver are alike invulnerable, as well as inaccessible, to "cnry, jealousy or rivalship," and may pardon their attacks without an effort.

The natural history of animals, in many respects even more interesting than botany ho man as an anmated being, and more 
striking in some of the phanomena which it displays, is in other points less pleasing to a tender and delicate mind. In botany all is clegance and delight. No painful, disgusting, unhealthy experiments or inquiries are to be made. Its pleasures spring up under our fect, and, as we pursue them, reward us with health and serene satisfaction. None but the most foolish or depraved could derive any thing from it but what is beautiful, or pollute its lovely scencry with unamiable or unhallowed inages. Those who do so, cither from corrupt taste or malicious design, can be compared only to the fiend cntering into the garden of Eden.

Let us turn fiom this odious picture to the contemplation of Nature, ever new, ever abundant in inexhaustible variety. Whether we scrutinize the damp recosses of woods in the wint:y montlis, when the numerous tribes of mosses are displaying 
their minute, but highly interesting structure; whether we walk forth in the early spring, when the ruby tips of the hawthorn-bush give the first sign of its approaching vegetation, or a little after, when the violet welcomes us with its scent, and the primrose with its beauty; whether we contemplate in succession all the profuse flowery treasures of the summer, or the more hidden sccrets of Nature at the season when fruits and seeds are forming; the most familiar objects, - like old fricnds, will always afford us something to study and to admire in their characters, while ilew discoveries will awaken a train of new jdeas. The yellow blossoms of the morning, that fold up their delicate leaves as the day advances; others that court and sustain the full blaze of noon; and the pale night-scented tribe, which cxpand, and dituse their very sweet fragrance, towards evening, will all plcase in their 
turn. Though spring is the season of hope and novelty, to a naturalist more especially, yet the wise provisions and abundant resources of Nature, in the close of the year, will yield an observing mind no less pleasure, than the rich variety of her autumnal tints affords to the admirers of her external charms. The more we study the works of the Creator, the more wisdom, beauty and harmony become manifest, eren to our limited apprehensions; and while we admirc, it is impossible not to adore.

"Soft roll your incense, herbs, and fruits, and flowers, In mingled clouds, to Him, whose sun exalts, Whose breath perfumes you, and whose pencil paints!" 

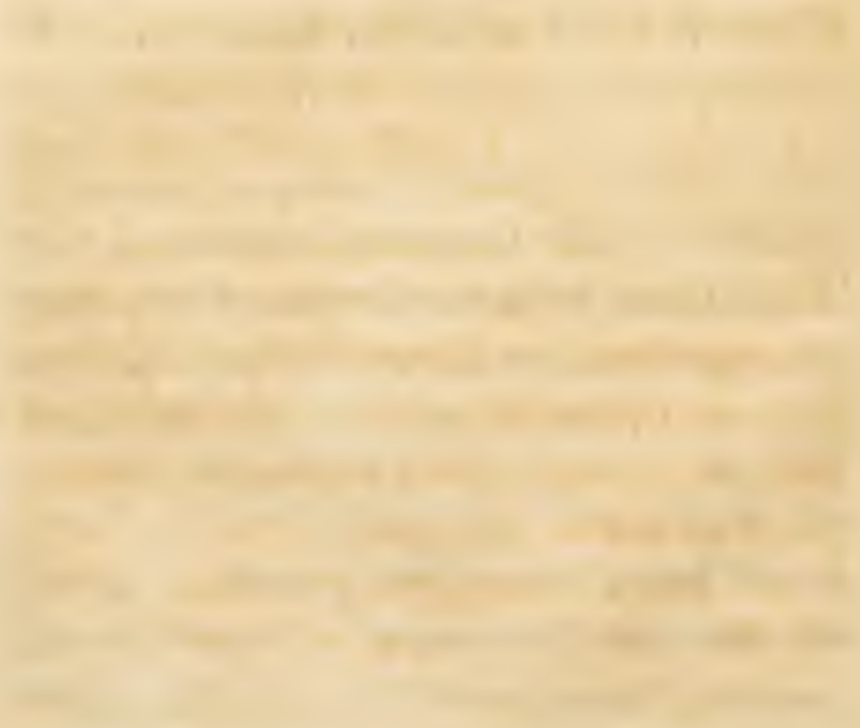


\section{INTRODUCTION}

To

PHYSIOLOGICAL AND SYSTEMATICAL

\section{BOTANY.}

\section{CHAPTER I.}

DISTINCTIONS BETWEEN ANIAALS, VEGETABLES, AND FOSSTLS.-ON TII VITAL PRINCIPLE ESSENTIA, TO THE TWO FORMER.

THose who with a philosophical eye have $_{\text {Ho }}$ contemplated the productions of Nature, have all, by common consent, divided them into three great classes, called the Animal, the Vegetable, and the Mineral or Fossil Kingdoms. These terms are still in general use, and the most superficial observer 
must be struck with their propriety. The application of then seems at first sight perfectly easy, and in general it is so. Difficulties occur to those only who look rery deeply into the subject.

Animals have an organized structure which regularly unfolds itself, and is nourrished and supported by air and food; they consequently possess life, and are subject to death; they are moreover endowed with sensation, and with spontaneous, as well as roluntary, motion.

Vegetables are organized, supported by air and food, endowed with life and subject to death as well as anmals. They have in some instances spontaneous, though we know not that they have roluntary, motion. They are sensible to the action of nomishment, air, and light, and either thrive or languish according to the wholesome or hurtful application of these stimulantg. This is evident to all who have ever seen a plant growing in a climate, soil, or situation, not suitable to it. Those who have ever gathered a rose, know but two well how soon it withers; and the 
familiar application of its fate to that of human life and beauty is not more striking to the imagination than philosophically and literally true. The sensitive plant is a more astonishing example of the capability of vegetables to be acted upon as living bodies. Other instances of the same kind we shall hereafter have occasion to mention.

The spontaneous movements of plants are almost as readily to be observed as their living principle. The general direction of their branches, and especially of the upper surface of their leaves, though repeatedly disturbed, to the light; the unfolding and closing of their flowers at stated times, or according to favourable or unfavourable circumstances, with some still more curious particulars to be explained in the sequel of this work, are actions undoubtedly depending on their vital principle, and are performed with the greater facility in proportion as that principle is in its greatest vigour. Hence arises a question whether Vegetables are endowed with sensation. As they possess life, irritability and motion, spontancously directing theip organs to what is natural and 
beneficial to them, and flourishing according to their success in satisfying their wants, may not the exercise of their vital functions be attended with some degree of sensation, however low, and some consequent share of happiness? Such a supposition accords with all the best ideas we can form of the Divine Creator; nor could the consequent uneasiness which plants must suffer, no doubt in a very low degree likewise, from the depredations of animils, bear any comparison with their enjoyment on the whole. Howerer this may be, the want of scnsation is most certainly not to be proved with regard to Vegctables, and therefore of no use as a practical means of distinguishing them, in doubtful cases, from Animals.

Some philosophers* have made a locomotive power peculiarly characteristic of Animals, not being aware of the true nature of those half-animated beings called Corals and Corallines, which are fixed, as immoveably as any plants, to the bottom of the sea, while indeed many living regetables swim around

*- Jungius, Roerhiaarc, Ludwig and many others. 
them, unattached to the soil, and nourished by the water in which they float. Some have characterized Animals as nourished by their internal, and Vegetables by their external surface, the latter having no such thing as an internal stomach. This is ingenious and tolerably correct; but the proofs of it must: fail with respect to those minute and simplyconstructed animals the Polypes, and the lower tribes of Worms, whose feclers, put: forth into the water, seem scarcely different from roots seeking their food in the earth, and some of which may be turned inside out, like a glore, without any disturbance of their ordinary functions. The most satisfactory remark I have for a long time met with on this difficult subject is that of M. Mirlsel, in his Traité d'Anatomie et de Physiologie Végétalest', a work I shall often have occasion to quote. He observes, vol.I. p. 19, "that plants alone have a power of deriving nourishment, though not indeed exclusirely, from

* Dr. Alston, formerly professor of botany at Edinburgh.

+ Published at Paris two or three years since, in two vols. 8 vo. 
inorganic matter, mere earths, salts or airs, substances certainly incapable of serving as food for any animals, the latter only fceding on what is or has been organized matter, either of a regetable or animal nature. So that it should seem to be the office of vegetable life alone to transform dead matter into organized living bodies." This idea appears to me so just, that I have in vain sought for any exception to it.

Let us however descend from these philosophical speculations to purposes of practical utility. It is sufficient for the young student of Natural History to know, that in every case in which he can be in doubt whether he has found a plant or one of the lower orders. of animals, the simple experiment of burning will decide the question. The smell of a burnt bone, coralline, or other animal substance, is so peculiar that it can never be mistaken, nor does any known vegetable give out the same odour.

The Mineral Kingdom can never be confounded with the other two. Fossils are masses of mere dead unorganized matter, subject to the laws of chemistry alone; grow 
ing indeed, or increasing by the mechanical addition of extraneous substances, or by the laws of chemical attraction, but not fod by nourishment taken into an organized structure. Their curious crystallization bears some resemblance to organization, but performis none of its functions, nor is any thing like a vital principle to be found in this department of Nature.

If it be asked what is this vital principle, so essential to animals and vegetables, but of which fossils are destitute, we must own our complete ignorance. We know it, as we know its Omnipotent Author, by its effects.

Perliaps in the fossil kingdom heat may be equivalent to a vital principle; but heat is not the vital principle of organized bodies, though probably a consequence of that principle.

Living bodies of animals and plants produce heat; and this phrnomenon has not; I think, been-entirely explained on any chemical principles, though in fossils the production of heat is in most cases tolerably well accounted for. In animals it seems to have the closest possible connexion with the vital energy. But the 
effects of this vital energy are still more stupendous in the operations constantly going on in every organized body, from our own elaborate frame to the humblest moss or fungus. Those different fluids, so fine and transparent, separated from each other by membranes as fine, which compose the eye, all retain their proper situations (though each fluid individually is perpetually removed and renewed) for sixty, eighty, or a hundred years, or more, while life remains. So do the infinitely small vessels of an almost invisible insect, the fine and pellucid tubes of a plant, all hold their destined fluids, conveying or changing them according to fixed laws, but never permitting them to run into confusion, so long as the vital principle animates their various forms. But no sooner does death happen, than, without any alteration of structure, any apparent change in their material configuration, all is reversed. The eye loses its form and brightness; its membranes let go their contents, which mix in confusion, and thenceforth yield to the laws of chemistry alone. Just so it happens, sooner or later, to the other parts of the animal as well as vegetable frame. Chemical changes, 
putrefaction and destruction, immediately follow the total privation of life, the importance of which becomes instantly evident when it is no more. I humbly conceive therefore, that if the human understanding can in any case flatter itself with obtaining, in the natural world, a glimpse of the immediate agency of the Deity, it is in the contemplation of this rital principle, which seems independent of material organization, and an impulse of his own divine energy. 


\section{CHAPTER II.}

DEFINITION OF NATURAL HISTORY, AND PARTICULARLY BOTANY.-OF THE GENERAL TEXTURE OF PLANTS.

Natural History properly signifies that study by which we learn to distinguish from one another the natural bodies, whether Animal, Vegetable or Mineral, around us; to discover as much as possible their nature and properties, and especially their natural dependence on each other in the general scale of beings. In a more extensive sense it may be said to teach their secondary properties, or the various uses to which they have been, or may be, converted, in the service of mankind or of other animals; inasmuch as an acquaintance with their natural qualities is our only sure guide to a knowledge of their artificial uses. But as this definition would in- 
clude many arts and sciences, each of them sufficient to occupy any common.mind, as Agriculture, Dietetics, Medicine, and many others, it is sufficient for a philosophical naturalist to be acquainted with the general principles upon which such arts and sciences are founded.

That part of Natural History which concerns plants is called Botany, from Borón, the Greek word for a herb or grass. It may be divided into three branches; 1st, The physiology of plants, or a knowledge of the structure and functions of their different parts;? $\mathrm{dly}$, The systematical arrangernent and denomination of their several kinds; and 3dly, Their aconomical or medical properties. All these objects should be kept in riew by an intelligent botanist. The two first are of essential service to each other, and the last is only to be pursued, with any certainty, by such as are versed in the other two. The present publication is intended to explain the fundamental principles of them all, with as much practical illustration as may be necessary for those who wish to become well acquainted with this delightful science. Botany has one 
advantage orer many other useful and necessary studies, that even its furst beginnings are pleasing and profitable, though pursued to ever so small an extent; the objects with which it is conversant are in themselves charming, and they become doubly so to those who contemplate them with the additional sense, as it were, which science gives; the pursuit of these objects is an exercise no less healthful to the body, than the observation of their laws and characters is to the mind.

In studying the functions of the Vegetable fiame, we must constantly remember that it is not merely a collection of tubes or vessels holding different fluids, but that it is endowed with life, and consequently able not only to imbibe particular fluids, but to alter their nature according to certain laws, that is, to form peculiar secretions. This is the exclusive property of a living being. Animals secrete milk and fat from food which has no resemblance to those substances; so Vegetables secrete gum, sugar, and various resinous substances fiom the uniform juices of the earth, or perhaps from mere water and air. Tire 
most different and discordant fluids, separated only by the finęst film or membrane, are, as we have already observed, kept perfectly distinct, while life remains; but no sooner does the vital principle depart, than secretion, as well as the due preservation of what has been secreted, are both at an end, and the principle of dissolution rejows absolute.

Pefore we can examine the physiology of regetables, it is necessary to acquire some idea ot their structure.

Much light has been thrown upon the general texture of Vegetables by the microscopic figures of Grew, Mialpighi and others, repeated by Dr. 'Thornton in his Illistration of the Linnxan System, but more especiall: by the recent observations and highly magnified dissections of M. Mirbel. See his Table of Vegetable Anatomy in the work already mentioned. From preceding writers we had learned the general tubular or rascular structure of the regetable bocly, and the existence of some peculiar spirally-coated vessels in many plants. On these slender foundations physiologists have, at their plea- 
sure, constructed various theories, relative to the motion of the sap, respiration and other functions, presumed to be analogous to those of animals. The anatomical observations of Mirbel go further than those of Grew, \&c., and it is necessary to give a short account of his discoveries.

He finds, by the help of the highest magnifying powers, that the regetable body is a continued mass of tubes and cells; the former extended indefinitely, the latter frequently and regularly interrupted by transverse partitions. These partitions being ranged alternately in the corresponding cells, and each cell increasing somewhat in diameter after its first formation, except where restrained by the transverse partitions, seems to account for their hexagonal figure* ${ }^{*}$. See Tab. I. $f$. $a$. The membranous sides of all these cells and tubes are very thin, more or less transparent, often porous, variously perforated or torn. Of the tubes, some are without any lateral perforations, $f . b$, at least for a considerable extent; others pierced with holes ranged in a

* In microscopic figures thej are generally drawn like circles intcrsecting each other. 
close spiral line, f. $c$; in others several of these holes run together, as it were, into interrupted spiral clefts, $f . d$; and in some those clefts are continued, so that the whole tube, more or less, is cut into a spiral line, f.e; which, in some young branches and tender leaves, will unroll to a great extent, when they are gently torn asunder. The cellular texture especially is extended to every part of the regetable body, even into the thin skin, called the cuticle, which corers every exterial part, and into the fine hairs or down which, in some instances, clothe the cuticle itself.

Before we offer any thing upon the supposed functions of these different organs, we shall take a general view of the Vegetable body, beginning at the external part and proceeding inwards. 


\section{CHAPTER III。}

OF THE CUTICLE OR EPIDERMIS.

$\mathrm{E}_{\mathrm{VERY}}$ part of a living plant is covered with a skin or membrane called the cuticle, which same denomination has been given by anatomists to the scarf skin that corers the animal body, protecting it from the injuries of the air, and allowing of due absorption and perspiration through its pores.

There is the most striking analogy between the animal and the regetable cuticle. In the former, it varies in thickness from the exquisitely delicate film which covers the eye, to the hard skin of the hand or foot, or the far coarser covering of a Tortoise or Rhinoceros; in the latter it is equally delicate on the parts of a flower, and scarcely less hard on the leares of the Pearly Aloe, or coarse on the trunk of a Plane tree. In the numerous layers 
of this membrane continually peeling off from the Birch, we see a resemblance to the scales which separate from the shell of a 'Tortoise. By maceration, boiling, or putrefaction, this part is separable from the plant as well as from the animal, being, if not absolutely incorruptible, much less prone to decomposition than the parts it covers. The vital principle, as far as we can judge, seems to be extinct in it.

The cuticle admits of the passage of fluids from within as well as from without, but in a due and definite proportion in every plant: consequently it must be porous; and the microscope shows, what reason would teach us to expect, that its pores are different in different kinds of plants. In very succulent plants, as Aloes, a leaf of which being cut off will lie for many weeks in the sun without drying entirely, and yet when partly dry will become plump again in a few hours if plunged into water, the cuticle must be very curionsly constructed, so as to admit of ready absorption, and very tardy perspiration. Such plants are accordingly designed to inhabit hot sandy countries, where they are long 
exposed to a burning sun, with very rare supplies of rain.

This part allows also of the passage of air, as is proved by experiments on the functions of leaves. Light probably acts through it, as the cuticle is a colourless membrane. We know the effects of light to be very important in the vegetable æconomy.

But though this fine membrane admits extraneous substances, so as to have their due effect upon the vegetable constitution, according to fixed laws, it no less powerfully excludes all that would be injurious to the plant, either in kind or proportion. Against heat or cold it proves, in general, but a feeble defence; but when clothed with hair or wool, it becomes a very powerful one. Against the undue action of the atmosphere it is so important a guard, that, when any tender growing part is deprived of it, the greatest mischiefs ensue. It forms in the Vegetable, as well as the Animal, a fine but essential barrier between life and destruction.

Some have imagined that the cuticle gare form to the vegetable body, because it sometimes being over tight causes contractions on 
the stem of a tree, as in the plum or cherry, and because it is found to be cracted wherever an unnatural excrescence is produced on the bark. No doubt the cuticle is formed so as to accommodate itself only to the natural grow th of the plant, not to any monstrosities, and those lumps cause it to burst; just as it happens to ripe fruits in very wet seasons. Their cuticle is constructed suitably to their usual size or plumpness, but not to any immoderate increase from too great absorption of wet. If the cuticle be removed from any part, no swelling follows, as it would if this membrane only kept the tree in shape.

The extension of the cuticle is astonishing, if we consider that it is formed, as Grew well observes, on the tenderest embryo, and oniy extended during the growth of the plant, and that it appears not to have any connexion with the vascular or living part of the regetable body. But though so accommodating in those parts where it is wanted, on the old trunks of most trees it cracks in every direction, and in many is entirely obliterated, tho old dead layers of their bark performing all the requisite offices of a cuticle. 
M. Mirbel indeed, though he admits the importance of this part in the several ways above mentioned, contends that it is not a distinct organ like the cuticle of animals, but merely formed of the cellular parts of the plant dilated and multiplied, and changed, by their new situation. This is very true; but upon the same principle the human cuticle can scarcely be called a distinct organ. Its texture is continually scaling off externally, and it is supplied with new layers from within. Just so does the cuticle of the Birch pcel off in scales, separable, almost without end, into smạller ones.

Examples of different kinds of cuticle may be seen in the following plants.

On the Currant tree it is smooth, and scales off in large entire flakes, both from the young branches and old stem. The same may be observed in the Elder.

The fruit of the Peach and the leaf of the Mullein have a cuticle covered with dense and rather harsh wool, such as is found on many Mexican plants, and on more Cretan ones. The latter we know grow in open places under a burning sun. 
The leaf of the White Willow is clothed with a fine silky or satiny cuticle.

The cuticle of the Betony, and of many other plants, is extended into rigid hairs or bristles, which in the Nettle are perforated and contain a venomous fluid.

On the fruit of the Plum, and on many leaves, we find a blueish dry powder covering the cuticle, which is a resinous exudation, and it is difficult to wet the surface of these plants. Rain trickles orer them in large drops.

In the Cork tree, the Common Maple, and even the Dutch Elm, thie cuticle is covered with a fungous substance most extraordinary in its nature, though familiar to us as cork.

In grasses and some other plants the ingenious Mr. Davy has found a flinty substance in the cuticle.

What seems to be the cuticle on the trunk of the Plane, the Fir, and a kind of Willow called Salix triandra, rather consists of scales of bark, which having performed their functions and become dead matter, are rejected by the increasing bark beneath them; and this accords with M. Mirbel's idea of 
the cuticle. The old layers of bark in the Chesnut, Oak, and many other trees, though not cast off, are of the same nature; and these under the microscope exhibit the same cellular testure as the real cuticle. 


\section{CHAPTER IV.}

OF THE CEILULAR INTEGUAENT.

Irifedately under the Cuticle we find a succulent cellular substance, for the most part of a green colour, at least in the leaves and branches, which is called by Du Hamel the Enveloppe cellulaire, and by Mirbel the Tissu herbacé. This is in general the seat of colour, and in that respect analogous to the rete mucosum, or pulpy substance situated under the human cuticle, which is pale in the European, and black in the Negro; but we must carry the analogy no further, for these two parts perform no functions in common. Du Hamel supposed this pulp to form the cuticle; but this is improbable, as his experiments show, when that membrane is removed, that the Cetlular Integument exfoliates, at least in trees, or is thrown off in consequence of the injury it has sustained, 
and a new cuticle, covering a new layer of the same succulent matter, is formed under the old one. Annual stems or branches have not the same power, any more than leaves.

But little attention has been paid to this organ till lately, though it is very universal, even, as Mirbel observes, in Mosses and Ferns. The same writer remarks that " leaves " consist almost entirely of a plate of this " substance, corered on each side by the " cuticle. The stems and branches of both " annual and perennial plants are invested " with it; but in woody parts it is dried up. " and reproduced continually, such parts " only having that reproductive power. The " old layers remain, are pushed outward " by the new ones, and form at length the: " rugged dry dead covering of the old trunks " of trees."

When we come to consider the curions functions of leaves, we shall find this part to be of the very first importance. In it the principal changes operated upon the juices of plants by light and air, and the consequent elaboration of all their peculiar secretions, take place. 


\section{CIIAP'TER V.}

OF TIIE BARK.

UNDer the Cellular Integument we find the Bark, consisting of but one layer in plants or branches only one year old, and often not distinguishable from the wood. In the older branches and trunks of trees, it consists of as many layers as they are years old, the innermost being called the liber; and it is in this layer only that the essential vital functions are carried on for the time being, after which it is pushed outwards with the Cellular Integument, and becomes like that a lifeless crust. These older layers, however, are for some time reservoirs of the peculiar secreted juices of the plant, which perhaps they may help to perfect.

In some roots the bark, though only of annual duration, is rery thick; as in the 
Carrot, the red part of which is all bark. In the Parsnep, though not distinctly colour. ed, it is no less evident. In the Turnip it is much thinner, though equally distinct fron: the wood or body of the root.

The Bark contains a great number of woody fibres, running for the most part longitudinally, which give it tenacity, and in which it differs very essentially from the parts already described. These woody fibres when separated by maceration exhibit in general a kind of net-work, and in many instances great regularity and beauty of structure. In a family of plants to which the Mezereon belongs, the fibres of the inner bark have a beautiful white shining appearance like silk. In one of this tribe, a native of Jamaica, and called Lace Bark, that part may be separated by lateral extension into an elegant kind of lace.

In the old bark of the Fir tribe, on the contrary, nothing of this kind is discernible. The bark of the Cluster Pine, Pinus Pinaster, some inches in thickness, is separable into thin porous layers, each of them the production of one season, which do really seem to 
be, according to M. Mirbel's theory, hardened and dried Cellular Integument; but they are rather perhaps that vascular part of the Bark which once contained the secreted fluid, or turpentine, so abundant in this tree.

The bark of Oak trees twenty or thirty years old, if cut and long exposed to the weather, separates into many fine thin layers, of a similar, tbough less delicate, texture to the Lace Bark of Jamaica. All these layers, in a living state, are closely connected with each other by the cellular texture which pervades the regetable body in general, as well as by transverse vessels necessary for the performance of several functions hereafter to be mentioned.

In the bark the peculiar virtues or qualities of particular plants chiefly reside, and more especially in several of its internal layers nearest to the wood. Here we find in appropriate vessels the resin of the Fir and Juniper, the astringent principle of the Oak and Willow, on which their tanning property depends, the fine and valuable bitter of the Peruvian Bark, and the exquisitely aromatic oil of the Cinnamon. The same secretions do indeed, 
more or less, pervade the wood and other parts of these plants, but usually in a less concentrated form.

When a portion of the bark of a tree is removed, the remainder has a power of extending itself laterally, though very gradually, till the wound is closed. This is accomplished by each new layer, added to the bark internally, spreading a little beyond the edge of the preceding layer. The operation of closing the wound goes on the more slowly, as the wood underneath, from exposure to the air, has become dead, and frequently rotten, proving an incumbrance, which though the living principle cannot in this instance free itself from, it has no power of turning to any good account. If, however, this dead wood be carefully removed, and the wound protected from the injuries of the atmosphere, the new bark is found to spread much more rapidly; and as every new layer of bark forms, as will be proved in the next chapter, a new layer of wood, the whole cavity, whatever it may be, is in process of time filled up.

This operation of Nature was turned to great advantage by the late Mr. Forsyth of 
Kensington gardens, the history of whose experiments is before the pulblic. Under his management many timber trees, become entirely hollow, were filled with new wood, and made to produce fresh and vigorous branches; and pear-trees planted in the time of King William, and become so decayed and knotty as to bear no fruit worth gathering, were by gradual paring away of the old wood and bark, and the application of a composition judiciously contrived to stick close and keep out air and wet, restored to such health and strength as to cover the garden walls with new branches bearing a profusion of fine fruit. These experiments have passed under my own actual observation, and I am happy to bear testimony to the merits of a real lover of useful science, and one of the most honest and disinterested men I evep knew. 


\section{CHAPTER VI.}

OY THE WOOD.

W HEN the bark is removed, we come to the substance of the wood, which makes the principal bulk of the trunk or branch of a tree or shrub. When cut across, it is found to consist of numerous concentric layers, very distinct in the Fir, and other European trees in general. Each of these circular layers is externally most hard and solid. They differ however among themselves in this respect, as well as in their breadth on the whole. It often happens that all the layers are broadest towards one side of the tree, so that their common centre is thrown very much out of the actual centre of the trunk.

The wood owes its strength and tenacity to innumerable woody fibres, and consists 
of rarious ressels running for the most part longitudinally; some laving a spiral coat, others not. Of these vessels, some in their youngest state convey the sap from the root to the extremities of the branches and leaves; others contain the various peculiar or secreted juices; others perhaps contain air. The whole are joined together by the cellular substance already described.

Linnæus and most writers believe that one of the abovementioned circular layers of wood is formed every year, the hard external part being caused by the cold of winter ; consequently, that the exact age of a sound tree when felled may be known by counting these rings. It has even been asserted that the date of peculiarly severe winters may be found in the harder more condensed rings formed at those periods; and moreover, that the north side of a tree may always be known by the narrowness and density of the rings on that side. All this is controverted by Mirbel, chiefly on the authority of Dı Hamel, who nerertheless scarcely says enough to invalidate the ancient opinion on the whole. It is very true that there may be occasional inter- 
ruptions in the formation of the wood from cold or fickle seasons, and that in some trees the thin intermediate layers, hardly discernible in general, which unite to form the principal or annual ones, may, from such fluctuation of seasons, become more distinct than is natural to them. Such intermediate layers are even found more numerous in some trees of the same species and age than in others. But as there is always a most material difference between summer and winter, so I believe will there always be a clear distinction between the annual rings of such trees as show them at all. Trees of hot countries indeed, as Mahogany, and evergreens in general, have them but indistinctly marked; yet even in these they are to be seen. With regard to their greater compactness on the north side of a tree, Du Hamel justly explodes this idea. In fact, there is most wood formed, and consequently these circles are broadest, on the side most farourable to vegetation, and where there are most branches and leaves. This in a solitary tree is generally towards the south; but it is easy to perceive the occasional varia- 
tions which must arise from local exposure, soil, moisture, and other causes.

In some trees, a number of the outermost rings differ greatly in colour from the innermost, and are called by workmen the sap. In the Laburnum the formier are yellow, the latter brown. In the Oak and many other trees a similar difference, though less striking, is perceptible, and in most the external rings are much less firm, compact, and durable than the rest, retaining more vital principle, and more of the peculiar juices of the plant. Such rings are all comprehended by Du Hamel under the name of Aubier, alburnum; and he rightly observes that this difference often extends to a greater number of rings on one side of a tree than on another. It seems that the more vigour there is in a tree, or side of a tree, the sooner is its alburnum made perfect wood. By this term, however, is properly understood only the layer of new unhardened wood of the present year. When the word alburnum is used in the following pages, it applies to this part only.

Physiologists have long differed and do still differ about the origin of the mood. 
Malpighi and Grew thought it was formed by the bark, and the best observations have confrmed their opinion. Hales supposed the wood added a now layer to itself externally every year. Linnaus had a pcculiar notion, that a new layer of wood was secreted annually from the pith, and added internally to the former ones. 'Truth obliges us to confess that the latter theory is most deroid of any kind of proof or probability.

Du Hamel, by many experiments, proved the wood to be secreted or deposited from the innermost part of the bark or liber. He introduced plates of tinfoil under the barks of growing trees, carefully binding up their wounds, and, after some years, on cutting them across, he found the layers of new wood on the outsicle of the tin. Ilis original specimens thre cxamined in the public musemu at Paris.

Dr. Hope, the late worthy Professor of Botany at Edinburgh, instituted an experiment, if possible more decisive, upon a branch of Willow three or four years old. The bark was carelilly cut through longitudinally on one side for the length of sererul inches, so 
that it might be slipped aside from the wood in the form of a hollow cylinder, the two ends being undisturbed. The edges of the bark were then united as carefully as possible, the wood covered from the air, and the whole bound up to secure it from external injury. After a few years, the branch was cut through transversely. The cylinder of bark was found lined with layers of new wood, whose number added to those in the wood from which it had been stripped, madie up the number of rings in the branch abore and below the experiment. For an account of this experiment I am indebted to Dr. Thomas Hope, the present Chemical Professor at Edinburgh.

Du Hamel engrafted a portion of the bark of a Peach-tree upon a Plum. After some time he found a layer of new wood under the engrafted bark, white like that of the Peach, and evidently different from the red wood of the Plum. Moreover, in this and other experiments made with the same intention, he found the layers of new wood always connected with the bark, and not united to the old wood. See his Physique des Artres, rol. 2. 29, \&c. It deserves 
also, to be mentioned, that by performing this experiment of engrafting a portion of bark at different periods through the spring and summer, the same accurate observer found a great difference in the thickness of the layer of new wood produced under it, which was always less in proportion as the operation was performed later in the season.

That the bark or liber produces wood seems therefore proved beyond dispute, but some experiments persuaded $\mathrm{Du}$ Hamel that in certain circumstances the wood was capable of producing a new bark. This never happened in any case but when the whole trunk of a tree was stripped of its bark. A Cherry-tree treated in this manner exuded from the whole surface of its wood in little points a gelatinous matter, which gradually extended over the whole and became a new bark, under which a layer of new wood was speedily formed. Hence Mirbel concludes, vol. 1. 176, that the alburnum and the wood are really the origin of the new layers of wood, by producing, first this gelatinous substance, or matter of organization, which he and Du Hamel call cambium, and which 
Mirbel supposes to produce the liber or young bark, and at the same time, by a peculiar arrangement of the vascular parts, the alburnum or new wood. His opinion is strengthened by the observation of a tribe of plants to be explained hereafter, Palms, Grasses, \&c. in which there is no real bark, and in which he finds that the woody fibres do actually produce the cambium. Dr. Hope's experiment will scarcely invalidate this opinion, because it may be said the cambium had already in that case formed the liber.

This matter will be better understood when we come to speak of Mr. Knight's experiments on the course of the sap. 


\section{CHAPTER VII.}

OF THE MEDULLA OR FITH.

Tue centre or heart of the vegetable body, within the wood, contains the Medulla or Pith. This, in parts most endued with life, as roots, and young growing stems or branches, is a tolerably firm juicy substance, of an uniform texture, and commonly a pale green or yellowish colour, Such is its appearance in the young shoots of Elder in the spring; but in the very same branches, fully grown, the pith becomes dry, snow-white, highly cellular, and extremely light, capable of being compressed to almost nothing. So it appears likewise in the common Red or White Currant, and numerous other plants. In many annual stems the pith, abundant and very juicy while they are growing, becomes little more than a web, lining the hollow of the complete stem, as in some This- 
tles. Many grasses and umbelliferous plants, as Conium maculatum or Hemlock, have always hollow stems, lined only with a thin smooth coating of pith, exquisitely delicate and brilliant in its appearance.

Concerning the nature and functions of this part various opinions have been held.

Du Hamel considered it as merely cellular substance, connected with what is diffused through the whole plant, combining its various parts, but not performing any remarkable office in the regetable nconomy.

Linnæus, on the contrary, thought it the seat of life and source of vegetation; that its vigour was the main cause of the propulsion of the branches, and that the seeds were more especially formed from it. This latter hypothesis is not better founded than his idea, already mentioned, of the pith adding new layers internally to the wood. In fact the pith is soon obliterated in the trunks of many trees, which nevertheless licep increasing, for a long series of years, by layers of wood added every year from the bark, even after the heart of the tree is become hollow from decay. 
Some considerations have led me to hold a medium opinion between these two extremes. There is, in certain respects, an analogy between the medulla of plants and the nervous system of animals. It is no less assiduously protected than the spinal marrow or principal nerve. It is branched off and diffused through the plant, as nerves are through the animal. Hence it is not absurd to presume that it may, in like manner, give life and vigour to the whole, though by no means, any more than nerves, the organ or source of nourishment. It is certainly most vigorous and abundant in young and growing branches, and must be supposed to be subservient, in some way or other, to their increase. Mr. Lindsay of Jamaica, in a paper read long ago to the Royal Society, but not published, thought he demonstrated the medulla in the leaf-stalk of the Mimosa pudica, or Sensitive Plant, to be the seat of irritability, nor can I see any thing to invalidate this opinion.

Mr. Knight, in the Philosophical Transactions for $1801, p .348$, supposes the medulla may be a reservoir of moisture, to supply 
the leaves whenever an excess of perspiration renders such assistance necessary, and he has actually traced a direct communication by ressels between it and the leaf. "Plants," says that ingenious writer, "seem to require some such reservoir; for their young leaves are excessively tender, and they perspire much, and cannot, like animals, fly to the shade and the brook."

'This idea of Mr. Knight's may derive considerable support from the consideration of. bulbous-rooted grasses. The Common Catstail, Phleum pratense, Engl. Bot.t. 1076, when growing in pastures that are uniformly moist, has a fibrous root, but in dry situations, or such as are only: occasionally wet, it acquires a bulbous one, whose inner substance is moist and fleshy, like the pith of young branches of trees. This is evidently a provision of Nature to guard the plant against too sudden a privation of moisture from the soil.

But, on the other hand, all the moisture in the inedulla of a whole branch is, in some cases, too little to supply one hour's perspiration of a single leaf. Neither can I find 
that the moisture of the medulla varies, let the leaves be ever so flaccid. I cannot but incline therefore to the opinion that the medulla is rather a reservoir of vital energy, even in these bulbous grasses.

Mr. Knight has shown that the part in question may be removed without any great injury to a branch, or at least without immediate injury, but I have had no opportunity of making any experiments on this particular subject, 


\section{CHAPTER VIIT,}

OF TIIE SAP-ILSSELS, ATD COURSE OT TIESAP; WITH MR, KNICII'S THEORY OF VEGETATION,

MUCi contrariety of opinion has existed among physiologists concerning the vascular system of plants, and the nature of the propulsion of the sap through their stems and branches. Indeed it is a subject upon which, till lately, very erroneous ideas have prevailed.

That the whole vegetable body is an assemblage of tubes and vessels is evident to the most careless observer; and those who arc conversant with the microscope, and books relating to it, have frequent opportunities of observing how curiously these ressels are arranged, and how different species of plants, 
especially trees, differ from each other in the structure and disposition of them. Such observations, however, if pursued no further, lead but a little way towards a knowledge of the wonderful physiology of vegetables.

In our $2 \mathrm{~d}$ chapter, merition is made of the general cellular and vascular texture of plants ; we must now be a little more particular in our inquiries.

That plants contain various substances, as sugar, gum, acids, odoriferous fluids and others, to which their various flavours and qualities are owing, is familiar to every one; and a little reflection will satisfy us that such substances must each be lodged in proper cells and vessels to be kept distinct from each other. They are extracted, or secreted, from the common juice of the plant, and called its peculiar or secreted fluids. Various experiments and observations, to be hereafter enlarged upon, prove also that air exists in the vegetable body, and must likewise be contained in appropriate vessels. Besides these, we know that plants are nourished and invigorated by water, which they readily absorb, and which is quickly conveyed through their 
stalks and leaves, no doubt by tubes or vessels on purpose. Finally, it is observable that all plants, as far as any experiment has been made, contain a common fluid, which at certain seasons of the year is to be obtained in great quantity, as from vine branches by wounding them in the spring before the leaves appear, and this is properly called the sap. It is really the blood of the plant, by which its whole bolly is nourished, and from which the peculiar secretions are made.

The great difficulty has been to ascertain the ressels in which the sap runs. Two of the most distinguished inquirers into the subject, Malpighi and Grew, believed the woody fibres, which make so large a part of the vegetable body, and give it consistence and strength, to be the sap-vessels, analogous to the blood-ressels of animals, and their opinion was adopted by Du Hamel. In support of this theory it was justly observed that these fibres are very numerous and strong, running. longitudinally, often situated with great uniformity (an argument for their great importance), and found in all parts of a plant, although in some they are so delicate as to be 
scarcely discernible: But philosophers sought in vain for any perforation, any thing like a tubular structure, in the woody fibres to countenance this hypothesis, for they are divisible almost without end, like the muscular fibre. This difficulty was overlooked, because of the necessity of believing the existence of sap-vessels somewhere; for it is evident that the nutrimental fluids of a plant must be carried with force towards certain parts and in certain directions, and that this can be accomplished by regular vessels only, not, as Tournefort supposed, by capillary attraction through a simple spongy or cottony substance.

I received the first hint of what I now belicre to be the true sap-vessels from the $2 \mathrm{~d}$ section of Dr. Darwin's P'hytologia, where it is suggested hat what lave been taken for air-ressels are really absorbents destined to nourish the plant, or, in other words, sapvessels. The same idea has been adopted, con- firmea by experiments, and carried to mucir greater perfection by Mr. Kinght, whose papers in the Plilosophical Transactions for 1801,1804 and 1805 throw the most brilliant light upon it, and, I think, establish no less 
than an entively new theory of vegetation, by which the real use and functions of the principal organs of plants are now for the tirst tine satisfactonly explained.

In a young branch of a tree or shrub, or in the stem of an herbac ous plant, are found, ranged round the cen ru or pi h, a number of longitudinal tubes or vessels, of a much more firm texture than the adj cent parts, and when examined minutely, these vesscls often appear to be constricted with a spiral coat. This may be seen in the young twigs and leaf sialks of Elder, Syringa, and many other shrubs, as well as in numerous herbaceous plants, as the Peony, and more especially many of the Lily tribe. If a branch or stalk of any of these plants be partly cut through or gently broken, and its divided portions slowly drawn asunder, the spiral coats of their vessels will unroll, exhibiting a curious spectacle eren to the naked eye. In other cases, though the spiral structure exists, its convolutions are scarcely separable at all, or so indeterminate as to be only marked by an interrupted line of perforations or slits, as shown by M. Mirbel. Indeed the very same branchos which exhibit 
these spiral vessels when young, show no signs of them at a more advanced period of growth, when their parts are become more woody, firm, and rigid. No such spiral-coated vessels have been detected in the bark at any period of its growth.

Malpighi asserts that these vessels are always found to contain air only, no other fluid; while Grew reports that he sometimes met with a quantity of moisture in them.' Both judged them to be air-vessels, or, as it were, the lungs of plants, communicating, as these philosophers presumed, with certain vessels of the leaves and flowers, of an oval or globular form, but destitute of a spiral coat. These latter do really contain air, but it rather appears from experiment that they have no direct communication with the former. Thus the tubes in question have always been called air-vessels, till Darwin suggested their real nature and use*. He is perhaps too decisive when he asserts that none of them are airvessels because they exist in the root, which is

* Du Hamel, indeed, once suspected that they contained "highly rarefied sap," but did not pursue the idea. 
not exposed to the atmosphere. We know that air acts upon the plant under ground, because seeds will not vegetate in earth under the exhansted receiver of an air-pump. Phil. Trans. No. 23. I do not howerer mean to contend that any of these spiml ressels are air-ressels, nor do I see reason to believe that plants have any systam of longitudinal air-vessels at all, though they nust be presumed to abound in such as are transverse or horizontal.

Dr. Darwin and Mr. Knight have, by the most simple and satisfactory en minent, proved these spiral ressels to be the chennel through which the sip is conry th. Thu former placed leaty twigs of a common ing ine about an inch deep in a decoction of makhe:, and others in one of logrood. Alrer some houns, on culting the branches across, the coloured liquors were found to have ascended into each brancl. by these ressuls, which exhibited a circle of red dots round the pith, surrounded by an external circle of ressels containing the white milky juce, or secreted fluid, so remanthle in the lig-tree. Mr. hnight, in a similar manner, inserted the 
lower ends of some cuttings of the Apple-tree and Horse-chesnut into an infision of the sking of a very black grape in water, an excellent liquor for the purpose. The result was similar. But Mr. Knight pursued his observations much further than Dr. Darwin had done; for he traced the coloured liquid eren into the leaves, "but it had neither coloured the barknor the sap between it and the wood; and the medulla was not affected, or at most was very slightly tinged at its cages." Phil. Trans. for 1801, p. 335.

'The result of all Mr. Knight's experiments and remarlis seems to be, that the fluids destined to nourish a plant, being absorbed by the root and become sap, are carried up into the leaves by these ressels, called by him central ressels, from their situation near the pith. A particular set of them, appropriated to each leaf, branches off; a tew inches below the leaf to which they belong, from the main channels that pass along the alburnum, and extend from the fibres of the root to the extremity of each annual shoot of the plant. Asthey approach the leaf to which they are destined, the central vessels become more numerous, 
or subdivided. "To these vessels," says Mr. Knight, "the spiral tubes are every where appendages." p. 336. By this expression, and by a passage in the following page $e^{*}, 337$, this writer might seem to consider the spiral line, which forms the coats of these vessels, as itself a pervious tube, or else that he was speaking of other tubes with a spiral coat, companions of the sap-vessels; but the plate which accompanies his dissertation, and the perspicuous mode in which he treats the subject throughout, prevent our mistaling him on the last point. In order to conccive how the sip can be so powerfully conveyed as it is through the vessels in which it flows, from the root of a tall tree to its highest branches, we must take into consideration the action of heat. We all know that this is necessary to. the growth and health of plants; and that it requires to be nicely adjusted in degrree, in

* s: The whole of the fluid, which passes from the wood to the leaf, seems to me cvidently to be conveyed through a single kind of vessel; for the spiral tubes will ncither carry coloured infusions, nor in the smallest degree retard the withering of the leaf, when the central vessets are divided." Knight. 
orter to suit the constitutions of difterent tribes of plimts destined for ditferent parts of the globe. It cammot but act as a stimulus to the living principle, and is one of the most powerful agents of Nature upon the vegetable as well ats animal constitution. Besides this, howerer, various mechanical causes may be supposed to have their effect; as the frequently spiral or screw-like form of the ressels, in some of which, when scparated from the plant, Malpighi tells us he once saw a very beantifil undulating motion that appeared spontaneons. This indeed has not been seen by any other person, nor an it be supposed that parts so clelicate can, in general, be removed from their matmal situation, without the destruction of that fune imitability on which such a motion must depend. We may also talie into consideration the agitation of the vegetable body by wimla, which is known by expericnee to be so wholesome to it ${ }^{*}$, and must serve powerlinliy to propel the fluids of lofty trees; the passage, and crolution perhaps, of

* See Mr. Knight's cxperiments in confirmation of this in the Phil. Trans. for 1503, p. 250. 
air in other parts or ressels, surrounding and - compressing these; and lastly the action, so ingeniously supposed by Mr. Knight, of those thin shining plates called the siticr grain, visible in oak wood, which pressing upon the sap-ressels, and being apparenty susceptible of quick changes from variations in heat or other causes, may have a powerful effect. "Their restless temper," says Mr. Knight, "after the tree has ceased to live, inclines me to beliere that they are not made to be idle whilst it continues alive." Phil. Trans. for 1801, p. 344. These plates are presumed by the author just quoted to be peculiarly useful in assisting the ascent of the sap through the alburnum of the trunk or chief branches, where indeed the spiral coats of the ressels are cither wanting, or less elastic than in the leat-stalks and summits of the more tender shoots.

Howerer its conveyance may be accomplished, it is certain that the sap does reach the parts above mentioned, and there can surely be now as little doubt of the ressels in which it runs. That these ressels have been thought to contain air only, is well ac- 
counted for by $\mathrm{D}_{i}$. Darwin, on the principle of their not collapsing when emptied of their sap; which is owing to their rigiclity, and the elastic nature of their coats. When a portion of a stem or branch is cut off, the sap soon exhales from it, or rither is pushed out by the action of the vessels themselves: hence they are found empty; and for the same reason the arteries of animals were formerly thought to contain air only. When the sap-ressels have parted with their natural contents, air and even quicksilver will readily pass through them, as is shown by various experiments. Arguments in support of any theory must be very cautiously deduced from such experiments, or from any other observations not made on regetables in their most natural state and condition; and, abore all, that great agent the vital principle must always be kept in view, in preference to more mechanical considerations.

These to which I give the common name of sap-vessels, comprehending the common tubes of the alburnum, and the central vessels, of Mr. Knight, may be considered as analogous to the arteries of animals; or ratho: 
Lhey are the stomach, lacteals and arteries all in one, for I conceive it to be a great error in Dr. Dirwin to call by this name the ressels which contain the peculiar secretions of the plint". These sap-ressels, no doubt, absorl the nutritious fluids afforded by the soil, in which possibly, as they pass through the root, some change analogous to digestion may take place; for there is evidently a great difference in many cases, between the fuids of the root, at least the secreted ones, and those of the rest: of the plant; and this leads us to presume that some considerable alteration may be wrought in the sap in its course through that important organ. The stem, which it next enters, is by no means an essential part, for we see many plants whose leaves asd flowers grow directly from the root.

Part of the sap is conreyed into the flowers and fruit, where rarious fine and essential secretions are made from it, of which we shall speak hereafter. $\quad P_{y}$ far the greater portion of the sap is carried into the leares, of the great importance and utility of which to the plant itselt Mr. Knight's theory is the only ont * Phiylologin, sect. . 
that gives us any adequate or satisfactory notion. In those orms the sap is exposed to the action of light, air and moisture, three powerfu! agents, by which it is enabled to form various secretions, at the same time that much supcrftous matter passes off by perspivation. These secretions not only give peculiar flavours and qualities to the leaf itself, but are returned by another set of vessels, as Ifr. Kuight has demonstrated, into the new layer of bark, which they nourish and bring to perfection, and which they enable in its twon to secrete matter for a new laycr of alburnum the ensuing year. It is presumed that one set of the returning vessels of trees nay probably be more particularly destined to this latter oftice, and another to the secretion of peculias fluids in the bark. See Phil. Irums. for 1801, p. 337 . In the bark principally, if I mistake not, the peculiar secretions of the plant are perfected, as gum, resin, \&c., each undoubtedly in an appropriate set of vessels. From what has just been said of the office of leaves, we readily perceive why all the part of a branch above a leaf or leaf-bud dies when cut, as each portion receires nou- 
rishment, and the means of increase, from the leaf above it.

By the above riew of the regetable neconomy, it appears that the vascular system of plants is strictly annual. This, of course, is admitted in herbaceous plants, the existence of whose stems, and often of the whole individual, is limited to one season; but it is no less true with regard to tiees. The layer of alburnum on the one hand is added to the wood, and the liber, or inner layer of the bark, is on the other annexed to the layers formed in preceding seasons, and neither have any share in the process of regetation for the year ensuing. Still, as they continue for a long time to be living bodies, and help to perfect, if not to form, secretions, they must receive some portion of nourishment from those more active parts which have takcn uy their late functions.

There is a tribe of plants called monocotyledones, having only one lobe to the seed", whose growth requires particular mention. To these belongs the natural order of Palms, which being the most lofiy, and, * Or rather no true cotyledon at all. 
in some instances, the most long-lived of plants, have justly acquired the name of trees. Yet, paradoxical as it may seem, they are rather perennial herbaceous plants, having nothing in common with the growth of trees in general. Their nature has been lcarnedly explained by $\mathbf{M}$. Desfontaines, a celebrated French botanist, and by M. Mirbel in his Traitéd'Anatomic et de Plyysiologyie V'egétales, vol. 1. p.209, and Linnæus has long ago made remarks to the same purpose. The Palms are tormed of successive circular crowns of leaves, which spring directly from the root. These leaves and their footstalks are furnished with bundles of large sap-ressels and returning vessels, like the leares of our trees. When one circle of them has performed its office, another is formed within it, which being confined below, necessarily rises a little abore the former. Thus successive circles grow one above the other, by which the rertical increase of the plant is almost without end, Each circle of leaves is independent of its prerlecessor, and has its own clusters of ressels, so that there can be no aggregation of woody circles; and yet in some of this tribe the 
spurious lind of stem, formed in the manner just described, when cut across shows something of a circular arrangement of fibres, arising from the original disposition of the leaves. The common orange lily, Lilium butbiferum, Curt. Mag. t. 36, and white lily, L. candidum, $t .278$, which belong to the same riatural family called monocotyledones, serre to elucidate this subject. Their stems, though of only annual duration, are formed nearly on the same principle as that of a Palm, and are really congeries of leaves rising one abore another, and united by their bases into an apparent stem. In these the spiral coats of the sap-ressels are very easily discernible.

To conclude this subject of the propulsion of the sap, it is necessary to say a few words on the power which the vessels of plants are reported to possess of conveying their appropriate fluids equally well in either direction; or, in other words, that it is indifferent whe ther a cutting of any lind be planted with its apper or lower end in the ground. On this subject also Mr. Knight has afforded us new information, by observing that, in cuttings so treated, the returning vessels retain so much 
of their original nature as to deposit new wood above the leaf-buds; that is, in the part of the cutting which, if planted in its natural position, would have been below them. It appears, however, that the sap-ressels must absorb and transmit their sap in a direction contrary to what is natural; and it is highly probable, that after some revolving seasons new returning vessels would be formed in that part of the stem which is now below the buds. I presume there can be no doubt that successive new branches would deposit their wood in the usual position. It is nevertheless by no means common for such inverted cuttings to succeed at all. An experiment to a similar purpose is recorded by Dr. Hales, Vegetable Staticlis, $p .132, t .11$, of engrafting together three trees standing in a row, and then cutting off the communication between the central one and the earth, so that it became suspended in the air, and was nourished merely through its lateral branches. The same experiment was successfully practised by the late Dr. Hope at Edinburgh upon three Willows, and in the years 1781,2 , and 3 , I repeatedly witnessed their health and rigour. It was observed that the 
central tree was several days later in coming into leaf than its supporters, but I know not that any other difference was to be perceived between them. The tree which wanted the support of the ground was, some years after, blown down, so that we have now no opportunity of examining the course of its vessels, or the mode in which successive layers of woor were deposited in its branches; but the experiment is easily repeated.

In the weeping variety of the Common Ash, now so frequent in garclens, the branches aro completely inverted as to position, yet the returning fluds appear to run exacty in their natural direction, depositing new wood, as they are situated above the huds or leares: and if the end of any branch be cut, all be-yond (or below) the next bud dies; so that in this case gravitation, to which Mr. Kniglat attributes considerable power orer the returning fluids, Phil. Trans. for 1804, does not comteract the ordinary conrse of natue. 


\section{CIIAPTER IX.}

OF TIE SAP, AND INSENSIBLE PERSPIRATION.

Tine sap of trees, as has been mentioned in the last chapter, may be obtained by wounding a stem or branch in spring, just before the buds open, or in the end of autumn, though less copiously, after a slight frost; yet not during the frost. In the Palm-trees of hot countries, it is said to flow from a wound at any time of the year. It has always been observed to flow from the young wood or alburnum of our trees, not from the bark; which agrees with Mr. Knignt's theory.

A common branch of the Vine cut through will yield about a pint of this fluid in the course of twenty-four hours. The Birch, Betula alba, affords plenty of sap; some other trees yield but a small quantity. It flows equally 
"pward and downward fiom a wound, at leust proportionally to the quantity of stem or branch in either direction to supply it. Some authors have asserted that in the heat of the day it flows most from the lower part of a wound, and in the cool of the evening from the upper; hence they concluded it was ascending during the first period, and descending in the latter. If the fact be true, some other solution must be sought; nor would it be difficult to invent a theory upon this subject: but we rather prefer the investigation of truth on more solid foundations.

This great motion, called the flowing; of the sap, which is to be detected principally in the spring, and slightly in the autumn, is therefore totally distinct from that constant propulsion of it going on in every growing plant, about which so much has been said in the preceding chapter, and which is prover by taking an cntire herb of any kind that has been gathered and suffered to begin to fiule, and immersing its root in water. By absorption through the sap-ressels it presenty revives, for those ressels require a constant sippply from the root. 
This flowing of the sap has been thought to demonstrate a circulation, because, there being no leares to carry it off by perspiration, it is evident that, if it were at these periods rumning up the sap-ressels with such velocity, it must run down egain by other channels. As soon as the leaves expand, its motion is no longer to be detected. The effusion of sap from plants, when cut or wounded, is, during the greater part of the year, comparatively very small. Their secreted fluids run much more abundantly.

I conceive therefore that this flowing is nothing more than a facility in the sap to run, owing to the peculiar irritability of the vegetable body at the times above mentioned; and that it runs only when a wound is made, being naturally at rest till the leaves open, and admit of its proper and regular conveyance. Accordingly, ligatures made at this period, which show so plininly the course of the blood in an animal body, have never been found to throw any light upon the vegetable circulation. This great facility in the sap to run is the first step towards the revival of vegetation from the torpor of winter: 
and its exciting cause is heat, most unquestionably by the action of the latter on the vital principle, and scarcely by any mechanical operation, or expansive power upon the fluids. The effect of heat is in proportion to the degree of cold to which the plant has been accustomed. In forced plants the irritability, or, to use the words of a late ingenious author*, who has applied this principle very happily to the elucidation of the animal œconomy, circitalility, is exhausted, as $\mathrm{Mr}$. Knight well remarlis, and they require a stronger stimulus to grow with vigour. See $p .91$. Hence regetation goes on better in the increasing heat of spring than in the decreasing heat of autumn. And here I cannot but offer, by way of illustration, a remark on the theory advanced by La Cepede, the able continuator of Buffon, relative to serpents. That ingenious writer mentions, rery truly, that these reptiles awake from their torpid state in the spring, while a much less degree of heat exists in the atmosphere than is perceptible

* Dr. John Brown, formerly of Edinburgh. See the 14th Section of Dr. Darwin's Phytologia on this subject. 
in the autumn, when, seemingly from the increasing cold, they become benumbed; and he explains it by supposing a greater degree of electricity in the air at the former season. Dr. Brown's hypothesis, of their irritability being as it were accumulated during winter, offers a much better solution, either with respect to the animal or regetable constitution. For the same reason, it is necessary to apply warmth very slowly and carefully to persons frozen, or even chilled only, by a more than usual degree of cold, which renders them more susceptible of heat, and a temperate diet and very moderate stimulants are most safe and useful to the unexhausted constitutions of children. The same principle accounts for the occasional flowing of the sap in autumn after a slight frost. Such a premature cold increases the sensibility of the plant to any warmth that may follow, and produces, in a degrce, the same state of its constitution as exists after the longer and severer cold of winter. Let me be allowed a further illustration from the animal kingdom. Every body conversant with labouring cattle must have observed how much sooner they are exhaust-. 
ed by the warm days of altumn, when the nights are cold, than in much hotter weather in summer, and this is surely from the same cause as the autumnal flowing of the regetable sip.

The sap, or lymph, of most plants when collected in the spring as above mentioned, appears to the sight and taste little else than water, but it soon undergoes fermentation and putrefaction. Even that of the Vine is scarcely acid, though it can liardly be obtained without some of the secreted juices, which in that plant are extremely acid and astringent. The sap of the Sugar Maple, Acer saccharinum; has no taste, though ac cording to Du Hamel every 200lb. of it will afford 10lb. of sugar. Probably, as he remarks, it is not collected without an admixture of secreted fluids.

As soon as the leaves expand, insensible perspiration takes place very copiously, chiefly from those organs, but also in some degree from the bark of the young stem or branches. The liquor perspired becomes sensible to us by being collected from a branch introduced into any sufficiently capacious glass vessel, I 2 
and proves, for the most part, a clear watery liquor like the sap, and subject to similar chenical changes. It is observed to be uniform in all plants, or nearly so, as well as the sap, except where odorous secretions transude along with it. Still there must be a very essential difference between the original sap of any plant and its perspiration, the latter no longer retaining the rudiments of those fine secretions which are elaborated from the former ; but that difference eludes our senses as well as our chemistry. The perspiration of sone plants is prodigiously great. The large Annual Sunflower, Helianthus anmus, Gerarde Emac. 751. f: 1, according to Dr. Hales, perspires about 17 times as fast as the ordinary insensible perspiration of the human skin. But of all plants upon record I think the Cornelian Cherry, Cornus mascula, is most excessive in this respect. The quantity of fluid which eraporates from its leares in the course of 24 hours, is said to be nearly equal to twice the weight of the whole shrub. Du Hamel Phys. des Arbres, v. 1. 145. 


\section{CHAPTER X.}

OF THE SLCRETED FLUIDS OF PIAN'TS. GRAFTIA. HFAT OF TIE VEGETABLE BODY.

TuE sap in its passage through the leaves and bark becomes quite a new fluid, possessing the peculiar flarour and qualities of the plant, and not only yielding woody matter for the increase of the vegetable body, but furnishing various secreted substances, more or less numerous and different among themselves. These accordingly are chiefly found in the bark; and the vessels containing them often prove upon dissection very large and conspicuous, as the turpentine-cells of the Fir tribe. In herbaceous plants, whose stems. are only of annual duration, the perennial. roots frequently contain these fluids in the most perfect state, nor are they, in such, confined to the bark, but deposited through- 
out the substance or wood of the root, as in Rhubarb, Rhenm palmatum, Timn. fil. Fasc. t. 4, and Gentian, Gentiana lutea and purpurea, Ger. emac. 432, $f$. 1, 2. In the wood of the Fir indeed copious depositions of turpentine are made, and in that of every tree more or less of a gummy, resinous, or saccharine matter is found. Such must be formed by branches of those returning vessels that deposit the new alburnum, These juices appear to be matured, or brought to greater perfection, in layers of wood or bark that have no longer any principal share in the circulation of the sap.

The most distinct secretions of vegetables require to be enumerated under several different heads.

Gum or mucilage, a viscid substance of little flavour or smell, soluble in water, is very general. When superabundant it exudes from many trees in the form of large drops or lumps, as in Plum, Cherry, and Peach-trees, and different species of Mimosa or Sensitive plants, one of which yields the Gum Arabic, others the Gum Senegal, \&c.

Resin is a substance soluble in spirits, and 
much more various in different plants than the preceding, as the Turpentine of the Fir and Juniper, the Red Gurn of New Solth Wales, produced by one or more species of Eucalyptus, Bot. of N. Holl. t. 13, and the fragrant Yellow Gum of the same country, see White's Toyage, 235, which exudes spontaneously from the Xanthorrtica Hastile. Most vegetable exudations partake of a nature between these two, being partly soluble in water, partly in spirits, and are therefore called Gum-resins. The milky juice of the Fig, Spurge, \&ic., which Dr. Darwin' has shown, and which every body may see, to be quite distinct from the sap, is, like animal milk, an emulsion, or combination of a-watery fluid with oil or resin. Accordingly, when suffered to evaporate in the air, such fluids become resins or gum-resins, as the Gum Euphorbium. In the Celandine, Chelidonium majus, Engl. Bot. t. 1581, and some plants allied to it, the emulsion is orange-coloured.

The more refined and rolatile secretions of a resinous nature are called Essential Oils, and are often highly aromatic and odoriferous. 
One of the most exquisite of these is afforded by the Cinnamon bark. They exist in the highest perfection in the perfumed effuvia of flowers, some of which, capable of combination with spirituous fluids, are obtainable by distillation, as that of the Lavender and Rose; while the essential oil of the Jasmine is best procured by iminersing the flowers in expressed oil which imbibes and retains their fragrance. Such Expressed or Gross Oils, ạs they are called, to distinguish them from essential oils obtained by distillation, are chiefly found in the seeds of plants. In the pulp of the Olive indeed they occur in the form of an emulsion, mixed with watery and bitter fluids, from which the oil easily separates by its superior lightness. These expressed oils are not soluble in spirits or water, though by certain intermediate substances they may be rendered capable of uniting with both.

The Bitter secretion of many plants does not seem exactly to accord with any of the foregoing. Some facts would seem to prove it of a resinous nature, but it is often perfectly soluble in water. Remarkable instances 
of this secretion are in the Cinchona cficinalis or Peruvian bark, Lambert Cinchona, t. 1, and every species, more or less, of Gentian.

Acid secretions are well known to be very general in plants. Formerly one uniform vegetable or acetous acid was supposed cómmon to all plants; but the refinements of modern chemistry have detected in some a peculiar kind, as the Oxalic acid, obtained from Oxulis or Wood Sorrel, and several others. 'The astringent principle should seem to be a sort of acid, of which there are many different forms or kinds, and among them the tamning principle of tle Oak, Willow, \&c.

On the other hand, two kinds of Alkali are furnished by vegetables, of which the most general is the Vegetable Alkali, properly so called, known by the name of Salt of Tartar, or Salt of Wormwood, or more correctly by the Arabic term Kiali. The Fossil Alkali, or Soda, is most remarkable in certain succulent plants that grow near the sea, belonging to the genera Chenspodium, Salsola, Nc. When these plants are cultivated in a common soil, they secrete Soda as copi- 
ously, provided their health be good, as in their natural maritime places of growth.

Sugar, more or less pure, is rery generally found in plants. It is not only the seusoning of most eatable fruits, but abounds in various roots, as the Carrot, Beet and Parsnip, and n many plants of the grass or cane kind besides the famous Sugar Cane Saccharum officinarum. There is great reason to suppose Sugar not so properly an original secretion, as the result of a chemical change in secretions already formed, either of an acid or mucilaginous nature, or possibly a mixture of both. In ripening fruits this change is most striking, and takes place very speedily, secming to be greatly promoted by heat and light. By the action of frost, as Dr. Darwin observes, a different change is wrought in the mucilage of the vegetable bocly, and it becomes starch.

A fine red liquor is afforded by some plants, as the Bloody Dock or Rumex sanguineus, Engl. Bot. t. 1533, the Red Cabbage and Red Beet, which appears only to mark a variety in all these plants, and not to constitute a specific difference. It is however perpetuated by seed. 
It is curious to observe, not only the various secretions of different plants, or tamilies of plants, by which they differ from each other in taste, smell, qualities and medical virtues, but also their great number, and striking difference, frequently in the same plant. Of this the Peach-tree offers a familiar example. The gum of this tree is mild and mucilaginous. The bark, leaves and flowers abound with a bitter secretion of a purgative and rather dangerous quality, than which nothing can be more distinct from the gum. The fruit is replete, not only with acid, mucilage and sugar, but with its own peculiar aromatic and highly volatile secretion, elaborated within itself, on which its fine flavour depends. How far are we still from understanding the whole anatomy of the regetable body, which can create and keep separate such distinct and discordant substances!

Nothing is more astonishing than the secretion of flinty earth by plants, which, though never suspected till within a few years, appears to me well ascertained. A substance is found in the hollow stem of the Bamboo, (Arundo Bambos of Linnæus, Nastos of "Theophrastus,) 
called Tabaxir or 'Tabasheer, which is supposed in the E:ast Indies (probably because it is rare and difficult of acquisition, like the imaginary stone in the head of a toad) to be endowed with extraordinary virtues. Some of it, brought to England, underwent a chemical examination, and proved, as nearly as possible, pure fint. See Dr. Russell's and Mr. Macie's papers on the subject in the Phit. Frans. for 1790 and 1791 . It is even found occasionally in the Banboo cultivated in our hot-houses. But we need not search exotic plants for finty earth. I have already, in speaking of the Cuticle, chapter $3 \mathrm{~d}$, alluded to the discoveries of Mr. Davy, Professor of Chemistry at the Royal Institution, on this subject. That able chemist has detected pure flint in the cuticle of various plants of the fatmily of Grasses, in the Cane (a kind of Palm). and in the Rough Horsetail, Equisetum hyemale, Engl. Bot. t.915. In the latter it is very copious, and so disposed as to make a natural tile, which renders this plant useful in various nanufactures, for even brass cannot resist its action. Common Wheat straw, when burnt, is found to contain a portion of 
Ainty earth in the form of a most exquisite powder, and this accounts for the utility of burnt straw in giving the last polish to marble. How great is the contrast between this production, if it be a secretion, of the tender vegetable frame, and those exhalations which coinstitute the perfume of flowers! One is among the most permanent substances in Nature, an ingredient in the primæval mountains of the globe; the other the invisible untangible breath of a moment!

The odour of plants is unquestionably of a resinous nature, a volatile essential oil and several phænomena attending it well deserve our attentive consideration. Its general nature is evinced by its ready union with spirits or oil, not with water; yet the moisture of the atmosphere seems, in many instances, powerfully to favour its diffusion. This I apprehend to arise more from the favourable action of such moisture upon the health and rigour of the plant itself, thus occasionally promoting its odorous sccretions, than from the fitness of the atmosphere, so circumstanced, to convey them. Both causes howerer may operatc. A number of flowers which have no 
scent in the course of the day, smell power fully in an evening, whether the air be moist or dry, or whether they happen to be exposed to it or not. "This is the property of some which Linnæus has elegantly called flores tristes, melancholy flowers, belonging to various tribes as discordant as possible, agreeing only in their nocturnal fragrance, which is peculiar, very similar and exquisitely delicious in all of them, and in the pale yellowish, greenish, or bromish tint of their flowers. Among these are Mesembryanthemum noctiflorum, Dill. Elth. t. 206, Pelargonium triste, Cormut. Canad. 110, and several species akin to it, Hesperis tristis, Curt. Mag. t. 730, Cheiranthus tristis, t. 729, Daphne pontica, An-. dreas's Repos. t. 73, Crassula odoratissima, t. 26, and many others*. A few more, greatly resembling these in the green hue of their

* These flowers afford the poet a new image, which is introduced into the following imitation of Martial, and offered here solely for its novelty :

Go mingle Arabia's gums

IVith the spices all India yields.

Go crop each young flower as it blooms. Go ransack the gardens and fields. 
blossoms, exhale, in the evening chicfly, a most powerful lemon-like scent, as Epidendrum ensifolium, Sim. Spicil. t. 24, and Chloranthus inconspicuus, Phil. Trans. for $1787, t .14$, great farourites of the Chinese, who seem peculiarly fond of this scent. There are other instances of odorous and aromatic secretions, similar among themselves, produced by very different plants, as Camphor. The sweet smell of new liay is found not only in Anthoxanthum odcratum, Engl. Bot.t. 6.1.7, and some other grasses, but in Woodruff or Asperula odoruta, t. 755, Melilot or Trifolimm officinale, $t$. 1340 , and all the varieties, by some deemed species, of Orchis milituris,

Let Pæstum's all-flowery groves

Their roses profusely lyestow.

Go catch the light zephyr that roves

Where the wild thyme and marjoram grow.

Let every pale night-scented flower, Sad emblem of passion forlorn, Resign its appropriate hour,

To enhance the rich breath of the morn.

All that art or that nature can find,

Not half so delightful would prove, Nor their sweets all together combined,

Half so sweet as the breath of my love. 
$t .16$ and $t .1873$, plants widely different from each other in botanical characters, as well as in colour and every particular except smell. Their odour has one peculiarity, that it is not at all perceptible while the plants are growing, nor till they begin to dry. It proceeds from their whole herbage, and should seem to escape from the orifices of its containing cells, only when the surrounding vessels, by growing less turgid, withdraw their pressure from such orifices. When this scent of new hay is vehement, it becomes the flavour of bitter almonds. The taste of syrup of capillaire, given by an infusion of Orange flowers, is found in the herbage of Gaultheria procumbens, Andr. Repos. t. 116, and Spircea Ulmaria, Engl. Bot. t. 960 , two very different plants.

Some of the abore examples show an evident.analogy between the smell and colours of flowers, nor are they all that might be pointed out. A variety of the Chrysanthemun indicum with orange-coloured flowers has been lately procured from China by Lady Amelia Hume. These faintly agree in scent, as they do in colour, with the Wall-flower, Chciranthus Cheiri; whereas the common purple 
variey of the same Chrysanthemum has a totally different and much stronger odour.

There is, of course, still more analogy between the smell of plants in general and their impression on the palate, insomuch that we are fiequently unable to discriminate between the two. The taste is commonly more permanent than the smell, but now and then less so. The root of the Arum maculatum, Engl. Bot. t. 1998, for instance, has, when fresh, a most acrid taste and irritating quality, totally lost by drying, when the root becomes simply farinaceous, tasteless and inert; so that well might learned physicians contrive the "Compound Powder of Arum," to excuse the continuance of its use in medicine, unless they had always prescribed the recent plant.-Many curious remarks are to be found in Grew relative to the tastes of plants, and their different modes of affecting our organs. Anatomy of Plants, p.279292.

To all the foregoing secretions of regetables may be added those on which their various colours depend. We can but imperfectly account for the green so universal in their 
berbage, but we may gratefuliy acknowledge the beneficence of the Creator in clothing the earth with a colour the most pleasing and the least fatiguing to our eyes. We may be dazzled with the brilliancy of a flower-garden, but we repose at leisure on the verdure of a grove or meadow. Of all greens the most delicate and beautiful perhaps is displayed by several umbelliferous plants under our hedges in the spring.

Some of Nature's richest tints and most elegant combinations of colour are reserved for the petals of flowers, the most transient of created beings; and even during the short existence of the parts they decorate, the colours themselves are often undergoing remarkable variations. In the pretty little weed called Scorpion-grass, Myosotis scorpioides, Engl. Bot. t.480, and several of its natural order, the flower-buds are of the most delicate rosecolour, which turns to a bright blue as they open. Many yellow flowers under the influence of light become white. Numbers of red, purple or blue ones are liable, from some unknown cause in the plant to which they belong, to vary to white. Such varieties are 
sometimes propagated by seed, and are almost invariably permanent if the plants be propagated by roots, cuttings or grafting. Plants of an acid or astringent nature often become very red in their foliage by the action of light, as in Rumer, Polygonum, Epilobium and Berberis; and it is remarkable that American plants in general, as well as such European ones as are particularly related to them, are distinguished for assuming various rich tints in their foliage of red, yellow, white or even blue, at the decline of the year, witness the Guelder-rose, the Cornel, the Vine, the Sumach, the Azalea pontica, Curt. Mag. t. 433, and others. Fruits for the most part incline to a red colour, apparently from the acid they contain. I have been assured by a first-rate chemist that the colouring principle of the Raspberry is a fine blue, turned red by the acid in the fruit. The juices of some Fungi, as Boletus borinus and Aguricus deliciosus, Sowerb. Fungi, t. 202, change almost instantaneously on exposure to the air, from yellow to dark blue or green.

These are a few hints only on a subject which opens a wide field of inquiry, and which,

cr 2 
in professedly chemical works, is carried to a greater length than I have thought necessary in a physiological one. See Thomson's Chemistry, v. 4, and Willdenow's Principles of Botany, 229. We must ever keep in mind, as we explore it, that our anatomical instruments are not more inadequate to dissect the organs of a scarcely distinguishable insect, than our experiments are to investigate the fine chemistry of Nature, over which the living principle presides.

Before we take leave of the secreted fluids of vegetables, a few more remarks upon their direct utility to the plants themselves may not be superfluous. Malpighi first suggested that these secretions might nourish the plant, and our latest inquiries confirm the suggestion. Du Hamel compares them to the blood of animals, and so does Darwin. But the analogy seems more plain between the sap, as being nearly uniform in all plants, and the animal blood, as in that particular they accord, while the secreted fluids are so very various. Mr. Knight's theory confirms this analogy, at the same time that it establishes the opinion of Malpighi. The sap 
returning from the leaf, where it has been acted upon by the air and light, forming new wood, is clearly the cause of the increase of the vegetable body. But it is not so clear how the resinous, gummy or other secretions, laid aside, as it were, in ressels, out of the great line of circulation, can directly minister to the growth of the tree. I conceive they may be in this respect analogous to animal fat, a reservoir of nourishment whenever its ordinary supplies are interrupted, as in the winter, or in seasons of great drought, or of unusual cold. In such circumstances the mucilaginous or saccharine secretions especially, perhaps the most general of all, may be absorbed into the regetable constitution; just as fat is into the animal one, during the existence of any disease that interrupts the ordinary supplies of food, or , interferes with its due appropriation. It is well known that such animals as sleep through the winter, grow fat in the autumn and awake very lean in the spring. Perhaps the more recent layers of wood in a Plum- or Cherry-tree, it they could be accuraty examined, might be found to contain a greater 
proportion of nucilage at the end of autumin than in the early spring. If these substances do not nourish the plant, they seem to be of no use to it, whatever secondary purposes they may answer in the schemes of Providence. The direct end, with respect to the plant, of the finer secreted fluids of its fruit can very well be perceived, as tempting the appetite of animals, and occasioning, through their means, the dispersion of the seeds; and the perfume of flowers may attract insects, and so promote the fertilization of the seed, as will be explained hereafter.

After what has been said we need not waste much time in considering the hypothesis, advanced by some philosophers, that the sap-vessels are veins and the returning ves. sels arteries. 'This is so far correct, that, as the chyle prepared by the digestive organs, poured into the veins and mixed with the blood, is, through the medium of the heart, sent into the lungs to be acted upon by the air; so the nutrimental juices of plants, taken up from the earth, which has been called their stomach, are carried by the sap-ressels into the leaves, for similar purposes already men- 
tioned. The improved sap, like the virid arterial blood, then proceeds to nourish and invigorate the whole frame. I rery much doubt, however, if those who suggested the abore hypothesis, could have given so satisfactory an explanation of it.

That the secretions of plants are worderfully constant appears from the operation of grafting. This consists in uniting the branches of two or more separate trees, as Dr. Hope's Willows, see $p .60$, and a whole row of Limetrees in the garden of Ncw College, Oxtord, whose branches thus make a network. This is called grafting by approach. A more common practice, called budding, or inoculating, is to insert a bud of one tree, accompanied by a portion of its bark, into the bark of another, and the tree which is thus cngrafted upon is called the stock. By this mode different kincls of fruits, as apples, pears, plums, \&c., each of which is only a variety. accidentally raised from seed, but no further perpetuated in the same manner, are multiplied, buds of the kind wanted to be propagated being engrafted on so many stocks of a wild nature. The mechanical part of 
this practice is detailed in Du Hamel, -Miller, and most gardening books. It is of primary importance that the liber, or young bark, of the bud, and that of the stock, should be accurately united by their edges. The air and wet must of course be excluded.

It is requisite for the success of this operation that the plants should be nearly alin. Thus the Chionanthus virginica, Fringe-tree, succeeds well on the Common Ash, Eraxinus excelsior, by which means it is propagated in our gardens. Varieties of the samo species succeed best of all; but Apples and pears, two different species of the same genus, may be grafted on one stock. The story of a Black Rose being produced by grafting a common rose, it is not worth inquiring which, on a black currant stock, is, as far as I can learn, without any foundation, and is indeed at the first sight absurd. I have known the experiment tried to no purpose. The rose rulgarly reported to be so produced is merely a dark Double Velvet Rose, a rariety, as we presume, of Rosa centifolia. Another report of the same kind has been raised concerning the Maltese Oranges, whose red juice has 
been attributed to their being butded on a Pomegranate stock, of which I have never been able to obtain the smallest confirmation.

Heat can scarcely be denominated a secretion, and yet is undoubtedly a production, of the vegetable as well as animal borly, though in a much lower degree in the former than the latter. The heat of plants is evinced by the more speedy melting of snow when in contact with their leaves or stems, compared with what is lodged upon dead substances, provided the preceding frost has been sufficiently permanent to cool those substances thoroughly. Mr. Hunter appears to have detected this heat by a thermometer applied in frosty weather to the internal parts of vegetables newly opened. It is evident that a certain appropriate portion of heat is a necessary stimulus to the constitution of every plant, without which its living principle is deștroyed. Most tropical plants are as effectually killed by a freezing degree of cold, as by a boiling heat, and have nearly the same appearance; which is exemplified erery autumn in the Garden Nasturtium, Tropceolum ma- 
jus. The regetables of cold climates, on the contrary, support a much greater degree of cold without injury, at least while in a torpid state; for when their buds begin to expand they become vastly more sensible, as is but too fiequently experienced in the fickle spring of our climate. Nor is this owing, as rulgarly supposed, merely to the greater power of the cold to penctrate through their opening buds. It must penetrate equally through them in the course of long and severe winter frosts, which are never known to injure them. The extremely pernicious effects therefore of cold on opening buds can only be attributed to the increased susceptibility of the vital principle, after it has been revived by the warmth of spring.

The vegetation of most plants may bo accelerated by artificial heat, which is called forcing them, and others may, by the same means, be kept in tolerable health, under a colder sky than is natural to them. But many alpine plants, naturally buried for months under a deep snow, are not only extremely impatient of sharp frosts, but will not bear the least portion of artificial heat. The 
pretty Primula margsinata, Curt. Magg.t.191, if bronght into a room with a fire when beginming to blossom, never opens arnther bud; while the American Cowslip, Dodecatheon Meadia, t. 12, one of the most hardy of plants with respect to cold, bears forcing admirably well.

Mr. Knight very satisfactorily shows, Phil. Trans. for 1801, 343, that plants acquire habits with regard to heat which prove their vitality, and that a forced Peach-tree will in the following season expand its buds prematurely in the open air, so as to expose them to inevitable destruction. See p. 65. A thousand parallel instances may be observed, by the sigacious gardener, of plants retaining the habits of their native climates, which very often proves one of the greatest impediments to their successful cultivation.

The most remarkable account that has fallen in my way concerning the production of heat in plants, is that given by Lannarck in his Flore Francoise, v. 3. 538, of the Common Arum maculatum, Enghl. Bot.t. 1298, (the white-reined variety,) the flower of which, at a certain period of its growth, he as 
serts to be, for a few hours, "so hot as to seem burning." The learned M. Senebier of Geneva, examining into this fact, discovered that the heat began when the sheath was about to open, and the cylindrical body within just peeping forth: and that it was perceptible from about three or four o'clock in the afternoon till eleven or twelve at night. Its greatest degree was seven of Reaumur's scale above the heat of the air, which at the time of his observation was about fourteen or fifteen of that thermometer. Such is the account with which I have been faroured by Dr. Bostock of Liverpool, from a letter of M. Senebier*, dated Nov. 28, 1796, to M. De la Rive. I have not hitherto been successful in observing the phrnomenon in question, which however is well worthy of attention, and may probably not be confined to this species of Arum.

* It is now published in his Physiologie Végétale, $v$. 3. 314, where nevertheless this ingenious philosopher has declared his opinion to be rather against the existence of a spontanenus heat in vegetables, and he explains even the above striking phrnomenon upon chemical principles, which secm to me very inadequate. 


\section{CHAP'IER XI.}

THE PROCESS OF VEGETATION. USE OE THE COTYLEDONS.

$W_{\text {HEN }}$ a seed is committed to the ground it swells by the moisture which its vessels soon absorb, and which, in conjunction with some degree of heat, stimulates its vital principle. Atmospherical air is also necessary to incipient vegetation, for seeds in general will not grow under water, except those of aquatic plants, nor under an exhausted receiver; and modern chenists have determined oxygen gas, which is always an ingredient in our atmosphere, to be absorbed by seeds in vegetation. An experiment is recorded in the Philosophical Transactions, No. 23, of sowing Lettuce-seed in two separate pots, one of which was placed in the comnon air, the other in the vacuum of an air-pump. In the 
frmer the young plants rose to the height of two inches, or more, in a week's time; in the other none appeared, till after the pot had becn removed for a similar period into the air again. Seeds buried in the ground to a greater depth than is natural to them da not vegetate, but they often retain their power of vegetation for an unlimited period. Earth taken from a considerable clepth will, when exposed to the air, be soon covered with young plants, especially of Thistles, or of the Cress or Mustard kind, though no seeds have been allowed to have access to it. If the ground in old established botanic grardens be dug much deeper than ordinary, it frequently happens that species which have been long lost are recovered, from their seeds being latent in the soil, as I have been assured by Mr. Fairbairn of Chelsea garden, and others.

The integuments of the seed, having fulfilled their destined office of protection, burst and decay. The young root is the first part of the infant plant that comes forth, and by an uncrring law of Nature it is sent downwards, to seek out nourishment as well as to fix the plant to the ground. In sea-weeds, 
Euci, Citce and Conferve, it seems merely to answer the latter purpose. In the Dodder, Cuscuta, a parasitical plant, the original root lasts only till the stems have established themselves on some vegetable, on whore juices they feed by means of other roots or fibres, and then withers away.

The descent of the root, and the ascent of the leaf-bud in a contrary direction, are ingeniously explained by Dr. Darwin, I'hylologia Sect.9. 3, on the principle of the former being stimulated by moisture, and the latter by air, whence each elongates itself where it is most excited. This is perhaps more satisfinctory than any mechanical hypothesis. In whatever position sceds happen to lie in the carth, the root makes more or less of a curve in order to shoot downwards. Mr. Hunter sowed a number of sceds in a basket of earth placed on an axis, by which their position was a little altered every day. After the basket had thus made two or three circumsolutions, the young roots were found to hare formed as many tums in attempting to attain their natural perpendicular direction. Mr. Knight has ascertained, Phil. Trans. for 1806, that 
a strong centrifugal force applied to vegetating seeds will considerably divert the root from this direction outwards, while the stem seems to have a centripetal inclination.

The young root, if it grew in a soil which afforded no inequality of resistance, would probably in every case be perfectly straight, like the radical fibres of bulbous roots in water; but as scarcely any soil is so perfectly homogeneous, the root acquires an uneven or zigzag figure. It is elongated chiefly at its extremity*, and has always, at that part especially, more or less of a conical or tapering figure.

When the young root has made some progress, the two lobes, commonly of a hemispherical figure, which compose the chief bulk of the seed, swell and expand, and are raised out of the ground by the ascending stem. These are called the Cotyledons, $f$. 4 . Between them is seated the Embryo or germ of the plant, called by Linnæus Corculum or little heart, in allusion to the heart of the walnut.

* As may be seen by marking the fibres of Hyacinth roots in water, or the roots of Peas made to vegctate in wet cotton wool. 
Mr. Knight denominates it the germen, but that term is appropriated to a very different part, the rudiment of the fruit. The expanding Einbryo, resembling a little feather, has been for that reason named by Linnæus Plumulu; it soon becomes a tuft of young leaves, with which the young stem, if there be any, ascends. Till the leaves unfold, and sometimes after, the cotyledons, assuming their green colour, perform their functions; then the latter generally wither. This may be seen in the Radish, Lupine, Garden Bcar, and various umbelliferous plants, in all which the expanded cotyledons are remarkably different from the true leaves. Such is the general course of regetation in plants furnished with two cotyledons, or dicotyledones; but I have already mentioned a very distinct tribe called monocotyledones; see p. 57. These are the Grass and Corn tribe, Palms, the beautiful Orckis family, and many others. In these the body of the seed does not ascend out of the ground, and they are rather to be considered as having no cotyledon at all. See Mr. Salisbury's paper in the Transactions of the Linnean Society, 7.7 , 
on the germination of the Orchis tribe. Ir reserve more particular remarks on this subject till we examine the structure of seeds.

Some plants are reckoned by Linnæus to hare many cotyledons, as the Fir and $\mathrm{Cy}_{\mathrm{y}}$ press. But the germination of these ciffiers in no respect from that of the generality of dicotyledones. Mr. Lambert, in his splendid history of the genus Pinus, has illustrated this peculiarity of structure in the Swiss P. Cembra; see our tab. 1, fig. 2. In the Dombeya, or Norfolk Island Pine, the cotyledons are rery distinctly four: see fig. 3.

The preservation of the vitul principle in seeds is one of those wonders of Nature which pass unregarded, from being erery day under our notice. Some lose their regetative power by being kept out of the ground ever so little a while after they are ripe, and in order to succeed must sow themselves in their ow way, and at their own time. Others may be sent round the world through every ricissitude of climate, or buried for ages deep in the ground, till farourable circumstances cause them to regetate. Great degrees of laeat, short of boiling, do not inpair the re- 
getative power of secds, nor do we know any degree of cold that has such an effect. Those who convey seeds from distant countries, should be instructed to keep them dry; for if they receive any damp sufficient to cause an attempt at vegetation, they necessarily die, because the process cannot, as they are situated, go on. If, therefore, they are not exposed to so great an artificial heat as might change the nature of their oily juices, they can scarcely, according to the experience of Mr. Salisbury, be kept in too warm a place. By the preservation of many seeds so long under ground, it seems that long-continued moisture is not in itself fatal to their living powers ; neither does it cause their premature germination, unless accompanied by some action of the air.

It is usual with gardeners to keep Melon and Cucumber seeds for a few years, in order that the future plants may grow less luxuriantly, and be more abundant in blossoms and fruit. Dr. Darwin accounts for this from the damage which the cotyledons may receive from keeping, by which their power of nourishing the infant plant, at its first germina- 
tion, is lessened, and it becomes stunted and dwartish through its whole duration.

Dr. Thomson of Edinburgh, in his System of Chemistry, vol. 4, 374, has published a very satisfactory explanation of one part of the functions of the cotyledons. Several philosophers have discovered that very soon after the seed begins to imbibe moisture, it gives out a quantity of carbonic acid gas, even though no oxygen gas be present. In this case the process stops here, and no germination takes place. But if oxygen gas be present, it is gradually absorbed in the same proportion. At the same time the farina of the cotyledons becomes sweet, being converted into sugar. "Hence, it is erident," says this intelligent writer, "that the farina is clianged into sugar, by diminishing its carbon, and of course by augmenting the proportion of its hydrogen and oxygen*. This is precisely the process of malting, during which it is well known that there is a considerable heat erolved. We may conclurle from this, that during the germination of

* This is also the opinion of M. de Saussure, Recherchos .Chimiqut's sur la Végétation, p. 16. 
eecels in the earth there is also an evolution of a considerable portion of heat. This incleed might have been expected, as it usually happens when oxygen gas is absorbed. So far seems to be the work of chemistry alone; at least we have no right to conclude that any other agent interfures; suce hay, when it happens to imbibe moisture, exhibits nearly the same processes."

I conceive the evolution of this heat may powerfully further the progress of regetation by stimulating the vital principle of the embryo, till its leaves unfold and assume their functions. It is necessary to observe, that the above process equally takes place, whether the farinaceous particles be lodged in the bulk of the cotyledons themselves, or compose a separate body called by authors the albumen, as in grasses and corn. 


\section{CHAPTER XII.}

OT THE ROOT, AND I'TS DIFEERENT KINDS.

$W_{\mathrm{E}}$ begin the description of the completely formed vegetable by its Root, as being the basis of all the rest, as well as the first part produced from the seed. Its use in general is two-fold ; to fix the plant to a commodious situation, and to derive nourishment for its support. This part is therefore commonly plunged deeply into the ground, having, as we have already shown, a natural tendency to grow downwards. In some cases however, when plants grow on the stems or branches of others, as the Dodder or Cuscuta, several Ferns, and a portion of the Orchis tribe, the root is closely attached to the bark, from which it draws nourishment, by the under side only, the upper being bare.

The Root consists of two parts, Caudcx 
the body of the Root, and Radicula the fibre. The latter only is essential, being the part which imbibes nourishment.

Roots are either of annual, hiemial or pereminal duation. The first belong to plants which live only one year, or rather one summer, as Barley; the second to such as are produced one season, and, living through the cnsuing winter, produce flowers and fruit the following summer, as Wheat; and the third to those which live and blossom through many succeeding seasons to an indefinite period, as trees, and many herbaceous plants. The term biennial is applied to any plant that is produced one year and flowers another, provided it flowers but once, whether that event takes place the second year, as usual, or whether, from unfarourable circumstances, it may happen to be deferred to any future time. This is often the case with the Lavatera arborea, Tree Mallow, Engl. Bot.t. 1841, and some other plants, especially when growing out of their natural soil or station. Linnaus justly observes that howerer hardy with respect to cold such plants may prove before they blossom, they perish at the 
first approach of the succeeding winter, nor can any artificial heat preserve them. This is, no doubt, to be attributed to the exhausion of their vital energy by flowering. Sereral plants of hot climates, naturally perennial and even shrubby, become annual in our gardens, as the Tropceolum, Garden Nasturtium.

In the Turnip, and sometimes the Carrot, Parsnep, \&c., the Cauder or body of the root is above-ground and bare, becoming as it were a stem. I.innxus indeed calls the stems of trees "roots abore-ground;" but this seems paradoxical and scarcely correct. Perhaps it would be more accurate to say the cauder is a subterraneous stem; but we rather presume it has functions distinct from the stem, analogous, as has been hinted p. 55 , to digestion, at least in those plants whose stems are annual though their roots are perennial.

The fibres of the root, particularly those extremities of them which imbibe nourishment from the earth, are in every case strictly annual. During the winter, or torpid season of the year, the powers of roots lie dor. 
mant, which season therefore is proper for their transplantation. After they have begun to throw out new fibres, it is more or less dangerous, or even fital, to remove them. Very young annual plants, as they form new fibres with great facility, survive transplintation tolerably well, provided they recerve abundant supplies of water hy the leaves till the root has recovered itsrlf.

Botanists distinguish several different linds of roots, which are necessary to be known, not unly for botanical purposes, but as being of syeat importance in agriculture and gardening. The generality of roots maty be arranged under the following heads.

1. Radixfibrosa, fig. 5. A Fibrous Root. The most simple in its nature of all, consisting only of fibres, either branched or undivided, which convey nourishment directly to the basis of the stem or leares. Many grasses, as Port annua, Engl. Bot.t. 1141, and the greater part of annual herbs, have this lind of root. The radical fibres of grasses that grow in loose sand are remarkably downy, possibly for the purpose of fixing thein more 
securely to so slippery a support, or to multiply the surface or points of absorption in so meagre a source of nutriment. The fibres of some parasitical plants already alluded to, chiefly of the beantiful genus Epidendrum, are peculiarly thick and fleshy, not only for the purpose of imbibing the more nourishment, but also to bind them so strongly to the branches of trees, as to defy the force of winds upon their large and rigid leares.

2. Racix repens, f. 6 . A Creeping Root, as in Mint, Mentha. A kind of subterraneous stem, creeping and branching off horizontally, and throwing out fibres as it goes. This kind of root is extremely tenacious of life, for any portion of it will grow. Hence weeds furnished with it are among the most troublesome, as the different sorts of Couch-grass, Triticum repens, Engl. Bot. t.909, Holcus mollis, t.1170, \&c.; while, on the other hand, many sca-side grasses, haring such a root, prove of the most important service in binding down loose blowing sand, and so resisting the encroachments of the ocean. These are principally Carex are- 
naria, Engl. Bot.t. 928, Arundo arenaria, t. 520, and Elymus arenarius, $t .1672$.

3. Radix fusiformis, f.7. A Spindle-shaped or Tapering Root. Of this the Carrot, Parsnep and Radish are familiar examples. Such a root is formed, on the principle of a wedge, for penetrating perpendicularly into the ground. It is common in biennial plants, but not peculiar to them. The caudex, which is the spindle-shaped part, abounds with the proper secreted juices of the plant, and throws out numerous fibres or radicles, which are in fact the real roots, as they alone imbibe nourishment.

4. Radix premorsa, f. S. An Abrupt Root, is naturally inclined to the last-mentioned form, but from some decay or interruption in its descending point, it becomes abrupt, or as it were bitten off. Scubiosa succisa, Devil's-bit Scabious, Engl. Bot. t. 878, Hedypnois hirta, t. 5 ว̌5, and some other Hawkweeds, have this kind of root, the old opinion concermung which cannot be better described than in Gerarde's Herbal, under the plant first named, p. 726 . 
"The great part of the root seemetl to be birten away: old fantasticke charmers report, that the divel did bite it for envie, because it is an herbe that hath so many good rertues, anrl is so beneficial to mankinde." The malice of the devil has unhappily been'so sliccessful that no virtues can now be found in the remainder of the root or herb.

5. Radix tuberosa, f.9. A Tuberous or Knobbed Root, is of many different kinds. The most genuine consists of fleshy knobs, various in form, connected by common stalks or fibres, as in the Potatoe, Salanum tuberosum, and Jerusalem Artichoke*, Iclianthus tuberosus Jacq. Hort. Vind. $t$. 161. 'These linobs are reservoirs of nourishment, moisture, and vital energy. Several of the Vetch or Pea kind are furnished with them on a smaller scale; see Vicia lathyroides, Engl. Bot. t. 30, and several

* A corruption, as I presume, of the Italian name Girasole Articiccco, sun-flower Artichoke, as the plant was first brought from Peru to Italy, and thence propasated throughout Europe. 
species of Trifolium, cither annuads, as glomeratum, t. 1063, or perennials, as fragiferum, t. 1050.-The knobs in these instances are only of annual duration; in the Pcconia, Prony, t. 1513, and Spirca Filipendula, Dropwort, t. 284, they are peremial.-In the Orchidece of Europe they are mostly biennial. The root in many of the latter consists either of a parir of globular or oval bodies, $f .10$, as in Satyrium hircinum, Engl. Bot. t. 34, Ophrys aranifera, t. 65, and apifera, t. 383 ; or are palmate, that is, shaped somewhat like the human hand, $f .11$, as in Orchis maculata, t. 632. Of ihese globular or palmate knobs or bulbs one produces the herb and flowers of the present year, withering away towards autumn, and the other is reserved for the following season, while in the mean time a third is produced to succeed the latter. The knobs of Ophrys spiralis, $t$. 541, are formed three or four years before they flower, and their flowering appears to be occasionally deferred to a more distant period. The root of Satyrium albidum, t. 505 , consists 
of three pairs of tapering knols or bulbs, $f .12$, which flower in succession. On the contrary, Ophrys monorchis, $t .71$, forms its new bulb so late that it is not perfectec till the autumn immediately preceling its flowering, and the plant seems to have but one bulb. Ophrys Nidus avis, t. 48, has clusters of cylindrical knobs, which are formed, and also wither away, in parcels, each parcel being equivalent to one of the above-mentioned bulbs.

Such of the Orchis tribe as have biennial bulbs are supposed to be very difficult of cultivation; but according to the experience of my excellent friend the late Mr. Crowe, in whose garden I have seen them many successive years, they are best removed when in full flower, the earth being cleared completely away from the roots, which are then to be replanted in their natural soil previously dried and sifted. Afterwards they must be well watered. The bulb for the following year has not at the flowering period begun to throw out its fibres, for after that happens it will not bear removal. Satyrium albidum 
having, as mentioned above, so many pairs of roots, the growth of some of which is always going on, has hitherto not been found to survive transplantation at all.

Iris tuberosa, Sm. Fl. Grac. Sibth.t. 41, has a root very analogous to these just described, but I. florentina and I. germanica, t. 39 and 40 of the same work, have more properly creeping roots, though so thick and fleshy in their substance, and so slow in their progress, that they are generally denominated tuberous.

6. Radix bulbosa. A Bulbous Root, properly so called, is either solid, $f: 13$, as in Crocus, Iria, Gladiolus, \&c.; tunicate, $f$. 14, tunicata, composed of concentric layers enveloping one another as in Allimm, the Onion tribe; or scaly; $f .15$, consisting of fleshy scales connected only at their base, as in Lilium, the White or Orange Lily. The two latter linds have the closest analogy with leaf-buds. They are reservolis of the rital powers of the plant during the season when those powers are torpid or latent, and in order to perform the functions of roots, they first produce fibres, which are the actual 
roots. The strict affinity between bulbs and buds appears from the scaly buds formed on the stem of the Orange Lily, Litium bulbif'erum, which fall to the ground, and, throwing out fibres from their base, become bulbous roots*. The same thing happens in Dentaria bulbifera, Engl. Bot. t. 309, and Saxifraga cermua, t. 664.

These two last-mentioned plants however have scaly roots, like the Toothwort, $L a$ thraa Squamaria, t. 50, which seem bulbs lengthened out. Whether they would, in the torpid season of the year, bear removal, like bulbs, we have no information. If disturbed at other times they are immediately killed. Many plants with solid bulbs are provided by Nature to inhabit sandy countries, over the face of which, in the dry season succeeding their flowering, they are scattered by the winds to a great distance, as happens to our own Poa bulbosa, Engl.

* I have had scaly buds form even on the flowerstalk of Lachenalia tricolor, Curt. Mag. t. S\&, whilst lying for many weeks between papers to dry', which, on being put into the ground, have become perfect plants, though of slow growth. 
Bot. t. 1071, as well as to numerous beautiful productions of the Cape of Good Hope.

7. Radix articulata, or granulata, $f .16$. A Jointed or Granulated Root agrees very much with those described in the last section. The Oxalis Acetosella, Wood Sorrel, Engl. Bot. t. 762, and Saxifraga granulata, White Saxifrage, $t .500$, are instances of it. The former has most affinity with scaly bulbs, the latter with solid ones.

It is evident that fleshy roots, whether of a tuberous or bulbous nature, must, at all times, powerfully resist drought. We have already mentioned, $p .41$, the acquisition of a bulb in Phleum pratense, Engl. Bot. $t$. 1076, whenever that grass is situated in a fluctuating soil, by which its vital powers are supported while the fibrous roots are deprived of their usual supplies. In this state it becomes the Phleum nodosum of authors; but on being removed to a thoroughly wet soil, it resumes the entirely fibrous root, and luxuriant growth, of Ph. pratense. I have also found Alopecurus geniculatus, t. 1250, (an 
aquatic grass, whose root is naturally fibrous and creeping,) growing with an ovate juicy bulb on the top of at dry wall. This variety has been taken for the true $A$. bulbosus, t. 1249, which has always bulbs even in its native marshes. We see the wisdom of this provision of Nature in the grasses above mentioncd, nor may the cause be totally inexplicable. When a tree happens to grow from sced on a wall, it has been observed, on arriving at a certain size, to stop for a while, and send down a root to the ground. As soon as this root was established in the soil, the tree continued increasing to a large magnitude*. Here the vital powers of the tree not being adequate, from scanty nourishment, to the usual annual degree of increase in the branches, were accumulated in the root, which therefore was excited to an extraordinary exertion, in its own natural direction, downward. There is no occasion then to suppose, as some have done, that the. tree had any information of the store of food

* A particular fact of this kind concerning an ash was communicated to me by the late Rev. Dr. Walker of Edinburgh. Sce also Trans. of Linn. Soc. v. 2. 26s. 
at the foundation of the wall, and voluntarily sent down its root to obtain it; nor is it wonderful that the Author of life should provide for it as effectually as it could for itself, had it really been a reflecting being. So in the case of the grasses in question, I presume the lierb being in the first instance starved, by a failure of the nutrimental fuids hitherto conveyed by the water of the soil, its growth would be checked, and wh n checked, the same growth could not, as we know by observation on vegetation in gneral, be instantaneously renewed. A sudden fresh supply of food would therefore cause an accumulation of vital energy in the root, which would consequently assume a degree of vigour and a luxuriant mode of growth not natural to it, and become bulbous. Thus it acquires a resource against such checks in future, and the herb is preserved alive, though in a very far less luxuriant state than wh. $\mathrm{n}$ regularly and uniformly supplied with its requisite nourislment. These are not solitary instances. It is well worthy the attention of an inteliigent cultirator to seek them out, and turn them to his adrantage. 


\section{CHAP'TER XIII.}

DIFFERENT KINDS OF STEMS $\Lambda N D$ STALKS OF PIANTS.

LIN N EUS enumerates seven kinds of 'Trunks, Stems, or Stalls of Vegetables. These are necessary to be known, for botanical distinctions, though some are more important than others, both in that respect and in a physiological point of view.

1. CAULIs. A Stem properly so called, which bears, or elevates from the root, the leaves as well as flowers. The trunks and branches of all trees and shrubs come under this denomination, as well as of a great proportion of herbaceous plants, especially annuals.

The Sten is either simple, as in the White Lily, or branched, as in most instances. When it is regularly and repeatedly divided, and a flower springs 
from each division, it is called caulis dichotomus, $f .17$, a forked stem, as in Chlora perfoliata, Engl. Bot. t. 60, as well as the common Mouse-ear Chickweeds, $\mathrm{Ce}$ rastium vulgatum, $t .789$, and viscosum, t. 790 .

Though generally leafy, a Stem may be partially naked, or even entirely so in plants destitute of leaves altogether, as the Creeping Cereus, Cactus flagelliformis, Curt. Mag. t. 17, rarious exotic species of Euphorbia or Spurge, and the whole genus of Stapelia. In Orobanche, it is scaly, f. 18, squamosus.

With respect to mode of growth, the Stem is

Erectus, upright, as in Yellow Loosestrife, Lysimachia vulgaris. Engl. Bot.t. 761.

Procumbens, procumbent, Wood Loosestrife, L. nemorum, t. 527.

Repens, creeping, Creeping Loosestrife, $L$. Nummularia, t. 528, and Creeping Crowfoot, Rununculus repens, $t .516$. Adscendens, ascending obliquely without support, as Panicum sanguinale, t. 849.

Prostratus, prostrate, or Depressus, depressed, when it lies remarkably flat, 
spreading horizontally over the ground, as in Coldenia procumbens; also Coronopus Ruellii, Swine's-cress. Engl. Bot. t. 1660.

Reclinatus, reclining, curved towards the ground, as in Ficus, the Fig, Nubus, the Bramble, \&c.

Radicans, $f .19$, clinging to any other body for support, by means of fibres, which do not imbibe nourishment, as Ivy, Hedera Helix, Engl. Bot. t. 1267 , Vitis quinquefolia, Sm. Insects of Georgia, $t .30$. Bignonia radicans, Curt. Mag. $t .485$. -Linnæus, Philosophia Botanica 39, has expressed this by the term repens, but has corrected it in his own copy. Still he does not distinguish between these plants, and those whose stems throw out real roots, which last only are justly called creeping, whether they grow on the ground, like those above mentioned, or on other plants like Cuscuta, Dodder, Engl. Bot. t. 55 and 378. See p.95.

Scandens, climbing; either with spiral tendrils for its support, as the Vine, Vitis, the various species of Passion-flower, Passifora corulea, Cart. Mag. t. 28, 
alata, t. 66, \&c. and Bryonira divica, Red-berried Bryony, Engl. Bot.t. 439; or by adhesive fibres, as in the preceding paragraph.

Volubilis, twining round other plants by its own spiral form, either from left to right, f. 20, supposing the observer in the centre, (or in other words, according to the apparent motion of the sun,) as the Black Bryony, Tamus communis, Engl. Bot. t. 91, the Honeysuckles, Lonicera Caprifolium, t.799, and Periclymenum, t. 800, and the Polygonum Convolvulus, t. 941 ; or from right to left, $f .21$, contrary to the sun, as the Great Bindweed, Convolvulus sepium, t. 313, the French Bean, Phaseolus vulgaris, Ger. em. 1212, fig. 1, \&c.-Figures of plants being sometimes reversed by the engraver, in that case give a wrong representation of the circumstance in question, witness Lonicera Periclymenum in Curtis's Flora Londinensis, fasc. 1.t.15, and many instances might be pointed out of its not being attended to at all.

Flagelliformis, long and pliant, like the 
Common Jasmine, Jasminum officinale, Curt. Mag. t. 31, or Blue Box-thorn, Lycium barbarum;

Sarmentosus, trailing. A creeping stem, barren of flowers, thrown out from the root for the purpose of increase, is called sarmentum or fagellum, a runner, f. 22, as in the Strawberry, Fragaria vesca, Engl. Bot.t. 1524. When leafy it is generally denominated stolo, a sucker or scyon, as in Bugle, Ajuga reptans, $t .489$, and Viola odorata, the Sweet Violet, t. 619. When the stolo has taken root, it sometimes flowers the first year, see Curt. Lond. fasc. 1 . t. 63, but generally not till the following season.

Rectus, straight, as in Lilium, the different species of garden Lily.

Strictus, expresses only a more absolute degree of straightness.

Laxus or Diffusus, loosely spreading, has a contrary meaning, as in Bunias Cakile, Sea Rocket, Engl. Bot. t. 231, and Sedum acre, Biting Stone-crop, $t .839$. Flexuosus, zigzag, forming angles alter- 
nately from right to left and from left to right, as in Smilax aspera, Ger. em. 859, and many of that genus, also Statice reticulata, Matted Sea Lavender, Lingl. Bot. t.328. In a less degree it is not unfrequent. See Atriplex pedunculatu, t. 232.

Alternè ramosus, alternately branched, as Polygonum minus, t. 1043, Dianthus deltoides, $t .61$, \&c.

Distichus, two-ranked, when the branches spread in two horizontal directions, as in the Silver Fir, Pinus picea, Duhamel, A.t.v. 1.t. 1.

Braclicatus, brachiatc, or four-ranked, when they spread in four directions, crossing each other alternately in pairs; a very common mode of growth in shrubs that have opposite leares, as the Comnon Lilac, Syringa vulgaris.

Ramosissimus, much branched, is applied to a stem repeatedly subdivided into a great many branches without order, as that of an Apple- or Pear-tree, or Gooseberrybush.

Prolifer, proliferous, shooting out now 
branches from the summits of the former ones*, as in the Scotch Fir, Pimus sylvestris, Lambert's Pimus, t. 1. and Lycopodium annotimum, Engl. Bot. t. 1727. This is obsolete, and seldom used.

Determinatè ramosus, $f$. 23, abruptly branched, when each branch, after terminating in flowers, produces a number of fresh shoots in a circular order from just below the origin of those Alowers. This term occurs frequently in the later publications of Linnaeus, particularly the second Mantissa, but I know not that he has any where explained its meaning. It is exemplified in Azalea mudiflora, Curt. Mag. t. 180, Erica Tetralix, Engl. Bot. $t .1014$, many Cape Heaths, and other shrubs of the same Natural Order. Articulatus, jointed, as in Samphire, $S a$ licornia annua, Engl. Bot.t. 415, and more remarkably in the Indian Figs, Cactus Tuna, \&c.

In shape the Stem is

Teres, f. 32, round, as in Trollius europaus,

* Limn, Phil. Bot. sect. 82, 28. 
Engl. Bot. t. 28, and Hydrangea hortensis, Sm. Ic. Pict.'t. 12.

Anceps, two-ediged, as Sisurinchium striaium, Sm. Ic. Pict. t. 9. S. gramineum, Curt. Mag. t. 464, and some of the genus Lathyrus.

Trigonus, or Triangularis, triangular or three-edged, as Cactus triangularis, Plukenet, t. 29. f. 3.

Triqueter, three-sided, is applied to a stem with 3 flat sides.

Tetragonus, or Quadrangularis, square, as Lamium album, White Dead-nettle, Engl. Bot.t.768, and a multitude of other plants.

Pentagonus, or Quinquangularis, firesided, as Asparugus horridus, Cavanilles Ic. $t$. 136, where however the character is not well expressed.

When the number of angles is either variable, or more than five, it is usual merely to describe the stem as angulosus, angular, except where the precise number makes a specific difference, as in the genus Cactus.

Alatus, $f .36$, winged, when the angles are extended into flat leafy borders, as L'assi- 
flora alata, Curt. Mag. t. 66, Lathyrus latifolius, Engl. Bot.t. 1108, and many others of the Pea kind, besides several Thistles, as Carduus acanthoides, $t .973$, palustris, t.974, and Centaurca solstitialis, t. 243.

The Surface of the Stem is

Glaber, smooth, opposed to all kinds of hairiness or pubescence, as in Petty Spurge, Euphorbia Peplus, Engl. Bot. t. 959, and numerous plants besides.

Levis, smooth and even, opposed to all roughness and inequality whatever, as , in the last example, and also Euonymus europarus, t. 362.

Nitidus, polished, smooth and shining, as Chcerophyllum sylvestre, $t .752$.

Viscidus, viscid, covered with a clanmy juice, as Lychnis Viscaria, t. 788.

Verrucosus, warty, like Euonymus verrucosus, Jacq. Fl. Austriaca, t. 49, and Malpighia volubilis, Curt. Mag. t. 809.

Papillosus, papillose, eovered with soft tubercles, as the Ice plant, Mesem- 
bryanthemum crystallinum. Dill. Elth. t. 130.

Scaber, rough to the touch from any little rigid inequalities, opposed to lexis, as Caucalis Anthriscus, Engl. Bot.t.987, Centaurea nigra, t. 278, and Stellaria holostea, t. 511.

Hispidus, bristly, as Borage, Borago officinalis, t. 36, and Chara hispida, t. 463. Hirtus, or Pilosus, hairy, as Salvia pratensis, t. 153, and Cerastium alpinum, t. $4.7 \%$

Tomentosus, downy, as Gcranium rotundifolium, $t .157$, very soft to the touch. Villosus, shaggy, as Cineraria integrifolia, t. 15 \%.

Lanatus, woolly, as Verbascum pulverulentum, t. 487, V.Thapsus, t.549, and Santolina maritima, $t .141$.

Incanus, hoary, as Wormwood, Artemisia Absinthium, t. 1230, and Atriplex portulacoides, t. 261, in the former case from close silky hairs, in the latter from a kind of scaly mealiness.

Glaucus, clothed with fine sea-green mealiness which casily rubs off, as Chlora 
perfoliata, $t .60$, and Pulmonaria maritima, $t .368$.

Striatus, striated, marked with fine parallel lines, as Oenanthe fistulosa, t. 363. Sulcatus, furrowed, with deeper lines, as Smymium Olusatrum, t. 230. Maculatus, spotted, as Hemlock, Conium maculatum, t. 1191.

The spines and prickles of the stem will be explained hereafter.

Internally the stem is either solidus, solid, as that of Inula crithmoides, $t .68$, and numerous others; or cavus, hollow, as in Cineraria palustris, $t .151$, as well as Hemlock, and many umbelliferous plants besides.

Plants destitute of a stem are called acaules, stemless, as Neottia acaulis, Erot. Bol.t.105, and Carduus acautis, Engl. Bot. t. 161. Such plants, when they belong to a genus or family generally furnished with stems, as in these instances and Carlina acaulis, Camer. Epit.428, are liable from occasional luxuriance to acquire some degree of stem, but seldom otherwise. Pinguicula, Engl. Bot. t. 70 and 145 , is a genus invariably stemless, while Primula, t. 4, 5, 6 and 513, is much 
less truly so. The term acaulis however must never be too rigidly understood, for logical precision is rarely applicable to natural productions.

Caulis fusciculatus, a clustered stem, is a disease or accident, in which several branches or stems are united longitudinally into a fiat broad figure, crowded with leaves or flowers at the extremity. It occurs in the Ash, several species of Daphne, Ranunculus, Antirrhinum, \&c. In a kind of Pisum, called the Top-knot $\mathrm{Pea}$, it is a permanent rariety propagated by seed.

2. Cularus. A Straw or Culm, is the peculiar Stem of the Grasses, Rushes, - and plants nearly allied to them. It bears both leaves and flowers, and its nature is more easily understood than defined. Many botanists hare thought this term superfluous.

The Culm is occasionally

Enodis, without joints, as in our common Rushes, Juncus conglomeratus, Engl. Bot.t.835, and effusus, t.836; 
Articulatus, jointed, as in Agroitis alba, t. 1189, Aira canescens, t. 1190, Avena strigosa, t. 1266, and most othe: grasses;

Geniculatus, bent like the knee, as Alopecurus geniculatus, $t$. 1250 .

It is either solid or hollow, round or triangular, rough or smooth, sometimes hairy or downy, scarcely woolly. I know of no instance of such a scaly culm as Linnæus has figured in his Philosophia Botanica, $t$. \&, f. 111 , nor can I conceive what he had in view.

3. Scapus. A Stalk, springs from the Root, and bears the flowers and fruit, but not the leaves. Primula vulgaris, the Primrose, Engl. Bot. t. 4, and P. reris, the Cowslip, t. 5, are examples of it. In the former the stalk is simple and singleflowered; in the latter subdivided and many-flowered. It is either naked, as in Narcissus, Engl. Bot. t. 17, or scaly, as in Tussilago Farfara, t. 429. In others of this last genus, t. 430 and 431, the 
scales become leafy, and render the Scapus a proper Caulis.

The Stalk is spiral in Cyclamen, Engl. Bot. . 548, and Valisneria spiralis, a wonderful plant, whose history will be detailed herenfter.

Linneus believed that a plant could not be increased by its Seapus, which in general is correct, but we have already recorred an exception, $1 \%$. 112, in Lachenalic tricolor. The same great author has observed that "a Scapus is only a species of Pedunculus.", 'The term might therefore be spared, were it not found very commodious in constructing neat specific definitions of plants. If abolished, P'edunculus radicalis, a radical flower-stalk, should be substituted in its room.

4. Prounculus, the Flower-stalk, springs from the stem, and bears the flowers and fruit, not the leares. Pedicellus, a partial flower-stalk, is the ultimate subdivision of a general one, as in the Cowslip, and Sarifraga umbrosa, Engl. Bot. t. 663.

$$
\text { * MSS. in Plil. Bot. } 40 . \text { + Ibia. }
$$


The Flower-stalk is

Caulimus, cauline, when it grows immediately out of the main stem, especially of a tree, as in Arerrhoa Bilimbi, Rumph. Amboin. r. 1. t. 36, the Indian substitute for our green gooseberries.

Rameus, growing out of a main branch, as in Aicrrhoa Carambola, ibid. t. 35, and Eugenia malaccensis, Erot. Bot. t. 61 .

Alillaris, axillary, growing either from the bosom of a leat, that is, between it and the stem, as Anchusa sempervirens, Engl. Bot. t. 45, and Campamula Trachelium, t. 12; or between a branch and the stem, as Ruppia maritima, t. 136 .

Oppositifolius, opposite to a leaf, as $\mathrm{Ge}$ raninm pyrenaicum, t. 40ั̆, G. molle, t. 778, and Sium angustifolinm, t. 139 .

Internodis, proceeding from the intermediate part of a branch between two leaves, as in Ehretia intcrnodis, L'Heritier Stirp. t. 24, Solanum carolinense, Dill. Hort. Elth. $t$. 259, and indicum, 
t. 260 ; but this mode of insertion is rare.

Gemmaceus, growing out of a leaf-bud, as the Barberry, Berberis vulgaris, Engl. Bot. t. 49.

Terminalis, terminal, when it terminates a stem or branch, as Tulipa syluestris, t. 63, and C'entaurea Scabiosa, t. 56. Lateralis, lateral, when situated on the side of a stem or branch, as Ericı vagans, t. 3.

Solitarius, solitary, either single on a plant, as in Rubus Chamcmorus, t. 716, or only one in the same place, as in $A n$ tirrhinum spurium, t. 691, and many common plants.

Aggregati Pedunculi, clustered flowerstalks, when several grow together, as in Verbascum nigrum, t. 59.

Sparsi, scattered, dispersed irregularly over the plant or branches, as Linum. perenne, t. 40, and Ranunculus sceleratus, t. 681.

Uniflori, biflori, triflori, \&c. bearing one, two, three, or more flowers, of which examples are needless. 
Multiflori, many-flowered, as Datphne Laureola, t. 119.

When there is no Flower-stalk, the flowers are said to be Sessiles, sessile, as in Centaurea Calcitrupa, $t .125$, and the Dodders, $t .55$ and 378.

The subject of inflorescence, or particular modes of flowering, will be explained in a future chapter.

5. Petrolus. The Footstalk, or Leafstalk. This term is applied exclusively to the stalk of a lcaf, which is either simple, as in Ranunculus parviflorus, Engl. Bot. t. 120, Sium angustifolium, t. 139, and all simple leares; or compound, as Coriundrum sutivum, t. 67, and Fumaria claviculata, $t .103$. In the latter the footstalks end in tendrils, and are called Petioli cirriferi.

This part is commonly channelled on the upper side. Sometimes it is greatly dilated and concave at the base, as in Angelica sylvestris, $t .1128$.

The Footstalk bears the Flower-stalk in Tumera ulmifolia, Linn. Hort. Cliff. t. 10, 
Menyanthes indica, Curt. Mag. t. 658, and perhaps Epimedium alpinum, Engl. Bot. t. 438 .

6. Froxs. A Frond. In this the stem, leaf and fructification are united, or, in other words, the flowers and fruit are producet from the leaf itself, as in the Fern tribe, Scolopendrium vulgare, Engl. Bot.t. 1150, Polypodiun vulgare, t. 1149, Aspidium, t. 1458-1461, Osmunda regalis, t. 209, \&c. It is also applied to the Lichen tribe, and others, in which the whole plant is either a crustaceous or a leafy substance, from which the fructification immediately proceeds. Linnæus consiclered Palm-trees as fronds, so far correctly as that they have not the proper stem of a tree, see $p .58$; but they are rather perhaps herbs whose stalks bear the fructification. It must however be observed that the deposition of wood in ferns, takes place exactly as in palms.

The term frond is now used in the class Cryptogamia only. 
7. Sripes, Stipe*, is the stem of a frond, which in ferns is commonly scaly. See the plates cited in the last section. The term is likewise applied to the stalk of a Fungus, as the Common Mushroom, Agaricus campesiris, Sowerby's Tungi, t. 305 .

* Martyn, Language of Botany. 


\section{CHAPTER XIV.}

OF BUDS.

GEMMA, a Bud, contains the rudiments of a plant, or of part of a plant, for a while in a latent state, till the time of the ycar and other circumstances favour their evolution. In the bud therefore the vital principle is dormant, and its excitability is accumulated. The closest analogy exists between buds and bulbs; and indeed the Dentaria bulbifera, Engl. Bot. t. 309, Lilinm bulbiferum, Jacq. F\% Austr. t. 226, and Gerarde emac. 193, with other similar plants, as mentioned p. 111, almost prove their identity.

Buds of trees or shrubs, destined for cold countries, are formed in the course of the summer in the bosoms of their leaves, and are generally solitary; but in the Blue-berried Honeysuctite, Lonicera carulea, Jac 
Fl. Austr. append. $t$. 17, they grow one under another for three successive seasons, $f .24$. The buds of the Plane-tree, Platamis, Du Famel Arb. v. 2. 171, are concealed in the footstalk, which must be removed bctore they can be seen, and which they force off by their increase; so that no plant can have nore truly and, necessarily deciduous leaves than the Plane. Shrubs in general have no burts, ncither have the trees of hot climates. Linnaus once thought the presence of buts might distinguish a tree from a shrub, but he was soan convinced of there being no real limits between them.

The situation of buds is necessarily like that of the leaves, altemate, opposite, Sc. Trees with opposite leaves have three buds, those with alternate ones a solitary bud, at the top of each branch. Du Hamel.

Buds are various in their forms, but rery mniform in the same species or even genus. They consist of scales closely enveloping each otiby, and enfulding the cmbryo plant or branch. Externally they have often an additional guard, of gum, resin or woolliness, against wet and cold. The Horse Clesinut, 
Asculus Hippocustanum, now so common with us, though, as I have learnt from Mr. Hawkins*, a native of Mount Pimlus in Arcadia, is a fine example of large and wellformed buds, f.25; and some of the American Wahuts are still more remarkable.

It has been already rematrked, p. g0, that buds resist cold only till they begin to grow : hence, according to the natuse and earliness of their buds, plants differ in their powers of bearing a severe or variable climate.

Grew is elaborate on the forms of buds, and the arrangement of the spots apparent within them when cut transversely, which indicate the number and situation of their vessels. It was the character of this excellent man to observe every thing, without reference to any theory, and his book is a storchouss of facts relating to vegetation. Loefling, a farourite pupil of Linnæus, wrote, under the eye of his great teacher, an essay on this subject, published in the Imonitates Academice, $v .2$, in which the varions forms of buds, and the different disposition of the

* See a note on this subject, which Mr. R. P. Knight has honoured with a place in the second edition of his pnem on Landscape. 
leaves whin then, are illustrated by numerous examples. The Abbé de Ramatuelle had taken up this subject with great zcal at Paris, about twenty years ago, but the result of his inquiries has not reached me.

Dr. Darwin, Plhytologia, sect. 9, has many acute observations on the physiology of buds, but he appears to draw the analogy too closely between them and the embryo of a seed, or the chich in the egg. By buds indeed, as we well lnow, plants are propagated, and in that sense each bud is a separate being, or a young plant in itself; but such propangation is only the extension of an individual, and not a reproduction of the species as by seed. Accordingly, all plants increased by buds, cuttings, layers or roots, retain precisely the. peculiar qualities of the individual to which they owe their origin. If those qualities differ from what are common to the species, sufficiently to constitute what is called a variety, that variety is perpetuated through all the progeny thus obtained. This fact is exemplified in a thousand instances, none more notorious than the different kinds of Apples, all which are raricties of the common $\mathrm{Crab}_{\text {, }}$ 
P'yrus Malus, Engl. Bot. t. 179; and I comrot but assent to Mr. Knight's opinion, that each indiridual thus propagated has only a determinate existence, in some cases longer, in others shorter; from which cause many valuable varieties of apples and pears, known in former times, are now worn out, and others are dwindling away before our eyes. New varieties of Cape Geraniums, raised from seed in our greenhouses, are of still shorter duration, and can be preserved by cuttings for a few successive seasons only; yet several of these stand in our botanic works, with all the importance of real species. Gurdeners know how many of the most hardy perennial herbs require to be frequently renewed from seed to exist in full vigour; and though other's appear, to our confined experience, unlimited in that respect, we have many reasons to bclicve they are not so. Propagation by seeds is therefore the only true reproduction of plants, by which each species remains distinct, and all variations are effaced; for though new varieties may arise among a great number of secdling plants, it does not appear that such varietics owe their pecu- 
liarities to any that may have existed in the parent plants. How propagation by seed is accomplished will be explained in a future chapter, as well as the causes of some varieties produced by that means.

Mr. Knight, in the M'hilosophical Transactions for 1805, has shown that buds originate from the alburnum, as might indeed be expected. The trunks and branches of trees, and the knobs of genuine tuberous roots, like the potatoe, are studiled with them; in which respect, as Professor Willdenow judiciously observes, Principles of Lotany, p. 15, such roots essentially differ fiom bulbous onts, which last are themselves simple buds, and produce their shoots, as well as their offsets, either from the centre or from the base.

The contents of buds are diflerent, even in different species of the same genus, as Willows. The buds of some produce leaves only, others flowers; while in other species the same bud bears both leaves and flowers. Different causes, depending on the soil or situation, seem in one case to generate leafbuds, in another flower-buds. Thus the Solandra grandiflora, Tr. of Lim. Soc. 2.6. 
99. t. 6, a Jamaica shrub, was for a number of years cultivated in the English stoves, and propagated extensively by cuttings, each plant growing many feet in length every season, firom abundance of moisture and nourishment, without showing any signs of fructification. At length a pot of the Solandra was accidentally left without water in the dry store at Kew; and in consequence of this mintentional neglect, the luxuriant growth of its branches was greatly checked, and a flower came forth at the extremity of each. By a similar mode of treatment the same. effect has since frequently been produced. Several plants, especially with bulbous roots, which blossom abundantly in their native soils, have hitherto defied all the art of our gardeners to produce this desirable effect; yet future experience may possibly place it within our reach by some very simple means. In general, whatever checks the luxuriant production of leaf-buds, favours the formation of flowers and seeds. That variety, or perhaps species, of the Orunge Lily, Lilium bulbiferum, which is most prolific in buds, seldom forms seeds, or even those organs 
of the flower necessary to their porfection. So likewise the sects of Mints, a tribe of plants which increase excessirely by roots, have hardly been detected by any botanist; and it is asserted by Doody in Ray's Simopsis, that when the elrgant little Omithopus perpusillus, Engl. Bot. to 369, does not procluce pods, it propagates itself by the grains or tubercles of its root, though in general the root is annual. 


\section{CHAPTER IV.}

OF LEAVES, THEIR SITUATIONS, INSERTIONS, SURFACES, AND VARIOLS FORAIS.

Foritu, the Leaf, is a very general, but not universal, organ of vegetables, of an expanded form, presenting a much greater surface to the atmosphere than all the other parts of the plant together. Its colour is almost unirersally green, its internal substance pulpy and vascular, sometimes rery succulent, and its upper and under surfaces commonly differ in hue, as well as in kind or degree of roughness.

Leaves are eminently ornamental to plants from their pleasing colour, and the infinite variety as well as elegnnce of their forms. Their many economical uses to mankind, and the importance they hold in the scale of 
nature as furnishing food to the brute creation, are subjects foreign to our present purpose, and need not here be insisted upon. Their essential importance to the plant which bears them, and the curious functions by which they contribute to its health and increase, will presently be detailed at length. We shall first explain their different situations, insertions, forms, and surfaces, which are of the greatest possible use in systematical botany.

The leaves are wanting in many plants; called for that reason plantce aphylla, as Salicornia, Eugl. Dot. t. 415, and 1691, Stapelia rariegata, Curi. Mag. t. 26, glanduliflora, Exot. Bot. t. 71, and all the specics of that genus. In such cases the surface of the stem must pertorm all their necessary functions.

1. With respect to Situation and Position, Folia radicalia, rudical leaves, are such as spring from the root, like those of the Cowslip, Engl. Bot. t. 5, and Anemone Pulsatillu, t. 51 .

- Caulina, stem-leares, grow on the stem 
as in Paris quadrifoliu, t. 7, Polemonium ceruleum, t. 14, \&c.

Ramea, branch-leaves, sometimes differ from those of the main stem, and then require to be distinguished from them, as Melampyrum arvense, $t$. 53 .

Alterma, f. 21, alternate leaves, stand solitarily on the stem or branches, spreading in different directions, as those of Borage, t. 36, and innumerable othler plarnts.

Sparsa, f.19, scattered irsegularly, as in Genista tinctoria, t. 44, Lilium chalcedonicum, Curt. Mag.t.30, and bulbiferum, t. 36.

Opposita, opposite to each other, as Saxifraga oppositifolia, Engl. Bot. t. 9, Ballota nigra, t. 46, \&c.

Conferta, clustered, or crowded together, as those of Trientalis europica, $t .15$.

Bina, only two upon a plant or stem, as in the Snowdrop, Galanthus nivalis, t. 19, Scilla bifolia, t. 24, and Convallaria majalis, $t$. 1035.

Terna, three together, as Verbena triphylla, Curt. Mag.t. 367. The plants of Chili and Peru seem particularly disposed to this arrangement of their leaves. 
Quaterna, quina, \&c. when 4, 5, or more are so situated, as in various species of Heath, Erica.

Verticillata, whorled, is used to express several leaves growing in a circle round the stem, without a reference to their precise number, as in Asperula cynanchica, Engl. Bot. t.33, and odorata, t. 755, which with the genus Galiun, and some others, are for this reason calied stellatce, star-leaved plants. Whorled leaves are also found in Hippuris iulgaris, $t .763$, and many besides.

Fasciculata, $f$. 26, tufted, as in the Larch, Pinus, Larix, Lamb. Pin. t.35, the Cedar, and some others of that gुenus.

Imbricata, f. 27 , imbricated, like tiles upon a house, as in the common Ling, Erica vulgaris, Engl. Bot.t. 1013, and Euphorbia paralia, t. 195.

- Decussaía, f. 28, decussated, in pairs alternately crossing each other, as Veronica decussata, Curt. Mag.t.240, and Melaleuca thymifolia, Errot. Bot.t. 36.

Disticha, f. 29, two-ranked, spreading in two directions, and yet not regularly op- 
posite at their insertion, as Pims canadensis, Lamb. Pin. t. 32, and the Yew, Tarus baceata, Engl. Bot. t. 746 .

Secunda, $f$. 30, unilateral, or leaning all towards one side, as Convallaria mulitflora, t. 279.

Adpressa, close-pressed to the stem, as Xeranthemum sesamoides, Curt. Mag. t. 425 .

Verticalia, perpendicular, both sides at right angles with the horizon, as Lactuca Scariola, Engl. Bot.t. 268.

Erecta, upright, forming a very acute angle with the stem, as Juncus articulatus, t. 238.

Patentia, spreading, forming a moderately acute angle with the stem or branch, as Atriplex portulacoides, $t$. 261.

Horizontalia, horizontal, or patentissima, spreading in the greatest possible degree, as Gentiana campestris, t. 237.

Reclinata, inclining downward, as Leonurus Cardiaca, t. 286.

Recuria, or reflexa, curved backward, as Erica retorta, Curt. Mag.t. 362.

\section{2}


Incurva, or imfexa, curred inward, as Lrica empetrifolia, $t .447$.

Obliqua, twisted, so that one part of each leat is vertical, the other horizontal, as Fritillaria obliqua, t. 857, and some of the large Protece.

Resupinata, reversed, when the upper surface is tumed downward, as Platus latifolius, Browne's Jamaica, t. 38. Limn. Mss., and Alstremeria pelegrina, Curt. Mag.t. 139.

Depressa, radical leaves pressed close to the ground, as Plantago media, Engl. Bot. t. 1559, and P.Coronopus, t. 892. The same term applied to stem-leaves, expresses their shape only, as being vertically flattened, in opposition to compressa.

Natrintia, floating, on the surface of the water, as Nymphea lutea, t. 159, and ulba, t. 160, and Potamogeton natans, and many water plants.

Demersa, immersa, or submersa, plunged muder water, as Potamogeton perfoliutum, t. 168, Hottonia palustris, t. 364, Lobeliu Dontmanna, t. 140, and the 
Iower leares of Rammentus aquatilis, t. 101, while its upperare folla natamtia. Emersa, labised above the water, as the npper leaves, accompanying the flowers, of Mhriophyllum zerticillatum, t.218, while its lower ones are demersa.

2. By Insertion is neant the mode in which one part of a plant is connecter wilu another.

Folia petiolata, leaves on footstallis, are such as are fumished with that organ, whether long or short, simple or eompound, as Terbascum nigrum, Engl. Bot. t. 59, Thalictrum minue, t. 11, alpimum, t. 262, \&c.

Peltata, f. 31, peltate, when the footstalk is inserted into the middle of the leaf, like the arm of a man holding a shield, as in the Common Nasturtiun, Tropecolum majus, Curt. Wasg.t. 23, Drosera peltata, Exot. Bot. t.41, Cotyledon. Umbilicus, Engl. Bot.1.325, Mydrocotyle rulgaris, $t .751$, and the noble Cyumus Nelumlio, Exol. Bot.t. 31, 32.

Sessiliu, sessile, are such as spring imme- 
diately from the stem, branch or root, without any footstalk, as in Anchusa sempervirens, Engl. Bot. t. 45, and Pinguicula vulgaris, $t .70$.

Amplexicaulia, f. 39, clasping the stem with their base, as the upper leaves of Glaucium luteum, t. 8, Géntiana campestris, t. 237, and Humea elegans, Exot. Bot. t. 1.

Comnata, $f .17$, connate, united at their base, as Chlora perfoliala, Engl. Bot. t. 60, whose leaves are comato-perfoliata.

Perfoliata, $f$. 33, perfoliate, when the stem runs through the leaf, as Bupleurum rotundifolium, $t .99$, and the Uvularice, Exot. Bot.t. 49, 50, 51.

Vaginantia, f. 34, sheathing the stem or each other, as in most grasses; see Phleum alpinum, Engl. Bot.t. 519, and Arundo arenaria, $t .520$. The same character is found in many of the Orchis tribe, as Satyrium albidum, $t$. 505 .

Equitantia, $f .35$, equitant, disposed in two opposite rows and clasping each other by their compressed base, as in Narthecium ossifragum, t.535, and the genus Iris; 
also Witsenia corymbosa, Exot. Bot. t. 63, and Dilatris corymbosa, t. 16.

Decurrentia, $f: 36$, decurrent, running down the stem or branch in a leafy border or wing, as Onopordum Acanthium, Eingl. Bot. t.977, Carduus temiflorus, t. 412, and many other Thistles, also the Great Mullein, I crbascum Thapsus, t. 549, and Comfrey, Symphytum officinule, t. 317.

Hlorifera, f: 37 , flower-bearing, when flowers grow out of the disk or margin of any leaf, as in Ruscus aculeatus, 1.560, Xylophylla latifolia, and X. falcatu, Andr. Repos. t. 331. This is equivalent to a frond in the class Cryptogamia; see p. 133.

3. With regard to form, Leaves are either simplicia, simple, like those of Grasses, Orchises, Lilies, and many other plants, as Ballota nigra, Engl. Bot. t. 46, and Berberis vulgaris, t. 49; or composita, compound, as in most Umbelliferous plants, Parsley, Hemlock, \&c.; also Roses, Engl. Bot.t. 990-092. 
In compound leaves the footstalk is either sumple, as in the instances last quoted, and Sium angustifolium, t. 139; or compound, as those of Selinum palustre, t. 229, and Thalictrum majus, t. 611.-In simple leaves the footstalk, if present, must of course be simple, while in compound ones it must alway,s be present, though not always subdivided.

Simple Leaves are either integra, undivided, as those of Grasses and Orchises; or lobata, lobed, like the Vine, the Thistle, most kinds of Cranesbill, as Geranium pratense, Engl. Bot. t. 404, \&c.

Leaves are frequently undivided and lobed on the same plant, as the Hop, Engl. Bot.t. 427.

4. The following are the most renarkable forms of Simple Leaves, considering their outline only.

Orbiculatum, f. 38, a circular or orbicular leaf, whose length and breadth are equal, and the circumference an even circular line. Precise examples of this are 
scarcely to be found. Some species of Piper approach it, and the leaf of IIedysarum styracifolium is perfectly orbicular, except a notch at the base.

Subrotundum, f: 39, roundish, as Pyrola, Engl. Bot.t. 146, 158 and 213, and many other plants.

Ovatum, $f .40$, ovate, of the shape of an ergs cut lengthwise, the base being rounded and broader than the extremity, a very common form of leaves, as Urtica pilulifere, $t .14 \mathrm{~S}$, and Vinca major, $t .514$. Obovatum, $f .41$, obovate, of the same figure with the broader end uppermost, as those of the Primrose, $t$. 4 , and the Daisy, $t$. 424. Linnæus at first used the words obversè ovatum.

Ellipticum, f. 42, or ovale, elliptical or oval, of a similar form to the foregoing, but of equal breadth at each end, as in the Lily of the Valley, and other Convallavice, t. 1035, 279 and 280.

Oblongum, oblong, three or four times longer than broad. This term is used with great latitude, and serves chiefly in a specific character to contrast a leaf 
which has a variable, or not very decided, form, with others that are precisely round, ovate, linear, \&c.

Spatulatum, $f .43$, spatulate, of a roundish figure tapering into an oblong base, as in Silene Otites, Fl. Brit. Engl. Bot. t. 85. Cuneiforme, $f .44$, wedgrc-shaped, broad and abrupt at the summit, and tapering down to the base, as in Saxifiaga cuneifolia.

Lanceolatum, $f .45$, lanceolate, of a narrow oblong form, tapering towards each end, very common, as Tulipa sylvestris, Engl. Bot. t. 63, Lithospermum purpurocarulcum, t. 117, Plontago lanceolata, t. 507, many Willows, \&c.

Iineare, $f .46$; linear, narrow with parallel sides, as those of most Grasses; also Gentiana Pneumonanthe, t. 20, and Narcissus Pseudo-narcissus, t. 17.

Acerosum, $f: 47$, needle-shaped, linear and evergreen, generally acute and rigir, as in the Fir, Pinus, Juniper, Juniperas communis, t. 110(), and Yew, Taxis baccata, t.746. Linnaus observes, Plill. Bot. 219, that this kind of leaf hais, for 
the most part, a joint at its union with the branch.

Triangulare, $f .48$, triangular, haring three prominent angles, without any reference to their measurement or direction, as in the genus Chenopodium, Cochlenria danica, t. 696, and some leaves of the Ivy.

Quadrangulare, $f .49$, with four angles, as the Tulip-tree, Liriodendrum tulipifera, Sm. Ius. of Georgia, t. 102. Curt. Mağ. t. 275.

Quinquangulare, $f$. 19, with five angles, as some Ivy leaves, \&c.

Deltoides, $f$. 50, trowel-shaped or deltoid, having three angles, of which the terminal one is much further from the base than the lateral ones, as Chenopodium BomusHemicus, Engl. Bot.t. 1033, and some leaves of Cochlearia danica. A wrong figure is quoted for this in Philosophia Botanica, which has caused much confusion.

Rhombeum, f. 51, rliomboid, or diamondshaped, approaching to a square, as Chenopodium olidum, t. 1034, Trapa 
matans, Camer. Ejpit.715, and Trillum erectum, Curt. Mag. t. 470.

Reniforme, f. 5\%, kidney-shaped, a short, broad, romdish leaf, whose base ishollowed out, as Asarum europaun, Engl. Bot. t: 1083, and Sibihorpia europeen, t. 649).

Cordutum, f.53, heart-shaped, according to the vulgar idea of a heart; that is, ovate hollowed out at the base, ats Tumus communis, t. 91.

Iumlatum, f. 54, crescent-shaped, like a hali-moon, whether the points are directed towards the stalk, or from it; as Passifiora lunata, Sm. Ic. Pict. t. 1.

Sagittatum, f.5.5, arrow-shaped, triangular, hollawed out rery much at the base, as Sagittaria sagitififolia, Engr. Bot. t. 84, and Rumer Acetosa, t. 127.

Sometimes the posterior angles are cut off, as in Convolvulus sepium, t. 313.

Masiatum, $f$. 56, halberd-shaped, triangular, hollowed out at the base and sides, but with spreading lobes, as Rumer Acetosella, t. 1674, Antirhimum Elatine, $t .692$, and the upper leares of Solanum Dulcamara, t. 565 . 
Panduriforme, f.5̄, fiddle-shraped, oblong. broand at the two extremities and contracted in the middle, as the Fiddle Doek, Rumex mulcher, t. 1576 .

Runcinatum, f.58, runcinate, or lion-toothed, cut int sornal tramsverse, acute sogments, pointmg brech wards, as the Dendelion, Leontodon Taraxacum, t. S1\%.

Inpratim, f. 59, lyate, or lyre-shaped, cut into sereral transwerse segments, gradually larger towards the extremity of the leaf, which is rounded, as Erysimum Barbareu, 1. 443 .

Fissum, f: 60, cloven, when the margins of the fissures and segments are straight, as in the Gingko-tree, Salisburia adiantifolia. Bifidum, trifidum, multifidum, \&c. express the number of the segments.

Lobatum, f. 61, lobed, when the margins of the segments are rounded, as in Anemone Hepatica, Cart. Mag. t. 10.

Bitobum, tritobum, \&c., according to the number of the lobes.

Simutum, f. 62, sinuated, cut into rounded or wide openings, as Statice simuata, $t .71$, and Tirgilia helioides, Erot. Bot. t. 37. 
Partitum, f. 63, decply civided, nearly to the base, as Helleborus viridis, Engl. Bot. t. 200.

Bipartitum, tripartitum, multipartitum, according to the number of the divisions. Laciniatum, $f .64$, laciniated, cut into numerons irregular portions, as Ramunculus parviflorus, t. 120, and Geranium columGimum, $t .259$.

Incisum, and Dissectum, cut, are nearly synonymous with the last.

It is remarked by Linnæus that aquatic plants have their lower, and mountainous ones their upper, leaves most divided, by which they better resist the action of the stream in one case, and of wind in the other. Probably these actions are in some mcasure the causes of such configurations.

Palmatum, $f .65$, palmate, cut into screral oblong, nearly equal segments, about half way, or rather more, towards the base, leaving an entire space like the palm of the hand, as Passifiora ccerulea, Curt. Mag. t. 28.

Pinnatificlum, $f .66$, pinnatifid, cut trans- 
versely into several oblong parallel segments, as in Ipomopsis, Erot. Bot.t.13, 14, Bunias Cakile, Engl. Bot.t.9s1, Lepidium didymum, t.248, petrceum, t.111, and Myriophyllum verticillatum, $t .218$. Bipinnatifidum, f. 67 , doubly pinnatificl, as Pupaver Argemone, t.643, and Eriocalic major, Erot. Bot. t.78.

P'ectinatum, $f$ : 68, pectinate, is a pinnatifid leaf, whose segments are remarkably narrow and parallel, like the teeth of a comb, as the lower leaves of Myriophyllum verticillatum, and those of Hottonia palustris, Engl. Bot.t. 364 .

Incequale, $f: 69$, unequal, sometimes called oblique, when the two halies of the leaf are unequal in dimensions, and their bases not parallel, as in Eucclyptus resinifera, Exot. Botot. t. 84, and most of that genus, as well as of Begronic.

5. The Terminations of Leares are various. Folium truncatum, $f .49$, an abrupt leaf, has the extremity cut off, as it were, by a transverse line, as Liriodendrun tulipifera, Curt. Mag. t. 270. 
Promorsum, f. 70, jagged-pointed, rery blunt, with various irregular noiches, as in Dr. Swartz's genus Ärrides, comprehended under the Epidena'vim of Lir. nacus. See E. tessellatum, Roxb. Pl. of Coromandel, t. 42, and promorsum, t. 43 .

Retusum, f.71, retuse, ending in a broad shallow notch, as Rumer digynus, Engl. Bot. t. 910.

Emarginatum, f.72, emarginate, or nicked, having a small acute notcl at the summit, as the Bladder Senna, Colutea arborescons, Curt. Mag. t. 81.

Obtusum, $f .39$, blunt, terminating in a segment of a circle, as the Primrose, Engl. Bot.t. 4, Snowdrop, t. 19, Hypericum quadrangulum, $t$. 370 , and Linum cathorticum, $t, 382$.

Acutum, $f .51$, sharp, ending in an acute angle, which is common to a great variety of plants, as Ladies'Slipper, $t$. 1, Campamila Trachelium, $t$. 12, and Linum aingustifolium, $t .381$.

Acuminatum, f. 73, pointed, having a taper or awlshaped point, as Arundo Phrag- 
mites, t. 401, and Scirpus maritimus, t. 542.

Obtusum cum acumine, $f .74$, blunt with a small point, as Statice Limonium, t. 102.

Macronutum or Cuspidatum, $f .75$, sharppointed, tipped with a rigid spine, as in the Thistles, t. 107, t.386, \&c., Ruscus aculeatus, t. 500, and II claleuca nodosa, Erot. Bat. 1. 35 .

Cirrosum, f.76, cirrose, tipped with a tendril, as in Gloriosa supcrba, Andr. Repos.t. 129.

6. The different Margins of Leaves are characterized as follows.

Folium integerrimum, $f: 39$, an entire leaf, as in the Orchis and Lily tribe, as well as Polygula wulgaris, Engl. Bot. t.76, Daphne Laureola, t. 119, \&c.

This term is opposed to all kinds of teeth, notches, or incisions. It regards solely the margin of a leaf; whereas integrum, p. 152, respects its whole shape, and has nothing to do with the margin. English writers who translate the one entire, and the other very entire, are therefore incorrect. 
Spinosum, $f .77$, spinous, beset with pricklcs, as Cardus lanceoiatus, t. 107, and Eryngium campestre, t. 57. The veins are spinous in Solanum Pyracantha, Erot. Bot. t. 64, \&c.

Inerme, $f .71$, unarmed, is opposed to spinous.

Ciliatum, $f .78$, fringed, bordered with soft parallel hairs, as Gulium cruciatum, Engl. Bot. t. 143.

Cartilagineum, cartilaginous, hard and horny, as Saxifrage callosa, Dicks. Dr. Pl. n. 63.

Dentatum, $f .79$, toothed, beset with projecting, horizontal, rather distant teeth of its own substance, as Atriplex laciniata, Engl. Bot.t. 165, Hypochcris maculata, t. 225, and the lower leaves of Contaurca Cyanus, t. 277 ; also Nymphrea Lotus, Curt. Mag. t. 797.

Serrutum, f. 80, serrated, when the teeth are sharp, and resemble those of a saw, pointing towards the extremity of the leaf. Examples of this are fiequent, as Urtica, t. 148 and 1.236, Rosa, t. 992, Sc., Comarum palustre, t. 172, and Senecio paludosus, t. 650; also Dillenia indica, Exot. Bot.t. 2. Some leaves 
are doubly serrated, duplicato-serrata, having a series of smaller scrratures intermixed with the larger, as Mespilus grandiflora, t. 18, and Campanula Trachelium, Engl. Bot.t.12.

Scrrulatum, f.63, minutely serrated, is used when the teeth are very fine, as in Polygomum amphibium, t. 436, and Empleurum serrulatum, Exot. Bot. t. 63.

Crcnatum, $f .81$, notched, or crenate, when the teeth are rounded, and not directed towards either end of the leaf, as in GroundIvy, Glechoma hederacea, t. 853, Chrysosplenium, t. 54 and 490, and Sibthorpia europaca, t. 649. In Saxifraga Geum, t. 1561, the leaves are sharply crenate. In the two British species of Salvia, $t .153$ and 154 , the radical leaves are doubly crenate, $f .82$.

Erosum, f: 83, jagged, irregularly cut or notched, especially when otherwise divided besides, as in Senecio squalidus, $t .600$. Repandum, f. S4, wavy, bordered with numerous minute angles, and smallsegments of circles alternately, as Menyanthes nymphacoides, t.217, and Inula diysenterica, t. 1115. 
Glandulosum, glandular, as Typericuirs montanm, $t .371$, and the Buy-leaved Willow, Salia pentandra.

Revolutum, revolute, when the margin is turned or rolled backwards, as Andromeda polifolia, t.713, and Tetratheca glandulosa, Eaot. Bot.t. 21.

Linnæus seems originally to have applied this term to the rolling of the whole leaf backwards, as in Solidago Virgutere, Engl. Bot. t.301, meaning to use the expression margine revolutum when the margin was intended; but this latter case being extremely frequent and the other very rare, he fell into the practice of using revolutum simply for the margin.

Inolutum, involute, the reverse of the preceding, as in Pinguicula, t. 70 and 145.

Concluplicatum, folded, when the margins are brought together in a parallel direction, as in Roscoea purpurea, Exot. Bot. t. 108.

7. Terms expressive of different kinds of surface, applying equally to the leaf and to the stem, have been already explained, 
p. 124. - To these may be added the following, chiefly appropriated to leaves.

Punctatum, dotted; either superficially as in Rhododendrum punctatum, Andr. Repos. t. 36, and Melaleuca linarifolia, Exot. Bot. t. 56 ; or through the substance, as in Hypericum perforatum, Engl. Bot. t. 295, and the whole natural order to which the Orange and Lemon belong.

Rugosum, rugged, when the reins are tighter than the surface between them, causing the latter to swell into little inequalities, as in various species of Sage, Salvia. See Flora Greca; also Tencrium Scorodonia, Engl. Bot.t.1543. Bullatum, blistery, is only a greater degree of the last, as in the Garden Cabbage, Brassica oleracea.

Plicatum, $f$. 85, plaited, when the disk of the leaf, especially towards the margin, is acutely folded up and down, as in Mallows, and Alchemilla vulgaris, Engl. Bot. t. 597, where, however, the character is but obscurely expressed.

Undulatum, $f .86$, undulated, when the disk near the margin is waved obtusely up and 
down, as Reseda lutea, t. 321, and Iria crispa (more properly undulata*) Curt. Mag. t. 599.

Crispum, $f .87$, curled, when the border of the leaf becomes more expanded than the disk, so as to grow elegantly curled and twisted, which Linnæus considers as a disease. Malva crispa, Ger. cm. 931, is an example of it, and may probably be a variety of $M$. verticillata, Jacq. Hort. Vind. v. 1. t. 40.

Concavum, hollow, depressed in the middle, owing to a tightness in the border, as Cyainus Nelumbo, Exot. Bot. t. 32.

$V$ enosum, $f$. 88, veiny, when the ressels by which the leaf is nourished are branched, subdivided, and more or less prominent, forming a network orer either or both its surfaces, as Cratcgus, or rather Pyrus, torminalis, Engl. Bot. t. 29s, and Verbascum Lychitis, t. 58.

Nervosum, $f$. 89, or cosiatum, ribbed, when they extend in simple lines from the base to the point, as in Cypripedium Calceolus, t. 1, the Convallarice, $t .279$ and 280 , Stratiotes alismoides, Erot. Bot, t. 15,

* Salist. Hort. 37 . 
and Roxburghia viridifora, t.57. The greater clusters of vessels are gencrally called nervi or costa, nerves or ribs, and the smaller vence, veins, whether they are branched and reticulated, or simple and parallel.

Arcnium, veinless, and encre, ribless, are opposed to the former.

Trinerve, $f$. 90, three-ribbed, is applied to a leaf that has three ribs all distinct from the very base, as well as unconnected with the margin, in the manner of those many-ribbed leaves just cited, as Blukea trineris", Curt. Mag.t. 451.

Basi trinerve, $f .91$, three-ribled at the base, is when the base is cut away close to the lateral ribs, as in Burdock, Arctium Lappa, Engl. Bot. t. 1298, Tussilago, t. 430 and 431, and the Great Annual Sumflower.

Triplinere, f.92, triply-ribbed, when a pair of large ribs branch off fiom the main one above the base, which is the case in

* Authors incorrectly use the termination trinerizis, trinervia, \&uc. for the more classical trinervis, trinerve, enervis, enerve. 
many species of Sunflower or Helianthus, Laurus Cinnamomum and Camphora, as well as Blakea triplineris, Aublet Guian. t. 210.

Coloratum, coloured, expresses any colour in a leaf besides green, as in Arum bicolor, Curt. Mag. t. 820, Amaranthus tricolor, and others of that genus, Justicia picta, Hedysarum pictum, Jncq. Ic. Rar. t.567, Tradescantia discolor, Sm. Ic. Pict. t. 10, Pulmonaria officim nalis, Engl. Bat. t. 118.

Variegatum, rariegated, is applied to a sort of variety or disease, by which leaves become irregularly blotched with white or yellow, like those of Striped Grass, Arumdo colorata, Fl. Brit.; as also the Elder, the Mentha rotundifolia, Engl. Bot.t. 446, and the Aucuba japonica, which last is not known in our gardens in its natural green state.

Nudum, nalied, implies that a leaf is destitute of all kinds of clothing or hairiness, as in the genus Orchis. Nudus applied to a stem means that it bears no leaves, and to a flower that it has no caljy. 
3. The following terms express the substance, peculiar configuration, or any other remaining circumitances of leaves, not already explained.

Teres, .93 cylindrical, as t!ose of Conchium gibbosum, White's Toyage, t. 22. f: 2 ; sce C'avanille's Icones, t. 533, and 534.

Semicylindraceum, f. 94, semicylindrical, flat on one side, as Salsola fruticosa, Engl. Bot. t. 635, and Chenopadium muritimum, $1,633$.

Silbulaium, f. 95, aw lshaped, tapering from a thickish base to a point, as Salsola Kali, t. 634 .

Tubulosum, tubular, hollow within, as 1 llimm Cepa, the Conmon Onion. The leal of Lobetia Dortmama, Enghl. Bot. t. 140, is very peculiar in consisting of a double tube, f: 96 .

Curmasum, f. 98, fleshy, of a thick pulpy substance, as in all those called succulent plants, Crassula lacter, Erot. Bot.t.33, Alae, Sedam, Musembryanthemum, \&c. See Semperrium tectorum, Engl. Bot. t. 1320.

Gibuum, gibbous, swelling on one side or 
both, from excessive abundance of pulp, as Aloe retusa, Curt. Mag. $t$. 455 .

Compressum, $f .98$, compressed, flattened laterally, as Mesembryanthemum uncinatum, Dill. Elth. t. 193, fand acinaciforme, $t .211$.

Depressum, diepressed, flattened vertically, as $M$.linguiforme, $t .183--185$. See $p .148$. Canaliculatum, $f .97$, channelled, having a longitudina! furrow, as $M$. pugioniforme, t. 210, Plantago maritima, Engl. Bot. t. 175, and Narcisisus poeticus, t. 275.

Carinatum, keeled, when the back is longitudinally prominent, as Narcissus biflorus, $t .276$.

Ensiforme, sword-shaped, is a two-edged leaf, tapering to a point, slightly convex on both surfaces, neither of which can properly be called upper or under, as in most of the genus Iris. See Curt. Mug. t. 671, t.9, \&ic., and F\%. Grec. t. 39 and 40 .

Anceps, two-cdged, is much the same as the last.

Acinaciforme, scimitar-shaped, compressed, with one thick and straight edge, the other thin and curved, as Mesem- 
bryanthemum acinaciforme abore mentioned.

Dolabriforme, f. 98, hatchet-shaped, compressed, with a very prominent dilated keel, and a cyliudrical base, as $M$. dola briforme, Dill. Eilth. t. 191, Curt. Mugr. t. 32 .

These two last terns might well be spared, as they seem contrived only for the plants in question, and indeed are not essentially distinct from each other.

Trigonum, f. 99, three-edged, having three longitudinal sides and as many angles, like M. deltoides, Dill. Elth. t. 195, Limn..Plil. Bot. t. 1, f. 58. Linnæus has erroneously referred to this figure to illustrate his term deltoides; misled, as it should seem, by the name of the plant to which it belongs; but his definition is foreign to the purpose, see p. 155, and allucles to the outline of a flat leaf.

Triquetrum differs from trigonum only in being used by Limmaus for a three-sided awl-shaped leat; as $M$. cmarginatum, Dill. Elih.t. 197, f. 950 , aind bicolorum, t. 209, also Saxifiaga burseriuna.

Tetragonum, $f .100$, four-edged, haring four 
prominent angles, as Iris tuberosa, Fl. Greec.t. 41 .

Lingulatum, tongue-shaped, of a thick, oblong, blunt figure, generally cartilaginous at the edges, as Mesembryanthemum linguiforme, Dendrobium linguiforme, Exot. Bot. t. 11, and several species of Saxifraga, as S. mitata, Curt. Mag. t. 351, S. Cotyledon, Sc.

Membranaccum, membranous, of a thin and pliable texture, as in Aristolochia Sipho, t. 534, Rubus odoratus, t. 323, Magnolia purpurea, t. 390, \&c.

Coriaccum, leathery, thick, tough and somewhat rigid, as Magrolia grandiflora, and Hydrangea hortensis, Sm. Ic. Pict.t. 12, Cuvt. Mag. t. 438.

Sempervircns, evergreen, permanent through one, two, or more winters, so that the branches are rever stripped, as the Iry, the Fir, the Cherry Laurel, the Bay, \&c.

Deciduum, deciduous, falling off at the approach of winter, as in most European trces and shrubs.

Alienutum, $f: 101$, alienated, when the first leaves of a plant give place to others totally different fiom them and from the 
natural habit of the genus, as in many Mimose of New Holland; see M. verticillata, Curt. Mag. t. 110, and myrtifolia, t. 302 ; also Lathyrus N'issolia, Engl. Bot. t. 112. The germination of this last plant requires investigation, for if its first leaves be pinnated, it is exactly a parallel case with the Ner Holland Mimose*

Cucullutum, $f: 102$, hooded, when the edges meet in the lower part, and expand in the upper, as those of the curious genus Sarracenia. See Curt. Mag.t.780 and 849, and S. aclunca, Exot. Bot.t. 53.

Appendiculatum, $f .103$, furnished with an additional organ for some particular purpose not essential to a leaf, as Dioncea muscipula, Curt. Mag.t.785, cultirated rery successfully by Mr. Salisbury, at Brompton, whose leaves each terminate in a pair of toothed irritable lobes, that close orer and imprison insects; or $\mathrm{Ne}$ penthes distillatoria, Rumph. Amboin. v. 5. t. 59, $f$. 2, the leaf of which bears a covered pitcher, full of water. Aldro-

$$
\text { * See p. } 516, \text { Note. }
$$

8 
vunda resicallosa, and our Utricularia, Engl. Bot.t. 253, 254, have numerous bladders attached to the leaves, which seem to secrete air, and float the plants. Many of the preceding terms applied to leaves are occasionally combined to express a form between the two, as ovato-lanceolatum, lanceolate inclining to ovate, or elliptico-lanccolatum, as in the Privet, Engl. Bot.t.764. When shape, or any other character, cannot be precisely defined, sub is prefixed to the term used, as subrotundum, roundish, subsessile, not quite destitute of a footstalk, to which is equivalent subpetiolatum, obscurely stalked. By the judicious use of such means, all necessary precision is attained. It is to be wished that anthors were always uniform and consistent, at least with themselves, in the application of terms; but as Linnæus, the father of accurate botanical phraseology, very frequently misapplies his own terms, it is perhaps scarcely to be avoided. I have observed botanists most critical in theory, to be altogether deficient in that characteristic phraseology, that power of defining, which bears the stamp of true genius, and which 
renders the works of Limmeus so luminous in despite of incidental errors. Perhaps no mind, though ever so intent on the subject, can retain all the possible terms of description and their various combinations, for ready use at any given moment. There are few natural objects to which a variety of terms are not equally applicable in description, so that no two writers would exactly agree in their use. Neither is Nature herself so constant as not perpetually to elude our most accurate research. Happy is that naturalist who can seize at a glance what is most characteristic and permanent, and define all that is essential, without trusting to fallacious, though ever so specious, distinctions!

9. Folia composita, compound leaves, consist of two or any greater number of foliola, leaflets, connected by a common footstalk. Folium articulatum, $f$. 104, a jointed leaf, is when one leatet, or pair of leaflets, grows ont of the summit of another, with a sort of joint, as in Fegrara tragodes, Jacq. Amer. t. 14. 
Digitatum, f.22, digitate or fingered, when several leaflets proceed from the summit of a common footstalk, as Potentilia verna, Engl. Bot. t. 37, reptans, t. s62, and Alchemilla alpina, t. 24t.

Binaium, $f^{\circ} .105$, binate, is a fingered leaf consisting of only two leaflets, as in Zygophyllim, Curt. Mag.t. 37?.

Ternutum, $f .106$, ternate, consists of three leatiets, as Hagonia cretica, t. 241, and the genus Trifolium, Trefoil. See Engl. Bot. t. 190, \&c.

Quinatum, quinate, of five leaflets, as Potentilla albas $\dot{i}$ 1381, reptans, t. 862, \&c.

Pimnatum, pinnate, when several leaflets proceed laterally from one footstalk, and imitate a pirnatifid leaf, p. 158. This is of several kinds.

cum impari, f: 116, with an odd, or terminal, leanet, as in Roses, and Elder, also Polemonium ceruleum, Enghl. Bot.t. 14, and Hedysarum Onobrychis, t. 96 .

cirrosxtm, f.115, with a tendril, when furnished with a tendril in place of the odd leaf- 
let, as the Pca and Vetch tribe; Pisum maritimum, t. 1046, Lathyrus palustris, t. 169, Vicia sativa, t. 334. abruptè, $f .101$, abruptly, without either a terminal leaflet or a tendril, as Cassia Chamcerista, Curt. Mag.t.i07, and the genus Mimosa. See M. pudica, the Common Sensitive-plant. This form of leaf is much more uncommon than the imparipimnatum, and we have no perfect example of it among British plants. The nearest approach to it is the genus Orobus, whose leaves have only the rudiments of a tendril. A truly wonderful variety of the Orobus sylvaticus, Engl. Bot. t. 518, with large simple leaves, has been found in Wales. opposite, oppositely, when the leaflets are opposite, or in pairs, as Saint-foin, t. 96, Roses, Sium angustifolium, t. 139, \&c. alternatim, altemately, when they are alternate, as Vicia dumetorum (Cracca sylvatica) Riv. Pent. Irr.t. 51, and occasionally in our $V$. sativa, butca, \&c. interruptè, $f$ : 107, interruptedly, when the principal leaflets are ranged alternately 
with an intermediate series of smaller ones, as Spircea Filipendula, Engl. Bot. ¿.2S4, S.Ulmaria, t.960, and Potentilla anserina, $t .861$.

articulate, jointedly, with apparent joints in the common footstalk, as Weinmannia pinnata.

decursivè, decurrently, when the leaflets are decurrent, as Eryngium campestre, Engl. Bot.t.57, and Potentilla fruticosa, t. 88 .

lyrato, $f .108$, in a lyrate manner, having the terminal leaflet largest, and the rest gradually smaller as they approach the base, as Erysimum procox, t. 1129, and, with intermediate smaller leaflets, Geum rivale, $t$. 106 ; also the Common Turnip. Such leaves are usually denominated lyrate in common with those properly so called (whose shape is simple, and not formed of separate leaflets); nor is this from inaccuracy in botanical writers. The reason is, that these two kinds of leaves, however distinct in theory, are of all leaves most liable to run into each other, even on the same plant, exam- 
ples of which are frequent in the class T'etradynamia.

verticillato, $f: 109$, in a whorled manner, the leaflets cut into fine divaricated segments embracing the footstalk, as Sium verticillatum, Fl. Brit. Engl. Bot.t. 395. Auriculatum, $f .110$, an auricled leaf, is furnished at its base with a pair of leaflets, properly distinct, but occasionally liable to be joined with it, as Salvia triloba, Fl. Grac. t. 17, and Dipsacus pilosus, Engl. Bot. t. 877. Linnæus in the last example uses the term appendiculatum, which is correct, but superfluous, and I have therefore ventured to apply it somewhat differently, $p .173$.

Conjugatum, $f .105$, conjugate, or yoked, consists of only a pair of pinnce or leaflets, and is much the same as binatum. Instances of it are in the genus zygophyllum, whose name, equivalent to Yokeleaf, expresses this very character; also in Lathyrus sylvestris, Engl. Bot.t. 805, and latifolius, t. 1108. Bijugum, trijugum, quadrijugum, multijugum, \&c., express particular numbers of pairs

$$
\text { ․ } 2
$$


of leaflets, and are used for that pur$p$ se where such discrimination is requisite for specific characters, as in .1 imosce. The different degrees in which leaves are compounded are thus distinguished, without any reference to the mode.

Compositum, $f: 111$, simply compound, as in the above instances.

Decompositum, f. 112*, doubly compound, as Athamanta Libanotis, Lingl. Bot. t. 138, Asgopodizm Podagraria, t.950, and Fumaria cluviculata, t. 103.

- Supradecompositum, f.113, thrice compound, or more, as Caucalis Anthriscus, t.987, C. daucoides, t. 197, and Bunium flexuosum, t. 988 . But

Bigeminatum, twice paired, as Mimosa Unguis cati, Plum.Ic.t.4; and tergeminatum, thrice paired, as $M$. tergemina; also

Biternatum, f. 112, twice ternate, as $\mathbb{E g} 0$ podium, Engl. Bot. t.940; twiternatum, thrice ternate, as Fumaria lutea, t.588; and

* Linnæus, in Phil. Bot. 47, gives an erroneous definition of this term, which does not accord wilh his own use of it. Professor Martyn has rightly defined it. 
Bipinnatum, doubly pinnate, tripinnatum, triply pinnate, of which examples have just been given: all apply to the morle, as well as the degree, in which leaves are compounded.

Pedatum, f. 114, pedate, is a peculiar kind of leaf, being ternate, with its lateral leaflets compounded in their fore part, as Helleborus fatidus, Engl. Bot. t. 613, and H. niger, Curt. Mag. t. 8. There is an affinity between a pedate leaf and those simple ones which are three-ribbed at the base, $p$. 167. See also the disposition of the lateral veins in Aristolochia Clematitis, Engl. Bot.t. 398.

In compounding the foregoing terms we must take care not to express a contradiction. Thus the leaves of many Mimosce, as the purpurea, Andr. Repos. t. 372, and sensitiva, are conjugata pinnata, conjugate in the first instance, pinnate in the next, not conjugrato-pinnata, of an intermediate nature between conjugate and pinnate, which is impossible. Neither are the leaves of Mimosr. 
pudica digitato-pinnata, for there is no me. dium between the two terms; but they are digitate, or composed of leaflets proceeding from the top of a common foot-stalk, and those leaflets are pinnate. On the other hand ovato-lanceolatum, lanceolate approaching to orate, or elliptico-lanceolatum, approaching to flliptic, as in the Privet, Engl. Bot.t. 764, already mentioned, whose leaves often assume that shape, are easily understood. 


\section{CHAP'TER XVI.}

OF THE FUNCTIONS OF LEAVES.

$T_{H E}$ knowledge of the functions of leares, and their real use with regard to the plant, is a curious branch of vegetable physiology, which made but a slow progress long after the nature of many other parts had been deeply scrutinized and thoroughly explained.

Crsalpinus (De Plantis, p. 6.) thought leaves merely a clothing, or a protection against cold and heat. He conceived that the rays of the sun, being moderated in passing through them, were prevented from acting too violently on the fruit and young buds. "Accordingly," says he, " many trees lose their leaves in autumn, when their fruits are perfected, and their buds hardened, while such as retain the fruit long, keep also their leaves; even till a now 
crop is produced, and longer, as in the Fir,

- the Arbutus, and the Bay. It is reported that in hot climates, where there is almost perpetually a burning sun, scarcely any trees lose their leaves, because they require them for shade." Cæsalpinus goes on to show that leavas proceed from the bark, with some remarks on the pith, (in which we may trace the origin of the Linnaan hypothesis . of vegetation,) but which are now superseded by more accurate inquiries.

The ab8re is certainly a very small part of the use of leaves. Yet the observations of this writer, the father of botanical philosophy among the moderns, are so far correct, that if the leaves of a tree be stripped off, the fruit comes to nothing, which is exemplified every year in Gooseberry bushes devoured by caterpiliars; and though the fruit-trees of warm climates, partly naturalized with us, Grapes and Peaches for instance, ripen their fruit sooner perhaps if partially deprived of their leaves, yet if that practice be carried too far, the fruit perishes, as gardeners who tried it soon discovered. The White Mulberry indeed, cultirated in the south of Ea- 
rope for the food of silliworms only, bears wonderfully the loss of its folinge three or four times a year. How far the fruit is injured nobody thinks it worth while to inquire, as it is never eaten, but it certainly does not fall off prematurely.

That Leaves imbibe and give out moisture has been long known, this being one of the most obvious facts belonging to them. Dr. Hales thought they might probably imbibe air; but since his time more certain discoveries have been made concerning this point, as well as the effects of light upon leares, which also did not escape the consideration of that great philosopher. All these subjects we shall mention in their turn.

That Leares give out moisture, or are organs of insensible perspiration, is proved by the simple experiment of gathering the leafy branch of a tree, and immediatcly stopping the wound at its base with mastick, wax, or any other fit substance, to prevent the effusion of moisture in that direction. In a very short time the leaves droop, wither and are dried up. If the same branch, partly faded, though not dead, be placed in a very 
damp cellar, or immersed in water, the leaves revive, by which their power of absorption is also proved. Hence the use of a tin box to travelling botanists, for the purpose of restraining the evaporation of plants, and so preserving them fiesh for some days till they can be examined, as well as of reviving faded plants, if the inside of the box be moistened before they are shut up in it.

Dr. Hales found that a plant of the Great Annual Sunflower, Helianthus anmuus, lost $1 \mathrm{lb} .14 \mathrm{oz}$. weight in the course of twelve hours in a hot dry day. In a dry night it lost about $3 \mathrm{oz}$; in a moist night scarcely any alteration was observable, but in a rainy night it gained 2 or $3 \mathrm{oz}$. The surface of the plant compared with that of its roots was, as nearly as could be calculated, in the proportion of five to two; therefore the roots must have imbibed moisture from the earth of the pot in which the plant grew, and which was all previously weighed, in the same proportion of five to two, otherwise the leaves would have faded. The same experiment was made on the Vine, the Cabbage, \&c., with various results as to the exact degree of 
perspiration, but all proving it to be considerable. Evergreens are found to perspire much less thin other shrubs.

The state of the atmosphere has a great effect on the rapudity of this perspiration. Practical hotanists know how much sooner plants fade, and haymakers experience how much faster their work is done, some days than others, and those days are by no means always the nost sunny. In a lot dry day plants are often exhauster, so as to droop very much towards evening, especially in the dry unsheltered bed of a garden. Such as have fleshy roots, indeed, have a singular power of resisting drought, which has already been explained p. 113. Succulent plants, destined to inhabit sunny rocks, or sandy deserts, imbibe with the greatest facility, and perspire very sparingly. Evergreens are not generally rery succulent, but their cuticle appears to be constructed like that of succulent plants, so as to allow of little evaporation. The Comelian Cherry, whose immense perspiration we have recorded, p. 68, has a thin dry leaf, capable of holding very little moisture. 
The nature of the liquor perspired has been already noticed, 1 . 68 . In hot weather it has been observed by Hales, Du Hamel and Guettard to partake occasionally of the peculiar scent of the plant that yields it, but in general the odorous matter is of too oily a nature to be combined with it.

The sensible perspiration of plants is of various kinds. When watery, it can be considered only as a condensation of their insensible evaporation, perhaps from some sudden change in the atmosphere. Groves of Poplar or Willo exhibit this phænomenon, even in England, in hot calm weather, when drops of clear water trickle firom their leaves like a slight shower of rain. Sometimes it is of a s.ccharin nature, as De la Hire observed in Orange trees; Du Hamel Avb. v. 1. 150 . It is more glutinous in the Tilia or Lime-tree, more resinous in Poplars, as well as in Cis us creticus, from v hich last the resin called Labdanum is collected, by beating the shrub with leather thongs. See Tournefort's Voyage, 29. In the Fraxinella, Dictammus albus, it is a highly inflammable vapour. Ovid has made an elegant use of the 8 
resirous exudation of Lombardy Poplars, Populus dilututa, Ait. Hort. Kew. v. 3.4.06, which he supposes to be the tear's of Phaëton's sisters, who were transformed into those trees. Such exurlations must be consi 'ered as effusions of the peculiar. secretions; for it has been observed that Manna may be scraped from the leaves of Fraximus Ornus, Fl. Grac. $t .4$, as well as procured by incision from its stem. They are often perhaps a sign of unhealthiness in the plant; at least such appears to be the nature of one lind of honeydew, to which the Beech in purticular is subject, and which, in consequence of an unfavourable wind, covers its leaves in the form of a sweet exudation, similar in flarour to the liquor obtained from its trunk. So liliewise the Hop, according to Linnaus, Fanu. Suec. 305, is affected with the honey-dew, and its flowers rendered abortive, in consequence of the attacks of the caterpillar of the Ghost Moth, Phalcna Humuli, upon its roots. In such case the saccharine exudation must decidedly be of a morbid nature*

* I do not mean to dispute the accuracy of Mr. Curtis's excellent paper, Tr. of Linn. Soc. v. 6, written to 
That wax is also an exudation from the leares of plants, appears from the experiments recorded by Dr. Thomson in his Chemistry, v. 4. 298, and it has been long ago asserted that wax may easily be gathered from the leaves of Rosemary. On this subject I have not made any experiments to satisfy myself.

With respect to the absorbing power of leaves, the best observations that have been made are those of Bonnet, recorded in the beginning of his Recherches sur l'Usage des Feuilles. His aim was, by laying leaves of various plants upon the top of a jar of water, some with their upper, and others of the same species with their under, surfaces applied to the water, to discover in which situntion the leaves of each plant continued longest in health and rigour, and also how far different species differed from each other in this respect. The results were in many instances highly curious.

Of fourteen herbaceous plants tried by this

prove honcy-dew to be the dung of Aphides. I only contend that there are more than one kind of honeydew. 
philosopher, six lived nearly as long with one surface applied to the water as with the other; these were the common Arum maculatum, the French Bean, the Sun-flower, Cabbage, Spinach and the Small Mallow. By the last I presume is meant Malia rotundifolia, Engl. Bot.t. 109?. Six others, Plantain, White Mullein, the Great Mallow (probably M.syliestris, t.671), the Nettle, Cock's-comb, and Purple-leared Amaranth (probably Amaranthus hypochondricicus), lived longest with their upper surface laid upon the water. The Nettle lived but three weeks with its under surface on the water, and about two months in a contrary position. The Mullein scarcely survived five or six days, and the Amaranth not a week, in the first-mentioned posture, while the leares of the former remained in vigour about five weeks, and of the latter three months, when their upper surfaces imbibed the water. Marvel of Peru and Balm, the two remaining plants of the fourteen on which the experiment was made, had also an erident advantage in receiring that fluid by their upper surfaces. The leaves of some of the above 
species were found to thrive better when their stalks only were immersed in water, than when either of their sides was supplied with it, and the reverse was observable in several others ; but the White Mullein, the Plantain and the Amaranth survived longer when they received the water by their stalk than by their under surface, though not so long as when it was applied to their upper sides.

Of sixteen trees tried by Bonnet, the Lilac. and the Aspen, Populus tremula, were the only leaves that seened to imbibe water equally well by either surface, whilst all the others evidently succeeled best with their under sides laid upon the water, being in that respect the reverse of herbaceous plants. Of these the White Mulberry leaf was the most remarkable, not living more than five days when supplied by the upper surface, while such as floated on their backs continued in perfection near six months. The Vine, the Poplar (probably Populus nigra), and the Walnut, were no less remarkable, for fading almost as soon, when fed by their upper surface, as when left without any water at all. Many of the other trees imbibed water as 
well, or better, by their foot-stalks as by their upper surfaces. Hazel-nut and Rose leaves, when laid with their backs upon the water, imbibe sufficiently to nourish - other leaves on the same branch; so will one leaflet of a French bean supply its neighbour that does not touch the water.

Those who wish to repeat these experiments should be careful to choose full-grown healthy leaves, all as nearly as possible of the same age and vigour. It is also desirable that the precise species of plant should be recorded by its scientific name. For want of this, Bonnet, who despised method and nomenclature, has left us in uncertainty concerning several of the plants he examifed. We ought to have been accurately informed what species of Poplar differed so remarkably in its power of absorption from the Aspen, another of the same genus. We ought likewise to have been told what Sın-flower, what Nettle, Amaranth and Mallows were examined; for want of which information the authority of such experiments is much impaired.

From the foregoing observations we learn 
the importance of shading and watering plants newly removed, cuttings, grafts, \&c. and on the other hand the benefit of heat and air to promote due perspiration and evaporation.

The perspiration of aquatic plants seems to be remarkably copious. Of these some grow constantly immersed in the water, as most species of Potamogeton, Pond-weed, Engl. Bot. t. 168, 297, 376, \&c. Their leaves are peculiarly vascular, and dry very quickly in the air, withering in a very few minutes after exposure to it. Their absorbing power seems equally great, so that they appear to be continually, in their natural situation, imbibing and giving out a quantity of water much greater than has been observed in land plants. Other aquatics, as the Nymphicea, Engl. Bot. t. 159, 160, float with only the upper surface of their leaves exposed to the air, which surface is so contrived that water will scarcely remain upon it. These leaves, though extremely juicy, dry with great rapidity, as does every part of the plants when gathered. It is probable that they imbibe copiously by their under sides, and perspire by the upper. 
The $œ$ conomy of the Sarracenia, an Amorican genus of which we now know four species, and of the East Indian Nepenthes distillutoria, deserves particular mention. Both grow in bogs, though not absolutely in the water: The former genus has tubular leaves which catch the rain like a funnel and retain it; at least such is the nature of $S$. purp) urea, Curt. Mag. t. 849, whose margin seems dilated expressly for this purpose, while the orifice of the tubular part just below is contracted to restrain evaporation. Linneus conceived this plant to be allied in constitution to Nymphaea, and consequently to require a more than ordinary supply of water, which its leaves were calculated to catch and to retain, so as to enable it to live without being immersed in a river or pond. But the consideration of some other species renders this hypothesis very doubtful. S. flava, t. 780 , and more especially $S$. adunca, Exot. Bot. $t .53$, are so constructed that rain is nearly excluded from the hollow of their leaves, and yet that part contains water, which seems to be secreted by the base of each leaf. What then is the purpose of this unusual contri- 
vance? An observation communicated tome two years ago, in the botanic garden at Liverpool, seems to unravel the mystery. An insect of the Sphex or Iclineumon kind, as far as $\mathbf{I}$ could learn from description, was seen by one of the gardeners to drag sereral large fies to the Sarracenia adunca, and, with some difficulty forcing then under the lid or cover of its leaf, to deposit them in the tubular part, which was half filled with water. All the leaves, on being examined, were found crammed with dead or drowning flies. The S. murpurea is usually observed to be stored with putrefying insects, whose scent is perceptible as we pass the plant in a garden; for the margin of its leaves is beset with inrerted hairs, which, like the wires of a mousetrap; render it rery difficult for any unfortunate $\mathrm{fy}$, that has fallen into the watery tube, to crawl out again. Probably the air erolied by these dead flies may be beneficial to vegetation, and, as far as the plant is concerned, its curious construction may be designed to entrap them, while the water is provided to tempt as well as to retain them. 'The Sphew or Ichneumon, an insect of prey, 
stores them up unquestionably for the food of itself or its progeny, probably depositing its egog in their carcases, as others of the same tribe lay their eggs in rarious caterpillars, which they sometimes bury afterwards in the ground. Thus a dauble purpose is answered; nor is it the lcast curious circumstance of the whole, that an Europran insect should find cut an American plant in a hot-house, in order to fulfil that purpose.

If the above explanation of the Sarracenia be achitted, that of the Nepenthes will not be difficult. Each leaf of this plant terminates in a sort of close-shut tube, like a tankard, holding an ounce or two of water, certainly secreted through the footstalk of the leai, whose spiral-coated ressels are uncommonly large and numerous. The lid of this tube either opens spontaneously, or is easily lifted up by insects and small worms, who are supposed to resort to these leares in search of a purer bererage than the surrounding swamps afford. Rumphius, who has described and figured the plant, says "various little worms" and insects crawl into the orifice, and die in the tube, except a certain small squilli 
or shrimp, with a protuberant back, sometimes met with, which lives there."-I have no doubt that this shrimp feeds on the other insects and worms, and that the same purposes are answered in this instance as in the Sarracenice. Probably the leares of Dioncea muscipula, as well as of the Droserce, Engl. Bot. t. 867-869, catcli insects for a similar reason.

I proceed to consider the effects of Air and Light upon vegetables.

Dr. Grew, by the assistance of the microscope, detected a quantity of vesicles full of air in the leaves of plants, as also the spiralcoated ressels of their stems, which last he and all other physiologists, till very lately, considered as air-ressels likewise. Malpighi made the same observations about the same time; and as these two acute and laborious philosophers pursued their inquiries without any mutual communication, their discoreries strengthen and confirm each other. Their books have long served as magazines of facts for less original writers to work with. From their remarks physiologists have theoretically supposed that leaves imbibed air, which the 
spiral vessels were beliered to convey all through the plant, in order that it might act on the sap as it does on the animal blood. The analogy thus understood was not correct, because air is conveyed no further than the lungs of animals; but without this hypothesis no use could be found for the supposed longitudinal air-vessels.

The observations of $\mathrm{D}_{\mathrm{r}}$. Hales come next in order to those of Grew and Malpighi. By means of the air-pump, an instrument much in use in his time, Hales obtained abundance of air from every part of the vegetable body, as well as from recently extracted sap. Plants were found to perish very soon in an exhausted receiver. Some of this great man's experinients, however, require to be received with caution. He rightly remarked that air was not only taken in by plants very copiously along with their foor, but also imbibed by their bark; see Veg. Staticks, chap. 5 . But when, from observing that it would freely from the bark pervade the longitudinal ressels of a branch, he concluded that Malpighi and Grew were right in their ideas of longitudinal air-vessels, he was misled by 
appearances. We cannot but be aware that, when a branch is gathered, the sap must soon flow out of those spiral-coated tubes, which are large, elastic, and, no doubt, irritable. After they are emptied, air may unquestionably pass through them, especially when the whole weight of the atmosphere is acting, as in Dr. Hales's experiments with the air-pump, upon so delicate a fabric as the internal vascular structure of a plant, forcing its way through pores or membranes not naturally designed to admit it. We must also recollect that a plant, cut eren for a short time, begins to lose its vital principle, after which no just judgment can be formed, by any experiments, concerning the movements of its fluids in life and vigour. See Chapter 1. These experiments of Dr. Hales therefore prove no more than that the regetable body is pervious in various directions; and perhaps the only point they correctly establish is, that air is imbibed through the bark, a part known to be full of air-ressels. But the seventh chapter of the Vegetable Staticks çontains some remarks much more to our purpose. Dr. Hales there clearly anticipates. 
by conjecture, what succecding philosoplers, more enlightened chemists, have ascertained. His words are remarkable:

" IVe may therefore reasonably conclude, that one great use of leaves is what has been long suspected by many, viz. to perform in some measure the same office for the support of the vegetable life, that the lungs of animals do, for the support of the animal life; plants very probably drawing through their leaves some part of their nourishment from the air." $\%$.326. A little further on he adds, "And may not light also, by freely entering the expanded surfaces of leaves and flowers, contribute much to the ennobling the principles of vegetables?" p. 1288.

Next in order of time to those of Hales follow the experiments of Bonnet. We have already detailed his observations on the power of leares to imbibe moisture; whence it is ascertained that plants are furnished with a system of cuticular absorbents, which carry fluids into their sap-ressels, so as to enable them in some degree to dispense with supplies from the root. With respect to the effects of air upon leares, this ingenious 
philosopher has not been equally successful. He is recorded as the discoverer of the expiration of plants, but it appears from his work that he merely observed the bubbles of air which cling to leares, dead as well as living, and indeed to any other body, when immersed in water and exposed to the light of the sun. He found these bubbles disappeared in the erening, and returned again when the sun shone, and he faithfully reports that by their attachment to the surfaces of leaves, the latter were rendered more buoyant, and rose in the water; a sure proof that the air had not previously existed, in the same volume at least, in the substance of those leaves. Accordingly, Bonnet concluded that the latter, in imbibing the surrounding water, Ieft the air which had been contained in the water, and that this liberated air became visible from being warmed and rarefied by the sum. This was as near the truth as Bonnet could come, it not being then known that light has a power of separating air of a peculiar kind, carbonic acid gas, from water.

I find no indications in his work of his haring had any idea of leares absorbing air and 
giving it out again; still less of their affecting any clange in its properties.

Dr. Priestley was the first who suggested this last-mentioned quality in regetables. He ascertained their power of absorbing carbonic acid gals, denominated by him fixed air, and giving out oxygen gas, or purc respirable air. It was also his opimion that leaves imbibed the former by their upper, and gave out the latter by their under surface. He found some aquatic or marsh plants extremely powerful in this respect, especially the Willow-herb or Epilobium, and the Conferva, a minute branching cotton-like vegetable which grows in putrid water, and the production of which, in water become foul from long keeping on ship-board, Dr. Priestley judged to operate principally in restoring that fluid to a state fit for use.

Dr. Ingenhousz, pursuing Dr. Priestley's inquiries, found light to be necessary to these functions, and that in the dark leares gare out a bad air. He observed moreover that fruits and flowers almost invariably gare out a birl, or carbonic, air, but more esperially in the clark. He probably carries his 
ideas, of the deleterious effects of this air on animal life, too far ; for no mischief has ever happened, as far as common experience goes, to persons sleeping in apple or olive chambers, neither do the inhabitants of the confined huts in Corent-garden market apparently suffer, from living day and night among heaps of drying heros. Mischiefs have unquestionably arisen from flowers in a bed-room, or any other confined apartment, but that is to be attributed to their perfumed effuvia. So the bad effects, observed by Jacquin, of Lobelia longifiora on the air of a hot-house, the danger incurred by those who sleep under the Manchinecl-tree, Hippomane Mancinclla, or, as it is commonly belicved, under a Walnut-tree, are probably to be attributed as much to poisonous secretions as to the air those plants erolve.

Dr. Ingenhousz introduced leaves into glass jars filled with water, which he inverted in a tub of the same water, and placed the whole together in the sun-shine. From their under sides came streams or bubbles of air, which collected in the inverted bottom of each jar. The air thus procured proved oxygen gas, 
more or less pure. The Nymphrea alba, Engl. Bot.t.160, aftords an extraordinary abundance of it. Dr. Ingenlıousz observed plants to be very rarious in their mode of emitting these bubbles, but it was always uniform in the same species. Ail collected from water placed in similar circumstances without plants, proved not oxygen, but much worse than common air, viz. carbonic acid gas, which following chemists have confirmed, and which we have alrearly mentioned. Ingenhousz also found the air collected from plants under water in the dark worse than common air, especially that from walnut-leares; which confirms the common opinion, abore alluded to, respecting this tree.

Plants purify air very quickly. A vineleaf in an ounce phial of carbonic acid gas, that immediately extinguished a candle, placer in the sun, without water, changed it to pure respirable air in an hour and half. Dr. Priestley found plants to alter even unmixed inflammable air, or hydrogen, especially the Filobium hirsutum, if I mistake not, and Polysionum Hydropiper.

Succulent plants aie found to afford most 
air, in consequence of the abundarice of their Cellular Integument, or Parenchyma, in which, as I have hinted in the fourth chapter, the chemical operations of the leaves are performed.

That Light has a very powerful effect upon plants has long been known, independent of the remarks of Hales or Ingenhousz. The green colour of the leares is owing to it, insomuch that plants raised in darkness are of a sickly white. It has even been observed that when light is admitted to the leaves through different glasses, each tinged of a different prismatic colour, the plant is paler in proportion as the glass approaches nearer to violet. The common practice of blanching Celery in gardens, by covering it up from the light, is an experiment under the eyes of every one. This blanching of plants is called by the French étiolation, and our chemists have adopted the term, though I think they err in deriving it from étoile, a star. When blanched plants are brought into the light, they soon acquire their natural green colour, and even in the dark they are green, if exposed to the action of hydrogen gas. Tulip and Crocus flowers have long 
ago been observed by Sennebier to be coloured even in the dark, apparently because their colour depends on a different principle from the green of leares.

Light acts bencficially upon the upper surface of leaves, and hurtfully upon the under side; hence the former is always turned towards the light, in whatever situation the plant may happen to be placed. Trees nailed against a north wall turn their leaves from the wall, though it be towards the north, and in direct opposition to those on a southern wall over against them. Plants in a hothouse all present the fronts of their leaves, and this influences even the posture of the branches, to the side where there is most light, but neither to the quarter where most air is admitted, nor to the flue in search of heat. If the branches of a trained fruit-tree in full leaf be disturbed in their position, the leaves resume their original direction in the course of a day or two. The brighter the day, the more quickly is this accomplished. If the experiment be often repeated, they continue to turn, but more weakly, and are much injured by the exertion. Black spots 
appear about the veins on their under sides, and the cuticle scales off. Succulent leaves, though so thick and firm as many of them are, have been observed to be peculiarly sensible to light, while other plants, as Mallows, according to Bonnet, are much less so. The Miseltoe, Viscum album, Engl. Bot. t. 1470, the two sides of whose leaves are alike in appearance, and both equally, in general, presented to the light, are not found to turn upon any change in the posture of the branch. Neither do upright sword-shaped leaves alter their position, because in them both sides must be presumed to perform the same functions with respect to light as well as air.

Mr. Calandrini found rine-leaves turned to the light when separated from the stem and suspended by a thread. Of this any one may be easily satisfied, provided the experiment be made with sufficient care and delicacy. It is important, as demonstrating the turning to be accomplished by an impression made on the leaf itself, and not upon its footstalk.

Nor is this effect of light peculiar to leaves alone. Many flowers are equally sensible to 
it, especially the compound radiated ones, as the Daisy, Sun-flower, Marigold, \&c. In their forms Nature seems to have delighted to imitate the radiant luminary to which they are apparenty dedicated, and in the absence, of whose beams many of them do not expand their blossoms at all. The stately Annual Sun-flower, Helianthus ammun, displays this phanomenon more conspicucusly on account of its size, but many of the tribe have greater sensibility to light. Its stem is compressed in some degree, to facilitate the morement of the flower, which, after following the sun all day, returns after sun-set to the east, by its natural elasticity, to meet his beams in the morning. Dr. Hales thought the heat of the sun, by contracting the stem on one side, occasioned the flower to incline that way; but if so, it would scarcely return completely at night. Their can be no doubt, from the observation of other similar flowers, that the impression is made on their radiated florets, which act as wings, and seem contrived chiefly for that purpose, being frequently destitute of any other use. A great number of leaves 
likewise follow the sun in its course; a cloverfield is a fimiliar instance of this.

Of all leaves those of pinnated leguminous plints are found most affected by light, insomuch that it appears, in several cases, the sole cause of their expansion, for when it is withdrawn they fold over each other, or droop, as if dying; and this is called by Linnæus the Sleep of Plants, who has a dissertation on the subject in his Amonitutes Academice. The term Sleep may not really be so hyperbolical as at first sight it seems, for the cessation of the stimulus of light, and of the consequent restrained position, of the leares, may be useful to the regetable constitution, as real sleep is to the animal. Another purpose is answered by the nocturnal folding of some leares, that they shelter their flowers from the dew, the adrantage of which we shall explain hereafter.

Some pinnated leaves display a more extraordinary sensibility, not merely to light, but to the touch of any extrancous body, or to any sudden concussion, as those of Mimosa scusiliza, and pudica, Oralis sensitiva, and Smithin sensitica, Hit. Hort. 
hew. v. 3. t. 13. An impression made even in the most gentle manner, upan one of their leallets, is communicated in succession to all of them, evincing an exquisite irritability, for it is in vain to attempt any mechanical solution of this phanomenon. One of this tribe, Hedysarum gyrans, lits a spontaneous motion in its leaves, independent of any external stimulus, even of light, and only requiring a very warm still atmosphere to be performed in perfection. Each leaf is ternate, and the small lateral lealets are frequently moving up and down, either equably or by jerks, without any uniformity or cooperation among themselves. It is difficult to guess at the purpose which this singular action is designed to answer to the plant itself; its effect on a rational beholder cannot be indifferent.

The chemical actions of light, heat, and the component parts of the atmospheric air, upon leaves, and, where the latter are wanting, on the green stems of plants, are now, as far as concerns all plants in common, tolerably well understood. The observations and experiments of Priestley and Ingenhousz have 
been confirmed, extended in a variety of ways, or explained on the principles of improved chemistry, by Dr. Percival and $\mathrm{Mr}$. Henry in England, Dr. Woodhonse in America, and M. Sennebier and M. Théodore de Saussurc, as well as various other philosophers, on the continent of Europe. It is agreed that in the day-time plants imbibe from the atmosphere carbonic acid gas, (which was formerly called fixed air, and is an union of oxygen and carbon), that they decompose it, absorb the carbon as matter of nourishment which is added to the sap, and emit the oxygen. So they absorb the same gas from water, when it is separated from that fluid by the action of light. The burning of a candle, or the breathing of animals, in confined air, produces so much of this gas, that neither of these operations can go on beyond a certain time, but the air so contaminated serres as food for regetables, whose leares, assisted by light, soon restore the oxygen, or, in other words, purify the air again. This beantiful discorery, for the main principles of which we are indebted to the colcbrated Dr. Priestley, shows a mutual depend- 
ance of the animal and regetable kingdoms on each other, which had never been suspected before his time. Comparative experiments upon the lower tribes of these lingdoms hare not yet been made, but they would probably atford us a new test for distinguishing them. The air so copiously purified by a Conferta, one of the most inferior in the scale of plants, may be rery extensively useful to the innumerable tribes of animated beings which inhabit the same waters. The abundant air-bubbles which have long ago given even a botanical name to one supposed species, Conferva bullosi, are probably a source of life and health to whole rations of aquatic insects, worms and polypes, wheneres the sun shines.

In the dark, plants give out carben and absorb oxygen: but the proportion of the latter is small, compared to what they exhale by day, as must likewise be the proportion of carbon given out; else the quantity of the latter added to their substance would be but trifing, especially in those climates where the proportion of day to night is nearly equal, and which, notwithstinding, we know 
to be excessirely luxuriant in regetation. Plunts also give cut azotic gas: but $\mathbf{M}$. de Salissure is of opinion that this proceeds from their internal substance; and it appears by his experiments to be rather a sign of disease or approaching decay, than a regular chemical production of their constitution when in health; for Sennebier found the quantity of oxygen emitted was in proportion to the thickness of the leaf, or quantity of parenchyma. Yet the parenchyma must be in its original organized state, for when bruised its functions are destroyed.

Possibly such an alternation in the functions of vegetables between day and night may afford a necessary repose to their vital principle, whose share in them we know to be of primary importance. Whatever may happen to plants in the dark, there can be no doubt of their principal business in the ceconomy of nature being what we have described. The most luminous and compendious view of the whole subject is given by Dr. Thomson of Ediriburgh in the fourth rol. of his Chemistry, which is well worth the attention of those who wish to enter niore 
deeply into all the rarious chemical examimations respecting it than suits our purpose. It is only necessary to add a short view of Dr. Darwin's hypothesis which Dr. Thomson has not mentioned, probably on account of its insufficiency. 'That lively writer thought the watery perspiration of leares, acted upon by light, gave out oxygen for the use of the plant itsell, such oxygen being immediately absorbed by the air-ressels. This is by no means adequate to explain any of the phanomena, but rather contradictory to most of them, and is totally superseded by the observations and experiments of other writers.

There can be no question of the general purpose answered to the regetable constitution by these finctions of leaves. They confirm Mr. Knight's theory of regetation, who has proved that rery little alburnum or new wood is secreted when light is kept fiom the leaves. They also help us to understand how essential oils may be produced, which are known, as well as sugar, to be composed of oxygen, hydrogen and carbon in different proportions. We call now liave a general idea how the nutritious sap, acted upon by 
all the agents above mentioned during its stay in the cellular substance of the leat, and returned from thence impregnated with tlem into the bark, may prove the source of increase, and of peculiar secretions, in the rogetable frame. That portion of sap sent to the flower and fruit undergoes no less remarkable changes, for purposes to which those curious organs are devoted; nor is it returned from thence, as from the leaves, to answer any further end. The existence of those organs is still more temporary, and more absolutely limited to their own purposes, than even that of the leaves, from whose secretions theirs are very distinct.

But when we attempt to consider how the particular sccretions of different species and tribes of plants are formed; how the same soil, the same atmosphere, should in a leaf of the vine or sorrel produce a wholesome acid, and in that of a spurge or manchineel a most virulent poison; how sweet and nutritious herbage should grow among the acrid crowfoot and aconite, we find ourselves totally unable to comprehend the existence of such wonderful powers in so small and seem- 
ingly simple an organ as the lnaf of a plant. The agency of the vital principle alone can account for these wonders, though it cannot, to our understanding, explain them. "The thickest veil," says Dr. Thomson at the end of his chapter on vegetation, "corers the whole of these processes; and so far have philosophers hitherto been from removing this reil, that they have not eren been able to approach it. All these operations, indeed, are evidently chemical decompositions and combinations; but we neither know what these decompositions and combinations are, nor the instrunents in which they take place, nor the agents by which they are regulated."

The vain Buffon caused his own statue to be inscribed "a genius equal to the majesty of nature," but a blade of grass was sufficient to confound his pretensions. 


\section{CHAPTER XVII.}

OF THE SIVERAJ KIXIS OE FULCRA; OR APIENDACES TO A PLAYT.

CHE mord Fulleum, whose proper meaning is a prop or support, lias been applied by Linnaus not only to those orgins of regetables correctly so denominated, such as tendrils, but also to various other appendages to the herbage of a plant, none of which are universal, or essential, nor is there any one plant furnished with them all. I prefer the English term Appendages for these organs in greneral, to Props, because the latter applies only to one of them. Seven kinds of these are distinguished by Linnieus, nor do I find it necessary to enlarge that number.

1. Stipula. The Stipula, a leafy appendage to the proper leaves or to their footstalls. 
It is commonly situated at the base of the latter, in pairs, and is extremely different in shape in different plants.

The most natural and usual situation of the Stipu'as is in pairs, one stipula on each side of the base of the footstalk, as, in Lathyms latifolius, Engl. Bot. t. 1103, whose stipulas are half arror-shaped, f. $11.5 ;$ also in Willows, as Salix stipuluris, t. 1214, and $S$. anrita, t. 1457. In Rosa, Potentilla, and many genera allied to them, the stipulas are united laterally to the footstall, f. 116. Sce Potentilla alba, t. 138s. In all these cases they are eatrufoliucea, external with respect to the leaf or footetalk; in others they are intrafoliacec, internal, and are then generally simple, as those of Polygonum, t. 1989, 756, ac. In a large natural order, called $R$ ubiacea, these internal stipulas in some cases enbrace the stem in an undrided tube above the insertion of the footstullis, like thse of I'olygomum just mentioned; in others, as the Coffee, Coffen ambica, and the Hamellia patens, Erot. Bot. t. 2S, they are separate leares between the footchalks, but meting 
just abore their insertion. 'The Europaan Fivbiacee have whorled leaves, as Asperula, Gulizm, Rubia, \&c.; hut Asperula cymanitica, Engyl. Bot. t. 33, has sometimes two of its four leares so small as to look like stipulas, seeming to form an intermediate link between such as have whorled leaves and such as have opposite ones with stipulas. The next step from Asperula is Diodia, and then Spermacoce. In the two last the bases of the stipulas and footstalks are united into a common tube.

Some stipulas fall off almost as soon as the leaves are expanded, which is the casc with the Tulip-tree, Liriodendron tulipifera; in general they last as long as the leaves.

The absence or presence of these organs, though generally an indication that plants belong to the same natural order and eren genus, is not invariably so. Some species of Cistas have stipulas, other's none, which is nearly the case with grasses. The stipula in this, one of the most distinct of all natural orders, is peculiar, consisting of an internal white membrane crowning 
the sheath of their leat, and clasping the eulm. Sce Phalnis canariensis, Engl. Bot.t 1910, and Lugurus ovatus, t. 1394. In Aria cerulea, $t$. 750, a few minute hairs supply its place, while Sesleria carulea, t. 1613, and some muritime grasses, have scarcely more than the rudiment of a stipula. Old writers call this organ in grasses by a peculiar name ligula, and others denominate it memirana foliorum, but both terms are superfluous. A curious instance of stipulas supplying the place of leares is observable in Lathyrus Aphaca, t. 1167, which lias only one or two pair of real leares on the seeriling plants, and those soon disippear, serving chiefly to prove, if any proof were wanted, that the rest are true stipulas.

Remarkably scuriose, or dry membranous stipulas are seen in Illecelrum Paronychiu, Fl. Grac. $t .246$, and in the genus Pinles.

$\because$ Bracter. The Roral leaf, a leafy apperdinge to the dower or its stalk. It is of a waricty of forms, and sometimes green, 
sometimes colowred. The I ime-trees, Tilia curopora, f. 117, t. 610, and parrifolin. t. 1705 , have a very peculia: oblong pals Horal leaf, attached to the Aower-stalk. The Lavenders, $f .118$, sec Curt. Mag. t. 400 and 401, have coloured biacteas, and the Purple-topped Clary, Sutiza Horminam, Fl. Grac. t. 20 , exhibits a gratation from the proper leaves to green bracteas, and from them to coloured ones, which last are barran, or unaccompanied by fiowers. Hence I am induced to believe this plant a mere variety of $S$. viridis, $t .19$, all whose bracteas are green and ferile. Bartsia alpina, Engi. Bot. t. 361, and Melampyrum arvense, t. 53, display an elegant transition froin leaves to coloured bracteas. The Orchis tribe have green leafy bracteas, different in size in different species. it most beautiful large and coloured bractea is produced in Musscenda frondost, Hort. Mal. ¿. 2. t. 18, from one of the teeth of the calyx, also in $M$. glatura of Willdenow, and iro new species brought fiom America by Mr. John Fraser. Spinons bracteas of a curious consturction guard the calyx 
in Atractylis cancellata, t. 119.' Linncus observes that no bracteas are to be found in the class 'I'ctradymamia.

'The ochrea of Rotuboll, Tilldenow's Principles of Botamy, 50, which enfolds the flower-stalks in Cyperus, see Iingl. Bot. t. 1309, seem; to me a species of bractea.

3. Spina, $f$. 120. A Thom. This proceeds from: the wood itself, and is either terminal like Iippopiace rhamnoides, Fugl. Bot.t.425, Rhammus catharticus, $t$. 1629; or lateral as Crategus (or Mcspilus) Crus-galli, tomentosa, parififolia, Ec.

Linnacus observes that this sometimes disappears by culture, as in the Pear-tree, Pyrus sativa, which when wild has strong thorns; hence he denominates such cultivated plants tamed, or deprived of their natural ferocity. Protessor Willdenow, Principles of Bot.t. 270, considers thoms as abortive buds, and thence very ingeniously and satisfactorily accounts for their disappearance whenever the tree receives more nourishment. 
The permanent footstalis of the Gum Tragacanth shrub, Astragalus Tragacantha, are hardened into real spines, as are the flower-stalls in Pisonia, as well as the stipulas of Xanthium spinosum and the Mimosce.-Limn. Mss.

4. Aculens, $f .121$, a Prickle, arises from the bark only, and comes off with it, having, no comnection with the wood, as in Rosa, Kulus (the Bramble Raspberry, \&c.), and Zizyphus, Willd. Sp. Pl. $\tau$. 1. 1102.

This is not liable to disapuear by culture, being very distinct in nature from the last.

5. Cirrus, t.9.f. 129. A Tendril. This is indeed properly called a fulcrum or support, being intended solely to sustain weak and climbing stems upon more firm and sturdy ones. By its means such climbers often reach, in tropical forests, to the summits of lofity trees, which they crown with adventitious blossoms. Tendrils or claspers when young are usually put forth in a straight direction; but they presently become spiral, 
making several circumvolutions, by which they take hold of any thing in their way, and then assume a firmer texture. After accomplishing a certain number of turns in one direction, some tendrils have a power of twining subsequently the contrary way; many of them moreover are branched or compound, so that the chances of their meeting with a support are multiplied. The Vine, Vitis vinifera, the various species of Passion-flower, and the Pea or Vetch tribe afford good examples of spiral tendrils. The Virginian Creeper Hedera, or, as it ought to be called, Vitis, quinquefolia, has branched tendrils, whose extremities adhere to the smoothest flint, like the fibres of Ivy. Gloriosa superba, f. 76, Andr. Repos. t. 129, and Flagellaria indica, have a simple spiral tendril at the end of each leaf; for they belong to the Monocotyledones, the structure of whose whole herbage is generally of the most simple and compendious kind. The flower-stalks of Cardiospermum Halicacabum bear tendrils; but a most singular kind of tendril, if it may so be called, which certainly has 
a right to the name of fulcrum, is found in the Annona lienapetala, Limn. Suppl. 270. The flower-stalk of this tree forms a hook, and grasps the neighbouring branch, serving to suspend the fruit, which is very heavy, resembling a bunch of grapes, and indicates the plant in question to be either a Michelia or an Uvaria.

6. Glandula, a Gland, is defined by Linnaus as a little tumour discharging a fluid. Such are abundant on the stalk and calyx of a Moss Rose, f. 123, Curt. Mag. t. 69, and between the serratures of the leaf of Salix pentandra, Bay-leaved Willow; also on the footstalks of Viburum Opulus, Engl. Bot. t. 332, and rarious species of Passion-flower. The liquor discharged is in the first-mentioned instances resinous and fragrant, in the latter a sort of honey.

7. Pilus, f. 124. A Hair. This, according to the Linnæan definition, is an excretory duct of a bristle-like form. Such it undoubtedly is in the Nettle, Urtica, Lngl. Bot. t. 148, and $t$. 1236, whose bristles are tubular and 
pervious, having each a bag of poison at its base, like the fang of a serpent; as well "ns in numerous plants whose hiriry coats exude a viscid moisture. But the hairs which clothe many plants are merely a protection against cold, heat, or insects. Sometimes they are hooked, sometimes branched and entangled, as in Mullein, Verbascum, t. 549, Exc. In Croton, Solanum, and Lavatera, they hare often a starry tigure. Very generally they are found, under a microscope, to be curiously jointed. Some Begronice bear on their leaves flat little straps called by authors ramenta, shavings, instead of cylindrical hairs; but I know not that they at all differ in nature from the usual pubescence, nor do they merit to be particularly distinguished. Some of the natural order of axperifolice, as Lichium, t. 181, and Ly- psis, t. 938, especially some exotic species of this order, are clothed with curious white hard tubercles from which their bristles proceed. Echium Tyrenaicum, Desfont. Atlunt. v. 1. 161, is an instance of thi.s, $f: 125$. 
The pubescence of plants raries greatly in degree according to differences of soil or exposure; several kinds, as Mentha hirsuta, $t .447,448$, naturally hairy, being occasionally found smooth, but if transe planted they soon resume their proper habit. Yet the direction of the hairs or bristles proves a very sure means of distinguishing species, especially in the genus Mentha, the hairs about whose calyx and flower-stalk point differently in different species, and I have found it the only infallible distinction between one Mint and another. See Trans. of Linn. Soc. v. 5. 171. The accurate Dr. Roth has lately applied the same test to the species of Myosotis, which all botanists before him had either confounded under M. scorpioides, Engl. Bot. t. 180, or else separated upon vague principles. Some species of Galium are admirably characterized by the bristles of their leares, or of parts of their leaves, being hooked backward or forward. We therefore accept the $272 \mathrm{~d}$ maxin of Linnæus's Philosophia Botanica with that limitation which he himself has allowed in his commentary 
upon it. "The Pubescence," says he, "is a ridiculous distinction, being for the most part effaced by culture." After quoting examples, he concludes: "We are therefore not to have recourse to the hairiness or spines of plants but in case of absolute necessity." Such necessity erery botanist will allow to have existed in the Menthce and in Myosotis scorpioides; and though the degree of pubescence varies from culture, and even its structure be changeable, as in Hedypnois hispida, Engl. Bot. t. 554, and hivta, $t .555$, its direction is I believe as little liable to exception as any character that regetables present. 


\section{CHAPTER XTII.}

OF THE INFLORESCENCF, OR MODE OF FLOWERING, AND ITS VARIOUS FORMIS.

INFLORESCenCe, inforescentia, is used by Linnæus to express the particular manner in which flowers are situated upon a plant, de, nominated by preceding writers the modus forendi, or manner of flowering. Of this the several kinds are distinguished as follows.

Verticilues, $f$. 196. A Whorl. In this the flowers surround the stem in a sort of ring; though they may not perhaps be inserted on all sides of it, but merely on two opposite ones, as in Dead Nettle, Lamium, Engl. Bot. t. 768-770, Mentha rubra,t.1413, and Clisoporlium vulyare, t. 1401; or even on ore side only, as Rumce maritimus, $t$. 725. The flowers of Itippuris 
vulgaris, $t .763$, are truly inserted in a ring round the stem, f. 127 ; but they are not whorled independent of the leaves, and are therefore more properly, with a reference to the leaves, denominated axillary and solitary.

RaCracs, f. 128, a Cluster, or Racenc, consists of numerous rather distant flowers, each on its own proper stalk, and all connected by one common stalk, as a bunch of Currants, Ribes rubrum, Engl. Bot. t. 1989, nigrum, t. 1291, and Orobus sylvaticus, t. 518. A cluster is most generally drooping or pendulous, and the fowers are all expanded nearly at the same time.

A compound racemus occurs in Solanum Dulcamara, $t .565$, and an aggregate one, sereral being gathered together, in Actar racemosa, Dill. Elth.t. 67 ; but the example of a bunch of Grapes, quoted by Limneus for a racemus, appears to me a true thyrsus; see below.

SpICA, f. 129, a Spike, bears numerous flowers ranged along one common stalk, 
without any partial stalks, as in Satyrium hircinum, Engl. Bot. t. 34, Orchis bifolia, t. 22, Plantago major, t. 1.558, and media, $t .1559$, Potamogeton heterophyllum, t. 1235, and fluitans, t. 1286; but this is so seldom the case, that a little latitude is allowed. Veronica spicata, $t .2$, therefore, f. 130, and hibes spicatum, t. 1290, as well as the Common Lavender, Lavandula Spica, are sufficiently good examples of a spike, though none of them has entirely sessile flowers; and Linnaus uses the term in numerous instances where it is still less correctly applicable. A spike generạlly grows erect. Its mode of expansion is much more progressive than that of the raceme, so that a long period elapses between the fading of the lowest flowers and the opening of the upper ones. The flowers are commonly all crowded close together, or if otherwise, they form separate groups, perhaps whorls, when the spike is said to be either interrupted, or whorled; as in some Mints. In Sanguisorba officinalis the spike begins flowering at the top. See Capitulum below: 
A compound spike is seen in Lavandula vimnata, Cart. Mag. t. 401, and L. abrotanoides of Willdenow.

Spica secunda, a spike whose flowers lean all to one side, occurs in Nardus stricta, Engl. Bot. t. 290.

Spicula, f: 131, a Spikelet, is applied exclusively to grasses that have many Horets in one calyr, such florets, ranged on a little stalk, constituting the spikelet, which is thercfore a part of the flower itself, and not of the inflorescence; see Poa aquatica, t. 1315, fluitans, t. 1520, Briza minor, t. 1316, \&c.

Comyarus, $f$. 132, a Corymb, is a spike whose partial flower-stallis are gradually longer as they stand lower on the common stalk, so that all the flowers are nearly on a level, of which Spirca opulifolia, a common shrub in gardens, is an excellent specimen. The Linnaan class Tetradynamia exemplifies this less perfectly, as Carclamine pratensis, Engl. Bot. t. 776 , Cheiranthus simutus, $t .462$, and the common Cabbage, Brassica olerucea, t. 637 , 
in which the corymbus of flowers becomes a racemus of fruit, as happens also in that section of the Veronice, entitled by Linnæus corymboso-racemose. The flowers of Yarrow, $f$. 133, Achillea, t. 757 and 758 , and several others of the compound class, as well as the Mountain Ash, $t .337$, grow in a corymbose nanner, though their inflorescence may not come exactly under the above definition. It is worthy of remark that Linnaus in that definition uses the word spica, not racemus, nor has he corrected it in his own copy of Plil. Bot. p. 41, though he has properly altered a slip of the pen in the same line, petiolis, to pedunculis*. This shows he did not restrain his idea of a spike absolutely to sessile flowers, but admitted that extended signification which nature justifies. Muny plants acquire partial stallis as the fruit advances towards maturity.

* It might be expected from the numerous learned editors and copiers of this and other works of Linnæus, that they should correct such manifest errors as the above; which any tyro might perceive. 
Fasciculus, $f$. 134, a Fascicle, is applied to flowers on little stalks, variously inserted and subdivided, collected into a close bundle, level at the top, as the Sweet William, Dianthus burbatus, Curt. Mag. t. 207, and D. Arneria, lingl. Bot. t. 317.

Capiturur, $f$. 13.5, a Head or Tuft, bears the flowers sessile in a globular form, as Statice Armeria, t. 226, Adoxa Moschatellina, $t$. 453, and Gomphrena globosa, the Globe Amaranthus of the gardens.

Perluaps the inflorescence of Sunguisorba officinalis, t. 1312, might be esteemerl a capitulum, because its upper flowers come first to perfection, as in Adora, which seems contrary to the nature of a spike; but it does not appear that all capitate flowers expand in the same way, and Sanguisorba canadensis has a real spilie, flowering in the usual manner, from the bottom upwards. So Allium descendens, Curt. Mag. $t .251$, opens its upper, or central, fowers first, contrary to the usual order in its genus; both which instances prove such a diversity to be of small moment. 
UMBELLA, an Umbel, for which some all. thors retain the obsolete old English name - of Rundle. In this several flower-stalks, or rays, nearly equal in length, spread from one common centre, their summits forming a level, convex, or even globose surface, more rarely a concare one. When each ray is simple and single-flowered, it is called a simple umbel, $f$. 136, as those of Allium ursinum, Engl. Bot. t. 122, Ivy, t. 1267, Primula veris, t. 5, farinosa, t. 6, clatior, t. 513, and Eucalyptus resinifera, Exot. Bot. t. 84. In a compound umbel each ray or stalk mostly bears an umbellula, or partial umbel, as Athamanta Libanotis, Engl. Bot. t. 138. This is usually the case in the very natural order of plants called umbelliferous, $f$. 138, to which the last-méntioned, as well as the common Carrot, Parsnep, Parsley, Hemlock, \&c. belongs.

A few only of this order have simple umbels, as Hydrocotyle vulgaris, $t$. 75̃ , and the curious Astrantice, $f .137$, and Eriocalice, Exot. Bot.t.76-79. In Euphorbia the umbel is differently compounded, consisting of 
3, 4, 5 or numerous rays, each of which is repeatedly subdivided, either in a threefold or forked manner. See Engl. Bot. t. 883,959 , \&c.

Crma, $f .199$, a Cyme, has the general appearance of an umbel, and agrees with it so far that its common stalks all spring from one centre, but differ's in having those stalks variously and alternately subdivided. Examples are found in Viburnum, Engl. Bot. t. 331, 332, and the common Laurustinus, as also in Sambucus, Elder, $t .475$, 476. This mode of inflorescence agrees with a corymbus also in general aspect, but in the latter the primary stalks have no common centre, though the partial ones may sometimes be umbellate, which last case is precisely the reverse of a cyma.

Panicula, $f$. 140, a Panicle, bears the flowers in a sort of loose subdivided bunch or cluster, without any order. When the stalks are distant, it is called diffusa, a lax or spreading panicle, as in Saxifraga umbrosa, t. 663, so frequent in gardens under the name of London Pride, and 
S. Geum, t. 1.561 , but particularly in many grasses, as the common culcivated Oat, and Avena strigosa, t. 1266 ; in this tribe the branches of the panicle are mostly seniverticillate; see Aira aquatica, t. 15j\%。 A divaricated panicle is still more spreading, like those of Prenanthes muralis, t. 457, and Spergula arvensis, t. 1535; the last being dichotomous or forked. A . dense or crowded panicle, coarctata, is observable in Milium Tendigerum, t. 1107, and Agrostis stolonifera, $t .1532$, but still more remarkably in Phleum paniculatum, t. 1077, whose inflorescence looks, at first sight, like a cylindrical spike, but when bent to either side, it separates into branched lobes, constituting a real panicle.

TiiY iz vs, f. 141, a Bunch, is a dense or close panicie, more or less of an ovate figure, of which the Lilac, Syringa valgaris, Curt. Mag. t. 183, Tussilago hybrida and Petasites, Engl. Bot. t. 430, 431, are examples cited by Linnens. I presume likewise to consider a bunch of grapes. 
ritis vinifera, as a true thyrsus, to the characters and appearance of which it correctly answers. Its ullinate terminations are sometimes obscurely umbellate, especially while in blossom, which is no objection here, but can never be the case in a racemus, whether simple or compound. See Racemus.

Of simple flower-stalks, whether solitary or clustered, radical or cauline, axillary, lateral or terminal, we have already spoken.

Linnaus renarls that the most elegant specific characters are taken from the inflorescence. Thus the Apple, Engl. Bot. t. 179, and the Peai, form two species of Pyrus, so far at least a most natural genus, the former of which bears an unibel, the latter a corymb. Pyrola unifora, t. 146, secunda, t. 517, and umbelluta, Curt. Mag. t. 778 , are admirably distinguished by their several forms of inflorescence. 


\section{CHAPTER XIX.}

OF THE FLOWER AND FRUIT:

HAvivg examined the general structurs and external form of plants, we now come to more important and even essential, though more transitory organs - the flower and fruit, or parts of fructification. By these each species is perpetually renewed without limits, so far at least as the observation of mankind has reached; while, as we have already mertioned, all other modes of propagation are but the extension of an individual, and sooner or later terminate in its total extinction.

Nothing can be more happy than the Linnxan definition of these organs; Phil. Bot.52. "The fructification is a temporary part of vegetables, destined for the reproduction of the species, terminating the old indiriduas and begimning the new." 
Pliny had long ago beautifully said that " blossoms are the joy of trees, in bearing which they assume a new aspect, ryeing with each other in the luxuriance and varisty of their colours." Linnens has justly applied this to plants in generul, and, improring upon the idea, he considers their herbage as only a mask or clothing, by no means indicative of their true nature or character, which can be learned from the flower and fruit alone.

Mr. Knight has traced his central vessels, by which the sap is conveyed from the root, into the flower and fruit. On the returning sap in the bark of these parts he has not been able to make any distinct observation; but he has determined that no matter of increase is furnished from the flowers or their stalks, as from leaves, to the part of the branch below them, nor indeed to any other part, Phil. Trans.for $1801, p .340$. There can be no doubt that certain parts of the flower, which we shall presently describe, perform functions respecting air and light analogous to those of leaves, but entirely subservient to the benefit of the flower and fruit. Their secretions, formed 
from the returning sap, are confined to their own parposes. As scon as these are accomplished, a decided separation of vessels takes. place, and the ripe fruit, accompanied perhaps by its stalk, falls from the tree. Dr. Hales tried in vain to give any flavour to fruit by the most.penetrating and volatile fluids conveyed through the sap-vessels; for the laws of secretion are absolute in the organs of the flower, and their various results are, if possible, more strikingly distinct than even those we have contemplated in the leaves.

It is scarcely necessary to repeat that the fructification is essential to vegetables. A plant may be destitute of stem, leaves, ar even roots, because, if one of these parts be wanting, the others may perform its functions, but it can never be destitute of those organs by which its species is propagated. Hence, though many individual plants may 'be long without blossoms, there are none, so far as nature has been thoroughly investigated, that are not capable, in favourable circumstances, of producing them, as well as seeds; to whose perfection the blossoms themselves are altogether subservient. 
Linnæus distinguishes seven parts of fructification, some of which are essential to the very nature of a flower or fruit, others not so indispensably necessary, and therefore not universal.

I. Calyx, the Calyx or Flower-cup, generally resembling the leaves in texture and colour, and forming the outermost part of a flower. This is not essential, and is often absent.

II. Corolla, the Corolla, or more delicate coloured internal leaf or leaves, properly petals, of a flower, likewise not essential.

III. Stamen, or Stamina, the Stamen or Stamens, commonly of a slender or thread. like form, bearing some kind of knob or cellular body, and ranged internally with respect to the Corolla: These are essential.

IV. Pistillum, or Pistilla, the Pistil, or Pistils, in the centre of the flower, consisting of the rudiments of the fruit, with one or 
more organs attached to them, and, of course, essential.

V. Pericarpium, the Seed-vessel, of a pulpy, woody, or leathery texture, enclosing the seeds, but wanting in many plants.

VI. Semen, the Seed, the perfecting of which is the sole end of all the other parts.

VII. Receptaculum, the Receptacle, basis or point of connection. This must necessarily be present in some form or other.

I. CALYX. The Flower-cup, or more correctly the external covering of the flower, when present, was originally divided by Linnæus into seven kinds, some of which are more justly so denominated than the others, and I have ventured to make an alteration in his list.

1. Perianthium, $f$.142. Calyx, properly and commonly so called, when it is contiguous to and makes a part of the flower, as the five green leaves which encompass a Rose, in- 
cluding their urn-shaped base; the two green bristly ones which enfold the bud in Glaucium luteum, Fl. Brit. Engl. Bot. t. 8 ; the tubular part, comprehending the scales at its base, in the Pinks, t. 61, 62, or the globular scaly cup in Centaurea, t. 56. The Tulip, t. 63, is a naked flower, having no calyx at all.

This part is of an infinite variety of forms in different genera, being either simple or compound, divided or undivided, regular or irregular. In some instances it is permanent till the fruit is ripe, in others it falls even before the flower is well expanded.

Some genera have a double perianthium, as Malva, $t .671$, or even a triple one, as Scabiosa, t. 1311.

2. Involucrum, $f$. 143. Involucre of Professor Martyn; but I generally retain the Latin termination. This is remote from the flower, and can scarcely be distinguished clearly from a Bractea. The term was first adopted by Linnaus, at the suggestion of his friend Artedi, in order to distinguish 
the genera of umbelliferous plants, for which purpose the latter deemed the part in question very important. But according to the laws which Linnæus had laid down, the parts of the flower and fruit alone were to afford generic characters, and the most sound botanists have ever since kept to this rule, with infinite advantage over less correct ones, however ready to derive ideas respecting the natural habit, and secondary characters, of a genus, not only from the inflorescence and bracteas, but even from the leaves, stipulas, or other parts. Linnæus and Artedi, therefore, were obliged to consider the involucra and involucella, the former accompanying the general and the latter the partial umbels, as a sort of calyx, and the umbel altogether as one aggregate flower, composed of florets united by a common radiated receptacle: Consequently a cyme must be considered in the same light; nor are reasons wanting in support of this hypothesis, which we shall consider after having first explained all the parts of fructification.

In Euphorbia, however, the term bractea 
would surely be more proper than involucrum or involucellum, as is evident from a consideration of the inflorescence of the whole genus, so very different in different species. In E. Peplis, and many others, the flowers are solitary and axillary; in others again, as E. amygdaloides, Engl. Bot. t. 256, and Characias, t. 442, some flower-stalks are umbellate, some scattered; and the subdivisions of the umbel in all are ultimately forked, that is, of a nature between umbellate and scattered. This genus has, moreover, a proper calyx or perianthium of a most distinct and peculiar nature. Some species of Anemone, a genus destitute of a perianthium, are said by Linnaus to have an involucrum, as A. Pulsatilla, t. 51, for which the name of bractea would be vastly more correct, though in A. Hepatica, Curt. Mag.t.10, it is placed so near the flower as to seem a part of it, which, however, is really not the case.

The name of Involucrum is applied by Gleditsch to the membrane covering the fructification of ferns, $f .144,145$; nor have I, 
in studying this part with peculiar attention in ordex to reform the genera of these plants, see Tracts relating to Natural History, p. 21.5, found reason to contrive any new appsllation. My learned friends Willdenow and $S$ wartz have judged otherwise, calling: this membrane the indusium, or corering; which seems to me altogether superfluous. See its various forms in Eng 7 . Bot.t. $1458-$ $60,1150,1159,1160$, \&c.

3. Amentum, f.146. Catkin, denominated by. authors before Iinnæus julus, nucamentum, or catulus; consists of a common recep. tacle of a cylindrical form beset with numerous scales, each of which is accompanied by one or more stamens or pistils, so that the whole forms an aggregate flower. The receptacle itself and the bases of the scales are firmly united, and the whole catkin falls off entire, except that in some instances the upper part of each scale withers away, as in the Willow genus, Salix, Engl. Bot.t. 1388-90, 1402-4, \&c., the seed-vessels in that genus being quite distinct from the scales. In others, 
the whole scrle remains, enlurges, hardens, and protects the seed, as in l'imus, the Fir tribe. Such is the case with catkins of fertite flowers, which are necessarily permanent till the seed is ripe; barren ones fall as soon as the stamens have performed their ofince. Every catkin consists generally of either one lind of flower or the other. There are few certain and invariable instances of stamens and pistils in the same catlin, that circumstance occurring chiefly in a few species of Salix and C'arex; nor is Typha, t. 1455-7, an exception to this. Examples of barrenflowered catkins are seen, not only in Sulix and P'imus, but in several plants whose fertile or fruit-bearing flowers are not catkins, such as the Walnut, and, unless I am much mistaken, the Hasel-nut, t. 723. Each nut or seed of the latter has a permanent coriaceous calyx of its own, inadvertently called by Grertner an involucrum, though he considers the whole as an amentum, which this very calys proves it not: to be*. Humulus, the Hop, $t$. 4.27, has at catkin for the fertilc flower only.

* It appears morcover that Carpinus, the Hornbean, 
4. Spatha, f. 147. Sheath, a covering which bursts longitudinally, and is more or less remote from the flower. This is exemplified in the Snow-drop, Galanthus nivalis; t. 167, the various species of Narcissus, t. 17,275 and 276, and the Arum, t. 1298. The Spatha of the latter encloses a Spadix, or elongated receptacle, common to many flowers, according to the genuine Linnæan idea of this kind of calyx, taken from Palmtrees. In these the Spadix is branched.

5. Gluma,f. 148. Husk, the popular calyx of. Grasses and Grass-like plants, of a chaffy texture. These husks are usually compressed, embracing each other at the base, as in Phleum pratense, t. 1076. Sometimes they are depressed, flattened vertically, as in Briza, t.540 and 1316. To the husk belongs the Arista, $f .149$, Beard or Awn, a bristle-shaped appendage, usually spiral, and possessing the property of an hygrometer. This, however, is not always

has hitherto erroneously been supposed to have an amentum for the fertile flower. The true nature of the covering of the seed, as well as of the common stalk, proves it otherwise. 
present, even in different individuals of the same species.

"Unfortunately for the science,

On the awn there 's no reliance."

So says, or rather sings, with more truth than sublimity, the ingenious author of the Flora Londinensis; fasc. 6, t. 8.

The spiral kind of awn is most frequently attached to the Corolla of grasses, which is precisely of the same husky nature as their calyx, and is, by some botanists, considered as such. Specimens of gluma mutica, beardless huslis, are seen in Phalaris canariensis, Engl. Bot. t. 1310, and gluma aristute, awned ones, in Lagurus ovatus, t. 1334, and Stipa pennata, t. 1356.

6. Perichatium, $f .150$. A scaly Sheath, investing the fertile flower, and consequently the base of the fruit-stalk, in some Mosses. In the genus Hypnum it is of great consequence, not only by its presence, constituting. a part of the generic character, but by its differences in shape, proportion, and s rucțure, serving frequently to discriminate 
species. See Engl. Bot.t.1037-9, 118\%, $1445-8$, \&c. ; see also the same part in Neckera, t. 1443, 4. Iinnzus appears by his manuseripts to have intended adding this to the different kinds of calyx, though it is not one of the seren enumerated in his printed works. Nor is he, surely, correct in allowing it to the genus Jungermannia. The membranous part which he there calls perichetima is strictly analogous indeed to the calyptra, $f .151,152 \mathrm{~b}$, or veil of real mosses, esteemed by him a kind of calyx; but as I presume with Schreber, to reckon it rather a corolla, and Hedwig once thought the same, and as Jungermannia has more or less of a real calyx besides, f. 152 a, see Engl. Bot. t. 771, \&c., I would no longer apply the term perichatium to this genus at all.

The part called calyptra being removed from the list, as being a corolla, the perichatium takes its place among the seren kinds of calyx. We lay less stress upon this coincidence than Linnæus might have done, when, according to the fashion of the times, he condescended to distribute 
his immortal Plílosophia Botanica into 12 chapters and 365 sections, and reckoned seren parts of fructification as well as seren. species of calyx.

7. Volva, f. 153. Wrapper, or covering of the Fungus tribe, of a membranous texture, concealing their parts of fructification, and in due time bursting all round, forming a ring upon the stalk, as in Agaricis procerus, Sowerb. Fung. t. 190, and A. campestris, the Common Mushroom, t. 305; such at least is the original meaning of this term, as explained in the Phil. Bot.; but it has become more generally used, even by Linnæus himself, for the more fleshy external covering of some otherFungi, which is scarcely raised out of the ground, and enfolds the whole plant when young, $f$. 154. 'See Agaricus volvaceus, t. 1, and Lycoperdon formicatum, t. 198 ; also the very curious L. phalloides, $t$. 390, now made a distinct genus by the learned Personn, under the name of Batarrea. phalloides. 
Linnæus adopted from Cæsalpinus the opinion that the Calyx proceeded from the bark, like the leaves, because of its similarity in colour and texture to those organs. He even refined upen the original idea, and supposed this part to proceed from the outer bark, while the more delicate corolla originated in the iiber. What is now known of the physiology of the bark, as explained in several of our preceding chapters, renders this hypothesis totally inadmissible.

The knowledge of the real use of leaves, see chapter 16, may however throw some light upon that of the calyx. Besides protection of the flower from external injuries, which is one evident use of this part, it appears highly probable that it may often contibute to the growth and strength of the stalk which supports it, as the leaves do to that portion of branch below them. The stalk often swells considerably during the growth of the flower, especially just below the calyx, becoming more woody, an alteration frequently necessary for the support of the ripening fruit. When the calyx falls very early, as in the 
Poppy tribe, Papaver and Glancium, I cannot find that the flower-stalk is subsequently enlarged, nor in any manner altered; while in genera without number, whose calyx is permanent, the stalk beconies not only more woody, but often considerably thickened.

II. Corolla. The Corolla, vulgarly called the leaves of the flower, consists of those more delicate and dilated, generally more coloured leaves, which are always internal with respect to the calyx, and constitute the chief beauty of a flower. In the Rose the Corolla. is red and fragrant; in the Violet purple; in the Primrose yellow.

This term includes two parts, the Petal, Petalum, and the Nectary, Nectarium. The former is either simple, as in the Primrose, in which case the Corolla is said to be monopetalous, of one petal; or compound, as in the Rose, in which it is polypetalous, of several. The Nectary is sometimes a part of the petal, sometimes separate from it.

A monopetalous Corolla consists of two parts; the tube, tubus, the cylindrical part 
enciosed in the calyx of the Primrose; and the limb, limbus, which is the horizontal sprearling portion of the same flower, $f .155$. The aralogous parts of a polypetalous $\mathrm{Co}$ rolla, as in the Wall-flower or Stock, $f .156$, are numed the claw, unguis, $f .157 \mathrm{a}$, and the border, lamina, b.

The Corolla is infinitely diversified in form in different genera, whence Tournefort and Rivinus derived their methods of arrangement. It is called regular when its general figure is uniform, as in the Rose, the Pink, the Columbine, Aquilegia vulgaris, Engl. Bot. t. 297, and Gentiana Pneumonanthe, $t$. 20; irregular when otherwise, as the Violet, $t .619$, 620, Deadnettle, t. 768, and Lathyrus, t. 805 and 110s. An equal Corolla, $f .156$, is not only regular, but all its divisions are of one size, like those of the Primrose, $t .5$, Campanula, t. 12, or Saxifraga, t. 9; an unequal one, $f .158$, is when some segments are alternately smaller than the others, as in-Butomus, t. 651, or otherwise different, as in Aquilegia, $t$. 297. It is by no means always necessary, in defining characters of genera, to use these last terms, it being 
sufficient in general to say that a Corolla is regular in opposition to one that is irregular; more especially as some species of a genus ma possibly hare an equal corolla. others an unequal one.

The most usual shapes of a monopetalous corolla are

campamulata, $f$. 159, bell-shaped, as in

Campanula, t. 12.

infundibuliformis, $f$. 160, funnel-shaped, Pulmonaria, t. 118.

hypocrateriformis, $f$. 155, salver-shaped, Primula, $t .4$.

rotata, wheel-shaped, that is, salver-shaped

with scarcely any tube, Borago, $t .36$. ringens, $f$. 161, ringent, irregular and gaping like the mouth of an animal, Lamium, $t .768$; called by former botanists labiata, lipped.

personata, $f .162$, personate, irregular and closed by a kind of palate, Antirrhinum, t. 129. Those of a polypetalous one are cruciformis, $f:$ 156, cruciform, regular and like a cross, Dentaria, $t .309$, and Cheiranthus, $t$. 462 .

rosacea, rosaceous, spreading like a rose, Dryas, t. 451 . 
papilionacea, $f$. 163, papilionaceous, irregular and spreading, somewhat like at butterfy, Latlyms, t. 1108. The various petals which compose such a flower are distinguished by appropriate names, as ievillum, $f .161$, standard, the large one at the back; alce, $f$. 165, wings, the two sicle petals; and carina, $f .166^{\circ}$, the keel, consisting of two petals, united or separate, embracing the internal organs, $f .167$. In Trifolium all the petals are sometimes united into one at the lower part.

incompleta, incomplete, when parts, which analogy would lead us to expect, are deficient, as in Amorpha, a papilionaceous flower apparently, but consisting of the rexillum only ; or Rittera of Schreber, $f .168$, a rosaceous one with a single lateral petal, seeming as if four others had been stripped off:

It is remarkable that irregular flowers sometimes vary to regular ones in the very same plant, as in Bingnonia radicans, Curt. Mug. t. 485 ; and Antirrhum Linaria, f. 169, Engl. Bot. t. 658 and 260. 
Linnaus was of opinion that the Corolla originated from the Liber or inner bark, as the Calyx from the outer, but this cannut be defended now the real physiology of the bark is better understood.

The whole use and physiology of the Corolla have not yet been fully explained. As a protection to the tender and important parts within, especially from wet, its use in many cases is obvious, but by no means in all. Linnæus imagined it to serve as wings, to waft the flower up and down in the air, and so to promote the functions of the Stamens and Pistils, as will hercatter be described; nor is this opinion unfounded.

Sprengel has ingeniously demonstrated, in some hundreds of instances, how the Corolla serves as an attraction to insects, indicating by various marks, sometimes perhaps by its scent, where they may find honey, and accommodating them with a convenient resingplace or shelter while they extract it. This elegant and ingrenious theory receives confirmation from almost every flower we examine. Proud man is disposed to think that "Full many a flower is born to blush unseen," 
because he has not deigned to explore it; but we find that even the beauties of the most sequestered wilderness are not made in vain. They have myriads of admirers, attracted by their charms, and rewarded with their treasures, which very treasures would be as useless as the gold of a miser to the plant itself, were they not thus the means of bringing insects about it. The services rendered by such visitants will be understood when we have described all the parts of a flower.

Besides the above purposes, I have always' conceived the Corolla to fulfil some important ofice to the essential parts of the flower with respect to air, and especially light. It not only presents itself in a remarkable manner to the sun-beams, frequently closing or drooping when they are withdrawn, but it is so peculiarly distinguished by beauty or brilliancy of colour, that one carnot but think its functions somewhat difierent from those of the leaves, even with regard to light itself. Dr. Darwin calls the Corolla the lungs of the stamens and pistils, and with great probability, for they abound in air-vessels. But when we consider the elaborate and peculiax 
secretions of a flower, the elastic and inflammable pollen, the loney, and the exquisitely volatile perfume, as we know from the curious discoveries of modern chemistry how great a share light has in the production of such, we cannot but conclude that the petals must be of primary importance with respect to their secretion by its means.

Sometimes the Corolla is rery short-lived; sountimes very lasting, even till the fruit is perfected, though mostly in a facied condition. In double flowers I have observed it to be much more dumale than in single ones of the same species, as Anemones and Poppies, because, as I conceive, of its not having performed its natural functions, the stamens and pistils of such flowers being obliterated, or changed to petals; hence the vital principle of their corolla is not so soon exhausted as usual. Phil. Trans. for 1758, p. 165.

The Corolla, as already observed, is not essential. Whaterer its functions may be, they can be occasionally perforned by the Calyx perhaps, or eren by the Filaments of the Stamens; as those of leares are, in leafless plants, by the stems. When a flower has only one corering, it is not always easy 
to say whether that be a Calyx or Corolla. When green and coarse in texture like the former, we call it so, as in Chenopodinm, Engl. Bot.t. 103.5, and 1721-4, and the natural relationship of this genus to Polygonrm, $t$. 1044, 989, 756, Sc., leads us to reckon the same part in the latter a coloured calyx. On the other hand, when the part present is delicate and finely coloured, like the generality of Corollas, we denominate it such; more especially if the plant to which it belongs be allied to others that have a Calyx besides, as in Tulipa, $t .63$, allied to Leucojum, t. 621, which has a Spatha. The great Jussicu denominates this part in the Tulip and other liliaceous plants, however bcautiful, a Calyx. His definition of a Corolla is " that corering of a flower which is invested with the calyx, being very rarely naked; a continuation of the inner bark of the flower-stalk, not of its cuticle; not permanent, but mostly falling off with the stamens; surrounding or crowning the fruit, but never growing united with it; and having its parts or segments for the most part alternate with the stamens, which are cqual to them in number." By this mule the tube and 
six segments of a Nurcissus, $t .17,275$ and 976, constitute the Calyx, and then surcly what Jussieu calls a Crown, f. 1476, and Linnaus a Nectary, must be allowed the name of Corolla. On the other hand, the Spratha becomes a Bractea. Consequently the whole order of Lilinceous fowers in general have a coloured Calyx only, which seems hardly admissible; and yet I cannot conceal a recent discovery which strongly confirms the opinion of my acute and candid friend. Two species of a new genus *, found by Mr. Menzies on the West coast of North America, have beautiful liliaccous flowers like an $A g g-$ panthus, with three internal petals besides! Tulbaghlia is a similar instance. I must howercr protest against the idea of the Corolla originating exclusively from the inner burk, as well as of the cuticle not bing continued over it, for reasons sufficiently apparent from the former part of this work.

It is a Limmean rule that the Stamens should be opposite to the segments of the Calyx, and alternate with the parts of the

* I have lately, in a paper to the Limman Snciety, named this genus Brodicea in honour of James Brodie, Est. F.L.S. 
Corolla. Its author nevertheless seems of opinion that no absolute means of distinction between these two parts can be pointed out, except colour ; of the insufficiency of which he is aware. If however the Corolla performs functions with respect to light which the Calyx does not, and those functions are indicated by its colour, a distinction founded on such a principle is both correct and philosophical. We must then conclude that in most liliaceous plants, not in all, the two organs are united into one, and indeed the outside is often green and coarse like a Calyx, the inner coloured and delicate; witness Ornithogalum, t. 21, 130 and 499, Narthecium, t. 535, \&c. Linnæus has the same idea respecting Daphne, t. 119 and 1381, and the analngy is confirmed by Gnidia, which is a Daphne with petals. In Trollius, t. 28, and Helleborus, t. 200 and 613, Linneus considers as petals what Jussieu, following Vaillant, thinks a Calyx. Of these plants we shall soon have occasion to speak again.

I cannot but consider as a sort of Corulla the Calyptra or Veil of Mosses, which Linnæus reckoned a Calyx. Schreber, very deep and critical in his inquiries concerning 
these plants, and Hedwig, so famous for his discoveries among them, were both of this opinion, though the latter seems to have relinquished it. The organ in question is a membranous hood, covering the unripe fruit of these diminutive regetables, like an extinguisher, $f .151$; but soon torn from its base, and elevated along with the ripening capsule. See Engl. Bot. t. 558, \&c. The great peculiarity of this part, whatever it be called, consists in its summit performing the office of a stigma, as Hedwig first remarked. In Jungermannia, $f .152, t .771, \& c$. , the very same part, differing only in usually bursting at the top to let the fruit pass, is named by Linnæus a perichetium, but very incorrectly, as we liave already hinted.

Whatever office the Petals may perform with respect to air and light, it is probable that the oblong summit of the Spadix in Arum, t. 1298, answers the same purpose. When this part has been for a short time exposed to the light, it assumes a purplish brown hue, which M. Senebier seems to attribute to the same cause which he thinks produces the great heat observed in this flower, the 
rapid combination of oxygen gas with the carbon of the plant; an hypothesis hardly adequate to explain either.

Nectarium, the Nectary, may be defined as that part of the Corolla which contains or which secretes honey. It is perhaps in effect nearly universal, as hardly a flower can be found that has not more or less honey, though that liquor is far from being miversally, or even generally, formed by any apparatus separate from the Petals. In monopetalous flowers, as Lamium album the Dead Nettle, $t$. 708 , the tube of the corolla contains, and probably secretes, the honey, without any crident Nectary. Sometimes the part under consideration is a production or elongation of the Corolla, as in Violets; sumetimes indeed of the Calyx, as in the Garden Nasturtium, Tropeolum, Curt. Mag. t. 23 and 98, whose coloured Calyx, $f$. 170 , partalies much of the nature of the petals. Sometimes it is listinct from both, either resembling the petals, as in Aquilegia, f. 171, Engl. Bot. t. 297, or more different, as in Epimedim, f. 172, 173, t. 438, Helleborus, $t$. 200 and 613, Aconitum, the Common Monkshood, and Delphinium, 
the Larkspur. Such at least is the morle in which Limneus and his followers understand the four last-mentioned florers; but we have already hinted that Jussieu is of a different opinion, and he even calls the decided Nectary of Eprimedium an internal petal! Diffculties attend both theories. It seems paradoxical to call petals those singular borlies in Aconitum, f. 174, like a pair of little birds, which are manifestly formed only to hold the honey, and not situated nor constructed so as to perform the proper functions of petals; but on the other hand Ramunculus, t. 100, 515 and 516 , one of the same natural order, has evident calyx and petals, which latter have a honey-bearing pore in their claw, evincing their identity with the less petal-like Nectaries just described. Other instances indeed of Nectaries in the claws of petals are found in the Crown Imperial and Lily; which only confirms more strongiy the compendious construction of the Lily tribe, the lcares of their flowers in these examples being Calyx, Petals and Nectaries all in one.

The most indubitable of all Nectaries, as actually secreting honey, are those of a 
glandular kind. In the natural order of Cruciform plants, composing the Linnæan class Tetradymamia, these are generally four green glands at the base of the Stamens. See Dentaria, Engl. Bot. t. 309, Sisymbrium, t. 525, and Brassica, t. 637. In Salix, t. 1483, and Geranium, t. 322, 75, \&c., similar glands are observable; whilst in Pelargonium, the African Geranium, the Nectary is a tube running down one side of the flower-stalk.

The elegant Parnassia, : 82, of which we are now acquainted with two new American species, has a most elaborate apparatus called by Linnæus Nectaries, $f .175$, but which the cautious Jussieu names Scales only. Linnæus usually called every supernumerary part of a flower Nectary, from analogy only, though he might not in every case be able to prove that such parts produced honey. This is convenient enough for botanical distinctions, though perhaps not always right in physio$\log y$; yet there is nothing for which he has been more severely and contemptuously censured. He was too wise to answer illiberal criticism, or he might have required his ad- 
versaries to prove that such parts were not Nectaries. Sometimes possibly he may seem to err, like L'Heritier, in calling abortire stamens by this name. Yet who knows that their filaments do not secrete honey as well as the tubes of numerous flowers? And though abortive as to Antheras, the Filament, continuing strong and vigorous, may do its office.

Honey is not absolutely confined to the flower. The glands on the footstalks of Passion-flowers yield it, and it exudes from the flower-stalks of some liliaceous plants.

The sweet viscid liquor in question has given rise to much diversity of opinion respecting its use. Ponterera thought it was absorbed by the seeds for their nourishment while forming, as the yolk of the egg by the chick. But Linneus observes in reply, that barren flowers produce it as well as fertile ones, witness Urtica and Sulix. In some instances the fertile flowers only are observed to bear honey, as Plyllanthus and l'amus, but such cases are rare. Even Darwin says the honey is the food of the stamens and pistils, not recollecting that it is often lodged in spurs or cells quite out of their reach. 
There can be no doubt that the sole use of the honey with respect to the plant is to tempt insects, who in procuring it fertilize the flower, by disturbing the dust of the Stamens, and even carry that substance from the barren to the fertile blossoms.

3. STAmuxa. The Stamens, formerly called Clives, are various in number in different flowers, from one to some hundreds. Their situation is internal with respect to the parts we have been describing; external to the Pistils, at least in simple flowers.

These organs are essential, there being no plant hitherto discovered, after the most careful research, that is destitute of them, either in the same flower with the pistils, or a separate one of the same species.

A Stamen, $f .176$, commonly consists of two parts, the Filament, a, Filamentum, and Anther, b*, Anthera, the former being merely what supports the latter, which is the only essential part. Variotis forms and pro-

* I submit to the opinion of Professor Martyn in adopting this word, for the reasons given in his Language of Botany, more especially as general practice secms to farour its use. 
portions of Filaments may be seen in the 'Tulip, where they are six in number, thick and short, Engl. Bot. t. 6:3; the Pink, where they are ten, much more slender, and answering to the idea of a filament or thread, t. 6o ; and Anemone, t.51, where they are numerous. 'They are commonly smooth, but sometimes, as in Verbuscum, t. 58, 59, bearded. In Melulenca, Frot. Bot. t. $36^{\circ}$ and 50, they are branched; and in Prunclla, Engl. Bot. t. 961, forked, one point only bearing an Anther. In Aristolochia, t. 398, they are wanting, and nearly so in P'otamogeton, t. 376, \&c.

The Anther is the only essential part of a Stamen. It is generally of a membramous texture, consisting of two cells or cavities, bursting longitudinally at their outer edges, as in the Tulip. In Evica, t. 1019 -15 , it opens by pores near the summit, as in the Potatoe-blossom. Very ramely

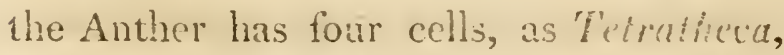
Bot. of $N$. Holl. t. 5, and lizut. Isut. t. $20 \%$ - 22. Sometimes it is crnamented

* In this plate the engraser has by mistake expresed the section of the anther so as to look more like a germen, though the original drawing was corr.et. 
with a crest, as in many Erica, and the genus Pinus. See Mr. Lambert's splendid work.

The Pollen, or Dust, is contained in the Anther, from which it is thrown out chiefly in warm dry weather, when the coat of the latter contracts and bursts. The Pollen, though to the naked eye a fine powder, and light enough to be wafted along by the air, is so curiously formed, and so various in different plants, as to be an interesting and popular object for the microscope. Each grain of it is commonly a membranous bag, round or angular, rough or smooth, which remains entire till it meets with any moisture, being contrary in this respect to the nature of the Anther; then it bursts with great force, discharging a most subtile vapour. In the Orchis family, and some other plants, the pollen is of a glutinous nature, very different from its usual aspect. See remarks on Mirabilis longiflora, Erot. Bot. v. 1. 44 .

The Stamens are changed to petals in double fowers, and rendered useless. They are often obliterated by excessive nourish- 
ment, or when the plant increases much by root, as in the Fiery Lily, or true Lilium bulbiferum.

4. Pistilla. The Pistils, no less essential than the Stamens, stand within them in the centre of the flower, and are generally fewer. When in a different flower, on the same or a different plant, they are not always central. Linnæus conceived them to originate from the pith, and the stamens from the wood, and hence constructed an ingenious hypothesis, relative to the propagation of vegetables, which is not desti. tute of observations and analogies to support it, but not countenanced by the anatomy and physiology of the parts alluded to.

Each Pistil, $f .177$, consists of three parts. 1, the Germen, a, or rudiment of the young fruit and seed, which of couse is essential; 2, the Stylus, b, style, various in length and thickness, sometimes altogether wanting, and when present serving merely to elevate the third part, Stigma, c. This last is indispensable. Its shape is various, either 
simple, scarcely more than a point, or capitate, forming a little round head, or variously lobed. Sometimes hollow, and gaping more especially when the flower is in its highest perfection; very generally downy, and always more or less moist with a peculiar viscid fluid, which in some plants is so copious as to form a large drop, though never big enough to fall to the ground. The moisture is designed for the reception of the pollen, which explodes on meeting with it; and hence the seeds are rendered capable of ripening, which, though in many plants fully formed, they would not otherwise be.

The Germen appears under a variety of shapes and sizes. It is of great moment for botanical distinctions to observe whether it be superior, that is, above the bases of the calyx and corolla, as in the Strawberry and Raspberry, or inferior, below them, as in the Apple and Pear. Very rarely indeed the Germen is supposed to be betwixt the calyx and corolla, of which Sanguisorba, Engl. Bot.t. 1312, is reckoned by Linnæus an example; but 
the corolla there has really a tube, closely embracing the Germen. In Adoxa, $t .453$, the calyx is half-inferior, the corolla superior. When in botanical language we say germen superior, it is equivalent to flower inferior; but it is sometimes more convenient and proper, for the sake of analogy or uniformity, to use one mode of expression than the other.

Pistils are sometimes obliterated, though oftener changed to petals, in double flowers, as well as the stamens; but I have met with a much more remarkable change in the Double Cherry, of the pistil into a real leaf, exactly conformable to the proper leaves of the tree, only smaller. By this we may trace a sort of round in the regetable constitution. Beginning at the herbage or leaves, we proceed insensibly to bracteas in many species of Salvia, or to both calyx and corolla in the Garden Tulip, which frequently has a leaf half green half coloured, either in the flower or on the stalk just below it. Anemone alpina produces occasionally a petal among the segments of its involucrum or bractea. 
Geum rivale, Engl. Bot. $t$. 1(1)6, when cultivated in dry gravelly ground, exhibits such transformations in abundance. Between petals and stamens there is evidently more connection, as to their nature and furictions, than between any other organs, and they common!y flourish and fall together. Yet only one instance is known of petals changing to stamens, which $\mathrm{Dr}$. Withering has commemorated, in the Black Currant, Ribes nigrum. On the other hand, nothing is more frequent than the alteration of stamens to petals. Here then the metamorphosis begins to be retrograde, and it is still more so in the Cherry above mentioned, by which we return to the herbage again.-The line of distinction seems to be most absolute between stamens and pistils, which never change into each other; on the contrary, pistils, as we see, rather turn into petals, or even into leaves.

5. Pericarpium. The seed-vessel, extremely various in different plants, is formed of the germen enlarged. It is not: 
an essential part, the seeds being frequently naked, and guarded only by the calyx, as in the first order of the Linnaan class Didynamin, of which Lamium, Engl. Bot. $t .768$, and Galeopsis, $t .667$, are examples; also in the great class of compound flowers, Syngenesia, as well as in Rumer, t. 724, Polygonum, t. 989, the Umbelliferous tribe, numerous Grasses, \&c.

The use of the Seed-vessel is to protect the seeds till ripe, and then in some way or other to promote their dispersion, either scattering them by its elastic power, or serving for the food of animals in whose dung the seeds vegetate, or promoting the same end by various other means. The same organ which remains closed so long as it is juicy or moist, splits and flies asunder when dry, thus scattering the seeds in weather most favourable for their success. By an extraordinary provision of Nature, however, in some annual species of Mesembryanthemum, $f .178$, natives of sandy cleserts in Africa, the seed-vessel opens only in rainy weather; otherwise the seeds might, in that country, lie long exposed 
before they met with sufficient moisture to. vegetate.

3. Capsula, a Capsule, is a dry seed-vessel of a woody, coriaceous or membranous texture, generally splitting into several valves; more rarely discharging its contents by orifices or pores, as in Campanula and Papaver; or falling off entire with the seed. Internally it consists either of one cell or several; in the latter case the parts which separate the cells are called dissepimenta, partitions. The central column to which the seeds are usually attached is named columella. See Datura Stramonium, f. 179, Engl. Bot.t. 1288.

Gartuer, a writer of primary authority on fruits and seeds, reckons scveral peculiar kinds of Capsules, besides what are generally understood as such; these are

Utriculus, a Little Bladder, which varies in thickness, never opens by any valves, and falls off with the seed. I be= lieve it never contains more than one seed, of which it is most commodiously, in botanical language, called an external coat, 
rather than a Capsule. Grertner applies it to Chenopodium, as well as to Clematis, \&c. In the former it seems a Pellicula, in the latter a Testa, as we shall hereafter explain.

Samara is indeed a species of Capsule, of a compressed form and dry coriaceous texture, with one or two cells, never bursting, but falling off entire, and clilated into a kind of wing at the summit or sides. It is seen in the Elm, the Maple, the Ash, Engl. Bot. t. 169\%, and some other plants. This term howerer may well be dispensed with, especially as it is the name of a genus in Linnæus; an objection to which Cotyledon too is liable.

Folliculus, a Follicle or Bag, reckoned by Limnaus a separate kind of seed-vessel from the Capsule, ought perhaps rather to be esteemed a form of the latter, as Gærtner reckons it. This is of one valre and one cell, bursting lengthwise, and bearing the seeds on or near its edges, or on a receptacle parallel therewith. Instances are found in Vinca, t. 514, Pconia, t. 1513, and Embothrium, Bot. of New Holland, t. $7-10$. 
Coccum of Gærtner, separated by hin from capsules, is a dry seed-vessel, more or less aggregate, not solitary, whose sides are elastic, projecting the seeds with great force, as in Euphorbia; alsu Boronia, Tracts on Nat. History, t. 4-7. This seems by no means necessary to be esteemed otherwise than a sort of capsule.

2. Siliqua, $f$. 180, a Pod, is a long dry solitary seed-vessel of two valves, separated by a linear receptacle, along each of whose edges the seeds are ranged alternately, as in the class Tetradynamia. See Cheiranthus, Engl. Bot.t. 462, and Cardamine, t. 80; also Bignonia echinata, figured by Gærtner, t. 52, $f .1$, which, though cautiously called by him a capsula siliquosa only, is as true a Siliqua, according to his own definition, and every body's ideas, as possible; so is also that of Chelidonium. He justly indeed names the fruit of Pconia, capsula leguminosa, a follicle with him. being a single-valved capsule, with the seeds marginal as in a legume.

Silicula, $f$. 181, a Pouch, is only a Pod of a short or rounded figure, like Draba verna, Engl. Bot. t. 586 . 
3. Legumen, f. 182, a Legume, is the peculiar solitary finit of the Pea kind, forned of two oblong valves, without any longitudinal partition, and bearing the seeds along one of its margins only. Sce Engl. Bot. t. 1046, 805, \&c. The Tamarind is a Legume filled with pulp, in which the seeds are lodgred. The Capsules of Melleborus and some other plants allied thereto, justly indicated by Gærtner as approaching very nearly to the definition of Legumes, differ essentially in not being solitary, and in consisting each but of one valve. Some Larkspurs indeed bear such capsules solitary, but analogy teaches us their true nature.

When a Legume is divided into several cells, it is either by transverse constrictions, or by inflexion of the valves; never by a separate longitudinal partition; see Dolichos purpureus, Exot. Bot. t. 74.

Sometimes this kind of fruit lodges but one seed, as in many species of Trifolium; see Engl. Bot.t. 1048, also Viminaria denudatu, Eiot. Bot.t.27. It is only by analogy that such are known to be Legumes. 
1. Drupa, f: 183, a Stone-fruit, has a fleshy coat, not separating into valves, containing a single bard and bony Nut, to which it is closely attached; as in the Peach, Plum Cherry, \&c.; see Engl. Bot. t.706 and 1383. The Cocoa-nut is a Drupa with a less juicy coat.

Sometimes the Nut, though not separating into distinct valves, contains more than one cell, and conscquently several seeds. Instances are found in Cormus, t. 24., Gertmer, t. 26, and Olea, the Olive, Fl. Grec. t. 3, though one cell of the latter is commonly abortive.

5. Pornum, $f .181$, an Apple, has a fleshy coat like the Drupa, but containing a Capsule with several seeds, as in common Apples and Pears; see Pyrus domestica, t. 350.

This is comprehended by Gærtner under the different kinds of Bacca, it being sometimes scarcely possible to draw the line between them; witness the Linnæan genus Sorbus.

๑. Bacea, f. 185, a Berry, is fleshy, without 
valves, containing one or more Seeds, enveloped with pulp. It becomes more juicy internally as it advances to maturity, quite contrary to the nature of a Capsule, though the difference between these two unripe fruits may not be discernible, and though some true Berries, when fully ripe, finally become of a dry and spongy texture; but they never open by valves or any regular orifice. Examples of a Bucca are seen in Atropa Belladonna, Engl. Bot. t. j92, and Ribes, $t$. 1289-92. The same part in Hedera, t. 1267, is of a more mealy substance. In Cucubalus, $t$. 1577, the coat only is pulpy. In Trientalis, t. 15, the coat becomes very dry and brittle as soon as ripe, and the cavity of the fruit is nearly filled by a globular columella. See Girtner, t. 50.

Bacca compositu, $f$. 186, a Compound Berry, consists of several single ones, each containing a seed, united together, as in Rubus, the Raspherry, Bramble, \&c., Engl. Bot.t.715, 716, 826, 827. Each of the separate parts is denominated an Acinus, or Grain, which torm Gartner extends to 
the simple many-seeded berries of the Vine, Gooseberry, \&c.

The Orange and Lemon are true Berries, with a thick coat. The Melon and Cucumber tribe have a peculiar sort of Berry for which Gærtner uses the name of Pepo, Gourd; and he defines it a Berry whose cells, together with the seeds, are remote from the axis or centre, the seeds being inserted into the sides of the fruit. Passifiora suberosa,f.187, Exot. Bot.t.28, shows this insertion, being nearly allied to the same tribe; but in this genus the pulp invests each seed separately, forming Acini within the common cavity.

Some fruits ranged by Linnæus as Drupe with many seeds, on account of the hardness of the shells of those seeds, are best perhaps, on account of their number, considered by Grertner as Bacce. Among these are Mespilus, the Medlar.

There are several spurious kinds of berries, whose pulp is not properly a part of the fruit, but originates from some other organ. Thus, in the Mulberry, as well as the Strawberry Spinach, Blitum, Curt. 
Mag. t. 276, the Calyx after flowering becomes coloured and very juicy, investing the seed, like a genuine berry. The Corolla of Commelina Zanonia undergoes a similar change, forming a black very juicy coat to the capsule, being totally altered both in shape and substance from its appearance in the flower. In the Juniper, Engl. Bot. t. 1100, a few scales of the fertile catkin become succulent, and coalesce into a globular berry with three or more seeds, to which Gertner applies the term galbulus, the classical name of the Cypress fruit, which last however is as true a strobilus or cone as that of the Fir. In the Yew, t. 746, some have thought it a calyx, others a peculiar kind of receptacle, which becomes red and pulpy, embracing the seed. Lamarck has, in his Encyclopédie, v. 3. 228 , considered this fruit as a real bacca or drupa, with the idea or definition of either of which it cannot by any means be made to accord, being open at the top, and having no connection with the stigma, which crowns the seed itself. The same writer mistakes for a calyx the scales, which 
analogy shows to be bracteas; and I cannot but think Jussieu and Gartner more correct in their ideas of this singular fruit, when they call the pulpy part in question a receptacle, though the term calyx seems less paradoxical, and is perhaps still more just*. We do not know enough of Taxus uncifera to draw any conclusions from thence. See Gartuer, $t .91$. In the Strawberry, Engl. Bot. t. 1524, what is commonly called the berry is a pulpy receptacle, studded with naked seeds. In the Fig, Gcertner, t.91, the whole fruit is a juicy calyx, or rather common receptacle, containing in its cavity innumerable florets, each of which has a proper calyx of its own, that becomes pulpy and invests the seed, as in its near relation the Mulberry. The Paper Mulberry of China is indeed an intermediate genus between the two, being as it were a Fig laid open, but without any pulp in the common receptacle.

7. Strobilus, $f$. 188, a Cone, is a Catkin hard-

* Hernandia, Gcertn. $t .40$, has a similar, though not succulent, calyx, and the green cup of the Hazelnut is equivalent to it. 
ened and enlarged into a Seed-ressel, as in Pinus, the Fir.

In the most perfect examples of this kind of Eruit the Seeds are closely sheltered by the scales as by a capsule, of which the Fir, Cypress, \&c., are instances. In the Birch and Alder they have a kind of capsule besides, and in the Willow and Poplar a stalked bivalve capsule, still more separate from the scales. The Plane-tree, $P$ latunus, the Liquidambar and the Comptonte. have globular catkins, in which bristles or tubercles supply the place of scales. See Gortner, t. 90 .

6. Semina. The Seeds are the sole "end and aim" of all the organs of fructifcation. Every other part is, in some manner, subservient to the forming, perfecting, or dispersing of these. A sced consists of several parts, some of which are more essential than others, and of these I shall speak first.

Embryo,f. 2, 4, the Embryo, or Germ, is the most essential of all, to which the rest are wholly subservient, and without which 
no seed is perfect, or capable of regetation, however complete in external appearance. Linnæus, after Cæsalpinus, names it the Corculum, or Little Heart, and it is the point whence the life and organization of the future plant originate, as we have already explained, p. 96. In some seeds it is much more conspicuous than in others. The Walnut, the Bean, Pea, Lupine, \&c., show the Embryo in perfection. Its internal structure, before it begins to vegetate, is observed by Gærtner to be remarkably simple, consisting of an uniform medullary substance, enclosed in its appropriate bark or skin. Vessels are formed as soon as the rital principle is excited to action, and parts are then developed which seemed not previously to exist, just as in the egg of a bird. In position, the Embryo is, with respect to the base of the whole flowe or fruit, either erect, as in the Dandelion and other compound flowers, reversed as in the Umbelliferous tribe, or horizontal as in the Date Palm, f. 199 b, Gcertner, t.9. In situation it is most commonly within the substance of the seed, and either central as in Um- 
belliferous plants, or excentric, out of the centre, as in Coffee ; in Grasses however it is external. Its direction is either straight, curved, or even spiral, in various instances. The Embryo of seeds that have a single cotyledon, or none at all, is peculiarly simple, without any notch or lobe, and is named by Gritner Embryo monocotyledoneus.

Cotyledones, the Cotyledons or Seedlobes, are immediately attached to the Embryo, of which they form, properly speaking, a part. They are commonly two in number, $f .7$; but in Pimus, and Dombeya, the Norfolk Island Pine, they are more, $f .3$, as already mentioned, $p .98$. When the seed has sufficiently established its root, these generally rise out of the ground, and become a kind of leaves. Such is the true idea of the organs in question, but the same name is commonly given to the body of the seed in the Grass and Corn tribe, the Palms, and several other plants, thence denominated monocotyledones, because the supposed Cotyledon is single. The nature of this part we shall presently explain. It 
neither rises out of the ground, nor performs the proper functions of a Cotyledon, for what thesc plants produce is, from the first, a real leaf; or, if the plant has no leaves, the rudiment of a stem, as in Cuscuta. In either ease, the part produced is solitary, never in pairs; hence Gartner was misled to reckon Cyamus Nelumbo, Exot. Bot.t.31, 32, among the monocotyledonous plants, the body of its seed remaining in the earth, and the leaves springing one at a time from the Embryo, just as in the Date Palm, Wheat, Barley, \&c.

The Seed-lobes of Mosses, according to the observations of Hedwig, Fund. part 2. $t .6$, are above all others numerous and subdivided, $f .195,196$, as well as most distinct from the proper leaves; so that these plants are very improperly placed by authors among such as have no Cotyledons, a measure originating probably in theory and analogical reasoning rather than observation.

Albumcn, the White, is a farinaceous, fieshy, or horny substance, which makes up the chief bulk of some seeds, as Grasses, 
Corn, Palms, Lilies, never rising out of the ground nor assuming the office of leares, being destined solely to nourish the germinating embryo, till its roots can perform their office. In the Date Palm, f: 199, Grertner, t. 9, this part is nearly as hard as a stone; in Mirabilis, Erot. Bot.t.2.3, it is like wheat flour. It is wanting in several tribes of plants, as those with compound, or with cruciform flowers, and the Cucumber or Gourd kind, according to Gærtner. Soms few leguminous plants hare it, and a great number of others which, like them, thave cotyledons besides. iVe are not however to suppose that so important an organ is altogether wanting, even in the abuvementioned plants. The farinaceous matter, destined to nourish their embryos, is unquestionably lodged in their cotyledons; whose sweet taste as they begin to germinate often evinces its presence, and that it has undergone the same chemical change as in Barley. The Albumen of the Nutmeg is remarkable for its eroded variegated appearance, and aromatic quality; the cotyledons of this seed are very small 
Vitellus, the Yolk, first named and fully illustrated by Gartner, is less general than any of the parts already mentioned. He characterizes it as very firmly and inseparably comnected with the Embryo, yet never rising out of the integuments of the seęd in germination, but absorbed, like the Albumen, for the nourishment of the Embryo. If the Albumen be present, the $V$ itcllus is always situated between it and the Embryo, and yet is constantly distinct from the former. The Vitellus is esteemed by Gartner to compose the bulk of the seed in Fuci, Mosses and Ferns, as well as in the genus Zamia, $f .200$, closely allied to the latter, see his $t .3$, and even in Ruppia, Engl. Bot.t. 136, and Cyamus. In the natural order of Grasses the part under consideration forms a scale between the Embryo and the Albumen.

I cannot but think that the true use of the Vitellus may be to perform the functions of a Cotyledon with regard to air if not to light, till a real leaf can be sent forth, and that the "subterraneous Cotyledons" of Gartner in the Horse Chesnut 
and Garden Nasturtium are, as he seems to indicate in his Introduction, $p .151$, rather of the nature of a Vitellus. It does not appear that any plant with genuine ascending Cotyledons is likewise furnished with this organ; on the other hand, it commonly belongs to such as have the most copious Albumen, and therefore should seen to answer some other end than mere nutriment, which is supplied by the latter.

We learn from the above inquiries, that the old distinction between plants with one Cotyledon and those with several may still be relied on, though in the former the part which has commonly been so denominated is the Albumen, as in Corn, the real Cotyledon of which is the scale or Titellus, which last organ however seems wanting in Palms, Lilies, \&c., such haring really no Cotyledon at all, nor any thing that can perform its office, except the stalk. of their Embryo*. In the Horse Chesnut, Oak and Walnut possibly, whose seed-lobes

* This may answer the purpose of a Cotyledon, just 2: the stems of unany plants fulfil the office of leares. 
do not ascend, the functions of a real Cotyledon, as far as air is concerned, and those of the Albumen may be united in these lobes, as is the case with most Leguminous plants; which is renclered more probable, as several of the latter have the corresponding parts likewise remaining under ground. Hence the divided Vitellus of the Cyamus is to be considered as a pair of subterraneous Cotyledons, and the plant consequently ranges near its natural allies the Poppy tribe, as $\mathrm{Mr}$. Salisbury, without the aid of physiology, has shown in the Annals of Botany, v. 2. p. 70,75.

Testa, f. 4, the Skin, contains all the parts of a seed above described, giving them their due shape; for the skin is perfectly formed, while they are but a homogeneous liquid. This coat differs in thickness and texture in different plants. It is sometimes single, but more frequently lined with a finer and very delicate film, called by Gartner Membrana, as may be seen in a Walnut, and the kernel of a Peach, Almond, or Plum. In the Jasmine a quantity of pulp is lodged 
between the Membrana and the Testa, constituting a pulpy seed, semen baccatum, which is distinct from the Acinus, or grain of a compound berry in the Raspberry, the seed of the latter having its proper double covering within the pulp. The Testa bursts irregularly, and only from the swelling of its contents in germination.

Hilum, the Scar, is the point by which the seed is attached to its sced-ressel or receptacle, and through which alone life and nourishment are conveyed for the perfecting its internal parts. Consequently all those parts must be intimately connected with the inner surface of this scar, and they are all found to meet there, and to divide or divaricate from that point, more or less immediately. In describing the form or various external portions of any seed, the Hilum is always to be considered as the base. When the seed is quite ripe, the communication through this channel is interrupted: it separates from the parent plant without injury, a Scar being formed on each. Yet the Hilum is 
so far capable of resuming its former nature, that the juices of the earth are inbibed through it previous to germination.

There are various accessory parts, or appendages, to seeds, which come under the following denominations.

Pellicula, the Pellicle, called by Gærtner Epidermis, closely adheres to the outside of some seeds, so as to conceal the proper colour and surface of their skin, and is either membranous, and often downy, as in Convolvulus, or mucilaginous, not perceptible till the seed is moistened, as in Salvia verbenaca, Engl. Bot.t. 154. Perhaps the covering of the seed in Chenopodium, called by Gærtner Utriculus, is merely a Pellicula.

Arillus, the Tunic, is either a complete or partial covering of a seed, fixed to its base only, and more or less loosely or closely enveloping its other parts. Of this nature is the pulpy orange-coloured coat in Euonymus, $t .362$, the beautiful scarlet cup in Afzelia, f.203, and the double membranous coat in Hippophaie, t. 425, which last invests the seed within the pulp of the berry. 
The outer of these coats only is described by Gartner, as a peculiar membrane lining the cell of the berry; his "integumentum duplex" refers to the testa, which I mention only to prevent misapprehension. The Mace which envelops the Nutmeg is a partial Arillus, beautifully drawn in Gxitner, t. 41. Narthecium, Engl. Bot.t. 535, has a complete membranous tunic, elongated beyond the seed at each end, as in many of the Orchis tribe; and such seeds, acquiring thence a light and chaffy appearance, have been denominated scobiformia, whence Bergius was perhaps led, very unscientifically, to call the seeds of ferns literally scols or sawdust! An elastic pouchlike Arillus, serving to project the seeds with considerable force, occurs in Oxalis, t. 762 and 1726. In the natural order of Rutacece the same part, shaped also like a pouch lining each cell of the capsule, is very rigid or horny; see Dictammus albus, or Fraxinella, Gartn. t. 69, and Boroniu, Tracts on Nat. Hist. t. 4-7. Besides this coincidence, there are many common points of affinity between these plants and 
Oxalis, concerning colour, fiavour, habit and structure. Fagonia and its allies forn the connecting link between them, which Gærtner and Jussieu did not overlook. We have pointed out this affinity in English Botany, p. 762, and it is confirmed by the curious circumstance of Jacquin's $O x$ alis rostrata, Oxal. t. 22, having the very appendages to its filaments which make a peculiar part of the character of Eoronia.

It is not easy to say whether the various, and frequently elaborate, coat of the seed among the rough-leaved plants, $B$ orago, Anchusa, Lithospermum, Cynoglossum, f. 201, Engl. Bot.t.921, \&c., should be esteemed an Arillus or a Testa; but the latter seems most correct, each seed having only a simple and very thin membranous internal skin besides. Gærtner therefore justly uses the term Nut for the seeds in question. The same may be observed of Ranunculus, Myosur'us, see Eugl. Bot. t. 435, Clematis, Anemone, \&c., whose external coats are no less various and elaborate; yet such seeds are as truly naked as those of the Didynamia class, figured 
in Gertner, t. 66, each having a double shin and no more, which is one covering less thin even the genuine nut or the stone finit, or of the Curylus. In Geranizun, dHuiva, fic., what has often been called Arillus, is rather a kind of Capsule, not enty because their seeds have a double or wen triple skin, quite unconnected with this outer cover, but because the latter is analogous to other Capsules.

The loose husky corering of the seed in Carer, f. 202, is surely an Arillus. See Engl. Bot. also the Rev. Mr. Woor's observations on this genus in Dr. Rees's Cyclopeedia, and Gertner, v. 1. 13. This seed has besides a double Testa, though most of the true Grasses have but one, which in ground Corn constitutes the bran, the husk of the blossom being the chafr.

Pappus, the Seed-down, is restrained by Gærtner to the chaffy, feathery, or bristly crown of many seeds that have no Pericarpium, and which originates from a partial calyx crowning the summit of each of those seeds, and remaining after the 
flower is fallen. Instances of this are the feathery appendages to the seeds of Dandelion, Engl. Bot.t.510, and Goat's-beard, $t$. 434, in which the part in question is elevated on a footstalk, $f .204$. In Carchuus, t. 973-6, it is sessile, though still feathery; but in Cichorium, t. 539, it consists of mere chaffy teeth, more clearly evincing its affinity to a Calyx. In Scabiosa it is double. In Bidens, $t$. 1113, 1114, the Pappus is formed of 2,3 or 4 rigid barbed bristles. The use of this organ is evidently to transport seeds to a distance from their native spot, either by resigning them to the power of the wind, or by attaching them to the shaggy coats of animals. In due time the feathery crown separates, and leaves the seed behind it, which happens sooner with the Thistle than most other plants. Hence the vacant down of that genus is frequently seen wafted in light masses over a whole country; which has not escaped the notice of poets.

The same term is used by the generality of botanists for the feathery crown of 
seeds furnished with a capsule, as Epilobium, t. 1177, Asclepias, Cynanchum, Eic., Gertn. t. 117, as well as for a similar appendage to the base or sides of any sceds, as Salix, Engl. Bot. t. 183, 1403, Eriophorum, $t .873$, \&c., neither of which can originate from a Calyx. For the former of these Gertner adopts the trim Coma, for the latter Pubes, which last aiso serves for any downiness or wool about the Testa of a seed, as in the Cotton plant, and Blandfordia nobilis, Exot. Bot. t. 4.

Cauda, f. 205, a Tail, is an elongated, generally feathery, appendage to someSeeds, formed from the permanent style, as in Clematis, Engl. Bot. t. 612, Dryas, t. 451, Geum, t. 1400.

Rostrum, a Beak, mostly auplies to some elongation of a Seed-ressel, originating likewise from the permanent siyle, as in Geranium, t. 272, Helleborus, t. 200, though it is also used for naked seeds, as Scandix, f. 206, t. 1397.

Ala, $f .207$, a Wing, is a dilated membre- 
nous appendage to Seeds, as in Eimbothrium, Bot. of N. Holl. t. 7, Banlisia, Conchinm, Bignonia echinata, Gartn. t. 52, Rhinanthus, Wingl. Bot. t. 657 , serving to waft them along in the air. Gartner wished to confine this term to a membranous cxpansion of the top or upper edge of a Seed or Seed-ressel, using margo membranaceus for one that surrounds the whole, but he has not alinered to it in practice. Capsules are sometimes furnished with one wing, as the Ash, oftener with several, as Halesia, Acer, Piegonia, Sic. In Seeds the Wing is commonly solitary, except some Umbelliferous plants, as Thapsia, Gartn. t. 21.

Seeds are occasionally fumished with Spines, Hooks, Scales, Crested appendages, particularly a little gland-like part, near the Scar, sometimes denominated Strophiolum, as in Asarum, Gartn. t. 14, Iossicea, T'entenat. Jard. de Cels. t. 7, Platylubium, Bot. of N. Holl. t. 6, Ulex, Spartium, \&c. In general however smoothness is characteristic of a seed, by which it best makes its way into the solt earth. 
though sometimes it is barbed, or at least its covering, as in Stipa, Engl. But. t.1356, that it may not easily be withdrawn again by the powerful feathery appendage of that plant, which after having by its circumvolutions forced the seed decper and deeper, breaks off at a joint, and flies away.

The various modes by which seeds are dispersed cannot fuil to strike an obscrving mind with admiration. Who has not listened in a calm and sumny day to the crackling of Furze bushes, caused by the explosion of thir little elastic pods; nor watched the down of imnumerable seeds floating on the summer breeze, till they are overtaken by a shower, which moistening their wings stops their further flight. and at the same time accomplishes its final purpose, by immediately promoting the germination of each seed in the inoist earth? How little.are children aware, as they blow away the seeds of Dandelion, or stick Burs in sport upon each other's clothes, that they are fulfilling one of the great ends of Nature! Sometimes the Calyx, beset with hooks, forms the bur, as in 
Arctium Lappa, Engl. Bot. t. 1228; sometimes hooks encompass the fruit itself, as in Tanthium, and some species of $G a-$ lium, particularly G. Aparine, t. 816 . Plants thus furnished are observed by Linnæus to thrive best in a rank manured soil, with which, by being conveyed to the dens of wild animals, they are most likely to mect. The Awns of grasses answer the same end. Pulpy fruits serve quadrupeds and birds as food, while their seeds, often small, hard and indigestible, pass uninjured through the intestines, and are deposited far from their original place of growth, in a condition peculiarly fit for vegetation. Even such seeds as are themselves eaten, like the various sorts of nuts, are hoarded up in the ground and occasionally forgotten, or carried to a distance, and in part only dcrourecl. Eren the ocean itself serves to waft the larger linds from their native soil to far-distant shores.

7. Receptaculum. The Receptacle is the common base or point of connexion of the other parts of fructification. It is not al- 
ways distinguishable by any particular figure, except in compound flowers constituting the Linnxan class Syngenesia, in which it is rery remarkable and important. In the Daisy, f: 208, Engl. Bot. t. 424, it is conical; in Chrysanthemum, $t .601$, conrex; in others flat, or slightly concave. Picris, t. 97?, has it naked, that is, destitute of any hairs or scales between the florets or sceds; Carduus, t. 675, hairy; Anthemis, t. 602, scaIy; and Onopordum, t.977, cellular like a honey-comb, $f$.209. On this and the seed-down are founded the most solid generic characters of these plants, admirably illustrated by the inimitable Grertner.

The term Receptacle is sometimes extended by Linnæeus to express the base of a flower, or even its internal part between the stamens and pistils, provided there be any thing remarkable in such parts, without reference to the foundation of the whole fructification. It also expresses the part to which the seeds are attached in a. seed-ressel. 
Having thus explained the various organs of fructification, we shall add a few remarks concerning flowers in gencral, reserving the functions of the Stamens and Pistils, with the Linnæan experiments and inquiries relacive to that curious subject, for the next chapter.

A flower furnished with both calyx and corolla is called flos completus, a complete flower; when the latter is wanting, incompletus ; and when the corolla is present without the calyx, nudus, naked. When the stamens and pistils are both, as usual, in one flower, that flower is called perfect, or united; when-they are situated in different flowers of the same species, such I would call separated flowers; that which has the stamens being named the barren flower, as producing no fruit in itself, and that with pistils the fertile one, as bearing the seed. If this separation extends no further than to differcut situations on the same individual plant, Limnæus calls sucli flowers monvici, monocious, as confined to one house or dwelling; if the barren and fertile fowers grow from two separate roots, they are said to be dioici, din- 
cious. Some plants have united flowers and separated ones in the same species; either from one, two or three roots, and such are called polygamous, as making a sort of compound household.

A Compound flower consists of numerous florets, flosculi, all sessile on a common undivided Receptacle, and enclosed in one contiguous Calyx or Perianthium. It is also essential to this lind of flower that the Anthers should be united into a cylinder, to which only the genus Tussilugo affords one or two exceptions, and Iruhnia another; and moreover, that the stamens should be 5 to each floret, Sigesbeckia flosculosa of L'Heritier, Stirp. Nov. t. 19, alone having but 3 . The florets are always monopetalous and superior, each standing on a solitary naked seed, or at least the rudiments of one, though not always perfected. Some Compound flowers consist of very few florets, as Fiumea elegans, Exot. Bot.t. 1, Prenanthes muratis, Engl. Bot. t. 4.57 ; others of many, as the Thistle, Daisy, Sunflower, \&c. The florets themselves are of two kinds, ligulati, ligulate, shaped like a strap or ribband, $f .210$, with 3 
or 5 teeth, as in Tragopogon, $t .434$, and the Dandelion; or tubulosi, tubular, crlindrical and 5-cleft, as in Cardurs, t. 107, and Tanacetum, $t .1229$. The marginal white florets of the Daisy, $f: 211$, are of the former description, and compose its radius, or rays, and its yellow central ones cone under the latter denomination, f. 212, constituting its discus, or disk. The disk of such flowers is most frequently yellow, the rays yellow, white, red, or blue. No instance is known of yellow rays with a white, red, or blue disk.

An Aggregatc flower has a common uindivicled Receptacle, the Anthers all separate and distant, Jasione only, Engl. Bot.t. 852, having them united at the base, but not into a cylinder, and the florets commonly stand on stalks, each haring a single or double partial calyx. Such flowers have rarely any inclination to yellow, but are blue, purple, or white. Instances are found in Scabiosa, $t .659$ and 1311, Dipsacus, t. 1032 and 877, and the beautiful Cape genus Protea.

Such is the true idea of an Aggregate flower, but Linnaus enumerates, under that 
denomination, 7 kinds, his farourite number; these are,

1. The Aggregate flower properly, so called, as just mentioned.

2. The Compound flower previously described.

3. The Amentaccons flower, or Catkin, of which we have spoken p. 248 .

4. The Glumose, or Chatfy flower, peculiar to the Grasses, see p. 250 .

5. The Sheathed flower, whose common receptacle springs from a Sheath, as in $1 \mathrm{rum}$. 6. The Umbellate; and

7. The Cymose flowers, concerning which two last a few observations are necessary.

Limmeus and his friend Artedi thought the great natural umbelliferous order could not be divided into good and distinct genera by the seeds or parts of the flower, without taling into consideration the general and partial involucral leaves, which they therefore chose to consider as a part of the fructification, and defined as a calyx remote from the flower. The rays of the umbel, of course, became the subdivisions of a 
branched receptacle, and the whole umbel was considered as one aggregate flower. It necessarily followed that a Cyme, see p. 237, must be considered in the same light, nor did the sagacity of Linnæus overlook the arguments in farour of this hypothesis. Many of the umbelliferous tribe, as Heracleum; t. 939, Caucalis, Coriandrum, \&c., have their marginal flowers dilated, radiant, and more or less inclined to be imperfect or abortive, thus evincing an analogy with real compound flowers like the Sunflower, which analogy is still more striking between Oenanthe, $t .363$, 347, 348, and the Marigold, Calendula. So the cymose plants, as Viburnum Opulus, t. 332, bear dilated and abortive marginal flowers, and Hydrangea hortensis, Sm. Ic. Pict. t. 12, has scarcely any others. Cormus sanguinea, Engl. Bot. t. 249, has a naked cyme, C. Suecica, t. 310, an umbel accompanied by coloured bracteas, or, as Linnæus judged, a coloured intolucrum, proving the close affinity between these two modes of inflorescence.

Notwithstanding all this, I presume to dis: sent from the above hypothesis, as offering: 
too great rio ence to Nature, and swerving from that bcautiful and philosophical Liun: an principle, of characterizing gẹnera by the fructication alone; a principlo which those who are competent to the subject at all, will, I believe, never find to fail. The seeds and flowers of the umbelliferous family are quite sufficient for our purpose, while the involucrum is very precurious and changeable; often deficient, often immoderately. luxuriant, in the same genus. In the cymose plants every body knows the real parts of fructification to be abundantly adequate, the involucrum being of small moment; witness that most natural genus Cormus. For all these, and other reasons, to particularize which would lead me too far, I have, p. 236 , reckoned the Umbel and $\mathrm{Cyme}_{\mathrm{y}}$ modes of flowering, and not themselves aggregate flowers, 


\section{CHAPTER XX.}

OF THE PECULIAR FUNCTIONS OF TII. STAMENS AND PISTILS, WITH THE EX- periments and observations of LINNEUS AND OTHERS ON THAT SUBJECT.

\section{$T_{11 \mathrm{E}}$ real use of the Stamens of Plants was} long a subject of dispute among philosophers, till Linnæus, according to the general opinion at present, explained it beyond a possibility of doubt. Still there are not wanting persons who from time to time start objections, prompted either by a philosophical pursuit of truth, or an ambitious desire of distinguishing themselves in controverting so celebrated a doctrine, as some have written against the circulation of the animal blood. I propose to trace the history of this doctrine, and especially to review the facts and 
experiment: upon which Limneus founderl his opinion, as well as the objections it has had to encounter. It would be endless, and altogether superfluous, to bring forward new facts in its support, nor shall I do so, except where new arguments may render such a measure necessary.

The Stamens and Pistils of flowers have, from the most remote antiquity, been considered as of great importance in perfecting the fruit. The Date Palm, from time immemorial a primary object of cultivation in the more temperate climates of the globe, bears barren and fertile flowers on separate trees. The ancient Greeks soon discovered that in order to have abundant and well-flavoured fruit, it was expedient to plant both trees near together, or to bring the barren blossoms to those which were to bear fruit; and in this chiefly consisted the culture of that valuable plant. Tournefort tells us that without such assistance dates have no kernel, and are not good food. The same has long been practised, and is continued to this very day in the Levant, upon the Pistacia, and the Fig. 
At the revival of leaming botanists were more occupied in determining the species, and inrestigating the medical properties of plants, than in studying their physiology; and when after a while the subject in question was started, some of them, as Morison, Tournefort and Pontedera, uniformly treated with great contempt the hypothesis which has since been established. We shall, as we proceed, advert to some of their arguments.

About the year 1670, Sir Thomas Millington, Sarilian Professor at Oxford, is recorded to have hinted to Dr. Grew that the use of the Stamens was probably to perfect and fertilize the secd. Grew adopted the idea, and the great Ray approved it. Several other botanists either followed them, or had preriously conceired the same opinion, among which R. J. Camerarius, Professor at Tubingen towards the end of the serenteenth century, was one of the most able and original. Vaillant wrote an excellent oration on the subject, which being hostile to the opi-rions of Tourncfort, lay in obscurity till published by Boerhaave. Blair and Bradley assented in England, and several continental 
botanists imbibed the sane sentiments. Pontedera, howerer, at Padua, an university long famous, but then on the decline, and consequently adverse to all new inquiry and information, in 1720 published his Anthologia, quite on the other side of the question.

Linnæus, towards the year 1732, reviewed all that had been done before him, and clearly established the fact so long in dispute, in his Fundamenta and Philosophia Botanica. He determined the functions of the Stamens and Pistils, proved these organs to be essential to every plant, and thence conceived the happy idea of using them for the purpose of systematical arrangement. In the latter point. his merit was altogether original; in the former he made use of the discoverics and remarks of others, but set them in so new and clear a light, as in a manner to rencler them his own.

We have already mentioned, p. 138, the two modes by which plants are multiplied. and have shown the important difference between them. Propagation by seed is the only genuine reproduction of the species, and it 
now remains to prove that the essential organs of the flower are indispensably requisite for the perfecting of the seed.

Every one must have obseried that the flower of a plant always precedes its fruit. To this the Meadow Saffion, Engl. Bot. t.133, seems an objection, the fruit and leaves being perfected in the spring, the blossoms not appearing till autumn; but a due examination will readily ascertain that the seed-bud formed in autumn is the very same which comes to maturity in the following spring. A Pinc-apple was once very unexpectedly cited to me as an instance of fruit bcing formod before the flower, because the green fruit in that instance, as in many others, is almost fully grown before the flowers expand. The seeds however, the essence of the fruit, are only in embryo at this period, just as in the germen of an Apple blossom.

It was very soon ascertained that flowers are invariably furnished with Stamens and Pistils, either in the same individual, or two of the same species, however defective they may be in other parts; of which Hippuris, Engl. Bot. t. 763, the most simple of blos- 
soms, is a remarkable example. Few botanists indeed had detected them in the Icmma or Duck-weed, so abundant on the surface of still waters, and Valisneri alone for a loug time engrossed the honour of having seen them. In our days however they rewarded the researches of the indefatigable Ehrhart in Germany, and on being sought with equal acuteness, were found in England. Three species have been delineated in Engl. IBot. t. 926, 1095 and 1239 , from the discovries of Mr. Turner and Mr. W. Borrer. The flowers of Mosses, long neglected and afterwards mistaken, were faithfully delineated by $\mathrm{Mi}$ cheli, carefully examined and properly understood by Limmus as he rambled over the wilels of Lapland*, and at length fully illustrated and placed out of all uncertainty by the justly celcbrated Hedwig. These parts indeed are still unknown in ferns, or at least no satisfactory explanation of them has reached nie, though the seeds and seedressels are sufficiently obrious.

* This hitherto unknown fact will appear in his Tour through that country, now preparing for the press in English. 
The existence of the parts under consideration is so incontrovertible in every flower around us, tlat Pontedera was reduced to seek plants without stamens among the figures of the Hortus IIalabaricus, but the plates in which he confided are now known to be faulty in that rery particular.

Plants indeed have occasionally abortive stamens in one flower and barren pistils in another, and the Plantain-tree, Mlusa, is described by Linnaus as having five out of its six stamcns perfected in such blossoms as ripen no fruit, while those with a fertile germen contain only a single ripe stamen, five being ineffective. This only shows the resources, the wistom, and the infinite variety of the creation. When the roots are luxuriantly prolific, the flowers are in some measure defective, Nature, relaxing as it were from her usual solicitude, and allowing her children to repose, and indulge in the abundance of good things about them. But when want threatens, she instantly takes the alarm; all her energies are exerted to secure the future progeny, even at the hazard of the parent stock, and to send them 'abroad to coJonise more favourable situations. 
Nost generally the aceess of the pollen is not trusted to any accidental modes of conveyance, howerer munerous, elaborate, and, if we may so express it, ingenious, such modes may be; but the stamens are for greater security lodged in the same flower, under the pretection of the same sillien reils, or more substantial gruards, which shelter their appropriate pistils. This is the case with the majority of our habs and shrubs, and eren with the trees of hot countries, whose leares being always present might impede the passage of the pollen. On the contrary, the trees of cold climates have generally separated flowers, blossoming betore the leaves come forth, and in a windy season of the year; while those which blossom liter, as the Oak, are either peculiarly fiequented by insects, or, like the numerous hinds of Fir, lave leaves so little in the way, and pollen so excossively abundant, that impregnation can scarcely fuil.

The pollen and the stigma are always in perfection at the same time, the latter commonly withering and fulling of a litte after the anthers, though the style may remain to become an usetil apponduge to the fruit. 
The Viola tricolor or Pansy, the Cratiola, the Martynia, and many plants besides, hare been observed to be furnished with a stigma gaping only at the time the pollen is ripe. The beautiful Jacobxan Lily, Amuryllis formosissima, Curt. Mag. t. 47, is justly described by Linnaus as provided with a drop of clear liquid, which protrudes every morning from the stigma, and about noon seems almost ready to fall to the ground. It is howerer reabsorbed in the afternoon, having receired the pollen whose rapour renders it turbid, and whose minute husks afterwards remain upon the stigma. The same phænomenon takes place severa! successive clays.

In opposition to similar facts, proving the synchronous operation of these organs, Pontedera has, witl more observation than usual, remarked that in the umbelliferous tribe the style frequently does not appear till the anthers are fallen. But he ought to have perceived that the stigma is previously perfected, and that the style seems to grow out afterwards, in a recurved and divaricated form, for the purpose of providing hooks to the secds. It is also observable that in this family the several organs are sometimes brought 
to perfection in different flowers at different times, so that the anthers of one may impregnate the stigmas of another, whose stamens were abortive, or long since withered. The same thing happens in other instances. Linnæus mentions the Jatropha urens as producing flowers with stamens some weeks in general before or after the others. Hence he obtained no seed till he preserved the pollen a month or more in paper, and scattered it on a few stigmas then in perfection. There can be no doubt that, in a wild state, some or other of the two kinds of blossoms are ripe together, throughout the flowering season, on different trees.

A similar experiment to that just mentioned was made in 1749 upon a Palm-tree at Berlin, which for want of pollen had never brought any fruit to perfection. A branch of barren flowers was sent by the post from Leipsic, twenty German miles distant, and suspended over the pistils. Consequently abunlance of fruit was ripened, and many young plants raised from the seedl."

* What species of Palm was the subject of this experiment does not clearly appear. In the origina! com- 


\section{* Tournefort and Pontedera supposed the} pollen to be of an excrementitious nature, and thrown off as superfluous. But its being so curiously and distinctly organized in every plant, and producing a peculiar vapour on the accession of moisture, shows, beyond contradiction, that it has functions to perform after it has left the anther. The same writers conceired that the stamens might possibly secrete something to circulate from them to the young seeds; an hypothesis totally subverted by every flower with separated organs, whose stamens could circulate nothing to germens on a different branch or root; a difficulty which the judicious Tournefort perceired, and was candid enough to allow.

munication to Dr. Watson, printed in the preface of Lce's Introduction to Botamy, it is called Palma major foliis flabelliformilus, which seems appropriate to Rhapis Aabelliformis, Ait. Hort. Kew.v. 3.473; yet Linnæus, in his Dissertation on this subject, expressly calls it Ploenix dactylifera, the Date Palm, and says he had in his garden many vigorous plants raised from a portion of the seeds above mentioned. The great success of the experiment, and the "fan shaped" leaves, make me rather take it for the Rhapis, a plant not well known te Linnous. 
Both the conjectures just mentioned vanish before one luminous experiment of Limmeus, of all others the most easy to repeat and to understand. He removed the anthers from a flower of Glaucium phaniceum; Engl.Bot. t. 1433, stripping off the rest of that day's blossoms. Another morning he repeated the same practice, only sprinkling the stigma of that blossom, which he had last deprived of its own stamens, with the pollen from another. The flower first mutilated produced no fruit, but the second afforded very perfect seed. "My design," says Linnaus, "was to prevent any one in future from believing that the removal of the anthers from a flower was in itself capable of rendering the germen abortive."

The usual proportion and situation of stamens with respect to pistils is well worthy of notice. The former are generally shortest in drooping flowers, longest in erect ones. The barren blossoms stand above the fertile ones in Carex, Coir, Arum, \&c., that the pollen may fall on the stigmas. This is the more remarkable, as the usual order of $\mathrm{Na-}$ ture seems in such plants, as well indeed 
as in compound, and even umbelliferous flowers, to be reversed, for the pistils are invariably central, or internal, in every simple flower, and would therefore, if drawn out into a monocious spike, be above the stamens.

Many curious contrivances of Nature serve to bring the anthers and stigmas together. In Gloriosa, Andr. Repos. t. 129, the style is bent, at a right angle from the very base, for this evident purpose. In Saxifraga, and Parnassia, Engl. Bot. t. 82, the stamens lean one or two at a time over the stigma, retiring after they have shed their pollen, and giving place to others; which wonderful œconomy is very striking in the garden Rue, Ruta graveolens, whose stout and firm filaments cannot be disturbed from the posture in which they may happen to be, and evince a spontaneous movement unaffected by external causes. The five filaments of the Celosia, Cock's-comb, are connected at their lower part by a membranous web, which in moist weather is relaxed, and the stamens spread for shelter under the concave lobes of the corolla. When the air is dry the con- 
traction of the membrane brings them together, to scatter their pollen in the centre of the flower. The elastic filaments of Parictaria, Eingl. Bot. t. 879, for a while restrained by the calyx, as those of the lovely Kalmice, Curt. Miag. t. 175, 177, are by the minute pouches in the corolla, relieve themselves by an elastic spring, which in botk instances serves to dash the pollen with great force upon the stigma. The same end is accomplished by the curved germen of Medicago falcata, Engl. Bot. t. 1016, releasing itself by a spring from the closed licel of the flower.

But of all flowers that of the Barberrybush, $t .49$, is most worthy the attention of a curious physiologist. In this the six stamens, spreading moderately, are sheltered under the concave tips of the petals, till some extraneous body, as the feet or trunk of an insect in searcl of honey, touches the inner part of each filament near the bottom. The irritability of that part is such, that the filament immediately contracts there, and consequently strikes its anther, full of pollen, against the stigma. Any other part of the 
filament may be touched without this effect, provided no concussion be given to the whole. After a while the filament retires gradually, and may again be stimulated; and when each petal, with its annexed filament, is fallen to the ground, the latter on being touched shows as much sensibility as ever. See Tracts on Nat. History, 165. I have never detected any sympathy between the filaments, nor is any thing of the lind expressed in the paper just mentioned, though Dr. Darwin, from some unaccountable misapprehension, has quoted me to that effect. It is still more wonderful that the celebrated Bonnet, as mentioned in Senebier's Physiologie V'egétale, v. 5. 105, should have observed this phænomenon in the Barberry so very inaccurately as to compare it to the relaxation of a spring, and that the ingenious Senebier himself, in quoting me, p. 103, for having ascertained the lower part only of each flament to be irritable, should express himself as follows:- "It has not yet been proved that the movement of the stamens is attended with the contraction of the filaments; which nevertheless was. the first proof necessary to have been given 
in order to ascertain their irrability; it is not even yet well known which is the irrituble part of the filaments, and whether it be only their base, as Smith has had the address to discover." In answer to which I need only request any one to read the above account, or the more ample detail in my original paper, and above all, to examine a Barberryblossom for himself; and if any doubts remain concerning the existence of vegetable irritability, let him read Senebier's whole chapter intended to disprove it, where that candid philosupher, while he expresses his own doubts, has brought together every thing in its favour. Among the whole of his facts nothing is more decisive than the remarks of Coulomb and Van Marum on the Euphorbia, whose milky juices flow so copiously from a wound, in consequence of the erident irritability of their vessels; but when the life of the plant is destroyed by electricity, all the flowing is at an end. It is superfluous to add any thing on this subject, and I return to that of the impregnation of flowers.

I have already mentioned that any moisture causes the pollen to explode, conse- 
quently its purpose is liable to be frustrated by rain or heavy dews. Linnæus observes that hus bandmen find their crops of rye to suffer more from this cause than barley, hecause in the latter the anthers are more protected by the husks; and the Juniper berries are sparingly, or not at all, produced in Sweden when the flowering season has been wet. The same great observer also remarks, what yearly experience confirms, that Cherry-trees are more certainly fruitful than Pear-trees, because in the former the opening of the anthers is, in each blosson, much more progressive, so that a longer period elapses for the accomplishment of the fertilization of the germen, and there is consequently less chance of its being hindered by a few showers.

To guard against the hurtful influence of nocturnal dews or drenching rains, most flowers either fold their petals together, or hang down their heads, when the sun does not shine; by which, their internal organs are sheltered. In some which always droop, as the Snowdrops Galanthus and Leucojum, Engl. Bot.t.19and 621, the Fritillary, t. 622, the Crown Imperial, various species of $\mathrm{Cam}$ - 
pamula, and others, while the over-shadowing corolla keeps oft rain, the air has free access underneath to blow the pollen to the stigma. Nor is this drooping caused by the weight of the flowers, for the fruit in most of them is much heavier, and yet stands erect on the very same stalk. The papilionaceous flowers in general spread their wings in fine weather, admitting the sun and air to the parts within; whereas many of them not only close their petals at night, but also derive additional protection from the green leares of the plant folding closely about them. Convolvulus arvensis, t.312, Anagallis arrensis, t. 529, Calendula pluvialis, and many others, are well known to shut up their flowers against the approach of rain; whence the Anagallis has been called the Poor Man's Weather-glass. It has been observed by Linnzus that flowers lose this fine sensibility, either after the anthers have performed their office, or when deprived of them artificially; nor do I cioubt the fact. I have hack reason to think that, during a long continuance of wet, the sensibility of the Anagallis is sometimes exhausted; and it is evi- 
dent that very sudden thunder-showers oficn take such flowers by surprise, the previous state of the atmosphere not having been such as to give them due waming.

That parts of regetables not only lose their irritability, but even their vital principle, in consequence of having accomplished the ends of their being, appears from an experiment of Linnacus upon Hemp. This is a dincious plant, see $p .306$, and Limæus kept several fertile-flowered individuals in separate apartments from the barren ones, in order to try whether they conld perfect their seeds without the aid of pollen. Some few however remained with the barren-flowered plants, and these ripened seed in due time, their stigmas having faded and withered soon after they had received the pollen. On the contrary, the stigmas which had been out of its reach continued green and vigorous, as if in rain expectation, nor did they begin to fade till they had thus lasted for a very long while. Since I read the history of this experiment, I have found it easy in many plants to tell by the appearance of the stigma whether the seed be fertilized or not. The above ex- 
periment is the more important, as the abbe Spallanzani has recorded one made by himself upon the same species of plant, with a contrary result. But as he has said nothing of the appearance of the stigmas, his experiment must yield to that of Limmus in point of accuracy; and even if his account be otherwise correct, the result is easily explained. Hemp, Spinach, some Nettles, \&c., naturally diocious, are occisionally not completely so, a few latent baren or fertile flowers being frequently found among those of the other sort, by which prorision is made against accidents, and the perfecting of a few seeds, at any rate, secured.

In general, germens whose stigmas have not received the pollen wither away without swelling at all, but some grow to a considerable size, and in such the substance of the seed, its skin, and even its cotyledons, are often to be found, the embryo only being wanting. In a Melon or Cucumber it is common to find, among numerous perfect seeds, many mere unimpregnated husks. In the magniticent $C_{y}$ cas revoluta which bore fruit at the bishop of Winchester's, and of 
which a history with plates is given in the sixth volume of the Linnaan Society's Transactions, I found the drupa and all its contents apparently perfect, except that there was only a minute cavity where the embryo should have been, in consequence of the want of another tree with stamens, which was not to be found perhaps nearer than Japan. Gardeners formerly attempted to assist $\mathrm{Na}$ ture by stripping off the barren flowers of Melons and Cucumbers, which, haring no germen, they found could not come to fruit, and were therefore, as they supposed, an unnecessary encumbrance to the constitution of the parent plant. But finding they thus obtained no fruit at all, they soon learned the wiser practice of admitting air as often as possible to the flowering plants, for the purpose of blowing the pollen from one blossom to the other, and even to gather the barren kind and place it over that destined to bear fruit.

The ceonomy of various aquatic plants throws great light upon the subject before us. Different species of Potamogeton, Engl. Bot. t. 168, 297, 376, \&c., Ruppia maritima, t. 136, and others, float entirely under wa- 
ter, often at some considerable depth, till the flowering season arrives, when they rise near the surlace, and throw up their flowering spikes above it, sinking afterwards to ripen and sow their seeds at the bottom. Nymphcea alba, $t$. 160 , is very truly described by Linnaus in his Flora Suecica, as closing its flowers in the aftemoon and laying them down upon the surface of the water till morning, when it raises and expands them, often, in a bright day, to several inches above the water. To this I can speak from my own knowledge, and it is confirmed by the history given by Theophrastus of his Lotus, which, according to all appearance, is the Nymphcea Lotus of Linn:eus. "This," says he, " as well as the Cyamus*, bears its fruit in a head. The flower is white, consisting of many crowded leaves about as broad as those of a lily. These leaves at sunset fold themselves together, corering the head (or seed-vessel). At sun-rise they expand, and rise above the water. This they continue till the head is perfected, and the flowers fall off." So far

$$
\text { * Exot. Bot. t. 31, } 32 \text {. }
$$


Theophrastus writes as of his own knowledge; he continues as follows; "It is reported that in the Euphrates the head and flowers keep sinking till midnight, when they are so deep in the water as to be out of reach of the hand, but towards morning they return, and still more as the day adrances. At sun-rise they are already above the surface, with the flower expanded; afterwards they rise high above the water." Pliny repeats the same account; and Prosper Alpinus, whose purpose is to prove the Lotus of Theophrastus not different from the common Nymphcea, in which, as far as genus is concerned, he is correct, has the following remarkable passage: "The celebrated stories of the Lotus turning to the sun, closing its flowers and sinking under water at night, and rising again in the morning, are conformable to what every body has observed in the Nymphcea."

I have been the more particular in the abore quotations, because the reracity of Theophrastus has lately been somewhat rudely impeached, on very questionable authority. For my own part, I think what we see of the Nymphae in England is sufficient to render 
the abore account highly probable in a country where the sun has so much more power, even if it did not come from the most fithlful and philosophical botanist of antiquity, and I have alwatys with confidence cited it on his authority. 'The reader, howerer, will perceire that the only important rircumstance for our purpose is the closing of the fiowers at night, which is sufliciently well established. But the most memorable of aquatic plants is the Valisneria spiralis, well figured and described by Micheli, Nov. Gen.t. 10, which grows at the bottoms of ditches in Italy. In this the fertile thowers stund on long spiral stalks, and these by uncoiling elevate them to the surfice of the water, where the calyx expants in the open air. In the moan while plenty of bermen flowars are produced on a distinct root, on short straight stalks, from which they rise like little separate white bubbles, suddenly expanding when they reachi the surface, and flouting about in such abundance as to corer it entirely. Thus their pollen is scattered over the stigmas of the firstmentioned blossoms, whose stalks soon afterwards resume their spiral tirure, and the 
fruit comes to maturity at the bottom of the water. All this Micheli has described, without being aware of its final purpose ; so different is it to observe and to reason!

Some aquatic vegetables, which blossom under water, seem to have a peculiar lind of glutinous pollen, destined to perform its office in that situation, as Chara, Engl. Bot: t. 336, \&c.; as well as the Fucus and Conferva tribe: but of the real nature of the fructification of these last we can at present only form analogical conjectures.

The fertilization of the Fig is accomplished in a striking manner by insects, as is that of the real Sycamore, Ficus Sycomoris. In this genus the green fruit is a hollow common calyx, or rather receptacle, lined with various flowers, scldom both barren and fertile in the same fig. This receptacle has only a very small orifice at the summit. The seeds therefore would not in general be perfected, were it not for certain minute flies of the genus Cynips, continually fluttering from one fig to the other all corcred with pollen, and depositing their eggs within the cavity. A very curious observation is recorded by 
Schreber and Willdenow concerning the Aristolochia Clematitis, Engl. Bot. t.398. The stamens and pistils of this flower are enclosed in its globular base, the anthers being under the stigmil, and by no means commodiously situated for conveying their pollen to it. This therefore is accomplished by an insect, the Tipula pemicornis, which enters the flower by the tubular part. But that part being thickly lined with inflexed hairs, thougli the fly enters easily, its return is totally impeded, till the corolla fades, when the hairs lie flat against the sides, and allow the captive to escape. In the mean while the insect, continually struggling for liberty, and pacing his prison round and round, has brushed the pollen about the stigna. I do not doubt the accuracy of this account, though I have never caught the imprisoned Tipula. Indeed I have never seen any fruit formed by this plant. Probably for want of some insect adapted to the same purpose in its own country, the American Aristolochia Sipho, though it flowers plentifully, rarely forms fruit in our gardens. That it sometimes does, I have been 
informed by Lady Amclia Hume since the first edition of this work was published.

The ways in which insects serve the same purpose are innumerable. These active little beings are peculiarly busy about flowers in bright sunny weather, when every blossom is expanded, the pollen in perfection, and all the powers of regetation in their greatest vigour. Then we see the rough sides and legs of the bee, laden with the golden dust, which it shakes off, and collects anew, in its risits to the honeyed stores inviting it on erery side. All Nature is then alive, and a thousand wise ends are accomplished by innumerable means that " seeing we perceive not;" for though in the abundance of creation there seems to be a waste, yet in proportion as we understand the subject, we find the more reason to conclude that nothing is made in vain. 


\section{CHAPTER XXI.}

ON THE DISFASES OF PLANTS, PARTICULARLY AS IILUSTRATIVE OF TIIEIR VITAL PRINCIPLE.

$T_{H E}$ diseases of Vegretables serve in many instances to prove their vitality, and to illustrate the nature of their constitution.

Plants are subject to Gangrene or Sphacelus, especially the more succulent kinds, of which a very curious account, concerning the Cactus coccinellifer, Indian Fig, or Nopal, extremely to our present purpose, is given by M. Thiery de Menonville, in his work on the culture of the Nopal as the food of the Cochineal insect. This writer travelled, about 20 years since, through the Spanish settlements in South America, chiefly noted for the cultivation of this precious insect; on purpose ti) transport it clandestinely to some of the 
French islands. Such were the supinenest and ignorance of the Spaniards, that he succeeded in conveying, not only the living insects, but the bulky plant necessary for their sustenance, notwithstanding severe edicts to the cuntrary. He had attended previously to the managenent of the Nopal, and made his renarks on the discases to which it is liable. Of these the Gangrene is cxtremely frequent in the true Nopal of Mexico, beginning by a black spot, which spreads till the whole leaf or branch rots off, or the shrub dies. But the same kind of plant is often affected with a much more serious disease, called by Thiery "la dissolution." This seems to be a sudden decay of the vital principle, like that produced in animals by lightning or strong electricity. In an hour's time, from some unknown cause, a joint, a whole branch, or sometimes an entire plant of the Nopal, changes from apparent health to a state of putrefaction or dissolution. One minute its surface is rerdant and shining; the next it turns yellow, and all its brilliancy is gone. On cutting into its substance, the inside is found to have lost all cohesion, being quite 
rotten. The only remedy in this case is speedy amputation below the diseased part. Sonetimes the force of the vital principle makes a stand, as it were, against the encroaching disease, and throws off the infected joint or branch. Such is the account given by Thiery, which evinces a power in regetables precisely adequate to that of the animal constitution, by which an injured or diseased part is, by an effort of Nature, thrown off to preserve the rest.

Nor need we travel to Mexico to find examples of this. Every deciduous tree or shmb exhibits the very same phanemenon; for the fall of their decaying foliage in autumn, leaving the branches and young buds rigorous and healthy, can be explained in no other way. Yet Du Hamel laboured in vain to account for the fall of the leat ${ }^{*}$; nor is it wonderful that he or any body clsc, who endeavours to explain the physiology of vegetables or of animals according to one principle only, whether it be mechanical or chemical, should entirely fail. To consider the fall of leares in autumn as a sloughing, or

* See his Phys. des Arlres, 2. 1. 127. 
casting off diseased or worn out parts, scems so simple and evident, as to be hardly worth insisting upon. Yet I find myself anticipated in this theory by one physiologist only, named Vrolick, cited by Villdenow, in his Principles of Botany, p. 304, though several learned speculations to no purpose are extant on the subject. It is but just, howcrer, that I should relate what led me to consider the matter with any attention. My observing friend Mr. Fairbairn of Chelsea garden long ago remarked to me, that when he had occasion to transplant any tree or shrub whilst in leaf, he could soon judge of its success by the ease with which its leaves were detached. The consequence of such treatment is more or less injury to the health of the plant, as will first appear by the drooping of the leaves, most of which will probably die, and the decay will generally be extended to the younger more delicate twigs. The exact progress of this decay may speedily be known, by the leaves of those branches which are irrecoverably dying or dead, remaining firmly. attached, so as not to be pulled off without a force sufficient to bring away the bark or 
buds along with them: whereas the leaves of parts that have received no material injury, and where the vital energy acts with due power, either fall off spontaneously, or are detached by the slightest touch. Plants of hot countries, kept in our stoves, exhibit the same phanomenon when transplanted or otherwise injured, even though not naturally deciduous.

So when fruits are thoroughly ripened, they become, with respect to the parent plant, dead substances, and, however strongly attached before, are then thrown off as extraneous bodies. Their stalks fade or wither, though the life of the adjoining branch continues unimpaired, and a line of separation is soon drawn. In a poor soil, or unfarourable climate, a bunch or spike which should naturally consist of a considerable number of flowers, bears perhaps not half so many. Its upper part very early withers, the vital principle ceases to act at the point beyond which it could not continue to act with effect, and all its energy is directed to perfect what lies within the compass of its rcsources. This is evident in Lathyrus odo- 
ratus, the Sweet Pea of our gardens, a native of a rery hot climate, at the summits of whose flower-stalks are generally found the rudiments of one or more flowers, not attempted to be perfected. So also the first Barley sown on the sandy heaths of Norfolk, and indeed too many a following crop, bears very few grains in an ear; for the same meagre supply of nourishment, bestowed equally on a numerous spike of blossoms, would infallibly starve them all. In like manner one seed only is perfected in the best wild Arabian Coffee, known by its round form; while the West Indian plantation Coffee has two in each berry, both consequently flattened on one side. The former grows in barren open places, in situations sufficiently farourable for the impregnation of its blossoms, but far less so for the perfecting of much seed; while the latter, well supplied with manure and moisture, is enabled to bring every germ to maturity.

Very strange effects are often produced upon plants by the attacks of insects, whence the various kinds of Galls derive their origin. These are occasioned by the punctures of 
those little animals, chiefly of the Hymenoptera order, and of the genus Cymips, in some vigorous part of the plant, as the leares, leaf-stalks, young stem or branches, and sometimes the calyx or germen. The parent insect deposits its eger there, which is soon hatched, and in consequence of the perpetual irritation occasioned by the young maggot, feeding on the juices of the plant, the part where-it is lodged acquires a morbid degree of luxuriance, frequently swelling to an immoderate size, and assuming the most extraordinary and whimsical shapes. This often happens to the shrubby species of Hawkweed, Hieracium sabaudum, Engl. Bot.t. 349, and umbellatum, t. 1771, whose stems in consequence swell into oral knots. Sereral different kinds of Galls are borne by the Oak, as those light spongy bodies, as bics as walnuts, vulgarly named Oak apples; a red juicy berry-like excrescence on its leaves; and the very astringent Galls brought from the Lerant, for the purposes of dyeing and making ink, which last are produced by a different species of Quevcus from either of our own. The com. mon Dog-rose, 1.992, frequently bears large 
moss-like balls, in whose internal parts numerous maggots are always to be found, till they become the winged Cynips Rose, and eat their way out. Many of our Willows bear round excrescences, as large as peas, on their leaves; but I remember to have been very much astonished in Provence with a fine branched production on the Willows in winter, which appeared like a tufted Lichen, but proved on examination a real Gall. Indeed our Salix Helix, t. 1343, is called Rose Willow from its bearing no less remarkable an excrescence, lilie a rose, at the ends of some of its branches, in consequence of the puncture of an insect, and these are in like manner durable though the proper leaves fall. The Mastic-tree, Pistacia Lentiscus, is often laden, in the south of Europe, with large red hollow finger-like bodies, swarming internally with small insects, the Aphis Pistacice of Linnæus. The young shoots of Salvia pomifera, Fl. Grec. t. 15, S. triloba, t. 17, and even $S$. officinalis, in consequence of the attacks probably of some Cynips, swell into large juicy balls, very like apples, and even crowned with rudiments of leaves resembling 
the calyx of that fruit. These are esteemed in the Levant for their aromatic and acid Ravour, especially when prepared with sugar.

It may be remarked that all the excrescences abore mentioned are generally more acid than the rest of the plant that bears them, and also greatly inclined to turn red. The acid they contain is partly acetous, but more of the astringent kind.

The diseases of the skin, to which many vegetables are subject, are less casily understood than the foregoing. Besides one kind of Honey-dew, already mentioned, $\mu .189$, something like leprosy may be observed in Tragopogon major, Jacq. Austr. t. 29, which, as I have been informed by an accurate observer, does not injure the seed, nor infect the progeny. The stem of Shepherd's Purse, Engl. Bot. t. 1485, is occasionally swelled. and a white cream-like crust, afterwards powdery, ensues. The White Garden Rose, Rosa alba, produces, in like manner, an orange-coloured powder. It proves very difficult, in many cases, to judge. whether such appearances proceed from a primary disease in the plant, arising from unseasomable cold 
or wet, or are owing to the baneful stimulus of parasitical fungi irritating the vital principle, like the young progeny of insects as above related. Sir Joseph Banks has, with great care and sagacity, traced the progress of the Blight in Corn, Uredo frumenti, Sazverb. Fung. t. 140, and given a complete history of the minute fungus which causes that appearance. See Aunals of. Botany, v. 2. 51, t. 3, 4. Under the inspection of this eminent promoter of science, Mr. Francis Bauer has made microscopical drawings of many similar fungi infecting the herbage and seeds of sereral plants, but has decided that the black swelling of the seed of corn, called by the French Ergot, though not well distinguished from other appearances by the generality of our agricultural writers, is indubitably a morbid swelling of the secd, and not in any way connected with the growth of a fungus. The anthers of certain plants often exhibit a similar disease, swelling, and producing an inordinate quantity of dark purplish powder instead of true pollen, as happens in Silene inflata, Fl. Brit. Engl. Bot. \$.164, and the white Lychnis dioica, t. 15s(), 
whose petals are, not uncommonly, stained all orer with this powder. Our knowledge on all these subjects is yet in its infancy ; but it is to be hoped, now the pursuit of agriculture and of philosophical botany begin to be, in some distinguished instances, mited, such examples will be followed, and science di= rected to one of its best ends, that of insproving useful arts. And here I cannot but mention the experiments continually groing on moler the inspection of the ingenious Mr. Knight, of fertilizing the germen of one species or variety with the pollen of another nearly akin, as in apples, garden peas, \&c., by which, judiciously managed, the adrantagés of different kinds are combinea. $\mathrm{By}$ the same means Limnus obtained intermediate species or varieties of sereral plants; and if any thing were wanting to confirm his theory respecting the stamens and pistils, this alone would place it out of all uncertainty. 


\section{CHAPTER XXII.}

OF TIE SYSTEMATICAL ARRANGEMENT OF PLANTS. NATURALAND ARTIFICIAL METIIODS. GFNERA, SPECIES $\Lambda N D$ VARIETIES. NOMENCLATURE.

Tine foregoing chapters have sufficiently explained the parts of plants, and the leading differences in their conformation, for us now to proceed to the Systematical part of our subject. In this, when properly understood and studied, there is no less exercise for the mind, no less employment for its observation and admiration, than in physiological or anatomical inquiries; nor are the organs of vegetables, when considered only as instruments of classification and discrimination, less conspicuous for beauty, fitness, and infinite variety of contrivance, than under any other point of view. The wisclom of an Infinite 
Superintending Mind is displayed throughout Nature, in whaterer way we contemplate her productions.

When we take into consideration the multitude of species which compose the vegretable kingdom, even in any one country or climate, it is obvious that some arrangement, some regular mode of naming and distinguishing them, must be very desirable, and even necessary, for retaining them in our own memory, or for communicating to others any thing concerning thens. Yet the antients have scarcely used any further classification of plants than the vague and superficial division into trees, shrubs and herbs, escept a consideration of their places of growth, and also of their qualities. The earlier botani-a. among the moderns almost incritubly foll into some rude arrangement of the objecte of their study, and distributed them under thes heads of Grasses, Bulluous plants, Medicinal or Eatable plants, \&c., in which their successors made several improvements, but it is not worth while to contemplate them.

The science of Botanical Arrangement fist assumed a regular form under the auspices of Conrad Gesner and Casalpinus, who, inde- 
pendent of each other, without any'mutual communication, both conceived the idea of a regular classification of plants, by means of the parts of fructification alone, to which the very existence of Botany as a science is owing. The first of these has left us scattered hints only, in various letters, communicated to the world after his premature death in 1565; the latter published a system, founded on the fruit, except the primary dirision into trees and herbs, in a quarto rolume printed at Florence in 1583. This work Linnaus studied with great care, as appears from the many notes and marked passages in his own copy now before me. Hence he adopted his ideas of the supposed origin of the calyx, corolla, stamens, and pistils, from the outer bark, imner bark, wood and pith, which are now proved to be erroneous. In his own Classes Plantarum he has drawn out a regular plan of the System of Casalpinus, the chief principles of which are the following:

1. Whether the embryo be at the summit or base of the seed.

2. Whether the germen be superior or inferior. 
3. Seeds 1, 9, 3, 4, or numerous.

4. Seed-ressels 1, 2, 3, 4, Sic.

The work of Cresalpinus, though full of information, was too deep to be of common use, and excited but little attention. A century afterwards Morison, Professor of Botany at Oxford, improved somewhat upon the ideas of the last-mentioned writer, but has been justly blamed for passing over in silence the source of his own information. Ray, the great Englisis naturalist, formed a considerably different system upon the fiuit, as did Hermann, Professor at Leyden, and the great Boerhaave, but in these last there is little. originality.

Rivinus, Ruppius and Ludwig in Germany proposed to arrange plants by the various forms of their Corolla, as did Toumefort the illustrious French botanist, whose system is by far the best of the lind; and this having been more celebrated than most others, I shall give a sketch of its plan.

In the first place we meet with the old but highly unphilosophical division into Herbs and Trees, each of which sections is subdi- 
vided into those with a Corolla and those without. The Trees with a Corolla are again distributed into such as have one or many petals, and those regular or irregular.- Herbs with a Corolla have that part either compound (as the Dandelion, Thistle and Daisy), or simple; the latter being either of one or many petals, and in either case regular or irregular. We come at last to the final sections, or classes, of the Tournefortian system. Herbs with a simple, monopetalous, regular corolla are either bell-shaped or funnelshaped; those with an irregular one either anomalous or labiate.

Herbs with a simple, polypetalous, regular corolla are either cruciform, rosaceous, umbellate, pink-like or liliaceous; those with an irregular one, papilionaceous or anomalous. The subdivisions of the classes are founded on the fruit.

It is easy to perceive that a system of this kind can never provide for all the forms of corolla which may be discovered after its first contrivance; and therefore the celebrated Dr. Garden, who studied by it, assured me that when he attempted to reduce the Ame- 
rican plants to Tournefort's classes, he found them so untractable, that, after attempting in vain to correct or augment the system, he should probably have given up the science in despair, had not the works of Linnseus fallen in his way.

Magnol, Professor at Montpellier, and even Linnæus himself, formed schemes of arranging plants by the calyx, which nobody has followed.

All preceding systems, and all controversies respecting their superior merits, were laid aside, as soon as the famous Linnæan method of classification, founded on the Stamens and Pistils, became known in the botanical world. Linnæus, after proving these organs to be the most essential of all to the very being of a plant, first conceived the fortunate idea of rendering them subservient to the purposes of methodical arrangement, taking into consideration their number, situation and proportion. How these principles are applied, we shall presently explain; but some previous observations are necessary.

Linnæus first made a distinction between a natural and an artificial method of botanical arrangement. His predecessors pro- 
bably conceived their own systems to be each most consonant with the order of Nature, as well as most commodions for use, and it was reserved for him to perceive and to explain that these were two very distinct things.

The most superficial observer must perceive something of the classification of Nature. The Grasses, Umbelliferous plants, Mosses, Sea-weeds, Ferns, Liliaceous plants, Orchises, Compound flowers, cach constitute at family strikingly similar in form and qualities among themselves, and no less evidently distinct from all others. If the whole regetable kingdom could with equal facility be distributed into tribes or classes, the study of Botany on such a plan would be no less easy thon satisfactory. But as we proceed in this path, we soon find ourselves in a labyrinth. The natural orders and fumilies of plants, so far from being connected in a regular series, appruach one another by so many points, as to bewilder instead of directing us. We may seize some striling combinations and analogies; but the further we proceed, the more we become sensible that, even if we had the whole vegretable world before us at one yiew, 
our knowledge must be imperfect, and that our "genius" is certainly not "equal to the Majesty of Niture." Nevertheless Limucus, and all true philosophical botanists since the first mention of the natural aftinities of plants, have ever considered them as the most inportant and interesting branch, or rather the fundamental part, of systematical botany. Without them the science is truly a study of words, contributing nothing to enlarge, little woithy to exercise, a rational mind. Linnæus therefore suggests a schene which he modestly calls Fragments of a Natural Method, which formed the subject of his occasional contemplation; but he daily and hourly studied the principles of natural aflinitics among plants, conscious that no true knowledge of their distinctions, any more than of their qualities, could be obtained withont; of which important truth he was not only the carliest, but erer the most strennous assertor.

In the mean while, however, Linnaus, we!l aware that a natural classification was scarcely crer to be completely discovered, and that if discovered it would probably be too dillictilt for common use, conrrised an arlificial sy- 
stem, by which plants might converiently be arranged, like words in a dictionary, so as to be most readily found. If all the words of a language could be disposed according to their abstract dorivations, or grammatical affinities, such a performance might be very instructive to a philosopher, but would prove of littlo service to a young scholar; nor has it erer beer mentioned as any objection to the use of a dictionary, that words of very different meanings, if formed of nearly the same letters, often stand together. The Method of Linnaus therefore is just such a dictionary in Batany, while his Philosopliza Botanica is the grammar, and his other works contain the history, and even the poetry, of the science.

But before we give a detail of his artificial system, we must first see how this great man fixed the fundamental principles of botanical science. Nor are these principles confined to botany, though they originated in that study. The Linnæan style of discriminating plants, la: been extended by himself and others to animals and even fossils; and his admirable principles of nomenclature are applied with 
great advantage even to chemistry itself, now become so vast and accurate a science.

Independently of all general methods of classification, whether natural or artificial, plants, as well as animals, are distinguished into Generu*", Species, and Varieties.

By Species are understood so many individuals, or, among the generality of animals, so many pairs, as are presumed to have been formed at the creation, and have been perpetuated erer since; for though some animals appear to have been exterminated, we have no reason to suspect any new species has been produced; neither have we any cause to suppose any species of plant has been lost, nor any new one permanently established, since their first formation, notwithstanding the speculations of some philosophers. We frequently indeed see new Varieties, by which word is understood a variation in an established species; but such are imperfectly, or

* Our scientific language in English is not sufficiently perfect to afford a plural for genus, and we are therefore obliged to adopt the Latin one, genera, though it exposes us sometimes to the horrors of hearing of " a new genera" of plants. 
for a limited time, if at all, perpetuated in the offspring.

A Genus comprehends one or more species, so essentially different in formation, nature, and often many adventitious qualities, from other plants, as to constitute a distinct family or kind, no less permanent, and founded in the immutable laws of the creation, than the different species of such a genus. Thus in the animal kingdom, a horse, ass and zebra form three species of a very distinct genus, marked, not only by its general habit or aspect, its uses and qualities, but also by essential characters in its teeth, hoofs, and internal constitution. The lion, tiger, leopard, panther, lynx, cat, \&c., also compose another sufficiently obvious and natural genus, and the numerous herd of monkeys, apes and baboons a third. The elephant is, as far as we know, a solitary species of a most distinct and striking genus.

So among vegetables, the various species of rose compose a beautiful genus, known to every one who ever looked at a plant, merely by a certain combination of ideas, but essentially distinguished, as we shall hereafter find, 
by clear and decisive characters. The pecies of Iris form also a numerous gemus, and the Villows another; while the curious Iipisnedium alpimum, Engl. Jot. t.438, is tow singular and distinct to be associated with any known plant besides, and constitutes a genus by itself, as well as the 1 dora, $t .453$, and Liman, t. 433.

The first great and successful attempt to define the genera of plants was made by Tournefort, and in this his transcendent merit will ever be conspicuous, though his system of arrangement sliould be entirely forgotten. Not that he has excelled in verbal definitions, nor built all lis genera on sure foundations; but his figures, and his enumera. tions of species under each genus, show the clearness of his conceptions, and rank him as the father of this branch of botany.

Linneus first insisted on generic charueters being exclusively taken from the 7 parts of fructification, and he demonstrated these, to be sufficient for all the plants that can be discovered. He also laid it down as a maxim, that all genera are as much founced in nature as the species which cormose thom; and 
hence follows one of the most just and valuable of all his principles, that a gemus should furnish a character, not a character form a genus; or, in other words, that a certain coincidence of structure, habit, and perhaps qualities, among a number of plants, should strike the judgment of a botanist, before he fixes on one or more technical characters, by which to stamp and define such plants as one natural genus. Thus the Hemerocallis comlea, Andr. Repos. t. 6, and alba, t. 194, though hitherto referred by all botanists to that genus, are so very different from the other species in habit, that a discriminative character might with confidence be expected in some part or other of their fructification, and such a character is accordingly found in the winged seeds. Yet in the natural genera of Arenaria and Spergula, winged or bordered seeds are so far from indicating a distinct genus, that it is doubtful whether they are sufficient to constitute even a specific character. See Engl. Bot. t. 958, 1535 and 1536. So Blandfordia, Exot. Bot.t. 4, is well distinguished from Aletris, with which some botanists have confounded it, by its 
hairy seeds; but the same circumstance will not justify us in separating a fe spe. iss from Convolvulus, which are attached to that genus by stronger ties of another kind.

Some genera are obvious and indubitable both in habit and character, as Quercus, Rosa, Euphorbia, Begonia, Exot. Bot.t.101, and Sarracenia, t. 53; others are obvious, but their character extremely difficult to define, as Valeriana. The greatest difficulty lies in distinguishing genera that belong to such very natural orders as the Grasses and Umbelliferous plants; and the ablest botanists differ about the best guides in these two particular cases. Yet other orders, equally natural, sometimes afford very excellent generic differences, as that to which Rosa, Rubus, Fragaria, \&c., belong; and even in the Papilionaceous plants with ten distinct stamens, a tribe hitherto judged inextricable, a regular examination on scientific principles has led to the discovery of very natural well defined genera. See Annals of Botany, v. 1. 501. I have in a preceding chapter hinted that the umbelliferous plants 
seem to me rery capable of being well discriminated by their seeds, and other botanists have held the same opinion.

But though I feel convinced, as fal as my experience goes, that genera are really founded in nature, I am far from asserting that Linnæus, or any other writer, has succeedied in fixing all their just limits. This deep and important branch of natural science requires the union of various talents. Many persons who can perceive a genus cannot define it; nor do acuteness of perception, solidity of judgment, and perspicuity of expression, always meet in the same person. Those who excel in this department are named by Linnaus, Phil. Bot. sect. 15\%, theoretical botarists; those who study only species and varieties, piactical ones.

In methodical arrangement, whether natural or artificial, every thing must give way to generic distinctions. A natural system which should separate the species of a good genus, would, by that very test alone, prove entirely worthless; and if such a defect be sometimes unavoidable in an artificial one, 
contrivances must be adopted to remedy it; of which Linnaus has set us the eximmple, iı will hereafter be explained.

Generic characters are reckoned by Linnous of three kinds, the factitions, the cssential, and the natural, all founded on the fructification alone, and not on the inflorescence, nor any other part.

The first of these serves only to discriminate genera that happen to come together in the same artificial order or section; the second to distinguish a particular genus, by one striking mark, from all of the same natural o:der, and consequently from all other plants; and the third comprehends erery possible mark common to all the species of one genus.

The factitious character can never stand alone, but may sometimes, commodiously enough, be added to more essential distinctions, as the insertion of the petals in Agrimonia, Engl. Pot. t. 1335, indicating the natural order to which the plant belongs, which character, though essential to that order, here becomes factitious.

Limneus very much altered his notions of the essential character after he had published 
his Philosophia Botanica, whence the above definitions are taken. Instead of confining it to one mark or idea, he, in his Systema Vegetabilium, makes it comprehend all the distinctions requisite to discriminate each genus from every other in the system, only avoiding a repetition at every step of the characters of the artificial class and order, which stand at the top of each page, and are not always essential to the character of the genus. This is the kind of generic character now universally adopted, and indeed the only one in common use. The learned Jussieu has given it the sanction of his approbation and adoption, as far as its plan is concerned, throughout his immortal work, subjoining in a different type such characters and remarks as belong to the habit, or refer to other circumstances. For my own part I profess to retain, not only the plan, but the very words of Linnæus, unless I find them erroneous, copying nothing without examination, but altering with a very sparing hand, and leaving much for future examination. I cannot blame my predecessors for implicitly copying the Linnæan characters, nor should I have 
been the first among English writers to set a contrary example, had I not fortunately been furnished with peculiar materials for the purpose.

The beauty and perfection of these essential generic characters consist in perspicuity, and a clear concise style of contrasting them with each other. All feebleness, all superfluity, should be avoided by those who are competent to the purpose, and those who are not should decline the task. Comparative words, as long or short, without any scale of coniparison, are among the grossest, though most common, faults in such compositions.

The natural character seems to have been, at one time, what Linnæus most esteemed. It is what he has used throughout his Genera Plantarum, a work now superseded by the essential characters in his Systema Vegetabilium, and therefore in some measure laid aside. The disadvantages of the natural character are, that it does not particularly express, nor direct the mind to, the most important marks, and that it can accord only with such species of the genus as are known to the author, being therefore necessarily im- 
his Philosophia Botanica, whence the above definitions are taken. Instead of confining it to one mark or idea, he, in his Systema Vegetabilium, makes it comprehend all the distinctions requisite to discriminate each genus from every other in the system, only avoiding a repetition at every step of the characters of the artificial class and order, which stand at the top of each page, and are not always essential to the character of the genus. This is the kind of generic character now universally adopted, and indeed the only one in common use. The learned Jussieu has given it the sanction of his approbation and adoption, as far as its plan is concerned, throughout his immortal work, subjoining in a different type such characters and remarks as belong to the habit, or refer to other circumstances. For my own part I profess to retain, not only the plan, but the very words of Linnæus, unless I find them erroneous, copying nothing without examination, but altering with a very sparing hand, and leaving much for future examination. I cannot blame my predecessors for implicitly copying the Linnæan characters, nor should I have 
been the first among English writers to set a contrary example, had I not fortunately been furnished with peculiar materials for the purpose.

The beauty and perfection of these essential generic characters consist in perspicuity, and a clear concise style of contrasting them with each other. All feebleness, all superfluity, should be avoided by those who are competent to the purpose, and those who are not should decline the task. Comparative words, as long or short, without any scale of comparison, are among the grossest, though most common, faults in such compositions.

The natural character seems to have been, at one time, what Linnæus most esteemed. It is what he has used throughout his Genera Plantarum, a work now superseded by the essential character in his Systema Vegetabilium, and therefore in some measure laid aside. The disadvantages of the natural character are, that it does not particularly express, nor direct the mind to, the most important marks, and that it can accord only with such species of the genus as are known to the author, being therefore necessarily im- 
perfect. This kind of character is, howerer, admirable for the illustration of any difficult natural order. Mr. Gawler's elucidations of the Ensatce, Sword-leaved plants, Amnals of Botamy, 0. 1. 219, and Curt. Mag. afford excellent specimens of it, serving as a store of facts and observations for following systematical writers.

Specific characters should be constructed on similar principles to the generic ones, as far as regards certainty, clearness and conciseness. The genus being first well defined, we are to seek for characters, not mentioned among the generic marks, for distinguishing the species. A specific difference for a solitary species of any genus, is therefore an absurdity. Linnæus at first intended his specific definitions should be used as names; but the invention of trivial names happily set aside this incontenient scheme. On this account however he limited each to twelve words, a rule to which all philosophical naturalists have adhered, except in cases of great necessity. Nor is the admission of one or tro words beyond the allotted number repichensible, provided the whole sentence be 
so neatly and perspicuously constructed, that the mind may comprehend it, and compare it with others, at one view; but this can hardly be done when the words much exceed twelve. This rule, of course, can be strictly applied to Lixtin definitions only, though it should be liept in riew in any language, as far as the genius of that language will allow. Linnæus says, "Genuine specific distinctions consritute the perfection of natural science;" which is strongly confirmed by the great inferiority of most botanists, in this department, to that great man, and especially by the tedious feebleness and insufficiency displayed among those who court celebrity by despising his principles.

In constructing generic and specific characters, the arrangement of the different parts on which they are founded is to be considered. Such as are most important in the natural order, or genus, are to stand first, and the subordinate, or more peculiar marks of the object before us, ought to close the sentence. On the contrary, in drawing up natural characters of a genus, as well as full descriptions of particular plants, it is proper 
to take, in the former instance, the calyr, corolla, stamens, pistils, seed-vessel, seed and receptacle, and in the latter, the root, stem, leaves, appendages, flower and fruit, in the order in which they naturally occur.

Nomenclature is no less essential a brancl of methodical science than characteristic definitions; for, unless some fixed laws, or, in other words, good sense and perspicuity, be attended to in this department, great confusion and uncertainty must ensue.

The vague names of natural objects handed down to us, in various languages, from all antiquity, could have no uniformity of derivation or plan in any of those languages. Their different origins may be imagined, but cannot be traced. Many of these, furnished by the Greek or Latin, are retained as generic names in scientific botany, though neither their precise meaning, nor even the plants to which they originally belonged, can always be determined, as Rosa, Ficus, Piper, \&ic. It is sufficient that those to which they are now, by common consent, applied, should be defined and fixed. Botanists of the Linnxan school, however, admit no such 
generic names from any other language than the Greek or Latin, all others being esteemed barbarous. Without this rule we should be overwhelmed, not only with a torrent of uncouth and unmanageable words, but we should be puzzled where to fix our choice, as the same plant may lave fifty different original denominations in different parts of the world, and we might happen to choose one by which it is least known. Thus the celebrated Indian plant now proved beyond all doubt to be the Cyamus of Theophrastus*, having been erroneously reckoned by Linnæus a Nymphcea, received from Gærtner, one of the first who well distinguished it as a genus, the Ceylon nane of Nelumbo; which being contrary to all rules of science, literature or taste for a generic name, has by others been made into bad Latin as Nelumbium. But the universal Hindu name of the plant is

* See Exot. Bot.v.1. 60, where the arguments in support of this opinion are given, and Curt. Mag. t.903, where some of them are with much candour and ingenuity controverted, though not so as 'to alter my' sentiments ; nor can any thing justify the use of Nelumlinum in a scientific work as a generic name. 
Tamard, which, independent of barbarism, ought to have been preferred to the very confined one of Nelumbo. In like manner the Bamboo, Arundo Bambos of Linnæus, proving a distinct genus, has received the appellation of Bambusa, though Jussieu had already given it that of Nastus from Dioscorides*. Perhaps the barbarous name of some very local plants, when they cannot possibly have been known previously by any other, and when that name is harmonious and easily reconcileable to the Latin tongue, may be admitted, as that of the Japan shrub Aucula; but such a word as Ginkgo is intolerable. The Roman writers, as Cæsar, in describing foreign countries, have occasionally latinized some words or names that fell in their way, which may possibly excuse our making Ailanthus of Aylanto, or Pandanus of Pan-

* It is not indeed clear that this name is so correctly applied as that of Cyamus, because Nastus originally belonged to " a reed with a solid stem," perhaps a palm; but not being wanted, nor capable of being correctly used, for the latter, it may very well serve for the Bamboo. There is no end of raking up old uncertainties about classical names. 
dang. Still I can only barely tolerate such nanues ont of defenence to the botanical me:rits, not the learning, of their contrivers; and I highly honnur the zeal and correctness of Mr. Sillisbury, who, in defiance of all undue authority, has ever opposed them, naming Aucuba, on account of its singular base or receptacle, Eubasis. I know not how P'andanus escaped his reforming hand, especially as the plant has already a good characteristic Greck name in the classical Forster, Alleroductylis.

Excellent Greek or Latin names are such as indicate some striking peculiarity in the genus: as Glycyrrhiza, a swcet root, for the Liquorice; Amaranthus, without decay, for an everlasting flower; Melianthus, a sunflower; Jithospermum, a stony seed; Erioculia*, aflower with a singularly woolly base or cup; Origanum, an ormarnentil mountain plant; Memerocallis, a beauty of a day;

* When I named this genus in Exotis: Rotany, I was not aware of its having previously been published by M. Pillardiere under the name of Actinotus; a name however not tenable in Botany, because it has long been prevecupied in Mineraloggy. 
Arenaria, a plant that inhabits sandy places; and Gypsophila, one that loves a chalky soil. Such as mark the botanical character of the genus, when they can be obtained for a nondescript plant, are peculiarly desirable: as Ceratopetalum, from the bianched hornlike petals; Lasiopetalum, from the very singularly woolly corolla; Calceolaria, from the shoe-like figure of the same part; Conchium, from the exact resemblance of its fruit to a bivalve shell.

In all ages it has been customary to dedicate certain plants to the honour of distinguished persons. Thus Euphorbia commemorates the physician of Juba a Moorish prince, and Gentiana immortalizes a king of Illyria. The scientific botanists of modern times have adopted the same mode of preserving the memory of benefactors to their science; and though the honour may have been sometimes extended too far, that is no. argument for its total abrogation. Some uncouth names thus unavoidably deform our botanical boolis; but this is often effaced by the merits of their owners, and it is allowable to model them into grace as much as 
possible. Thus the elegant Tournefort made Gundelia from Gundelscheimer; which induced me to choose Goodenia, for my much honoured and ralued friend Dr. Goodenough, though it has, when too late, been suggested that Goodenovia might have been preferable. Some difficulty has arisen respecting French botanists on account of the additional names by which their grandeur, or at least their ranity, was displayed during the existence of the monarchy. Hence Pittonia was applied to the plant consecrated to Pitton de Tournefort; but Linnaus preferred the name by which alone he was known out of his own country or in learned language, and called the same genus Tournefortia. Thus we have a Fontrinesia and a Lonichea, after the excellent Louiche Desfontaines; but the latter proving a doubttul genus, or, if a good one, being previously named Pteranthus, the former is established. We have even in England, by a strange oversight, both Stuartia and Butea after the famous Earl of Bute; but the former being long ago settled by Limnaus, the latter, since given by Kœnig, is totally inarluissible on any pretence what- 
ever, and the genus which bears it must have a new appellation. In like manner my own Humea, Exot. Bot. $t$. 1, has been called in France Calomeria after the present Emperor, by the help of a pun, though there has long been another genus Bonapartea, which last can possibly be admitted only in honour of the Empress, and not of her consort, who has no botanical pretensions. Our own beloved sovereign could derive no glory from the Georgia * Ehrhart; but the Strelitizia of Aiton stands on the sure basis of botanical knowledge and zeal, to which I can bear ample and very disinterested testimony.

Linnæus, in his entertaining book Critica Botanica, p. 79, has in sereral instances drawn a fanciful analogy between botanists and their appropriate plants, thus -

Bauhiniu, after the two distinguished brothers John and Caspar Bauhin, has a twolobed or twin leaf.

Scheuchzerin, a grassy alpine plant, commemorates the two Scheuchzers, one of whom excelled in the knowledge of alpine productions, the other in that of grasses.

* Tetraphis of Hedwig and Engl. Bot t. 1020. 
Dorstenia, with its olssolete flowers, devoid of all beauty, alludes to the antiquated and uncouth book of Dorstenius.

Hernamdia, an American plant, the most beautiful of all trees in its foliage, but furnished with trifling blussoms, bears the name of a botanist highly favoured by fortune, and allowed an ample salary for the purpose of investigating the natural history of the Western world, but whose labours have not answered the expense. On the contrary

Magnolia with its noble leaves and flowers, and

Dillenia with its beautiful blossoms and fruit, serve to immortalize two of the most meritorious among botanists.

Iinnca, "a depressed, abject, " apland plant, long overlooked, flowering at an early agुe, was named by Gronovius after its prototype Linnæus."

In pursuance of the same idea Dicksonia, a beantiful and curious fern, is well devoted to our oreat cryptogamist; Knappia, a small and singular grass, to an author celebrated for his minute and curious drawings of that tribe; Sprengelia, to one distinguished for 8 
illustrating the impregnation of plants, which the remarkable form and union of its anthers serve to indicate; while Smithia sensitiva, named by Mr. Dryander in the Hortus fiezcusis of our mutual friend Aiton, could at that time be merited only by an original treatise on the Irritability of Plants 1 , to which the specific name happily alludes.

The generic name being fixed, the specific one is next to be considered. With respect to this, Rivinus has the merit of originality, having been the first to contrive naming each plant in two words. But his names were meant for specific definitions, for which they are totally inadequate. Limmeus, in constructing his more accurate and full specific characters, intended the latter should serve as names, and therefore called them nomina specifica. When he, most fortumately for the science and for the popularity of his whole System of Nature, inrented the present simple specific names, he called them nomina irivialia, trivial, or for conmon use; but that term is now superiluous.

- Salisl. Hort. 342. + Phil. Trans. for 1;ss. 
Specific names should be formed on similar principles to the generic ones; but some exceptions are allowed, not only without inconrenience, but with great advantage. Such as express the essential specific character are unexceptionable, as Banksia serrata, integrifolia, dentata, \&c.; but perhaps those which express something equally certain, but not comprehended in that character, are still more useful, as conveying additional information, like Irora alba and coccinea, Scleranthus ammus and perennis, Aletris fragrans, Suxifraga cernua, \&c.; for which reason it is often useful that vernacular names should not be mere translations of the Latin ones. Comparative appellations are very good, as Banlisia ericifolia, Andromeda salicifolia*, Saxifiraga bryoides, Milium cimicinum, Elymus Hystrir, Pedicularis Sceptrum. Names which express the local situations of different species are excellent, such as Melampyrum

* Some botanists write cricafolia, salicisfolia, lingucoformis, Sic., instead of following the analogy of the Latin in forming adjectives with an $i$, as palmifer from palma, $a$; baccifer, from lacca, $a$; larliger, from baría, $a$; \&ic. 
arvense, pratense, nemorosum and sylvaticum, Carex arenaria, uliginosa and sylvatica, as well as aquatica, maritima, rupestivis, alpina, nivalis, used for many plants. But names derived from particular countries or districts are liable to much exception, few plants being sufficiently local to justify their use. Thus Ligusticum cormuliense is found, not only in Cornwall, but in Portugal, Italy and Greece; Schwenkia americana grows in Guinea as well as in South America. Such therefore, though suffered to remain on the authority of Linnæus, will seldom oi never be imitated by any judicious writer, unless Trollius europceus and asiaticus may justify our naming the third species of that genus, lately brought from America, americanus. The use of a plant is often commodiously expressed in its specific name, as Brassica oleracea, Papaver somniferum, Inocarpus edulis; so is likewise its time of flowering, as Primula veris, Leucojum vernum, cestivum and autumnale, and Helleborus hyemalis.

When a plant has been erroneously made into a new genus, the name so applied to it may be retained for a specific appellation, as 
Luthrca Phelypaa, and Bartsia Gymmandra; which may also be practised when a plant has been celebrated, either in botanical, medical, or any other history, by a particular name, as Criganum Dictamnus, Artemisia Diacunculus, Laurus Cimnamomum, Selinum Carvifolia, Carica Papaya. In either case the specific name stands as a substantive, retaining its own gender and termination, and must begin with a capital letter; which last circumstance should be observed if a species be called after any botanist who has more particularly illustrated it, as Cortusa Matthioli and C. Gmelini, Duranta Plumierii, and Mutisii. The latter genus suggests an improvement in such kind of names. The genitive case is rightly used for the person who founded the genus, D. Plumierii; $D$. Mutisiana might serve to commemorate the finder of a species, while D. Ellisia implies the plant which bears it to have been once called Ellisia.

There is another sort of specific names in the genitive case, which are to me absolutely intolerable, though contrived by Linnæus in his latter days. These are of a comparative 
kind, as Lobelia.Columnec, meaning Ca lumnece formis. We may allow a few such, already established, to remain, but no judicious author will imitate them.

Botanists occasionally adapt a specific name to some historical fact belonging to the plant or to the person whose name it bears, as Linnea borealis from the great botanist of the north; Murrea crotica after one of his favoturite pupils, a foreigner; Browallia demissa and clata, from a botanist of humble origin and character, who afterwards became a lofty bishop, and in whose work upon water I find the following quotation from Seneca in the hand-writing of Linnicus: "Many might attain wisdom, if they did not suppose they had already reached it." In like manner Buffonia tenuifolia is well known to be a satire on the slender botanical pretensions of the great French zoologist, as the Hillia parasitica of Jacquin, though perhaps not meant, is an equally just one upon our pompous Sir John Hill. I mean not to approve of such satires. They stain the purity of our lorely science. If a botanist does not deserve commemoration, let him sink peaceably 
into oblivion. It savours of malignity to malie his crown a crown of thorns, and if the application be unjust, it is truly diabolical.

Before I conclude the subject of nomenclature, I beg leave to ofter a few reflections on changes of established names. It is generally agreed among mankind that names of countries, places, or things, sunctioned by general use, should be sacred; and the study of natural history is, from the multitude of objects with which it is conversant, necessarily so encumbered with names, that students require every possible assistance to facilitate the attimment of those names, and have a just right to complain of crery need less impedinent. The grateful Hollanders named the island of Mauritius after the hero who had established their liberty and prosperity; and it ill becane the French, at that period dead to such feelings, to change it, when in their power, to Iste de France, by which we have in some late botanical works the barbarous Latin of Insula Irancice. Nor is it allowable to alter such names, even for the better. Americo Vespueci had no rery great pretensions to give his own name to a 
quarter of the world, yet it is scarcely probable that Columbia will supersede America. In our science the names established throughout the works of Linnaus are become current coin, nor can they be altered without great inconvenience. Perhaps, if he had foreseen the future authority and popularity. of his writings, he might himself have improved upon many which he adopted out of deference to his predecessors, and it is in some. cases to be regretted that he has not sufficiently done so. In like manner, the few great leaders in natural knowledge must and will be allowed to ward off and to correct, from time to time, all that may deform or enfeeble the prevailing system. They must choose between names nearly of the same date, and eren between good and bad ones of any date. A botanist who, by the strength of his own superior knowledge and authority, reforms and elucidates a whole tribe of plants hitherto in confusion, as a Hedwig in Mosses, or Acharius in Lichens, ought to be unshackled in every point in which he can be of service. His wisdom will be evinced by extreme caution and reserve in using his liberty with re- 
spect to new liames, but more especially new terms; and, after all, he will be amenable to the general tribunal of botanists, and the judgment of those who come after him. Few indeed are illustrious enough to claim such privileges as these. Those who alter names, often for the worse, according to arbitrary rules of their own, or in order to aim at consequence which they cannot otherwise attain, are best treated with silent neglect. The system should not be encumbered with such. names, even as synonyms.

When, however, solid discoverics and improvements are made in the science; when species or genera hare been confounded by Linnæus himself, and new ones require to be separated from them, the latter must necessarily receive appropriate appellations; as also when a totally wrong and absurd name has by mistake been given, as Begonia c $a$ pensis; in such cases names must give place to things, and alterations proceeding from such causes must be submitted to. Thus I believe Mr. Salisbury's Castalia is well separated from Nymphcea. See Annals of Botany, v. 2. 71. 
A great and just complaint has arisen in my time among the cultivators of botany, who found the names of many garden plants, with which they had long been conversant, altered for others without any apparent cause, and in many instances for the worse; as Aristolochia macroplyylla, an excellent and expressive nanic, for a rery unappropriate one, A. Sipho. For this I am obliged to censure my much regretted and very intelligent friend L'Heritier. When he came to England to reap the rich harvest of our undescribed plants, he paid no respect to the gereric or specific names by which Dr. Solander or others had called them, because those names were not printed; but he indulged himself, and perliaps thought he confirmed his own importance, by contriring new ones; a factitious mode of gaining celebrity, to which his talents ought to hare been infinitely superior. Nor would it have been easy to say how far this inconrenient plan of innovation might have extended, had not the Hortits Kewensis come forth to secure our remaining property.

I have only to ads! a few words respecting 
a kind of generic names that has of late become more conmon than Linneus probably would have approved, though he has once or iwice allowed it; I allude to those compounded either of two established names, or of one combened with any other word. Of the former number is Calamagrostis, formed of Calamus and Agrostis, two Linnaan names; and this is no where sanctioned by any good authority. Happily the genus to which it has negligently been applied is an Arundi). Of the latter sort is Cissampelos, formed of Cissus, another established genus, and Ampelos, a Vine; the litter not among Limman names: also Eleagnus, constructed of two old Greek names, neither of which is now in botanical use by itsclf. These are both expressly allowed by Linnaus, nor indeed can there be any objection to the latter. Cissampelos may certainly justify IIyoscyamus, conuposed of Cyamus and a word denoting swine; if not, tlis would prove an gbjection to the reestablishment of Cyamus, much more to the purpose than any that has been adranced ; for Hyoscyamus having been so long and universally used in systematic 
botany, could scarcely give place, even to its renerable prototype. On the same ground only can several new generic names, used in the fern tribe, be admitted. These are formed out of Pteris, the established generic appellation of a common Brake, with some other Greek word prefixed ; as Angiopteris, a Brake with a capsule, Tmesipteris, a cloren Brake, and Canopteris a new Brake. Whatever may become of the former two, I must always protest against the last, given by the celebrated Bergius to the Darea of Jussieu, on account of its unexampled impropriety. As well might any new genus, resembling a Rose, be called Novarosa; for though the Greek language may assist us with regard to sound, it can never malie amends for a radjcal deficiency of sense. 


\section{CHAPTER XXIII.}

EXPLANATION OF TIE LINNEAN ARTIFICIAL SYSTEM.

Tre Linnaan System is, as I have already observed, professedly artificial. Its sole aim is to help any one to learn the name and history of an unknown plant in the most easy and certain manner, by first determining its Class and Order in this system; after which its Genus is to be made out by comparing the paits of fructification with all the generic characters of that Order; and finally its Species, by examining all the specific definitions of the Genus. We thus ascertain the generic and specific name of our plant in Linnæus, and under those we find an enumeration, more or less ample, of its Synonyms, or the different appellations it has received from other writers, with a reference to figures in 
various books; and as Linnæus always cites Bauhin's Pinax, which is the common botanical catalogue, or index to all previous works, we thus gain a clue to every thing recorded concerning our plant. of all this mass of information and cntertainment we shall find nothing more concise, luminous, or engaging, either with respect to the distinctions, uses, or history of plants, than what is diffused through the various publications of Linnaus himself; and the same may, with at least equal truth, be said of those of his works which illustrate the Animal kingdom. His magic pen turns the wilds of Lapland into fairy land. He has all the animals of Sweden as much at his call, as our first parent while the terrestrial paradise was yet in primaval tranquillity. No writer whativer has rendered the natural productions of the happiest and most luxuriant climates of the globe half so interesting or instructive as Linnaus has made those of his own northern country

The CLAssis of the Linnean System are 24, and their distinctions are founded on the number, situation, or proportion of the Stamens. The Orders are founded either on the 
number of the Pistils, or on some circumstance equally easy, which we shall in due tine $x-$ plain.

The first eleren Classes are characterized solely by the number of the Stamens, and distinguished by names, of Greek derivation, expressive of these distinctions.

1. Moxamizia. Stamen 1.

A small Class.

2. Diandria. Stamens 2 .

3. Triandria 3 .

4. Tetrandria - 4 :

5. PENTANDRI - 5.

A numerous Class.

6. Hexatida - 6 .

7. Hretaxdra

A very small Class.

3. Octaidria - 8 .

9. ENNFANDRIA 9 . A small Class.

10. DECANDRIA

10

11. Dopecanpria — 12 to 19 .

12. I COSANDRIA, - 20 or more Stamens, inserted into the Calys: Here we first find the situation of the Stamens 
taken into consideration. They grow out of the sides of the Calyx, often from a sort of ring, as in the Strawberry. This is truly a natural Class, as are several of the following ones; so that in these instances the Linnæan method of arrangement performs more than it promises. The character of this Class is the more important, as such a mode of insertion indicates the pulpy fruits which accompany it to be infallibly wholesome, and this holds good, not only when the stamens are numerous, but in all other cases. Thus Ribes, the Currant and Gooseberry genus, whose 5 stamens grow out of the calyx, stands in the fifth class, a wholesome fruit, among many poisonous berries. No traveller in the most unknown wilderness need scruple to eat any fruit whose stamens are thus situated; while on the other hand he will do well to be cautious of feeding on any other parts of the plant.

13. Poly N NRIA. Stamens numerous, commonly more so than in the last Class, and inseried into the Receptacle, ar base of 
th fower, as in the Poppy, Anemone, \&c. The plants of this fine and numerous Class are very distinct in nature, as well as character, from those of the Icosandria.

14. Didramia. Stamens 2 long and 2 short. Here proportion comes to our assistance. This is a natural Class, and contains most of the labiate, ringent or personate flowers, as the Dead-nettle, Snapdragon, Fox-glove, Sic.

15. Tetraditamia. Stamens 4 long and 2 short. A very natural Class, comprehending all the Cruciform flowers, as the Wall-flower, Stock, Ridish, Mustard, \&c. Cleorne only does not properly belong to the rest.

16. Monadelphia. Stamens united by their filaments, more or less extensively, into one tube, as the Mallow tribe, in which such union is very remarkable, and the Geranium family, in which it is less evident.

17. Diaderpura. Stamens united into 2 
parcels, both sometimes cohering together at the base. This Class consists of Papilionaceous flowers, and is therefore natural, except that some such genera having distinct Stamens are excluded, and referred to the tenth Class, in consideration of their number solely; as some ringent flowers with only 2 Stamens are necessarily placed, not in the 14th Class, but the $2 \mathrm{~d}$.

18. PoLYADELPiA. Stamens united into more than 2 parcels, as in St. John's-wort. A small Class, in some points related to Icosandria.

19. Syngexesta. Stamens united by their Anthers into a tube, rarely by their Filaments also; and the flowers are Compound. A very natural and extremely numerous Class. Examples of it are the Dandelion, Daisy, Sunflower, \&c.

20. Gynandria. Stamens united with, or growing ont of the Pistil ; either proceeding from the Germen, as in Aristolochia, Engl. Bot.t. 398, or from the Style, as in 
the Orchis family. The Passion-flower is wrongly put by Linnaus and others into this Class, as its stamens merely grow ont of an elongated receptucle or column supporting the Germen.

21. Monozcia. Stamens and Pistils in se, parate flowers, but both growing on the same plant, or, as the rame expresses, dwelling in one house, as the Oak, Hazle, and Fir.

22. Droecia. Stamens and Pistils not only in separate flowers, but those flowers situated on two separate plants, as in the Willow, Hop, Yew, \&c.

These two last Classes are natural when the barren flowers have, besides the difference in their essential organs, a different structure from the fertile ones in other respects; but not so when they have the same structure, because then both organs are liable to meet in the same flower. In some plants, as Rhodiola, Engl. Bot.t.508, each flower has always the rudiments of the other organ, though generally inefficient. 
23. Polygamia. Stamens and Pistils separate in some flowers, united in others, either on the same plant, or on two or three different ones.

This Class is natural only when the several flowers have a different structure, as those of Atriplex; but in this genus the Pistil of the united flower scarcely produces seed. If, with Linnreus, we admit into Polygamia every plant on which some separated barren or fertile flowers may be found among the united ones, while all agree in general structure, the Class will be overwhelmed, especially with Indian trees. I have therefore proposed that regard should be had to their general structure, which remores all such inconvenience, and renders the Class much more natural.

24. Cryptogamil. Stamens and Pistils either not well ascertained, or not to be numbered with any certainty, insomuch that the plants cannot be referred to any of the foregoing classes. Of this Ferns, Lichens, Sea-weeds and Mushrooms are examples. 
Appendix. PALME, Palm-trees, a magnificent tribe of plants, chiefly tropical, whose flowers were too little known, when Limneus wrote, to serve the purposes of classification; but they are daily clearing up, and the Palms are found generally to belong to the Classes Monoecia, Divecia, or Hexundria.

The Orders of the Linnam System arr, in the first 13 Classes, founded on the number of the Styles, or on that of the Stigmas when the Styles are wanting, which occurs in Viburnum. Such Orders are accordingly named

Moxogria. Style, or sessile Stigma, 1: Digy nia. Styles, or sessile Stigmas, 2. TrigYNia 3.

TETRAGYNIA

PentagYNIA-—

HEXAGYNA ——— - 6 , of very rare occurrence.

HEPTAGYNIA 7 . still more unusual.

OCTAGYNIA 8, scarcely occurs at all. 
Linnxus has a 6 th Order in this Class, named Monogamia, consisting of simple flowers with united anthers; but this I have presumed to disuse, because the union of the anthers is not constant throughont the species of each genus referred to it, witness Lobelia and Viola, while on the contrary several detached species in other Classes have united anthers, as in Gentiana, Engl. Bot. t. 20. These reasons, which show the connection of the anthers of a simple flower to be neither important in nature, nor constant as an artificial character, are confirmed by the plants of this whole Linnaean Order being natural allies of others in the 5th Class, and totally discordant, in crery point, from the çompound syngenesious flowers.

The Orders of the 20th, 21st and 22d Classes are distinguished by the characters of some of the Classes themselves which precede them, that is, almost entirely by the number of their Stamens; for the union of the anthers in some of them is, for the reasons just given, of no moment. 
The: Orderes of the: 2asel Class, Polyesamia, are, accosdiner to the heatutiful uniforrsity of plan which rous throurgh this ingronious system, distinguisherl upon the prinseiples of the Classes innaredintely prosed dingeg.

1. Movolicis has flowers wille Stamens and Pistils of the sarre plasut with others that bave only Pistiles, or only Stamens; or

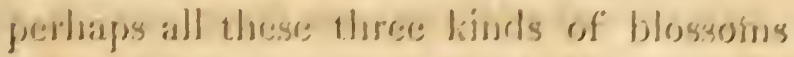
orceus; bus whatever the different linds may bee, 1hery are confined to one plant.

2. Drosices has the two or theere lineds of Alowers on two srepiltinte plants.

2. Tiesolecis lats them on three separate: plants, of which the figg is the only real csamples, and in thete the structure of the flowers is alilec ist all.

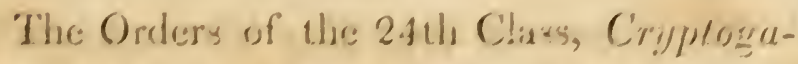

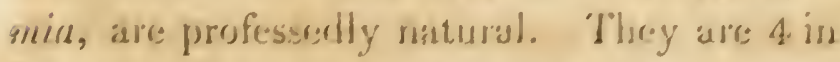
Limaress, but we now reckosn 5.

1. Fisscess. Ferse, whose fructification is robscure, and grows either on the back, surumit, or near the base of the leat, thence denominated a frond. See $\mu .133$. 
2. Muscr. Mosses, which have real separate leaves, and often a stem; a hood-like corolla, or calyptra, bearing the style, and concealing the capsule, which at length rises on a stalk with the calyptra, and opens by a lid.

3. HePatice. Liverworts, whose herb is a frond, being leaf and stem united, and whose capsules do not open with a lid. Linnæus comprehends this Order under the following.

4. Alge. Flags, whose herb is likewise a frond, and whose seeds are imbedded, either in its very substance, or in the disk of some appropriate receptacle.

5. Fungi. Mushrooms, destitute of herbage, bearing their fructification in a fleshy substance.

Such are the principles of the Linnæan Classes and Orders, which have the advantage of all other systems in facility, if not conformity to the arrangement of nature; the latter merit they do not claim. They are happily founded on two organs, not only essential to a plant, but both necessarily pre- 
sent at the same time; for though the Orders of the 14th and 15 th Classes are distinguished by the fiuit, they can be clearly ascertained even in the earliest state of the germen*.

Tournefort founded his Orders on the fruit ; and his countryman Adanson is charmed with the propriety of this measure, because the firuit comes after the flower, and thus precedence is given to the nobler part which distinguishes the primary divisions or Classes! But happily the laws of a drawing-room do not extend to philosophy, and we are allowed to prefer parts which we are sure to meet with at one and the same moment, without waiting a month or two, after we have made

* An instance apparently to the contrary occurs in the history of my Hastingia coccinea, Exot. Bot. $t$. so, a plant most evidently, both by character and natural affinity, belonging to the Didynamia Gymnospermia, but as I could no where find it described in that Order, I concluded it to be unpublished; and was not a little surprised to be told some time afterwards, that it was extant in the works of my friends Retzius and Willdenow, under Didynamia Angiospermia, by the name of Holmskioldiu, afier a meritorious botanist. This last name therefore, however unutterable, must remain; and I wish the Linnæan system, as well as myself, might be as free from blame in all other cases as in this.

$$
2 \text { D } 2
$$


out the Class of a plant, before we can settle its Order.

The Linnæan System, however, like all human inventions, has its imperfections and difficulties. If we meet in gardens with double or monstrous flowers, whose essential organs of fructification are deformed, multiplied, or changed to petals; or if we find a solitary barren or fertile blossom only; we must be at a loss, and in such cases conld only guess at a new plant from its natural resemblince to some known one. But the principal imperfection of the System in question consists, not merely in what arises from variations in number or structure among the parts of a flower, against which no system could praride, but in the differences which sometimes occur bctween the number of Stamens, Styłes, \&c., in different plants of the same natural genus. Thus, some species of Cerastium have only 4 , others 5, Stamens, though the greater part have 10. Lychmis dioica has the Stamens on one plant, the Pistils on another, though the rest of the genus has them united in the same flower; and there are several similar instances; for number in the parts of fructifica- 
tion is no more invariable than other characters, and even more uncertain than such as are founded on insertion, or the connexion of one part with another. Against these inconveniences the author of this System hats provided an all-sufficient remedy. At the head of every Class and Order, atter the genera which properly belong to them, he enumerates, in italics, all the anomalous species of genera stationed in other places, that, by their own peculiar number of Stamens or Styles, should belong to the Class or Order in question, but which are thus easily found with their brethren by means of the index.

It is further to be observed that Linneus, ever aware of the importance of keeping the natural aflinities of plants in view, has in each of his artificial Orders, and sections of those Orders, arranged the genera according to those affinities; while at the head of each Class, in his Systema Vegretabilizm, he places the same genera according to their technical characters; thus combining, as far as art can keep pace with nature, the nerits of a natural and an artificial system. His editors have seldom been aware of this; and Mumay 
especially, in his 14th edition of the bool: just mentioned, has inserted new plants without any regard to this original plan of the work.

From the foregoing remarks it is easy to comprehend what is the real and highly important use of the Genera Plantarum of Jussieu arranged in Natural Orders, the most learned botanical work that has appeared since the Species Plantarum of Linnæus, and the most useful to those who study the philosophy of botanical arrangement. The aim of this excellent author is to bring the genera of plants together as much as poscible according to their natural affinities; constructing his Classes and Orders rather from an enlarged and general view of those affinities, than from technical characters previously assumed for each Class or Order ; except great and primary divisions, derived chiefly from the Cotyledons, the Petals, and the insertion of the Stamens. But his characters are so far from absolute, that at the end of almost every Order we find a number of genera merely related to it, and not properly belonging to it, and at the end of the 
system a very large assemblige of genera incapable of being referred to any Order whatever. Nor could a leaner possibly use this system as a dictionary, so as to find ont any unknown plant. 'The characters of the Orders are necessarily, in proportion as those Orders are natural, so widely and loosely constructed, that a student has no where to fix; and in proportion as they are here and there more defined, this, or any other system, becomes artificial, and liable to the more exceptions. The way therefore to use this raluable work, so as to ascertain an unknown plant, is, after turning to the Order or Genus to which we conceive it most probably allied, to read and study the characters and observations there brought together, as well as all to which they may allude. We shall find we learn more from the doubts and queries of Jussieu than from the assertions of most other writers. We shall readily perceive whether our plant be known to him or not; and if at the same time we refer it, by its artificial characters, to the Linnean System, we can bardly fail to ascertain, even under the most alifficult circumstances, whether it be de- 
scribed by either of these authors. A student may acquire a competent knowledge of natural orders, with very great pleasure to himself, by repeatedly turning over the work of Jussieu with any known plants in his hand, and contemplating their essential generic characters in the first place, and then what regards their habit and affinities; proceeding afterwards to combine in his own mind their several points of agreement, till he is competent to form an idea of those assemblages which constitute natural Classes and Orders. This will gradually extend his ideas; whereas a contrary mode would only contract them, and his Jussieu would prore merely an artificial guide, without the advartages of facility or perspicuity. 


\section{9}

\section{CHAPIER XXIV.}

ILLUSTRATIONS OF TIE LINNMAN CIASSES AND ORDERS.

I PROCEEI) to a compendious view of the Limnean Classes and Orders, which will serve to illustrate many things in the preceding pages.

\section{Class 1. Monandria. Stamen 1.}

This contains only two Orders.

1. Monogynia. Style 1. Here we find the beautiful exotic natural order called Scitaminece, consisting of Cardamoms, Ginger, Turmerick, \&c., hitherto a chaos, till Mr. Roscoe, in a paper printed in the 8 th rol. of the Linncean Society's Transactions, reduced them to very natural and distinct genera by the form of the filament. See Exot. Bot.t. 102, 103, 106-8. 
Salicornia, Eng\%. Bot.t. 415 and 1691, and Ifippuris, t. 763, are British examples of Monandria Monogynia.

Valeriana (Class 3) has some specics with one stamen.

2. Digmnia. Styles 2. Contains C'orispermum, Fl. Grac.t. 1, Blitum, Curt. Mag.t.276, and a few plants besides.

Class 2. Diandria. Stamens 2.- Orders 3. 1. Monogynia. This, the most natural and numerous Order, comprehends the elegant and fragrant Jasminee, the Jasmine, Lilac, Olive, \&c.-also T cronica, Engl. Bot. t. 2, 1027, 623, 783, \&c.-and a few labiate flowers with naked seeds, as Salvia, Engl. Bat.t. 153, 154, Rosemary, \&c., natural allies of the 14th class; but having only two stamens, they are necessarily ranged here in the artificial system.

2. Dignmia consists only of Anthoxanthum, a grass, Engl. Bot.t. 647, which for the reason just given is separated from its natural family in the third class.

S. Trigynia-has only Piper, the Pepper, a large tropical genus. 
CLass 3. Triandria. Stamens 3.-Orders S.

1. Monogynia. Faleriana, Engl. Bot.t.698, 1.591 and 1531, is placed here because most of its species have three stamens. See Class 1. Here also we find the swordleared plants, so amply illustrated in Curtis’s Maghazine, Iris, Gludiolus, Ixia, Sc., also Crocus, Engl. Bot.t. 343, 344, 491, and numerous grass-like plants, Schomus, Cyperus, Scirpus, see Fl. Groce.v. 1, and Engl. Bot, t. 950, 1309, 542, 873, \&c.

?. Digynia. This important Order consists of the true Grasses; see p. 127. Their habit is more easily perceired than defined; their value, as furnishing herbage for cattle, and grain for man, is sufticiently obvious. No poisonous plant is found among them, except the Lolium temulentum, Enggl. Bot. t.1124, said to be intoxicating and pernicious in bread. Their genera are not easily defined. Linneus, Jussieu, and most botanists pay regard to the number of florets in each spikelet, but in Arundo this is of no mo- 
ment. Magnificent and valuable works on this family have been published in Germany by the celebrated Schreber and by Dr. Host. The Fl. Greca also is rich in this department, to which the late Dr. Sibthorp paid great attention. Much is to be expected fiom scientific agriculturists ; but Nature so absolutely, in general, accommodates each grass to its own soil and station, that nothing is more difficult than to orercome their habits, insomuch that few grasses can be generally cultivated at pleasure.

3. Trigynia is chiefly composed of little pink-like plants, or Caryophyllea, as Holosteum, Fngl. Bot. t. 27.

Tillea muscosa, $t .116$, has the number proper to this order, but the rest of the genus bears every part of the fructification in fours. This in Linnean language is expressed by saying the flower of Tillca is quadrifidus*, four-cleft, and $T$. muscosa excludes, or lays aside, one fourth of the fructification.

* Sec Linn. Sp. Pl. 186, and Curt. Lond. fasc. 6.t. 31. 
Cinss 4. Tetrandria. Stamens 4.-Orders 3.

1. Monogynia. A very numerous and various Order, of which the Proteacece make a conspicuous part, consisting of Protea, Pankisia, Tambertiu, Embothium, Sic. See Botany of New Molland, t. 7-10. Scabiosa, Fingl. Bot. t.659; Plantago, Ł. 1558, 1559, remarkable for its capsula circumscissa, a membranous capsule, separating by a complete circular fissure into two parts, as in the next genus, Centunculus, t. 531; Rubia, t. 851, and others of its natural order, of whose stipulation we have spoken p.219, are found here, and the curious Epimedium, t. 138.

?. Drgynis. Buffonia, t. 1313.

Cuscutu, placed here by Linnæus, is best removed to the next class.

3. Teтragrisa. Ilex, t. 496, a gonus sometimos furnished with a few barren flowers, and therefore removed by Hudson to the $23 d$ class, of which it only serves to show the disadvantage; Potamogeton, t. 168,376 , and Ruppia, t. 136, are ex- 
amples of this Order. They all have sessile stigmas.

Cuass 5. Pentandria. Stamens 5. A very large class.-Orders 6 .

1. Monogyniu. One of the largest and most important Orders of the whole system. The genera are enumerated first artificially, according to the corolla being of one petal or more, or wanting; inferior or supcrior; with nalsed or covered seeds; but stand in the system according to their affinities, and compose some natural orders; as Asperifolice, rough-leaved plants, which have a monopetalous inferior corolla, and four naked seeds, with always more or less of spinous bristles or callous asperities on their foliage; see Borago, Engl. Bot. t.36, Lycopsis, t. 938, and Echium, t. 181. Next comes that most elegant tribe of spring plants denominated Precice by Linneus, Primula, t. 4-6, Cyclamen, t. 548, the charming alpine Aretia, and Androsace, Curt. Mag. t. 743. These are followed by another Linnæan order, nealy akin, called Rotacer, from the wheel-shaped corolla, Hottonia, Engl. Bot. t. 364, Lysi- 
machia, t.761.-Convolvulus and Cumpanula, two large well-known genera, come afterwards: then Jobelia, $t$. 140, Impaticns, t.937, and Violu, t.619, 620, brought hither from the abolished Linnxan order Syngenesia Monogamia. The Tauride follow, so called from their frequently dark, gloomy aspect, indicative of their narcotic and very dangerous qualities; as Datura, t. 1288, Hyoscyamus, t. 591, Atropa, t. 592, and Nicotiana, or Tobacco. In a subsequent part we meet with the Vine, Currant and Iry, and the Order finishes with some of the natural family of Contortce, so called from their oblique or twisted corolla, and which are many of them very fue plants, as Vinca, t. 514, 917. They often abound with milky juice, generally highly acrid; but Dr. Afzelius met with a shrub of this order at Sierra Leone, the milk of whose fruit was so sweet, as well as copious, as to be used instead of cream for tea. This is certainly what no one could have guessed from analogy. Gardenia is emoneously reckoned a contorta by Limnæus. 
2. Digynia begins with the remainder of the Contorta; then follow some incomplete flowers, as Chenopodium, t. 1033, Beta, $t .285$, and afterwards the fine alpine genus of Gentiana, $t$. 20, 493, 896, famous for its extreme bitterness and consequent stomachic, virtues.

The rest of the Order consists of the very natural Umbelliferous family, characterized by haring five superior petals, and a pair of naked seeds, suspended vertically when ripe from the summit of a slender hair-like receptacle. Of the inflorescence of this tribe, and the difficulties attending their generic distinctions, we have spolien p. 309. In Eryngium, t.718 and 57, the umbel is condensed into a capitulum, or conical scaly head, showing an approach towards the compound flowers, and accompanied, as Jussien observes, by the habit of a 'Thistle. Lagoecia is justly referred to this natural order by the same writer, though it has only a solitary seed and style.

The Umbellifere are mostly herbaceous; the qualities of such as grow on dry ground are aromatic, while the aquatic species are 


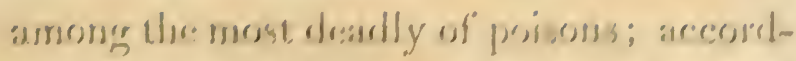

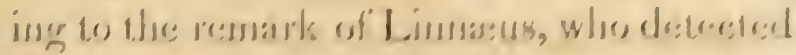

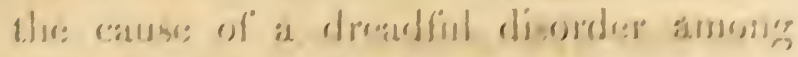

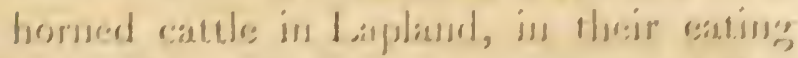

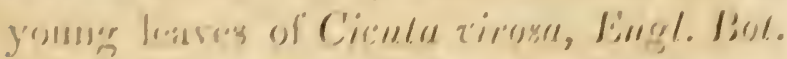
1. 4.79, umber wistcer.

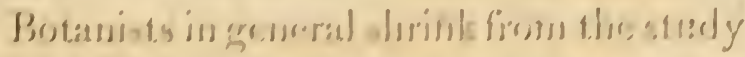

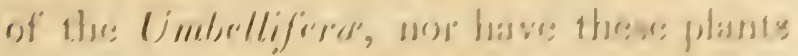

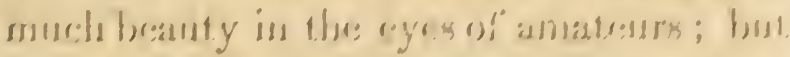

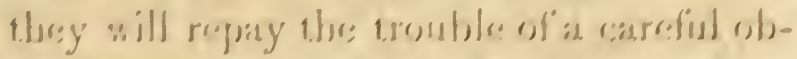
morvation. 'Thre latre M. Cis son of Monq-

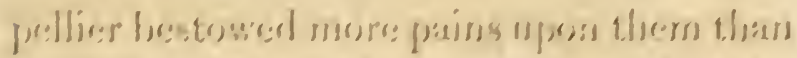

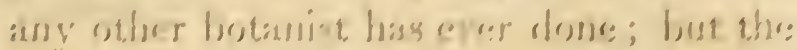

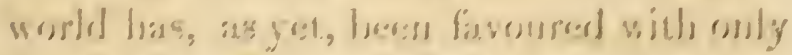

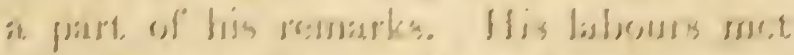

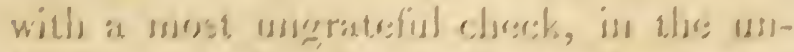

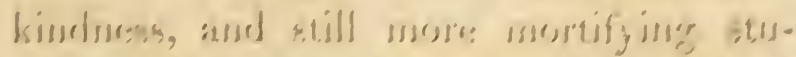

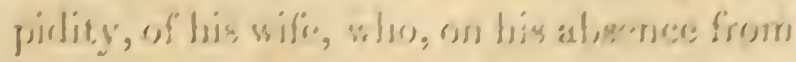

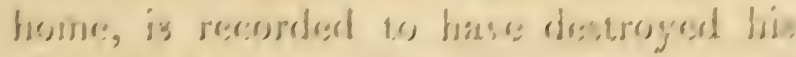
whole: feertarium, soraging off the dried

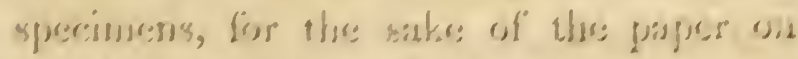
whicht they sose prasteral!

3. Trengune is illumtroted by thes Elder, tise

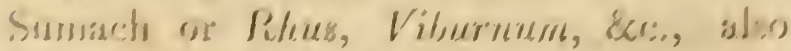

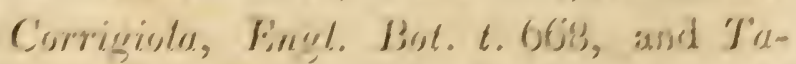
marie, t. 1318, of which last cose: specosos, germanica, bexs 10 stamens. 
4. Tetragynia has only Evolvulus, nearly allied to Convolvulus, and the elegant and curious Parnassia, $t$. 82.

5. Pentagynia contains Statice, t. 226, 102, and 328, a beautiful maritime genus, with a kind of everlasting calyx. The Flora Greca has many fine species. Linum or Flax follows; also the curious exotic Aldroranda, Dicks. Dr. Pl. 30; Drosera, Engl. Bot.t. 867-9; the numerous succulent genus Crassula; and the alpine Sibbaldia, t. 897 , of the natural order of Rosacece.

6. Polygynia. Myosurus, $t$. 435, a remarkable instance of few stamens (though they often exceed five) to a multitude of pistils.

Cuass 6. Herandria. Stamens 6. Orders 6. 1. Monogynia. This, as usual, is the most numerous. The Liliaceous family, with or without a spatha, called by Linnæus the nobles of the vegetable kingdom, constitute its most splendid ornament. The beautiful White Lily is commonly chosen by popular writers to exemplify the stamens and pistils. The less ostentatious geis us of Juncus or Rush, which soon follows, 
is more nearly allied to the Lilies than a young botanist would suppose. Near it stand several genera which have little affinity to each other, and of these Capura is a mistake, having beeir made out of a specimen of Daphlue indica, which chanced to have but six stamens.

2. Digymia has but few genera. The valuable Oryza, Rice, of which there now seems to be more than one species, is the most remarkible. It is a grass with six stamens.

S. Trigynia. See Rumex, Engl. Bot.t.1533, 127, \&c., some species of which have separated flowers; Tofieldia, t.536; and Colchicum, t. 135 and 1432.

4. Tetragynia. Petiveria alliacea, a plant the number of whose stamens is not very constant, and whose specific name is supposed to allude, not only to its ga:lic scent, but also to the caustic humour of the botanist whom it commemorates.

5. Hexagynia. An order in Schreber and Willdenow, contains Wendlandia populi- 
folia of the latter; with Damasonium of the former, a genus consisting of the Linnæan Stratiotes alismoides, Exot. Bot. t. 15.

6. Polyggnnit. Alisma only-Engl. Bot. 1. $83 \%, 775$, \&c.

Crass 7. Meptandria. Stamens 7: Orders 4. 1. Monogyniu. Trientalis, Engl. Bot.t.15, a farourite plant of Limnicus; and Aisculus, the Horse Chesnut. Several genera are remored to this order by late writers.

2. 1)igynia. Limeum, an African genus, only.

3. Ictragynia. Sanrums, a Virginian plant. Aponogeton, placed here by Linneus, is now properly removed to Dodecandria. It is an East Indian and Cape aquatic genus, bearing above the water white fragrant flowers in a peculiar spike, which is either solitary or clouble.

4. Heptagynia. Septas, a Cape plant, very nearly akin to Crassula, to which Thunberg refers it. If its character in Linnxus be constant with respect to number, it is very 
remarkable, having the calyx in 7 deep segments, 7 petals, 7 germens, and consequently 7 capsules.

Cunss 8. Octendria. Stamens 8. Orders 4.

1. Monogyniu. A rery varions and rich order, consisting of the well-known Troperolum or Nastutium, whose original Latin name, given from the flavour of the plant, like Garden Cresses, is now hecone its English one in every body's mouth. 'Whe elegant and finciful Linnan appllation, equiralent to a trophy plant, alludes to its use for decorating bowers, and the resemblance of its pelate leares to shields, as well as of its flowers to golden helmets, pierced through and through, and stained with blood. See Limn. Hort. Cliff. 143.Epilobium, Engl. Bot. t. 838, 795, Sc., with its allies, makes a beautiful part of this orcler; but abore all are conspicuous the favourite Inchsia, the chiefly American genus Vuccinium, t. 456, 319, Sc.; the immense and most elegant genus Erica, 60 abundant in southern Africa, but not known in America; and the fragrant 
Daphne, $t .1381$, of which last the Levant possesses many charming species.' Acer, the Maple, is removed hither in Fl. Brit. from the $23 \mathrm{~d}$ class.

2. Diginnia has a few plants, but little known; among them are Galenia africana, and Moehringia muscosa.

3. Trigynia. Polygonum, t. 436, 509, 941, is a genus whose species differ in the number of their stamens and styles, and yet none can be more natural. Here therefore the Linnæan system claims our indulgence. Puullinia and Cardiospermum are more constant.

4. Tetragynia. Here we find the curious Paris, t. 7, and Adoxa, t. 453. Of the forner I have lately received a new species, gathered by my liberal friend Buchanan among the mountains of Nepal.

Class 9. Enneandria. Stamens 9. Orders 3.

1. Monogynia. Of this the precious genus Ialurus, including the Cimnamon, Bay, Sassafras, Canphor, and many other noble plants, is an example. 
2. Trignmia has only Rheum, the Rhubarb, nearly related to Rumex.

3. Hexagynia. Butomus umbellatus, Engl. Bot.t. 6 $\mathrm{s} 1$, a great ornament to our rivers and pools.

Crass 10. Decamdria. Stamens 10. Orders 5.

1. Monogynia. A numerous and fine asscmblage, beginning with a tribe of flowers more or less correctly papilionaceous and leguminous, which differ very materially from the rest of that natural order in having ten stout, firm, separate stamens. See Cassia, Curt. Mag. t. 107, 633, and Sophora, t. 167 ; also Exot. Bot. t.2527, and Annals of Botany, v. 1. 501.

The Ruta, Rue, and its allies, now become very numerous, follow. See Tracts on Nat. Hist.287. Dictamnus, vulgarly called Fraxinella, is one of them. Dioncea Muscipula, see $p .174$, stands in this artificial order, as do the beautiful Kalmia, Rhododendron, Andromeda, Arbutus and Pyrola, Engl. Bot. t. 213, dic. 
2. Digynia. Saxifraga, remarkable for having the germen inferior, half inferior, and superior, in different species, a very rare example. Sce Engl. Bot. t. 167, 440, 663, 1009, 500, 501. Dianithus, the Pink or Carnation tribe, and some of its very distinct natural order, Caryoplyyllec, conclude the Decandria Disynia.

3. Trigynia. "The Caryopliyllece are here continued, as Cucubalus, t. 1577, Silene, t. 465, 1998, Arcnaria, t. 189, 512, very prolific and intricate genera in the Levant. Malpighia and Banistcria, beautiful plants of the Maple family, which next occur, have no affinity to the foregoing.

4. Pentagynia. Abounds in more Caryophyllece, as Lyclinis, t. 573, and Cerastium, t. 789, 790. Cotyledon, t. 325, Seclum, t. 1319, and Oxalis, t. 762, are placed here. Some of the last genus have the filaments united at their base, and therefore should belong to the 16th class,-another defect in the artificial system.

5. Decagynia. Consists of only Neurada, with Phytolacca; the latter an irregular 
genus as to stamens and styles, which therefore aftord good marks to discriminate the suecies.

Cu.sss 11. Dudecandria. Stamens 12 to 19. Orders 6 .

1. Monogynia. A rather numerous and rery various order, with scarcely any natural affinity between the genera. Some of them hare twelve, others fifteen or more stamens, which should be mentioned in their characters. Asarum, Engl. Pot.t. 1083, and the handsome Lythrum Salicaria, t. 1061, also the American Snow-drop-trec, Halesia, not rare in our gardens, may serve as examples of this order. Sterculia is very properly removed hither from Gynandria by Schreber and Willdenow, as its stamens are not inserted above the germen.

2. Digynia consists of Heliocarpus, a rery rare American tree with a singularly fringed or radiated fruit; and Agrimonia, Engl. Bot.t. 1335. The latter might as well have been placed in the next class, with which it agrees in natural order. 
5. Trigynia is chicfly occupied by Resedu, the Mignonette, t. 320, 321, and Euphorbia, t.256, 383, \&c., one of the most well defined and natural genera, of which the punicer, Ic. Pict. t. 3, is a splendid exotic species.

4. Tetragynia, in Schreber and Willdenow, consists of Calligonum, a genus illustrated by L'Heritier in the Transactions of Lim. Society, v. 1 ; and Aponogeton, already mentioned $p .420$.

5. Pentrgymia has Glinus, an insignificant genus; and Blackwellia, a doubtful one.

6. Dodecagynia is exemplified in Sempervivum, the Houseleek, Engl. Bot.t. 1320, whose styles vary from 12 to 18 or 20 . Sempervivum sediforme, Jacq. Hort. Vind. t. 81 , is a Scdum with a superabundance of parts in the fructification. Linnæus confounded it with $S$. rupestre.

Class 12. Icosandria. Stamens 20 or more, inserted into the Calyx. Orders 3.

1. Monogynia consists of fine trees, bearing for the most part stone fruits, as the Peach, 
Plum, Cherry, \&c., though the lcaves and other parts are bitter, acrid, and, as we have already mentioned, sometimes rery dangrerous, owing to a peculiar essential oil, known by its bitter-almond flavour. See specimens of this family in Engl. Bot. t. 1383, 706, 841, 84.2. The Myrtle tribe is another natural order, comprehended chicfly under Icosandria Monogynia, abounding in a fragrant and wholesome aromatic oil. These are plentiful in New Holland. Sec Tr. of Lim. Soc. v. 3.255, also Erot. Bot. t.42, 59, and 84. Caryophyllus aromaticus, the Clore, should on cvery account be removed hither.

2. Pentagynia. In this order it is most convenient to include such plants as have from two to five styles, and occasionally, from accidental luxuriance only, one or two more. An example of it is the rery natural family of the Pomacea, as Pyrus, the Apple, Pear, \&c. Engl. Bot.t.179, 350, 337 ; and Mespilus, t. 15\%3, Exot. Bot. t. 18, 85. In this family some species of the same genus have five, others three, two, or only one style, and a corrc- 
sponding number of sceds. Sprirea, nearly allied to it, stands here, most of its species having five styles, though some have a much greater number; see Engl. Bot. t. 284, 960. Mesembryinthemum, a vast and brilliant exotic genus, of a succulent habit, abounding in alkaline salt, and a few genera naturally allied to it, make up the rest of the order.

3. Polysymia. An entirely natural order of genuine hosaccous flowers, except possibly Calycanthus. Here we find Rosa, Lingl. Bot.t. 1S7, 990-2; Rubus, t. 826, 827. 716; Fragaria, t. 1524; Potentilla, t. 85, 89, 862; Tormentilla, t. 863, 864; Geum, t. 106; Dryas, t. 451; and Comarum, t. 172: all elegant plants, agreeing in the astringent qualities of their roots, bark and foliage, and in their generally eatable, always innocent, fruit. The regetable kingdom does not afford a more satisfactory example of a natural order, composed. of natural genera, than this; and Linnæus has well illustrated it in the Flora Lapponica. His genus Tormentilla, differing from Potentilla in number of petals and 
sergments of the calyx, though retained by Jussicu, may perhaps be scarerly distinct; yet there is a difference in their habit, which has induced me to leave it for further consideration. Haller united them both with Lragaria and Comarum, which the character and habit of the latter totally forbid, and Giertner his well suggested a mark fiom the smoothness of the seeds in Fragaria, (as well as (omarum,) to strengthen that of its pulpy receptarle. Whaterer difficulties may attend these genera, how admirably does the firuit serve us in Rosa, Rubus, Dryas and Geim, to discriminate those whose lares, flowers, and habit all stamp them as distinct! A student cammot do better than to study this order and these genera, as an introduction to the knowledge of more obscure ones; and the beatiful plants which compose it, mostly fimiliar to every body, are easily obtained.

Grass 1S. Polyandria. Stamens numerous, inserted into the Receptacle. Orders 7.

1. Monogynia. The genera of this order are 
artificially distributed according to the number of their petals, but not so arranged in the body of the system. They form a numerous and various assemblage of handsome plants, but many are of a suspected quality. Among them are the Poppy, the Caper-shrub, the Sanguinaria canadensis, Curt. Mag. t. 162, remarkable for its orange juice, like our Celandine, Engl. Bot. t. 1.581; also the beautiful genus Cistus with its copious but short-lived flowers, some of which (Engl. Bot.t.1321) have irritable stamens; the splendid aquatic tribe of Nymphrea, \&c., t. 159, 160. But the precious Nutmeg and the Tea are perhaps erroneously placed here by Linnaus, as well as the Clove; while on the other hand Cleome more properly belongs to this part of the system than to the 15th Class.

2. Digynia has principally the Paonia, t. 1513, variable in number of pistils, and Fothergilla alnifolia, an American shrub.

3. Trigynia. Delphinium the Larkspur, and Aconitum the Monk's hood, two variable 
and uncertain genera as to number of pistils.

4. Tetragynia. Tetracera ought, by its name, to have constantly four pittils, but the rest of this order are very doubtful. Caryocar, whose large rugged woddy nuts contain the most exquisite kenel ever brought to our tables, and which is the same plant with Gartner's and Scllreber's Rhirobolus, as the excellent Wildenow rightly judged, is not certain in number ; and still less the Cimicifuga; whilst Wallbomia is probably a Tetracera: see Willdenow.

5. Pentagynia contains chiefly Aquilegia the Columbine, and Nigella-both strictly allied to genera in the third order. Reaumuria indeed is here well placed. Some Nigelle have ten styles.

6. Hexagynia consists of Stratiotes, Engl. Bot.t. 379; and Brascuia, a new genus of Schreber's with which I am not acquainted.

I would recommend an union of the last five orders, for the same reason that 
influenced me in the preceding class. 'They now only serve to keep natural genera asunder, the species of which not only differ among themselves as to number of pistils, but each species is often-variable besides. The genera are so few that no inconvenience could arise on that account. I conceive such reforms, founded in experience not in theory, serve to strengthen the system, by greatly facilitating its application to practice.

7. Pulygynia. An order for the most part naural, comprehending some fine exotic trecs, as Dillenia, Frot. Bot.t.2, 3, .92 and 93 ; Liriodendron, the Tulip-tree; the noble Magnolia, $\mathcal{S}$ c.; a tribe concerning whose genera our periodical writers are falling into great mistakes. To these succced a family of plants, either herbaceous or climbing, of great elegance, but of acrid and dangerous qualities, as Anemone, in a single state the most lorely, in a double one the most splendid, ornament of our parterres in the spring; Atragene and Clematis, so graceful for bowers ; Thalic- 
trum, Adonis, Ranunculus, Trollius, Hetleborkes and Caltha, all conspicuons in our grardens or meadows, which, with a few less faniliar, close this class.

Nothing can be more injudicious than miting these two last classes, as some inexperienced authors have done. They are immutably distinct in nature and characters, whether we call the part which immediately bears the stamens in the Icosandria a calyx, with most botanists, or a receptacle, with Mr. Salisbury in the 8th vol. of the Linnean Socicty's Transactions, where, among inany things which I wish had been omitted, are sone good remarks concerning the distinction between calyx and corolla. This the writer in question considers as decided in cloubtful cases by the latter sometimes bearing the stamens, which the former, in his opinion, nerer really does.

Crass 14. Didynamia. Stamens 2 long and 2 short. Orders 2 , ench on the whole very natural.

1. Gymnospermia. Sceds naked, in the bot() $\mathrm{i}$ 
tom of the calys, 4, except in Phryme, which has a solitary seed.-Corolla monopetalous and irregular, a little inflated at the base, and holding honey, without any particular nectary. Stamens in 2 pairs, incurred, with the style between them, so that the impregnation rarely fails. The plants of this order are mostly aromatic, and rone, I beliere, poisonous. The calyx is either in 5 rearly equal segments, or 2lipped. Most of the genera afford excellent essential characters, taken frequently from the corolla, or from some other part. Thus, Perilla has 2 styles, of which it is an unique example in this class.

Mentha a corolla whose segments are nearly equal, and spreading stamens. Engl. Bot. t. 446-8.

Lacandula the Lavender, and Hestringia, Tracts on Natural History, 277, t. 3, have a corolla resupinata, reversed or laid on its back.

Teucrium a deeply disided upper lip, allowing the stamens and style to project between its lobes. Engl. Bot.t. 680.

Ajuga scarcely any upper lip at all, t. 77 and 439 . 
Iaminm has the mouth toothed on each side, t. 768.

Prmella, t. 961, has forked filaments; Cleonia 4 stigmas; Prusium a pulpy coat to its seeds. These instances will suffice as clear examples of natural genera, distinguished by an essential technical character, in a most nutural order.

2. Angiospermia. Seedis in a capsule, and generally very numerous. - The plants of this order have the greatest possible affinity with some families in Pentandria Monogynia. Some species even vary from one class to the other, as Bignonia radicans, Curt. Mag. t. 485, and Antirrlimum Linaria, Engl. Bot.t.658, 260, in which the irregular corolla becomes regular, and the 4 unequal stamens are changed to 5 equal ones; nor does this depend, as has been asserted, on the action of any extraneous pollen upon the stigmas of the parent plant, neither are the seeds always abortive. No method of arrangement, natural or artificial, could provide against such anomalies as these, and therefore imperfections must be expected in every system. 
Cuass 15. Tetradynamia. Stamens 4 long and 2 short. Orders 2 , perfectly natural. Flowers cruciform.

1. Siliculosa. Fruit a roundish pod, or pouch. In some gencra it is entire, as Draba, Engl. Bot. t.586, and the Honesty or Satin flower Lunaria: in others notched, as 'Thluspi, t. 1659, and Iberis, t. 52; which last genus is unique in its natural order in having unequal petals. Crambe, t. 924; Isatis, t.97; and Bunias, t. 231; eertainly belong to this Order, though. placed by Limieus in the next.

2. Siliquosil. Fruit a very long pod. Some genera have a calya clausus, its leares slightly coliering by their sides, as Raphanus, t. 856; Cheiranthus, t. 462: HIcsperis, t. 731; Brassica, t. 637, \&c. Others have a spreading or gaping calyx, as Cardamine, t.1000; Sisymbrium, t.855; and especially Sinapis, $t .969$ and $t .1677$.

Cleome is a very irregular genus, allied in habit, and even in the number of stamens of scveral species, to the Polyandria Monogynia. Its fruit, moreover, is a capsule of one cell, not the real two-celled 
pod of this Order. Most of its species are fatid and very poisonous, whereas scarcely any plants properly belonging to this Cliss are remarkably noxious, for I have greati doubts roncerning the disease called $R a$ 3) hamiu, attributed by Linnwus to the seerts of Raphamus Raphanistrum.

The Cruciform plants are vulgarly called antiscorbutic, and supposed to be of an alkalescent nature. Their essential oil, which is generally obtainable in very small quantities by distillation, smells like volatile alkali, and is of a very acrid quality. Hence the fortid scent of water in which cabbages, or other plants of this tribe, have been boiled.

Crass 16. Monadetphia. Stamens united by their firments into one tube. Orders 8, distinguished by the number of their stamens.

1. Triandria is exemplified by Sisyrinclizen, Ic. Pict.t.9, and Ferraria, Cust. X? t.144, 5ร2, both erroneonsly placed Linnaus in Gynandria. Also the sinmlin Cape plant Aphyieia, consisting of a lares 
flower and succulent fruit, springing immediately from the root, without stem or leaves. On this plant Linnaus published a dissertation in 1775. Tamarindus has lately been removed hither from the third Class, perhaps justly.

2. Pentandria. Eradium, Engl. Bot.t. 902, separated, with great propriety, from Ge. ranium by L'Heritier; Hermannia, a pretty Cape genus, Curt. Mag.t. 307 ; and a few other plants, more or less akin to the Mallow tribe, compose this Order; to which also strictly belong some species of Limum, Geranim, Sc. Passiftora, remored from Gynandria, belongs most unguestionably to Pentandria Irigynia, and by no means to this Class.

3. Heptandria consists only of Pelarnonium of L'Heritier, an excelleat genus, comprising most of the Cape Geraniums, and marked by its irregular Alower, 7 stamens, and tubular nectary.

4. Octandria contains Aitonia, Curt. Mag. $t .173$, named in honuur of the excellent and universally respected author of the 
Mortus Kezensis. Pistia is, I believe justly, placed here by Schreber and Willdenow.

5. Decandria. Geranium, proprely so called, Engrl. Bot.t.40t, 405, 279, Sic., is the principal genus here. 'The late Protessor Caranilles, howerer, in his Dissertationtes J3otanice, referred to this Order a vast number of genera, never before stispected to belong to it, as Bammisteria, Malpightia, Turreca, Melia, Se., on account of some fancied union of their filaments, perhaps through the medium of a tubular nectary ; which principle, is absolutely inadmissible ; for we might just as well refer to MLnadelphia every plant whose filaments are connected by insertion into a tubular corolla. Some species of Cralis, see p.424, belong to this Order; as do several papilionaccous genera, of which we shall speak under the next Class.

6. Endecandria contains only the splendid South-American genus Brownea, the mumber of whose stimens is different in different species.

7. Dodecandria, Stamens mostly 15, is com- 
posed of some fine plants allied to the Mallows, as Pterospermum, t. 620, Pentapetes, \&c.

8. Polyandria, a very numerous and magnificent Order, comprises, among ather things, the tiue Cohmmiferce or Malvacece, as Malva, Eingl. Bot.t.671, 754, Althaa, t.147, Hibiscus, Spicil. Bot.t. 8, Gossypiun, the Cotton-tree, Alcea the Hollyhock, \&c. Stately and beautiful plants of this Order, though not Malvacea, are Carolinea, whose angular seeds are sold in our shops by the name of Brasil nuts; Gustavia, named after the late King of Sweden, a great patron of botany and of Linnæus; Camellia, Curt. Mag. t. 42, whose splendid varieties have of late become favourites with collectors; Stucirtia, Exot. Bot.t. 110; and Barringtonia, the original Commersonia, Sonnerat Voy. d la Nouv. Guinée, t. 8, 9.

Class 17. Diadelphia. Stamens united by their filaments into 2 parcels, both sometimes cohering at the base. Orders 4, distinguished by the number of their Sta- 
mens. - Flowers almost universally papjlionaceous.

1. Pentandria. The only grenus in this $\mathrm{Or}$ der is Momieria, Lemurele, $t$. 5) 56 , a rare litule South American plant, whose nitural order is uncertain. It las a ringent corolla, termate leaves, a simple bristly pubescence, and is besprinklert with resinous dots.

2. Ilexandria. Saraca, in this Order, is as little known as the Momieria, excent that it undoubtedly belongs to the leguminous family. It seems most allied to Brvwner, Jonesia, dfaclia, \&c. Fumaria, the only genus besides, is remarkable tor the great variety of forms in its seed-ressel, whence botanists who make genera from technical chamcters, without regard to natural pinciples, have injudiciously subciridad it. Sec Engl. Bot. t. 588-590, 943, $14 \div 1$.

3. Octandria. Polygala, t. 76, is the principal gerus here. America and the Cape of Good Hope abound in beantifil species of it, and New Holland afforts some new. genera, long confounded with this. Dil- 
bergiu is perhaps as well placed in the next Order.

4. Decandria is by far the most numerous, as well as natural, Order of this Class, consequently the genera are difficult to characterize. They compose the family of proper Papilionacee or Leguminosa, the Pea, Vetch, Broom, \&c. Their stamens are most usually 9 in one set, with a single one separate.

The genera are arranged in sections variously characterized.

* Stamens all united, that is, all in one set. The plants of this section are really not diadelphous but monadclphous. Sce Spartium, Engl. Bot. t. 1399. Some of them, as Lum pinus, and Ulex, t. 742, 743, have indeed the tenth stamen evidently distinguished from the rest, though incorporated with them by its lower part. Others have a longitudinal slit in the upper side of the tube, or the latter easily separates there, as Ononis, $t$. 682, without any indication of a separate stamen. Here therefore the Linuxan System swerves from its strict artificial laws, in compliance 
with the decivive natural clearacter which marks the plants in question. IVe easily perceive that, character, and have only to ascertain whether any papilionaceons plant we may have to examine has 10 stimens, all alike scparate and clistinct, in which case it belongs to the 10th Class, or whether they are in any way combined, which refers it to the 17 th.

* Stigna downy, without the character of the preceding section, for this and all the following are truly diadelphous. Very nice, but accurate, marks distinguish the grenera, which are suficiently natural. The style and stigma afford the discriminative characteristics of Orobus, t. 1153 ; Pisum, t. 1016; Lathyms, t. 670, 1108 ; Vicia, t. 334, 481183; and no less decisively in Errum, t.970, 1223, which last genus, notwithstanding the remark in Jussieu 360, "stigma non barbatum," (taken probably from no genuine sper cies,) most evidently bclongs to this section, as was first remarked in the Flora Britumica; and it is clearly distinguished from all the other genera of the section by the capitate stigma hairy all over; nor is any genis in the whole Class more naturd, when the hiw 
therto mistaken species are removed to their proper places. Sec Fl. Brit.

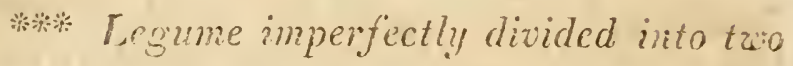
aln, always, as in all the following, withous the chardeter of the preceding sections. This is composed of the singular Biserrula, known hy its doubly serrated finit, of which there is on! one specios; the I'leaca, Jacq. Ic. Rar.t. 151 ; and the rast genus of Astragalus, Engl. Bot.t. 274, \&c., lately illustrated in a splendid work by an able French botanist, Decandolle.

米洛紫 Legume with scarcely more thun one seed. Of this Psoralea, Curt. Magु.t. 66.5; the curious Stylosanthes of Swartz; the Hallia of Thunberg; and our own Trifolium, Engl. Bot. t. 1770, 1048-1050, are examples. The last genus, one of the most natural as to halit and qualities, is extremely untractable with respect to botanical characters. Some species, t. 1047, 1340, 1769, have many seeds in each pod; some hare not even the capniate inflorescence made a part of the generic definition. The diffeulty is lessened by cstablishing Mélilotus as a genus, with Jus- 
sien: but the whole requires to be will reconsidered : for, if possible, so rreat a laxity of detinition, with such glaring exceptions, should not disgrace any system.

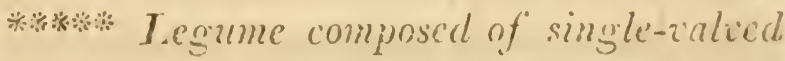
joints, which are rarely solitary. Hedysurum, t. 96, is the most important genus of this section, and is known by its obtuse $\mathrm{Ol}^{*}$ rectangular licel. Ilippocrepis, t. 31; Omithopus, t. 569 ; and Scorpiurus, known in gardens by the name of Caterpillar, from its worm-like pod, are further examples. Smithin, Ait. Hort. Kea. t. 13, is renarkable for having the joints of the legume connected by means of the style, as by a thread; the statmens in 2 equal divisions, with 3 anthers to each: and a two-lipped calyx. Hedys:anns respertilionis, Jacq. Ic. Rar.t. 568 , in some points approaches this genus, and wore certain species are possibly latent among the numerous unsettled papilionaceous plants of India.

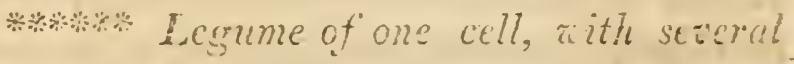
secels. To this belong the genus Melilutus.

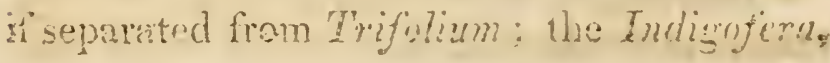


several species of which are so valuable for dyeing blue; the handsome Robiniu, Curt. Mag..t. 311 ; Cytisus, t. 176, Sc.; and Clitoria ${ }^{*}$, Ins. of Georgia, t. 18: also Latus, Engl. Bot. t. 925, and Medicago, t. 1616; which last is justly transferred by Willdenow from the foregoing section to this.

Papilionaceous plants are rarely noxious to the larger tribes of animals, though some species of Galega intoxicate fish. The seeds of Cytisus Laburnum have of late been found violently emetic, and those of Lathyrus sativus have been supposed at Florence to soften the bones, and cause death; we know of no other similar instances in this Class, which is one of the most abundant in valuable esculent plants. The negroes have a notion that the beantiful little scarlet and black seeds of Abrus precatorius, so frequently used for necklaces, are extremely poisonous, insomuch that half of one is sufficient to kill a man. This is totally incredible. Limaus howerer asserts rather too absolutely, that "among all the leguminous or papilionaceous tribe there is no deleterious plant to be found."

* From $x \lambda \varepsilon i \omega$, to close or shut up, ir allusion to the - situation of the wings and keel. 
Cuass 18. Polyadelphia. Stamens united by their filamenty into more than 2 parcels. Orders 3, distinguished by the number or insertion of their stamens, which last particular Linnaus here overlooked.

No part of the Limnean system has been less accurately defined or understood than the Orders of the 18th Class. Willdenow, aware of this, has made some improvements, but they appear to me not sufficient, and I venture to propose the following arrangement.

1. Dodecandria. Stamens, or rather Anthers, from 12 to 20, or 25 , their filaments unconnected with the calyx. Of this the first example that presents itself is Theobroma, the Chocolate tree, Merian. Surin. t.26, 63, Lamarck Encycl. t. 635. The flowers have not been seen fresh in Europe, and we only know them from drawings made in the West Indies, one of which, preserved in the Linnaan herbarium, is my authority for the following descriptions. The filaments are inserted between the long tapering segments of a s-cleft nectary, on its 
outside, and each bears at its sunmit 4 scssile, obtuse, spreading anthers. Aublet's figure of this genus, which Schreber and Willdenow seem to have followed, represents but 2. The fruit is perhaps most properly a berry with a hard coit, whose seeds, when roasted, make chocolate. Bubroma of Schreber, Guazuna Lamarcli, t. 637 , confomded by Linneus with the preceding genus, has similar flaments, but each bears 5 anthers; Jussieu and Cavanilles say 3 . The fruit is a woody capsule, with 10 rows of perforations. Abroma, Jacq. Hort. Vind.v.3.t.1. Miller Illustr. t. 63 , has 5 parcels of anthers, nearly sessile on the outside of the nectary, between its obtuse, reflexed, notched lobes. It is difficult to say how many anthers compose each parcel, for the different accounts on record are totally irreconcileable. We have found 3 ; the drawing sent to Linnæus represents 6 ; and Miller has a much greater number. Perhaps they may vary. In this uncertainty the genus in question is best placed with its natural allies in this order, with a reference to it in italics at the end of Polyadelphia Polyan- 
dria. Its fruit is a membranous winged capsule, opening at the top. Monsonia, Curt. Magg. t. 73, Lamaicli, t. 638, removed by Schreber and Willdenow to Monadelphia, rather, I think, belongs to this class where Limneus placed it. The 5 filiments, bearing each 9 long-stalked anthers, are merely inserted into a short membranous cup, or nectary, for so the analogy of the 3 preceding genera induces us to cali it; and if we refer Mronsonia to Monadelphia, we fall into the error of $\mathrm{Ca}$ ranilles mentioned p. 4:39. Lastly, Citrus, the Orange, Lemon, \&c., Lamarck, t. 639, most unquestionably belongs to this $\mathrm{O}$. der. Its stamens are about 19 or 20 , combined variously. and unequally in several distinct parcels; but those parcels are inserted into a proper receptacle, by no means into the calyx, as the character of the Class Icosandria indispensably requires. Eren the number of the anthers of Citrus accords better with most plants in Dodecandria than in Icosandria, notwithstanding the title of the latter.

2. Icosandria. Stamens numerous, their 
fllaments inserted (in several parcels) into the calyx.-To this Order Professor Willdenow properly refers Melaleuca, Exot. Bot. t. 34-36, 55, 56, which had previously stood in Polyandria, botanists having only considered number and not insertion in the Orders of Polyadelphia, whence a double mistake has arisen, concerning Citrus on the one hand, and Melaleuca on the other.

3. Polyandria. Stamens very numerous, unconnected with the calyx. This Order consists of several genera. The most remarkable is Hypericum, Engl. Bot. t. 109, 1225-1227, \&c., whose stamensare united into 3 or 5 parcels, corresponding with the number of its styles. Munchhausia is a Lagerstromia, nor does it appear to be polyadelphous at all. Linneus seems to have intended bringing Thea into this Oider.

Crass 19. Symgenesia. Anthers united into a tube. Flowers compound. Orders 5.

This being truly a natural Class, its Orders are most of them equally so, though 
some are liable to exceptions, as will presently be explained.

1. Polygamia cequalis. In this each floret, taken separately, is perfect or united, being furnished with its own perfect stanens and pistil, and capuble of bringing its seed to maturity without the assistance of any other floret. The Order consists of 3 sections.

* Florets all ligulate, or strap-shaped, called by Tournefort semiflosculons. These flowers are generally yellow, sometimes blue, very rarely reddish. They expand in a morning, and close towards noon or in cloudy weather. Their herbage is commonly milky and bitter. Leontodon, Engl. Bot. t. 510; Tragopogon, t. 434, 638; Hicracium, t. 349, \&c.; and Cichorium, t. 539, exemplify this very natural section.

** Flowers globose, generally uniform and regular, their florets all tubular, 5-cleft, and spreading. Carduns, t. 107, 675, 973976; Onopordum, t. 977; and Arctium, t. 1228, well exemplify this. Carlina, t. 1144, 
does not so exactly agree with the abore definition, having a flat disk; but its affinity to the other genera is indubitable. Its flattened disk and radiating coloured calyx seem contrived to imitate the radiated flowers of the following Order.

***** Flower's discoid, their florets all tubuiar, regular, crowded and parallel, forming a surface nearly flut, or exactly conical. Their colour is most generally yellow, in some cases pink. Santolina, t. 141; and Bidens, $t .1113,1114$, are genuine examples of this section: Eupatorium, $t$. 428, and the exotic Stcehelina, Dicks. Dr. Pl. 1S, approach to the preceding one. There is however the most absolute difference between these two sections, collectively, and the first; while, on the other hand, they have considerable affinity with some of the following Orders, as will be hereafter explained.

2. Polygamia superfua. Florets of the disk perfect or united; those of the margin furnished with pistils only; but all producing perfect seed. 
* Discoid, the florets of the margin being obsolete or inconspicuous, from the smallness or peculiar form of the corolla; as Artemisia, Engl. Bot. t. 338, 978, 1230 ; Tanacetum, t. 1.29); Comysa,t.1195 ; and Guaphalium, t. 267, 1157. In the last the marginal florets are mostly 5 -cleft and tubular like the rest, only wanting stamens. Caution is requisite to detect the difference between this section and the preceding Order.

* Ligulate, 2-lipped, of which Perdicium, a rare exotic genus, is the only instance.

* Radiant, the marginal florets ligulate, forming spreading conspicuous rays; as Bellis the Daisy, t. 424; Aster, t. 87, a very numerous genus in America; Chrysanthemum, t. 6()1, 540; Inula, t. 1546, \&c. This section seems, at first sight, a combination of the first and third sections of the former Order, but this is chiefly in the form of its corollas. It is rather an approach of that third section towards what is equiralent to becoming double in other tribes. Accordingly, the Chamomile, Authemis nobilis, t. 980 ; Chrysanthemum Leucanthemum, t. 601; and 
some others, occasionally have their whole disk changed to ligulate white florets, destitute of stamens, and consequen!ly abortive. Such are actually called double flowers in this Class, and very properly. Many exotic species so circumstanced are met with in gardens. A few very strange anomalies occur in this section, as already mentioned, p. 306, one Sigesbeckia having but 3 stamens, instead of 5 , the otherwise universal number in the Class; and Tussilago hybrida, t. 430, as well as paradora of Retzius, having distinct anthers. Nature therefore, even in this most natural Class, is not quite without exceptions.

3. Polygamia frustranea. Florets of the disk, as in the preceding, perfect or united; those of the margin neuter, or destitute of pistils as well as of stamens; only some few genera liaving the rudiments of pistils in their racliant florets.

This Order is, still more evidently than the last, analogous to double flowers of other Classes. Accordingly, Coreopsis is the very same genus as Bidens, only furnished with unproductive radiant florets. C. bidens of Linnæus is the same species 
as his $P$. cermua; $C$. coronata is his $P$. firondosa; and C'. lencantha, B. pilosa. Some species of Coreopsis indeed have never been found without rays. Linnæus expresses his difficulties on this subject in Phil. Bot. sect.209, but seens inclined to mnite the two genera. A similar ambignity occurs between Gorleria and Atractylis, Relhania (of the last Order) and Athanasia, and in some degree beEween Centanrea, Engyl. Bot.t. 273, 1678, 56 , Sc., and Carduus, or Serralula; only the scales of the calyx of Contaurea grenerally keep that genus distinct.

I should be much inclined to abolish this Order. Those of its genera which have rudiments of pistils in their radiant florets, as Rudbechia and IIelianthus, would very commodiously range with their near relations in Polygamia superfurn, nor are we sure that such radiant florets are in all circumstances abortire, neither can a student often know whether they are so or not. It does not follow, from what has just been observer, that the presence of radiant florets, whether abortive or not 
can never afford a generic character, prorided there be no corresponding genus without them. This must be determined by exprience and observation. They are indeed to be considered as a very secondary mark, the most essential in this Clasí being derived from the receptacle, crown of the seed, and calyx. These Grertner has illustrated with the greatest accuracy and skill, but even these must not be blindly followed to the destruction of natural genera.

4. Polygamia necessaria. Florets of the disk furnished with stamens only, those of the margin, or radius, only with pistils; so that both are necessary to each other. This is well seen in the common Garden Marigold, Calendula, in whose calyx, when ripening seed, the naked and barren disk. is conspicuous. Othonna, Curt. Mag. t.306, 768, Arctotis, Osteospermum and Silphium, not rare in gardens, are further examples of this Order, which I believe is constant and founded in nature. We have no British specimens either of it or the following. Filago, at least as far as our 
Flora is concerned, belongs to Gnaphatium. See Engl. Bot. t. 9\$6, 1193, Si.

5. Polygrmia segregata. Several flowers, either simple or compound, but with united tubular anthers, and with a partial calyx, all included in one general calyx. Of these the Globe-thistle, Echinops, and Stoebe, with Seriphium and Corymbium, (which two last require to be remored hither from the abolished Linnxan Order Syngenesin Mionogamia,) have only 1 foret in each partial calyx; Jungia has 3, Elephantopus 4 , others more. In every case the partial calyx is distinguished from the chaffy seedcrown observable in several genera of the other Orders, (though the latter is indeed analogous to a calyx.) either by being inferior, or by the presence of a seed-crown, or feathery down, besides. See Lamarck, t. 713-723, where the plants in question are well represented.

CIAss 20. Gynandria. Stamens inserted either upon the style or germen. Orders 9 in Linnarus, but some alterations conceming them atre necessary. 
This is one of those Classes abolished by the celebrated Thunberg, and by several less intelligent witers who have followed him. The reasons which led to this measure appear to have been that Linnæus has erroneously placed in Gynandria several plants which have not the requisite character ; hence that character itself has been judged ambiguous, or not founded in nature, and the system has been supposed to be simplified by overlooking: it. This appears to me a great mistake. The character of the Class, taken as above, is as evident, constant and genuine as that of any other in the system. No doubt can arise, if we be careful to observe that the stamens actually grow out of the germen or style, and not merely out of 'any part that supports the germen; as will appear by examples.

1. Monandria. Stamen, or sessile Anther, 1 only. This contains all the beautiful and curious natural family of the Orchidea, or Orchis tribe, except only Cypripedium, which belongs to the next Order. I am induced to consider the bulk of this family as monandrous, upon a careful review of 
Professor. Swartz's representation of the subject, in his excellent treatise, just come to my hands in English. See Tracts relutive to Botuny translated from different Languages (by Mr. König), printed for Phillips and Fardon, 1805. I have already, p. 272, mentioned the glutinous nature of the pollen of these plants. This forms yellow elastic masses, oftrn stalked, in each cell of the anther, and the cells are either parallel and close together, or renored from each other to the opposite sides of the style: which serves to comnect them, just as the filament does in many Scitamineous plants, alike therefore decided to be monandrous. Such a decision rith regard to those also is justified by the ana logy of other species, whose cells being approximated or conjoined, properly constitute but one anther. The grand and absolute subdivision of the Orchidece is justly founded by Dr. Swartz, after Haller, on the structure of the anther, whether it be, as just described, parallel, like that of Orchis, Fingl. Bot. t. 2.2; Ophrigs, t. 65; and Diuris, Exot. Bol.t.9, \&c. ; or zer- 
tical, consisting of a moveable lid on the top of the style, like Dendrobium, $t .10-$ 12; or Mulaxis, Engl. Bot.t.72. Thic style of the Orchidece has been called a column, but I think that term now altogether superfuous. It is really a style, and the stigma is a moist shining space, generally concare, and situated, for the most part, in front of the style beneath the anther. In Orchis bifolia, $t .22$, and others, it is just above the orifice of the spur. Concerning the nectary of these plants there has been much diversity of opinion. The calcar, spur, in Orchis, and some other genera, is acknowledged to be such, and holds abundance of honey. This spur is judged by Swartz, as well as Linnæus, it decisive generic mark of distinction, and it commonly is so; but some Indian species brought by Dr. Buchanan prove it not to be absolute. The remarkable and often highly ornamented lip, considered by Swartz as the only corolla, for he takes all the other leaves of the flower for a calyr, has, by Linneus and others, been thought, either a part of the nectary, or, where no 
spur is present, the only nectary. Nor is this opinion so ill-founded as many botanists suppose; for the front of the lip cridently secretes honey in Oplurys (or Epipactis) ocuta, t. 1548, and probably in others not yet attended to. Nerertheless, this lip might, like the petals of lilies, be deemed a nectariferous corolla, were it certain that all the other leares were truly a calyx. But the 2 inner are so remarkably different from the 3 outer ones in Ophrys, t. 64, 65, 71, 383, and above all, in Stclis, Exot. Bot. t. 75, that I am most inclined to take the former for the corolla, the latter being, according to all appearance, a calyx. An insensible gradation from one to the other, of which we have pointed out other instances in treating of this subject already, occurs in Diuris, t. 8, 9; while in some Orchidece the leaves all partake more of the habit of a calyx, and in others of a corolla. Eren the lip in Thelymitra, t. 29, assumes the exact form, colour, and texture, of the rest of the flower; which proves that a dissimilarity between any of these parts is not always to 
be expected in the family under consideration. I'alal appears by the preface to his Enumeratio Plantam to have removed the Scitaminece to Gynandria, because the stamen of Cumua ariheres to the style. This, if constant, could only concern that genus, for the rest of the Order are in no sense gynandrous.

2. Diandria. To this Order Cypripedium, Engl. Bol.t. 1, must be referred, having a pair of very distinct double-celled anthers. See Tr. of Linn. Soc. v. 1.t.2, 3. Here we find Forstera, so well illustrated by Professor Swartz in Sims and König's Annals of Botany, v. 1.291, t.6; of which genus Phyllachne, $t .5$ of the same volume, is justly there reckoned a species. Of the same natural order with Forstera is Stylidium, but that having, I think, 4 anthers, belongs to the fourth Order of the present Class. Gumnera, placed by Linnæus in Gynandria Diandria, is not yet sufficiently well understood.

3. Triandria. Salacia, if Linnæus's descrip- 
tion be right, is properly placed here; but Jussieu doubts it, nor does my dried specimen serve to remove the uncertainty. Stilugo proves to be merely the barren plant of Antidesma alexiteria, and belongs to Dioecia; as Sisyrinchium and Ferraria do to Monadelphia, the tubular united stamens of the two last having been mistaken for a solid style. Rhopizm of Schreber (Meborea of Aublet, t. 323,) seems therefore the only certain genus of the Order under consideration; unless Lamarck be right in referring to it Jacquin's Strumpfice, upon which I have not materials to form any opinion. The original discoverer attributes to this plant 5 stamens with united anthers; hence it found a place in the Syngenesia Monogamia of Linnicus. Lamarck merits attention, as he appears to have had an authentic specimen. See his t. 731 .

4. Tetrandria. Nepenthes, of whose extraordinary lind of leaf mention is made $p .197$, is the only genus of this Order in Linnæus, but very erroneously placed here. 
for it belongs to Dioecia Monadelphia. The Order however must be retained for the sake of Stylidium, a New Holland genus, related, as above mentioned, to Forstera. This is my Ventenatia, Exot. Bot.t. 66, 67; but another genus liaving previously, without my lnowledge, receired the latter denomination, that of Stylidium, under which I had, some time ago, communicated this genus to the French botanists*, and which they have adopted, becomes established. Sec La Billardiere's excellent work on New Holland plants, where several species of it are figured.

5. Pentandria. The original genera of this Order, Ayenia, Glutu, and Passifiora, Exot. Bot. t. 28, most unquestionably have nothing to do with it, their stamens being inserted below the germen, merely on a

* I was not aware of Loureiro's Stylidium, a plant, according to his description, of the ith Class; Fl. Cochinch.v. 1.221; but this can scarcely interfere with ours, being probably, as it grows about Canton, some well-known shrub that happened to have a 7 -cleft flower. It should seem to belong to the Rubiacece, notwithstanding sowe points in the description. 
columnar receptacle. The learned Schreber therefore removed them to the 5th Class.

But this Order may receire a reinforcement from the Linnean Pentandria Digynia. Several of the Contorte have long been thought to belong to Gynandria; see Pergularia, Ic. Pict. t. 16, and Andr. Repos.t. 184. In this genus, as well as Cynanchum and Asclepias, the pollen is borne in 5 pair of glutinous masses, exactly like the pollen of Orchidece, by 5 glands upon the stigma. Some obscurity arises from each mass of pollen being received into a bag or cell, formed by a peculiar valvular apparatus that encircles the organs of impregnation, and bears a great resemblance to stamens. The pollen however is, in the above genera, not attached to these cells or ralves, but to the 5 glands, each of which is double, and all of them seated on that thick abrupt angular body which acts as a stigma*. Nor is

* Mr. R. Brown believes the cells secrete the pollen, and project it on the stigma, as the pollen of some Orchidece sticks to any part of the plant. If so, these plants must remain in Pentandria. 
it worth while to dispute whether this whole body be a stigma or not, with regard to the question under consideration, for it is borne by the styles, above the germen, and itself bears the anthers. I humbly conceive, however, with Linnaus and Jacquin, that as part of it, at least, receives the pollen, stigma is full as good a name for this body as. Haller's term dolium, a tub! Still less is it worth while to controvert with Folreuter the propriety of the term pollen, - because the substance in question is not actually a dry powder, any more than in the Orchis tribe, or in Mirabilis, Exot. Bot.t.25. That term is technically used for the matter which renders the seeds fertile, including its relicle, whether the latter be capsular or glutinous, in short, whatever the appearance or texture of the whole may be. Another question remains, more immediately to our present purpose, whether these plants have 5 stamens or: 10? Jacquin, who has well illustrated several of them in his Miscell. Austr. r. 1.t. $1-4$, and Rottböll in a dissertation on the subject, contend for the latter. Rottböll wrote to 
Haller, that "finding Linnæus deaf to all that had been said, he sent him his treatise, to see whether he would persist in fulsifying nature." Thus sordid underlings foment the animosities and flatter the failings of their superiors! Linnæus judiciously suspended his opinion, and, after all, proves to be most correct. The analogies of the Orcliclece and Scitaminece very clearly decide that the 2 cells, or the double masses of naked pollen, can only be considered as one anther of 2 lobes. Even Periploca greca, though not gynandrous, confirms this. Each lobe of its anthers stands, as in many Scituminec, on the outermost edge of the filament; thus meeting that on the adjoining filament, and in appearance constituting with it a 2-lobed anther, as the lobe of the Scitaminece, where there is but one filament, meets its corresponding lobe by embracing the style.

6. Hexandria. Aristolochia, Engl. Bot. $t$. 398, a curious genus, of which there are many exotic species, is the only example

$$
2 \text { मा } 2
$$


of this, Pistia being removed to Moncdelphia Octandria.

7. Octandria. The Scopolia of Linnæus, which originally constituted this Order, proves to be a Daphne; see Plant. Ic. ex Herb. Linn. t. 34. Cytinus however, $\mathrm{Ca}$ san. Ic. t. 171, a singular parasitical plant on the roots of Cistus in the south of $\mathrm{Eu}$ rope, has properly been brought hither from the Order Dodecandria, of which it originally formed the only example. The observations of Dr. Sibthorp and Mr. Ferd. Bauer confirm those of other botanists, that the anthers are 8 , not 16 , and that they are truly inserted upon the style.

8. Decandria is now abolished. Of the two. genera which constituted it, Kleinhovia belongs to the Class Dodecandria, having 15 stamens, see Cavan. Monadelph.t.146; and Helictcres to Decandria Monogynia.

9. Dodecandria is likewise abolished.

10. Polyandria is in a similar predicament, for I am not aware of any genus that can 
be admitted into it. Xylopia goes with the greatest propriety to its natural allies in Polyundria Polygynia, Annona, \&c., its short stamens being inserted into the receptacle below the germen. Grewia, as well as Schreber's Microcos if a good genus, belong to Polyandria Monogynia, the organs of impregnation being merely elevated on a common stalk, like those of Passiflor and Ayenia. Ambrosinia, Arum, and Calla, are all justly removed by Schreber to Monoecia, though I think, for reasons hereafter given, they are more commodiously and naturally placed in the Order Polyandria of that Class, than in the Order Monandria. Dracontium and Pothos, of the same natural family, having perfect or united flowers, the former with 7 stamens to each, the latter with 4 , are undoubtedly to be referred to their corresponding Classes, Heptandria and Tetrandria. Zostera, the only remaining genus of Gynandria Polyandria in Linnæus, I have long ago rentured to remove to $\mathbf{M o -}$ mandria Monogynia; see Engl. Bot. t. 467 . 
Class 21. Monoecia. Stamens and Pistils in separate flowers, but both growing on the same individual plant. Orders 9 or 10.

Several reformers of the Linnæan system have also abolished this Class and the two following, by way of rendering that system more simple. Ten years' additional experience since the preface to the 7 th volume of English Botany was written, have but confirmed my opinion on this subject, If any plants ought to be removed from these Classes, they must be such as have the structure of all the accessory parts of the flower exactly alike, (the essential parts, or stamens and pistils only, differing,) in both barren and fertile flowers; and especially such as have in one flower perfect organs of one kind, accompanied by rudiments of the other kind, for these ruciments are liable occasionally to become perfect. By this means dioecious species of a genus, as in Lychinis, Valeriana, Rumex, \&c., would no longer be a reproach or inconvenience to the system. But, on the other hand, some difficulty would occasionally arise to a student, in 
deciding whether there wcre any real difference of structure between these accessory parts or not, and it might puzzle an adept to determine the question. For instance, whether the rectary in Sulix, different in the barren and fertile flowers of some species, should lead us to keep that genus in Dioecia, though in other specios the nectary is precisely alike in both the kinds, and occasionally an abortive germen occurs in the barren flowers, as stamens do, more rarely, in some fertile ones. Considering all this, I should refer Salix to Diandria Monogynia.

With respect to those Monoecious or Dioecious genera whose barren flowers are decidedly unlike the fertile ones, the former being in a catkin, the latter not, as Corylus, Quercus, \&c., I conceive tsothing more pernicious or troublesome can be attempted than to remove them to the Classes of united flowers. They meet with no allies there, but, on the contrary, form so natural an assemblinge by themselves, as to be unanimously kept separate by the authors of erery natural system that bas ap- 
peared. But even if this were not the case, there is a most important reason for keeping them as they are, which regards the artificial system more particularly, and of which its author was well aware; they are of all plants most uncertain in the number of their stamens. Now this uncertainty is of little moment, when we have them primarily distinguished and set apart from other plants by their Monoecious or Dioecious character; because the genera being few, and the Orders constructed widely as to number of Stamens, we find little difficulty in determining any genus, which would be by no means the case if we had them confounded with the mass of the system. Even the species of the same genus, as well as individuals of each species, differ among themselves. How unwise and unscientific then is it, to take as a primary mark of discrimination, what nature has evidently made of less consequence here than in any other case! It is somewhat like attempting a natural system, and founding its primary divisions on the artificial circumstance of number of stamens. 
I proceed to give some illustrations of the Orders in Monoecia.

1. Monandria. Zunnichellia, Mill. Illustr. t. 77, and Aegopricon, Plant. Ic. ex Herb. Lim. $t$. 12, are genuine examples of this Class and Order, having a different structure in the accessory parts of their barren and fertile flowers. Artocarpus, the celebrated Bread-fruit, may likewise be estecmed so on account of a partial caly $y$ in the baren flowers. The other amentaceous genera may most intcligibly perhaps be referred to the Ordér Polyandria. Chara is now removed to the first Class in the System; see Engl. Bot. i. 336.

2. Diandria. Anguria can remain here only till the proposed reformation takes place, having no difference of structure in its flowers. Lemna, so imperfectly known when Linnaus wrote, is now well understood, and, having fiequently united flowers, belongs to the second Class; see Engl. Bot. t. 926, 1095, 1233. 
3. Triandria. The great genus of C'arer, i. 1051, 928, 993-995, \&c., and some other grassy plants, are found here. Typha, t. $1455-1457$, is less clear in its structure; Sparganium, t. 744, 74.5, 273, is sufficiently so. Tragia, Hernandia and Phyllanthus are properly placed in this Class and Order.

4. Tetrandria. Littorella, t.468; the valuable genera Betula, t. 1508, and Buxus, t. 1341; also the Nettle Urtica, t. 1236; are good examples of this. Morus the Mulberry, of the same natural order as the Nettle, has scarcely any difference of structure in the accessory organs of the flowers. This tree however is remarkable for being often inclined to become even dioecious in its constitution, one individual bearing most fruit when accompanied by another whose barren flowers are more effective than its own. Empleurum, Erot. Bot. t. 63, is one of those ambiguous genera which are but imperfectly monoe. crious, 
5. Pentandria. Xanthium, Ambrosia, Nephelium, I'arthenium, Iva and Clibadium all partake, more or less accurately, of the nature of componnd flowers, but their anthers not being united, they could not be referred to the Class Syngenesia; particularly Xanthium and Nephelium, whose fertile flowers have no resemblance to that Class. Amaranthus, an extensire dunghill genus in warm countries, anlogous to our Chenopodium, follows next. Lcea is the same with Aquilicia, and belongs to Pentandria Monogynia, the former name being retained for the sake of the highly meritorious botanist and cultivator whom it commemorates. The Gourd tribe, Cucurbita, Cucumis, Bryonia, Engl. Bot. t. 439, might be brought hither from the abolished Order Syngenesia, unless it should be thought better to consider them as polyadelphous, to which I am most inclined,

6. Hexandria. Zizania, Tr. of Linn. Suc. v. 7. t. 13; and Pharus, Browne's Ja. maicn, $t, 38$, both grasses, compose this 
Order, to which Schreber has added Fpibaterium and Pometia of Forster, as well as the splendid Guettarda, Hort. Mal. v. 4. t. 48. The latter varies from 6 to 9 in the parts of the flower, and constitutes the Order Heptandria in Linnæus, according to his usual principle, of placing such irregular plants, as much as possible, in small Classes or Orders, that they might be the more easily found.

7. Polyandria. Stamens more than 7. Ceratophyllum, Engl. Bot. t. 947, 679; Myriophyllum, $t .83,218$; and the handsome Sagittaria, t. 84, stand here at present, but the accessory parts in their two kinds of flowers are alike. Begonia, Exot. Bot. $t .101$, has the number of its petals, though various in several species, always sufficiently different in the barren and fertile flowers to fix it here.-The most indubitable plants of this Order are amentaceous, Quercus, Engl. Bot. t. 1342; Fagus, t. 886; Corylus, t. 723 ; Carpinus, Juglans, Platanus, \&c.-Arum, t. 1298, Calla and Ambrosinia, all brought hither 
from the 20th Class, seem to me perfectly intelligible as simple monoecious flowers, the barren one, with many stamens, being superior or interior with respect to the fertile, like the generality of monoecious as well as all compound flowers, and not inferior, or, as in every simple one, exterior.

8. Monadelphia. The Fir, Pinus, so magnificently illustrated by Mr. Lambert, is very distinct in its two kinds of flowers. Each barren one consists of a naked tuft of monadelphous stamens, accompanied only by a few bracteas at the base. The fertile ones are catkins, with similar bracteas, each scale bearing on its upper side a pair of winged seeds, and on its under $a^{\circ}$ leaf-like style and acute stigma; as Jussicu first, rightly I believe, suggested, though some botanists have understood these parts otherwise. Acalypha, Croton, Jutroplia, Ricinus, and several others of the natural order of Euphorbice, acrid milky plants, form a conspicuous and legitimate part of Monoecia Monadelphiu. Omplualea is 
justly associated with them by Schreber, though placed by Linnæus in the Order Triandria, and this alteration is the more fortunate, as one of its species is diandrous. Sterculia is best removed to the 11 th Class, next to Kleinhoria.

9. Polyadelphia. If the system should be preserved in its present state, without regard to agreement or difference in the accessory parts of the barren and fertile flowers, I conceive this Order might be established for the reception of the Gourd tribe, as already linted under the 5th Order. Their filaments are united, in 3 sets, a character much more intelligible and constant than the casual and irregular connexion of their anthers, which led Linneus to reckon them syngenesious; for they only afford an additional proof that union of anthers is, in simple flowers, neither a good natural nor artificial guide. If the monoecious and dioecions Classes be reformed according to the plan to which I have so often adverted, these plants should go to the Class Polyadelphia. 
10. Gynundria is scarcely tonable, being paradoxical in its character, and the two Linnean genera which compose it, $A n$ drachne and Asyneia, seem most properly, even as the system stands at present, to belong to the 8th Order, to great part of which they are, moreover, naturally related.

Crass 22. Dioccia. Stamens and Pistits in separate flowers, situated on two sepurate plants. Orders 8.

The foregoing remarlis on the Orders of Monoccia apply also to those of this Class. I shall thereforc only briefly mention some genera properly illustrative of each Order, more particulaily specifying such as requirc to be pliced elsewhere.

1. Monandria. Brosimum of Swartz, and Ascarina of Forster, scem, by their descriptions, to be well placed here. Panciumus (Athrodactylis of Forster) is more doubtful, not having any partial calyx or corolla to divide the stamens into separate blossoms, so that the whole may be taken 
either for a polyandrous or a monadelphous flower, as well as for an assemblage of monandrous ones. Najas is a good and immutable example of this Order. Of Thunberg's Plielypea I have not materials to form a judgment.

2. Diandria. The wonderful Valisneria, already described $p .335$, is a decisive example of this. Cecropia also seems unexceptionable. Of Salix, see Engl. Bot. v. 20 and 21 , \&c., I have already spoken, p. 471. The scales of its barren and fertile catkins are alike; its nectaries various.

3. Triandria. Elegia and Restio, hard rushy plants chiefly of the Cape of Good Hope and New Holland, appear to be without any difference in the accessory parts of their flowers, which is certainly the case with Empetrum, Engl. Bot.t. 526, Ruscus, $t$. 560, brought hither from Dioecia Syngenesia, Osyris, Excacaria and Maba; Caturus only seeming differently constructed in this particular; but I have not been able to examine the three last. 
4. Tetrandria. Trophis, Batis, and Hippophae, $t$. 425, are good examples of this, though Mr. Viborg is recorded by Schreber to have occasionally found united flowers intermised with the barren ones in the last-mentioned genus. If this be usual, Hippophae must be removed to Polygamia Dioecia. The rest of the Order appear to have the accessory parts alike in both flower's, as Viscum, t. 1470.

5. Pentendria. Humulus, $t .427$, is almost the only certain instance here. Spinacia, Acnida and Cannabis would be unexceptionable, but they are less absolutely dicecious, being sometimes monoecious; sce p.331. The rest of the Order is at best doubtful; nor can the pretended amentum of the barren-flowered Pistacia entitle it to a permanent place in this Class, for its fructification is truly a panicle. Clutia, more properly Chuytia, may possibly remain here. It has no business in the Order Gynandria.

6. Hexandria. No difference of structure is 
discernible between the barren and fertile flowers of any genus in this Order; witness Tamus, $t .91$, though something to the contrary is mentioned in the Genera Plantarkm of Linnæus.

7. Polyandria. Under this Order I would certainly comprehend all dioecious plants that have from 8 to any greater number of stamens, according to the example set by Limaus himself in the last Class. The genera are exceedingly variable in this respect; and if all those the accessory parts of whose flowers are uniform were taken away, the remainder would be so few, that it is hard to say whether any would remain at all. Instances of the Order as it now stands are Populus, $t$. 1618, 1619; Hydrocharis, t. S08; Mercurialis, t. 559. The fertile flowers of the latter have, in some cases, a nectary or corolla of two slender leaves, not found in the barren ones, which

- may entitle it to a-permanent place here. Carica will also probably remain. Rhodivala can scarcely be kept distinct from Sedum. Coriaria and Ailanthus, having 
often united flowers, are best in the 10th Class, as finclea in the $11 \mathrm{hh}$. I find no grencrat truly icosandrous here, though Schreber esteems Flacourtia and IJedyrarya to be so.

S. Monalelphia. 'Turus, t. 746, and perhaps Juniperus, t. 1100, also the exotic Ephedru, are legitimate cxamples of this Order. Spurious ones are Nepenthes, Myristica the Nutmeg, and Schreber's Xanthe, all placed by him in the now abolisher Order Syngenesin, and which can only take shelter here while the Class remains as it is, for they have no difference of structure in the accessory parts of their flowers.

Cuass 23. Polygamia. Stamens and Pistils separate in some flowers, united in others, either on the same plant or on two or three distinct onces; such difference in the essential organs being moreorer accompanied with a diversity in the accessory parts of the flowers. Orders 3. 
1. Monoecia. United flowers accompanied with barren or fertile, or both, all on one plant. Atriplex, Engl. Bot. t. 261, 232, \&c., is an instance of this, having the barren flowers of 5 regular spreading segments, the united ones of 2 compressed valves, which, becoming greatly enlarged, protect the seed. In several species however the flowers are none of them united, each having only stamens or only pistils. Throughout the rest of the Order, as it stands in Linnæus and Schreber, I can find no genus that has the requisite character. Some of the grasses indeed have awns to one kind of flower only, but that part is too uncertain to establish a character upon; and this family is so natural in itself, and so liable to variations in the perfecting of its flowers or florets, that there can be no doubt of the propriety of classing its genera sinuply by the number of their stamens and styles, which are very constant.

2. Dioecia. The different flowers on two different plants. I can scarcely find a cer- 
tain instance of this, except Hippophae, already mentioned under Monoecia Tetrandria.

3. Trioecia. Of the only two genera which have ever been placed here, Ceratonia, Cavan. Ic. t. 113, belongs to Pentandria Monogynia. Ficus is so celebrated for the diversity of its flowers, as connected with the history of vegetable impregnation, see p. 336, that we are glad to take advantage of a trifling difference in the calyx of the two florets, (the barren one being most frequently three-cleft, the fertile five-cleft, ) to keep it here.

All things being considered, this Class may be thought scarcely worth retaining. Yet as we know two or three genera entitled to a place in it, upon principles which the analogy of the two preceding Classes shows to be sound, we cannot tell but others may exist in the unexplored parts of the globe. For this reason, and for the uniformity of the system, I would venture to preserve it. If the 21 st and $22 \mathrm{~d}$ Classes should hereafter be reformed by some judicious and experi- 
enced hand, according to the principle I - have suggested, of retaining in them such genera only as have a permancnt difference in the accessory as well as the essential parts of their flowers, their bulk being by such a reformation much diminisher, it might be adisable to reduce them to one Class, in which the slenter remains of Polyganuia might conmodiously be included, and the title of such a Class should be $\mathrm{Di}$ clinia, expressing the two distinct seats or stations of the organs of fructification.

Crass 24. Cryptogamia. Stamens and Pistils either not well ascertained, or not to be numbered with any certainty. Orders 5.

1. Filices. Ferns. The parts of their flowers are almost entirely unknown. The fructification, taken collectively, and proved to be such by the production of prolific seeds, grows either on the back, summit, or near the base of the frond. Some are called annulutio, annulated, their capsules being bound with an elastic transverse ring; others thecata, or more properiy exammulate, from the want of such an appendage, 
of which some of the latter have nevertheless a spurious restige. All the former, and some of the latter, are dorsiferous, bearing fruit on the back of the frond, and of these the fructification is cither naked, or else covered with a membramous inrolucrum. The genera are distinguished by Linnaus according to the shape and situation of the spots, or assemblages of capsules, besides which I have first found it necessary to take into consideration the absence or presence of the involucrum, and especially the direction in which it bursts. See Tracts relating to $N^{\prime}$ ut. Hist. $215, t .1$.

Polypodium, Engl. Bot. t. 1149, has no involucrum; Aspidium, $t$. 1458-1461, has a single, and Scolopendrium, t. 1150, a double one. Osmundı, 1.209, has been remarked by Professor Swartz to have a spurious ring. It is one of those ferns the lohes of whose frond are metamorphosed, as it were, into spikes of capsules. Botrychimm of Swartz, more distinctly spiked, and laving no restige of a ring, is separated by him from Osmunda. See one species of it in Engl. Bot. t. 318. Ophioglos- 
sum, t. 108, and Equisetum, t. 915, 929, are other examples of spiked ferns. Each seed of the latter is embraced by 4 filaments, judged by Hedwig. to be the stamens. Supposed ferns with radical fructifications are Pilularia, t. 521, and Isoetes, $t$. 1084; but the former might possibly be referred to Monoecia Polyandria, and the latter to Monoecia Monandria, as the system at present stands. Lycopodium, t. 224, 1148, \&c., is a fern, at least in my opinion, with axillary fructification.

2. Musci. Mosses. These are really herbs* with distinct leaves and frequently as distinct a stem. Their conical membranous corolla is called a calyptra, $f .15 \mathrm{~b} 1$, or veil, its summit being the stigna. This veil clothes the capsule, which, before the seed ripens, is elevated on a fruit-stalk. The capsule is of one cell and one valve, opening by a vertical lid, $f .213 \%$. Seeds very numerous and minute. The barren flowers of mosses

* Hedwig's term musci frondosi is incorrect.

+ This part in Phascum only does not separate from the capsule. 
consist of an indefinite number of nearly cylindrical, almost sessile anthers, f: 190 ; the fertile flowers of one, rarely more, perfect pistils, accompanied by several barren pistils, $f .192$. Both stamens and pistils are internixed with numerous succulent jointed threads, $f$. 191, which perhaps answer the purpose of a calyx or corolla, as far as protection is concerned. Some few species of moss have the stamens and pistils associated in the same flower, but they are generally separate. Hypmum, Fingl. Bot. t. 1424, 1425, has a scaly sheath, or perichatium, $f .150$, at the base of its truit-stalk, composed of leaves very different from the foliage of the plant. This is considered as a sort of calyx, see $p .251$, and as such is allowed to enter into the generic character; but there is some reason to esteem it rather of the nature of bracteas. The capsule of Splachnum, Engl. Bot. t. 144, \&c., stands on a peculiar fleshy base, called apopliysis, $f .189$ a.

Micheli in his Genera Plantarum, published in 1729, tab. 59, has well represented the parts above diescribed, though 
he mistook their use, being quite ignorant of the fecundation of plants. Dillenius took the one flower precisely for the other, and yet absurdly called capsula what he believed to be anthera. Linnæus, who had previously formed just ideas on the subject, as appears from his manuscript Tour to Lapland, too implicitly submitted his own judgment to that of Dillenius, and adopted his hypothesis, at the same time correcting, as he thought, his phraseology. Hence the whole glare of the blunder of Dillenius has fallen on Linnæus; for while we read in the Linnæan definitions of mosses every where the word anthera, and in those of Dillenius, usually accompanying them, capsula; few persons, who have lately been instructed by Heawig that the part in question is really a capsule, take the trouble to recollect that Dillenius so grossly misused that word. Various ideas have been started on this subject by Haller, Necker, and others, which could only claim attention while it remained in great obscurity. The excellent Hedwig has entirely the merit of an original discoverer in this 
branch of physiology. He examined all that had been clone before his time, detected the truth, ritised mosses from seed, f. 193390, and established their characters on the principles we have already explained.

The Limwan gentera of Mosses are chiefly founded on the sitution of the capsule, whether lateral or teminal, with some other circumstances. They are too few, and not strictly matural. Hedwig first brought into notice the structure of the fringe, peristominm, which in most mosses horders the orifice of the capsule. This is either simple, f. 189 b, or clonble, f. 219,214 , and consists either of separate tecth, or of a plaited and jagged nembrane. The external fringe is mostly of the former lind, the inner, when present, of the latter. The number of tecti, remarkibly consiant in each genus and species, is either $4,8,16,32$ or 61. On these therefore Hedwig and his followers have placed great dependence, only perhaps going into too great refurements relative to the internal fringe, wheh is more difficult to examine, and less cerfain, than the outer. Their great error 
has been laying down certain principles as absolute in forming genera, without observing whether all such genera were natural. Such mistakes are very excusable in persons not conversant with botany on a general scale, and whose minute and indefatigable attention to the detail of their subject, more than compensates the want of what is easily supplied by more experienced systematics. Thus Barbula of Hedwig is separated from Tortula, Engl, Bot. t. 1663, and Fissidens from Dicramum, $t .1272,1273$, on account of a difference of form or situation in the barren flowers, which is evidently of no moment, and merely divides genera that ought to be united. The same may be said of genera founded on the union of the stamens and pistils in one flower. On this subject I have, been more diffuse in a paper on Mnium, in Tr. of Linn. Soc. v. 7. 254, to which I beg leave to refer those who are desirous to study it further. Various and abundant specimens of this tribe of plants, showing the various structure of the fringe, lid and other parts, may be 
- seen in the latter volumes of English Botamy more especially.

Mosses are found in the hottest and coldest climates. They are extremely tenacious of life, and, after being long dried, easily recover their health and vigour by moisture. Their beantiful structure caunot be too much admired. Their species are numerous, and in some cases difficult to determine, particularly in the genera Tortula and Orthotrichum; nor is the generic character of the latter so easy or certain as most others. Schreber, Dickson, Swartz, Bridel, Weber, Mohr and Turner are great names in this department of Botany, besides those of whom we have already spoken.

3. Hepatica. Liverworts. Of these the herbage is commonly frondose, the fructification originating from what is at the same time both leaf and-stem. This character, however, proves less absolute than one founded on their capsules, which differ essentially from those of the preceding Order in having nothing like a lid or operculum. The 
corolla or veil of some of the genera is like that of Mosses, but usually bursts at the top. The barren flowers are unlike the organized stamens of the last-mentioned plants, being either undefined powdery heads, as in Jungermannia, see Hedwig's Theoria, t. 15, or of some peculiar conformation, as in Marchantia, Engl. Bot. $t .210$, where they are imbeded in a disk like the seeds of Lichens, in a manner so contrary to all aralogy, that botanists can scarcely agree which are the barren and which the fertile flovers of this genus. The four-valved capsule of Jungernannia, with the veil bursting at its summit to let the fruit-stalk pass, may be seen in Engl. Bot. t. 185, 186, which are both frondose species, like J. epiphylla, $t .771$, whose calyx as well as corolla are evident; and $t .60) j-$ 608, which have apparently distinct leares, lilie Mosses. Anthoceros, t. 1537, 1535, is a curious genus of the Hepatica. Linnæus comprehended this Order under the following one, to which it is, most - assuredly, far less akin than to the foregoing. 
4. Algce. Flags. In this Order the herbage is frondose, sometimes a mere crust, sometimes of a leathery or gelatimous texture. The seeds are imbedded, either in the frond itself, or in sonse peculiar receptacle. The barren flowers are but imperfectly known. Here we find that great natural Order, comprehended by Linnas under one genus by the name of Lichen, the fructificattion of which, for the most part, consists of a smooth round disk, $f$. 1) 8, flat, convex, or concave, with or without an adventitious border, in the substance of which disk the seeds are lodged. In some others they are placed in powdery warts, or in fibrous receptacles. The barren flowers are supposed to be powdery also, $f: 197$, very much like those of Jungermunnia. See Engl. Bot.t. 126, and various other parts of that work, where a great number of species are figured. The whole tribe has been much investigated, and attempted to be divided into natural genera founded on habit, by Dr. Hoffmann of Goettingen, whose figures are perfect in their kind. But a more complete scheme for reducing this family 
to systematic order has been recently made known to the world by Dr. Acharius, a learned Swede; who in his Prodromus, and Methodus Lichenum, has divided it into genera founded on the receptacle of the seeds alone. Hence those genera, though more technical, are less natural than Hoffmann's; but they will, most likely, prove the foundation of all that can in futwe be done on the subject, and the works of Acharius form a new xera in cryptogamic botany. It is only perhaps to be regretted that he has been somewhat too prodigal of new terms, which when not wanted are always a burthen to science, and rather obscure than illustrate it. Thus Hedwig used the term sporangiumi for a seed-ressel, pericarpium, in which the learner would seek in vain for any distinction, or new idea. A student might very justly complain if, in a science necessarily so overburthened with words, he were required to call the same part by a different name in every different family. I would gladly therefore retain the word frons in preference to the thallus of Acharius, re- 
ceptaculum for his apothecium, perlicellus for his bacillum or podetium, and seminu for his spore, because I see no improvement in the change. When this or any other writer strikes out new ideas, and discriminates parts hitherto mistaken or unknown, we thankfully receive from him new terms to express his discoveries. Thus the cyphella of Acharius is a peculiar sort of pit or pore on the under side of the frond in that section of Lichens called Sticta, see Engl. Bot.t. 1103, 1104; his lirelle are the black letter-like receptacles of the geuus Opegrapha, t. 1753-1756; his trice the analogous parts, resembling a coiled horse-hair, in Gyrophora, the Umbilicaria of Foffmann, $t$. 522. These terms are necessury and instructive, and are chosen with that accuracy and taste for which Dr. Acharius is conspicuous.

The aquatic or submersed Algce form a distinct and peculiar tribe. Some of these abound in fresh water, others in the sea, whence the latter are commonly denominated sea-weeds. The chief genera are Ulva, t. 419, 420, 1276, well defined by 
its seeds being dispersed under the cuticle throughout the membranous or gelatinous substance of the firond; Fucus, $t$. 10661069, \&c., whose sceds are collected together in tubercles or swellings, of various forms and sizes; and Conferra, of which the 24th and 2.5th volumes of Engl. Bot., more especially, show various specimens. This last genus is commonly known by its capillary, and, for the most part, jointed frond. The seeds of some species are lodged in external capsules or tubercles; of others in the joints of the frond; and hence the ingenious Dr. Roth has formed a genus of the former, called Ceramium. His Rivularia, Engl. Bot.t. 1797-1799, is perhaps more satisfactorily separated from Conferta, as we trust is Vaucheria, t.1765, 1766, a fresh-water genus named atter M. Vaucher of Geneva, who has published an elaborate and faithful microscopical work on Fresh-water Confervas. The submersed Alga in general are merely fixed by the roots, their nourishment being imbibed by their surface. Many of them float without being attached to any 
thing. The genus fucus has received more botanical attention than the rest of this tribe, and the works of Gimelin, Eoper, Stackhouse and Velley have aseertaned many species, which the labours of Dr. Goodenough, Mr. Woodward and Mr. Turner have reduced to systematic order. Still a more perfect combination of the skill of the painter and the botanist is to be desired, relative to the genus in question, and this is about to be supplied by the Historic Fucorum of the writer last montioned, and his firend Mr. W. J. Hookcr.

5. Fungi. Mushrooms. These cannot properly be said to have any herbage. Their substance is fleshy, generally of quick growth and short duration, differing in. firmness, from a watery pulp to a leathery or even woody texture. By some naturalists they have been thought of an animal nature, chiefly because of their foetid scent in decay, and because little white bodies like eggs are found in them at that period. But these are truly the eggs of flies, laid there by the parent in- 
sect, and destined to produce a brood of maggots, to feed on the decaying fungus, as on a dead carcase. Ellis's beautiful. discoveries, relative to corals and their inhabiting polypes, led to the strange analogical hypothesis that these insects formed the fungus, which Munchausen and others have asserted. Some have thought fungi were composed of the sap of corrupted wood, transmuted into a new sort of being, an idea as unphilosophical as the former, and unsupported by any semblance of truth.

Dryander, Schæffer and Hedwig have, on much better grounds, ạsserted their regetable nature, detected their seeds, and in many cases explained their parts of fructification. In fact, they propagate their species as regularly as any other organized beings, though, like others, subject to varieties. Their senuestered and obscure habitations, their short duration, their mutability of form and substance, render them indeed more difficult of inrestigation than common plants, but there is no reason to suppose them less perfect, 
or less accurately defined. Splendid and accurate works, illustrative of this Order, have been given to the world by Schatfer, Bulliard and Sowerby, which are the more useful as the generality of fungi cannot well be preserved. The most distinguished writer upon them, indeed the only good systematic one, is Persoon, who has moreover supplied us with some exquisite figures. His Synopsis Methodica Fungorum helps us to the following arrangement.

1. Angiocarpi, such as bear seeds internally. These are either hard, like Splactia, Sowerb. Fung. t. 159, 160 ; or membranous, tough and leathery, like Lycoperdon, t. 331, 332; Cyathus (Nidularia) t. 28, 29; or Batarrea (Lycoperdon) t. 390 .

2. Gymnocarpi, such as bear seeds imbedded in an appropriate, dilated, exposed. membrane, denominated hymenium, like Heliella, t. 39, in which that part is smooth and even; Boletus, t. 34, 87, 134, in which it is porous; and the vast genus Agaricus, t. 1, 2, \&c., in which it consists of parallel plates called lamellec, or gills. 
Persoon has been commendably sparing of new terms. - Besides hymenium above explained, he has scarcely introduced any other than peridium, for the round membranous dry case of the seeds in some of the 1 st section. The term pileus, a hat, is used by all authors for the head of those fungi that compose the $2 \mathrm{~d}$ section.

Appendix. Palme. The natural order of Palms was so little understood when Iinnæus formed his systematical arrangement of plants, and so few of their fowers had been scientifically examined, that he was under the necessity of leaving this order as an appendix to his system, till it could be better investigated. To its peculiar habit and physiology we have adverted in several of the foregoing pages, see p. 57-59, 62, 133, \&c.

Late observations șhow Palms to have for the most part 6 stamens, rarely 3 or 9 , with 3 or 6 petals, and 1 or 3 styles; which last are sometimes in the same flower with the stamens, sometimes in a separate one; but both flowers always agree in gencral structure. Their fruit is generally a drupa. They 
are akin to the liliuceous tribe, and Limnas bappily terms them the princes of the verertable lingrom. His nost numerons remarks concerning them ocem in his P'ralectiones in Ordinc's Naturales Planturum, published by Professor Giscke at Hamburegh in 179), from private lectures and converations of finnaws. This work howerer is necessarily finll of prors and mistalise, not only from its mode of compilation and the intricacy of the sub)ject, but because Linnacus lad only partially sturlied certain parts of that sulject, and was undecided in his sentiments upon those parts. It was a singular instance of indulgent liberality in him to allow his disciples Fibricins and Giscke to make notes, for their own use, of what he considered himself as scarcely competent to lay in a finished form before the public. Tre are obliged to the editor for preserving these valuable though crude materials, and he has shown ability in digesting and elucidating them. I should scarcely, for my nwn part, hare thought it right to funish still more crude and imperfect guesses and opinions, from manuscripts which their illustrious anthor had purposely, 
as it appears, withheld from his auditors, lest he should lead them into error. This will explain a note in Professor Giseke's preface, $p .19$, which however was printed before his request came to my linowledge ; for two rery intelligent friends, through whom it was meant to be conveyed, judged it unreasonable to be made, as well as improper to be complied with, and therefore suppressed the message.

I have only to add a few practical remarks on the preparation and use of an Herbarium or Ilortus Siccus. The advantages of preserving specimens of plants, as far as it can be done, for examination at all times and seasons, is abundantly obvious. Notwithstanding the multitude of books filled with descriptions and figures of plants, and however ample or perfect such may be, they can teach no more than their authors observed; - but when we have the works of Nature before us, we can investigate them for ourselves, pursuing any train of inquiry to its utmost extent, nor are we liable to be misled by the 
errors or misconceptions of others. A good practical botanist must be educated among the wild scenes of nature, while a finished theoretical one requires the additional assistance of gardens and books, to which must be superadded the frequent use of a good herbarium. When plants are well dried, the original forms and positions of even their mimutest parts, though not their colours, may at any time be restored by immersion in hot. water. By this means the productions of the most distant and various countries, such as no garden could possibly supply, are brought together at once under our eyes, at any season of the year. If these be assisted with drawings and descriptions, nothing less than an actual survey of the whole regetable world, in a state of nature, could exccll such a store of information.

Some persons recommend the preservation of specimens in weals spirits of wine, and this mode is by far the most eligible for such as are very juicy. But it totally destroys their colours, and often renders their parts less fit for examination than the abore-mentioned mocie. It is besides incommodious for frc- 
quent study, and a very expensive and bulky way of making an herbarium.

The greater part of plants diry with facility between the leaves of books, or other paper, the smoother the better. If there be plenty of paper, they often dry best without shifting; but if the specimens are crowded, they must be taken out frequently, and the paper dried before they are replaced. The great point to be attended to is that the process should meet with no check. Sereral vegetables are so tenacious of their vital principle, that they will grow between papers, the consequence of which is a destruction of their proper habit and colours. It is necessary to destroy the life of such, either by immersion in boiling water, or by the application of a hot iron, such as is used for linen, after which they are easily dried. I cannot howerer approve of the practice of applying such an iron, as some persons do, with great labour and perseverance, till the planis are quite dry, and all their parts ineorporated into a smooth flat mass. This renders them unfit for subsequent examination, and destroys their natural habit, the most important thing to be 
preserved. Eren in spreading plants betwen papers, we should motian fom that precise and artificial disposition of their branches, leares. and other parts, which talies away from ther matural aspect, except for the purpose of dimpliying the internat parts of some one or two of their flowers, for ready observallol\%.

Alter all we can do, plants dry very variously. 'llie blue colnuis of thoj fowers generily fate, nor arr recis always permanent. Iellows are mueh more so, but rery few whte flowers rotain their natural aspect. The Snowtrop and l'amassia, if well dricel, continue white. Some erreons ane much more permanint than oturess for there are some natural familes mhose loares as well an flowers turn almost black by drying, as Helampyrum, burtsiu, and their allies, serenal Willows, anci most of the Orchidece. The Heaths and Fus in general cast off their leares between papers, which appears to be an cfiort of the living principle, for it is prevented by immersion of the fiesh specimen in boiling. water. Nandina domestica, a Jipanose shrub, lately introduced among us by Lady 
A. Hume and Mr. Evans of Stepney, is very remarkable in this respect. Every leaflet of its very compound leares separates firom its slalk in drying, and cren those stalis ail fall to pieces at their joints.

Dried specimens are best preserved by being fastened, with weak carpenter's glue, to paper, so that they may be turned orer without damage. Thick and heary stalks require the additional support of a few transverse strips of paper, to bind them more firmly down. A half sheet, of a convenient folio size, should be allotted to each species, and all the species of a genus may be placed in one or more whole shcets. On the latter the name of the genus should externally be written, while the name of every species, with its place of growth, time of gathering, the finder's name, or any other concise piece of information, may be inscribed on its appropriate paper. This is the plan of the Linnaan Herbarium, in which every species, which its original possessor had before him when he wrote his great work the Speries Plantarum, is numbered both in pencil and in ink, as well as named, the former kind of 
numbers having been temporary till the hook to which they reter was printed, after which they were confirmed with a pen, and a copy of the book, now atleo in my hands, was marlied in referenes to thens. Here therefore we do so i reprenel vin the oprinion merely, cren of Limnau, for we hare always before our eres the very object which was under his inspection. Ve have similar indications of the plants described in his sulssequent works, the herbarium being most defective in those of lis 2d Mantissu, his least accurate publication. We often fund remarks there, made fiom specimens acquired after the species Plontarem was published. These the herbarium orcasionally shows to be of a different species from the original one, and it thus enables us to correct such errors.

The specimens thus pasted, are conveniently liept in lockers, or on the shelves of a proper cabinet. Linnass in the Philosophia Botmica exhibits a figne of one, divided into appropriate spaces for each class, which Jie supposed would liold lis whole collection. But he lived to fill two more of equal size, and his herbarium has been perliaps doubled 
since his death by the acquisitions of his son and of its present possessor.

One great and mortifying impediment to the perfect preservation of an herbarium arises from the attacks of insects. A little bectle called Ptimus Fur is, more especially, the pest of collectors, laying its egrgs in the germens or receptacles of flowers, and others of the more solid parts, which are speedily devoured by the maggots when hatched, and by their devastations paper and plants are alike involved in ruin. The most bitter and acrid tribes, as Euphorbia, Gentiana, Prumus, the Syngenesious class, and especially Willows, are preferred by these vermin. The last-mentioned family can scarcely be thoroughly dried before it is deroured. Ferns are scarcely ever attacked, and grasses but seldom.-To remedy this inconvenience I have found a solution of corrosive sublimate of mercury in rectifed spirits of wine, about two drams to a pint, with a little camphor, perfectly efficacious. It is easily applied with a camel-hair pencil when the specimens are perfectly dry, not before; and if they are not too tender, it is best done before they 
are pasted, as the spirit extracts a yellow dye from many plants, and stains the paper. A few drops of this solution should be mixed with the glue used for pasting. 'This application not only destroys or keeps off all reimin, but it greatly revires the colous of most plants, giving the collection a most pleasing air of freshmess and neatness. After several years' experience, I can find no inconvenience from it whatever, nor do I see that any dried plants can long be preserved without it.

The herbarium is best kept in a dry room without a constant fire. Linneus had a stone building for his museum, remote from his dwelling-house, into which, I have bcen told, neither fire nor candle was erer acimitted, yet nothing can be more free than his collection from the injuries of chimpness, or other causes of decar. 


\section{EXPLANATION OF TIE PLATES.}

TAB. 1. fig. 1. Anatomy of wood, after Mirbel. See $p$. 14. f. $\quad$. Embryo of Pinus Cembra, shown in a section of the seed, then separate, and magnified, from Mr. Lambert's work. See p. 98, 287289. f. 3. Seedling plant of the Dombeya, or Norfolk Island Pine, with its 4 cotyledons, and young leafy branches, of the natural size, p.98. $f .4$. A garden bean, Ficia Faba, laid open, showing its? cotyledons, p. 96; f the radicle, or young root, p. 94; g the germ or corculum, p. 96 . Above is a bean which has made some progress in vegetation, showing the descending root, the ascending plumula, p. 97, and the skin of the seed bursting irregularly, p. 295.

ТАв. 2. Roots. f. 5. Fibrous, in Grass, p. 105. f. 6. Creeping, Mint, p. 106. f. 7. Spindle-shaped, Radish, accompanied by its cotyledons and young leaves, $p .107$. 
f. 3. Abrupt, Scabiosa succisa: if. 9. Tuberols, Potatoe, p. $108 . \quad f .10$. Oval knobs of some Orchidece: f. 11. Palmate ones of others: $f$. 12. Several pairs of knobs in Satyrium albidum: p. 109. $f:$ 13. Solid Bulb in Crocus: $f: 14$. Tunicate Bulb in Allium: $f$. 15 . Scaly one in Lilium: p. 111. f. 16. Granulated Root of Saxifraga granulata, p.113.

TaE. 3. Stems and Burls. f. 17. Forked Stem, in Chlora perfoliata, p. 117. $f .18$. Scaly, in Orobunche: f.19. Radicans, or Clinging, in Ivy, p. 118. f. 20. Twining firom left to right, in Lonicera; $f .21$ : from right to left, in Convolvulus, p. 119.

- f. 22. Sarmentum, a Runner, in the Strawberry, p. 120. f. 23. Caulis cieterminate ramosis, as in the dzater family, $p$. 12\%. f. 24. Three pair of Buds, in Lonicera cerulca, p. 135. f. $\quad$.25. Bud of the Horse Chesnut, p. 197.

TA s. 4. Leaves. f. 26. Tufted Leares, $p .146$. f. 27. Imbricated: $f$.23. Decussated: $f .29$. Two-ranked, Yew: f. 30. Unilateral, p. 147. 
f. S1. Peltate, Nasturtium, p. 149. f. 32. Clasping the stem, $p .150 . \quad f .33$. Perfoliate: $f$. 34. Sheathing: f. 35 . Equitant: f. 36. Decurrent, p. 151, and spinous, p. 162. f. 37 . Flower-bearing, Ruscus aculeatus, p. 151 .

Tа в.5. f. 38. Orbicular, Hediysaruñ styracifolium, p. 153. f. 39. Roundish, pyrola: $f .40$. Ovate: $f .41$. Obovate: $f .4 .2$. Elliptical or oval: $f .43$. Spatulate, $p .154$. $f .44$. Wedge-shaped: $f .45$. Lanceolate: $f .46$. Linear: $\quad f: 47$. Needle-shaped: $f .48$. Triangular, $p .155 . \quad f .49$. Quadrangrular, (also abrupt, p. 159), Tulip-tree: f.50. Deltoid: $f .51$. Rhomboits: $f .52$. Kidney-shaped, p. 156 . f. 53 . Heartshaped: f.54. Crescent-shaped: f.55. Arrow-shaped: fi.56. Halbert-shaped, (also. acute, $p .160), f_{.57}$. Fiddle-shaped, (also: obtise, p. 160), Rumev pulcher, p. 1.57. $f .58$. Runcinate: f.59. Lyrate: f. 60 . Cloven: $f .61$. Three-lobed, Ancmone Ilepatica: f. 62. Sinuated, Oak: f.63. Deeply divided, Kelleborus, p. 158. f. 64 . Laciniated: , 
TA B. 6. f. 65. Palmate: $f .66$. Pinnatifid: $f$. 67. Doubly pinnatifid, p. 159. f. 68 . Pectinate: $f: 69$. Unequal, Begonia: $f$. 70. Jagged-pointed, p. 160. f: 71. Retuse, Riemex digymus: f:72. Emargin nate: $f .79$. Pointed: $f .74$. Blint with a small point, $p .161 . \quad f: 75$. Sharp-pointed, Ruscus aculcatus: f. 76 . Cirrose: $f .77$. Spinous, p. 162. $f$. 78. Fringed: $f$.79. Toothed: $f$.80. Serrated: $f: 81$. Crenate, p. 163.

TAB.7. $f$. 82. Doubly as well as sharply crenate, approaching to $f .80: f$. 83 . Jagged: f. 84. Wavy, Menyanthes nymphaoides: f. 85. Plaited, p. 165. f. 86 . Undulated: $f$. 87. Curled, $p .166 . \quad f:$ s8. Veiny : f. s9. Ribbed: $f .90$. Three-ribbed, p.167. f.91. Three-ribbed at the base: f. 92 . Triply-ribbed: $f .93$. Cylindrical, Conchium, p. 169, f. 94. Semicylindrical: $f .95$. Awl-shaped: $f .96$. Doubly tubular, Lobelia Dortmanna: f.97. Channelled, p. 170. f. 98. Hatchet-shaped, p. 171. f. 99. Threesedged, Mesembryanthemum deltoides : $f$. 100. Four-edged: 
ТА в. 8. f. 101. Alienated, Mimosa verticit. lata, p. 172.\% f. 10?. Hooded, Sarra: cenia, $p .173 . \quad f .103$. Furnished with an appendage, Dioncea muscipula: f. 104. Jointed, Fagara tragodes, p. 175. f. 105. Binate, p.176. $f .106$. Ternate: $f .107$. Interruptedly Pinnate, p. 177. $\quad f .108$. Pinnate in a lyrate form, p. 178. f. 109. Pinnate in a whorled manner, p.179. f. 110. Auricled: f. 111. Compound, p.180. f. 112. Doubly compound, or Twice ternate: $f .113$. Thrice compound, or Thrice ternate: $f .114$. Pedate, Helleborus, p. 181.

TA r. 9. Appendages. $f .115$. Stipulas of Lathyrus latifolines, p. 219 ; also an abruptly pinnated leaf, ending in a tendril, p. 176. f. f16. Stipulas united to the footstalk, in Rosa, p: 219; also a pinnated leaf with a terminal leaflet, $p .176 . \quad f .117$. Floral leaf of Tilia, p. 222. $\quad f$. 118. Coloured floral leaves, Lavandula Stoechas :

* I have found by recent experiment, that the first leaf of Lathyrus Nissolia is like the rest, not pinnated, but simple and sessile. See p.173. 
f. 119. Spinous ones, Atractylis cancellata: fi.120. Thorns, Hippopläe rhamnoicles, p. 223. f. 121. Prickles, p. 224. f. 122. Tentril, Lathyrus latifolius: $f$. 123. Glands of the Moss Rose, p. 226. f. 124. Hairs: f. 125. Bristles of Echimm pyrenaicum, p. 227.

Ta в. 10. Inflorescence. f. 126. Whorl, in Lamium, p. 230. f. 127. Whorled leaves, and axillary flowers, of Hippuris vulgaris, p. 231. f: 128. Cluster, Ribes: f: 129. Spike, Ophrys spiralis: $f$. 130. Less correct Spike, T'eronica spicata, p. 232. f. 131. Spikelet, Bromus, p. 233. f. 132. Corymb: f'. 133. Corymbose fascicle, Achillea, p. 234. f: 134. Fascicle, Dianthus Armeria, p. 235. f. 135. Hearl or Tuft, Trifolium: $f$. 1s6. Simple Umbel, Eucalyptus piperita, p. 236. $f$. 137. Simple Umbel in the natural order of Umbellate, Astrantia major, with the Involucrum, $a$ :

Tax. 11. f. 138. Compound Umbel, Laserpitium simplex, with its general Invo- 
lucrum, $a$, and partial one, $b, p .246$. f. 139. Cyme, Laurusinus, p. 237. f. 140. Panicle, Oat, p. 238. f. 14.1. Bunch, Common Vine, p. 239.

Calyx. f. 142, Perianthinm, or Calyx properly so called, Dianthus dcltoides, p. 245. $f$. 143. Involucrum, so called, in Anemone, p. 247. $f$. 144. Involucruni or Indusium of Ferns, p. 248. $f$. 145. One of the same separate, with a capsule and its ring. $f \cdot 146$. Catkin of the Hasel-nut p. 249 .

TA . 12. Calyx and Corolla, with Nectary. $f .147$. Sheath of the Narcissus; $a$, the Petals, called by Jussieu, Calyx; $b$, the Crewn or Nectary, see p. 263. $f, 118$. Husk of Giasses, p. 250. f. 149. Awns. $f:$ 150. Scaly Sheath, Pterogonium Smithii, p. 251. f. 151. Veil of the same, p.252, 264. $f .15 \%$. Iungermania epiphylla, showing $a$, the Calyx, p. 252; $b$, the Veil or Corolla, $p .252,265$; and $c$, the unopened Capsule. $f$, 133. Wrapper, Agaricus: $\quad f$. 154. Racical Wrapper, p. 253, $f .155$. Monopetalous Salver-shaped 
Corolla, p. 256, 257. f. 156. Polypetalous Cruciform Corolla: $f: 157$. A separate Petal of the same; $($, Claw ; b, Border ; f. 158. Unequal Corolli, Butomus, p. 256.

TА в. 13. f. 159. Bell-shaped Corolla: f. 160. Funnel-shaped: $f .161$. Ringent: f. 162. Personate, Antirrhinum reticulatum, p. 257. f. 163. Papilionaceous, Lathyrus; f. 164 . Standard of the same; $f .165$. One of the Wings ; $f$. 166. Keel; f. 167. Stamens, style, \&c.: f. 168, Incomplete Corolla, Rittera. f, 169. Peloria, or regular-flowered varicty of Antirrtinum Linaria, p. 258. f. 170. Nectary in the Calyx of Tropcolum: $f$.171. Nectary of Aquilegia, p.266. $f .172,173$. The same part in Epimedium: $\quad f .174$. Pair of Nectaries in Aconitum, p.267. f. 175. Fringed Nectaries in Parnassia, p. 268.

TA B. 14. Stamens, Pistils and Fruit. f. 176. A Stamen: $a$, filament ; $b$, anther, p. 270, 271. $f$. 177. Pistil: $a$, germen; $b$, style; c, stigma, p. 273. $\quad f .178$. Capsule of an annual Mesembryanthemum, open and 
shut, p.277. $f .179$. Transverse section of the capsule of Datura, $p .278$, showing the partitions and columella. $f .180$. Siliqua, or Pod: $f$.181. Silicula, or Pouch, p. 280. f. 182. Legume, p. 281. f. 183. Stone-fruit, p. 282. f. 184. Apple: $f$. 185. Berry: 'f.186. Compound Berry, p. 233. $f .18 \%$. Berry of Passiflora siberosa, p. 284. f. 183. Cone, Larch, p. 286. $f .189$. Capsule of a Moss, Splachnum, with its fleshy base, or apon physis, a, and fringe, $b, p .489,491$.

TA B, 15. $f .190$. Barren flower of a Moss, much magnified, after Hedwig: $f .191$. Stamens, with the Pollen coming forth, and the jointed filaments, p.489. f. 192. Fertile flower of a Moss, consisting of numerous pistils, only one of which in general comes to perfection. They are also accompanied by jointed filaments : $f .193$. A germinating seed of Gymosiomuin pyriforme, from Hedwig likewise, showing its expanding embryo: f. 194 . The same more adranced: $f: 195$. The same much further advanced, and become a young 
plant, showing its leaves and branched cotyledons, p. 290. f. 196. Young plant of Funaria hysgrometrica, exhibiting the same parts, p. 491 . f.197. Powdery wart of a Lichen, presumed to be its barren Nower: f. 198. Perpendicular section, magnified, of the shield or fruit of a Lichen, showing the sceds imbedded in its disk, 1). 495. f. 139. Section of the secd of a Date, Phenix dactylifcra, from Gartner, the builk of which is a hard Albumen, p. 291, haring a lateral coll in which is lodged the horizontal embiyo, a, p. $283 . \quad f .900$. Section of the l'itellus in Zamia, from the same author, with its embryo a, with which it is, like a cotyledon, closely connected, 1. 292. f. 201. Rough coats of the seeds in Cynoglossum, p. 298. f. 202. Arillus of a Carex, p. 299. f. 203. Seed of Af:celia, with its cup-shaped Arillus, p. 296. f. 204. Pappus, or Seed-down, of Trugropogon, p. 300. f.205. Tail of the seed in Dryus: : f. 206. Beaked fruit of Scandix, with its seeds separating from their base, p.301. f. 20\%. Winged seed of Eirtbothrium, p.302. f.208. Section of the 
conical Receptacle of the Daisy, with its calyx: f. 209. Cellular Receptacle of Onopordum, p. 305. $\quad f .210$. Ligulate floret with both stamens and pistil, in a Dandelion, $p$.308. $f .211$. Ligulate floret with only a pistil, in the radius of a Daisy, p. 307. f. 212. Tubular floret from the disk of the same, having stamens and a fertile pistil, p. 308 . f. 213. Capsule of a Moss with a double fringe, the lid shown apart, p. 488 . f.214. A portion of the same fringe magnified, $p .491$. 


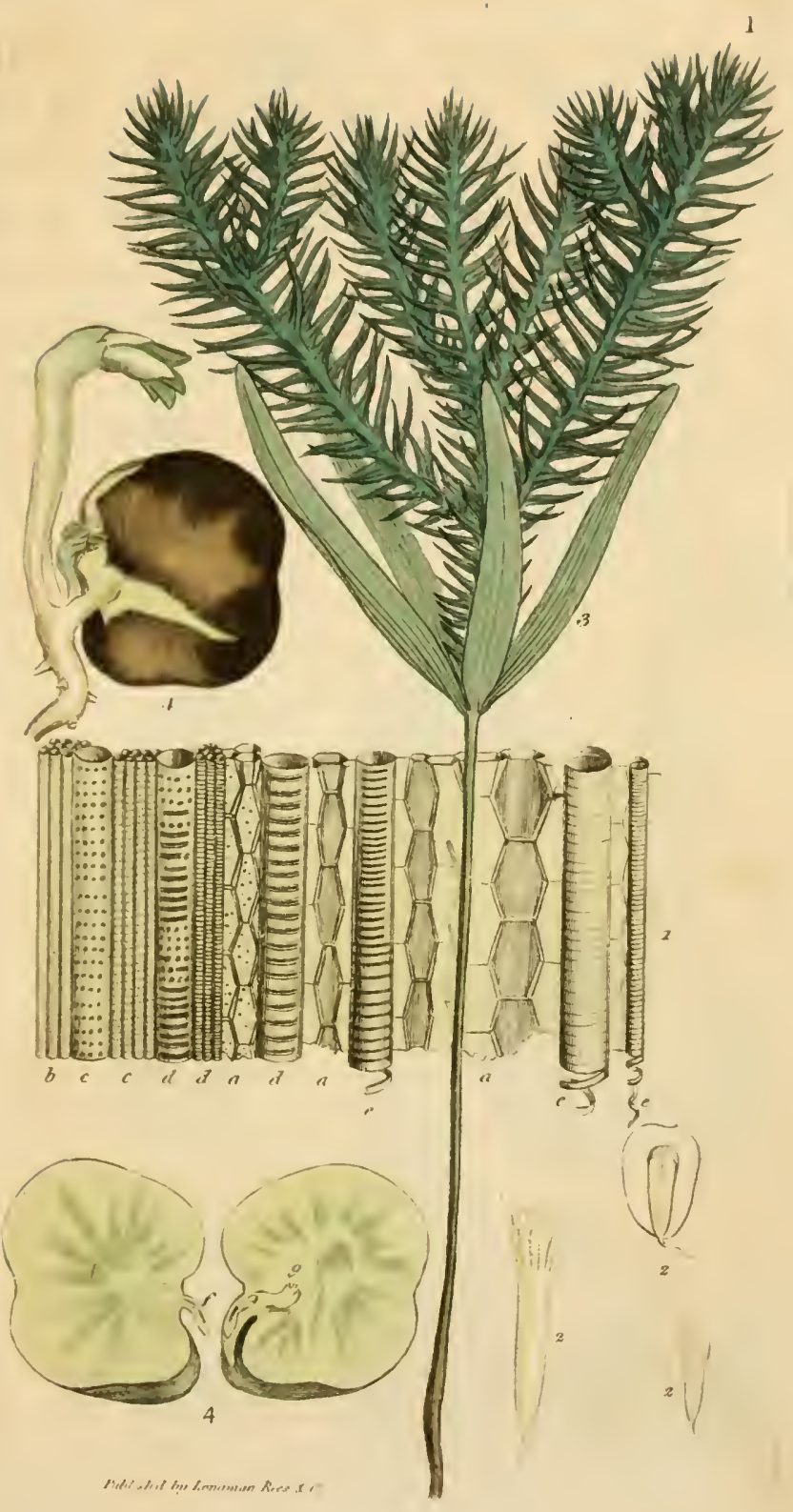




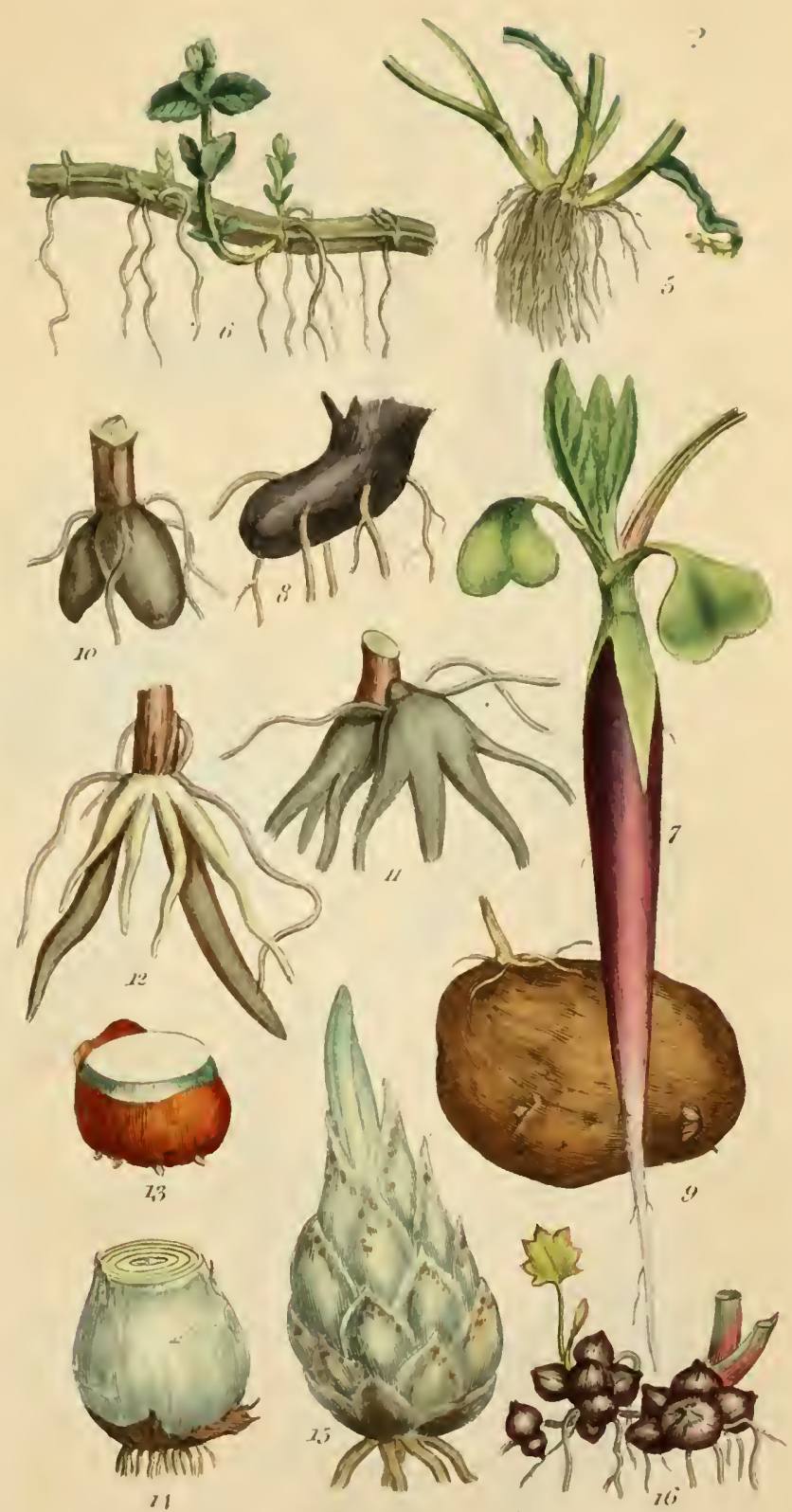



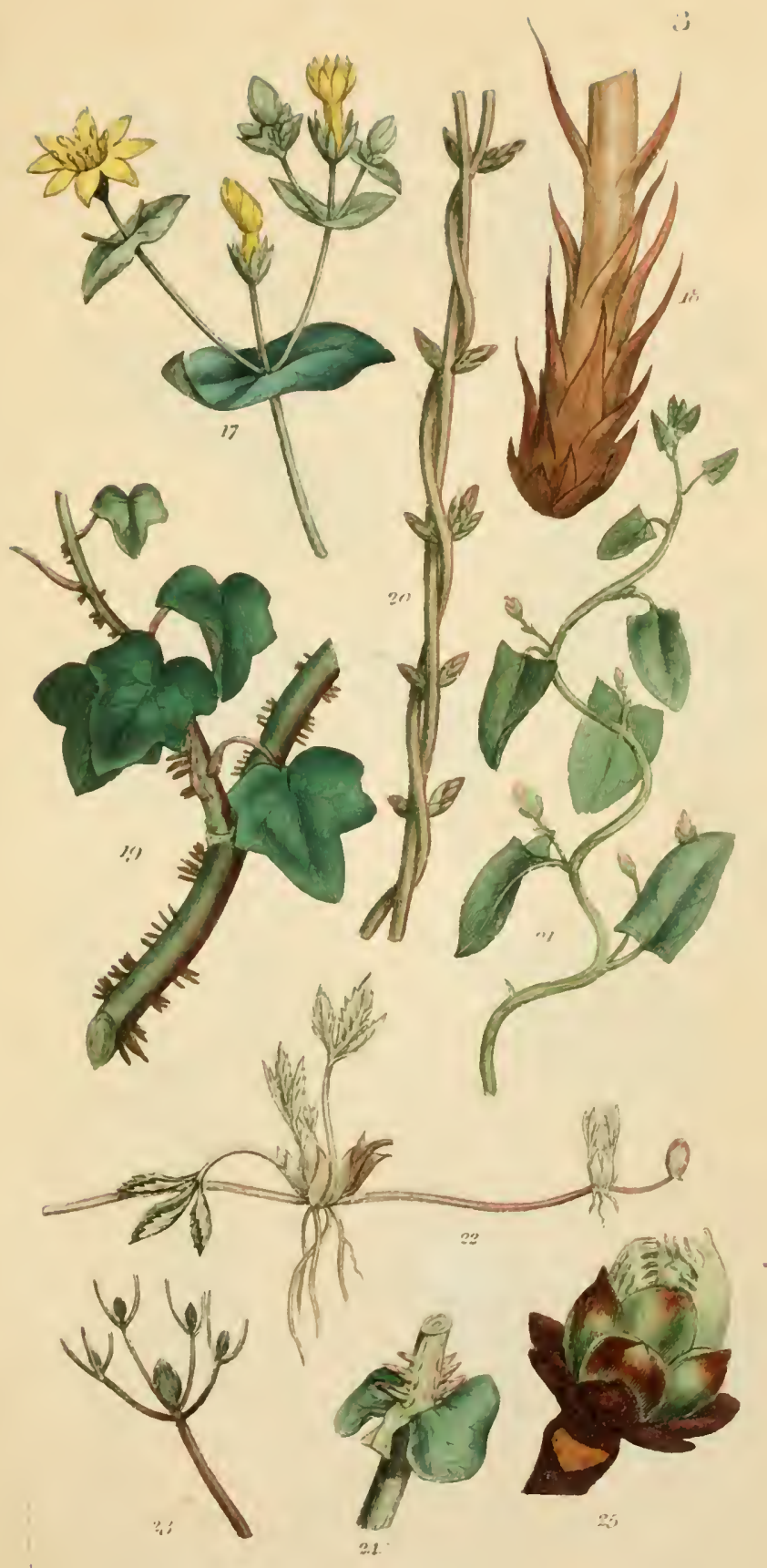




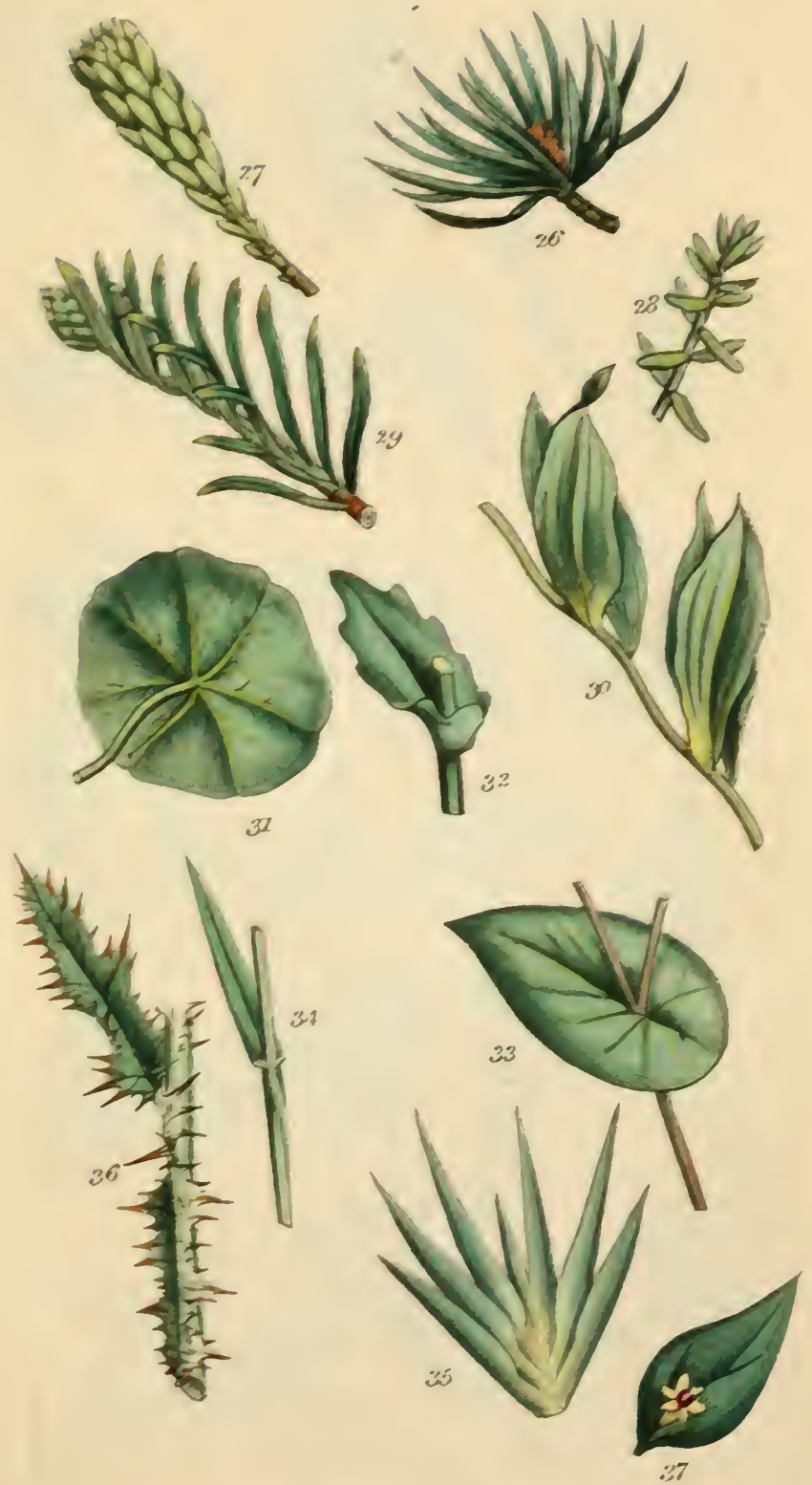

Fidented by Lamemeen roes if 6 : 


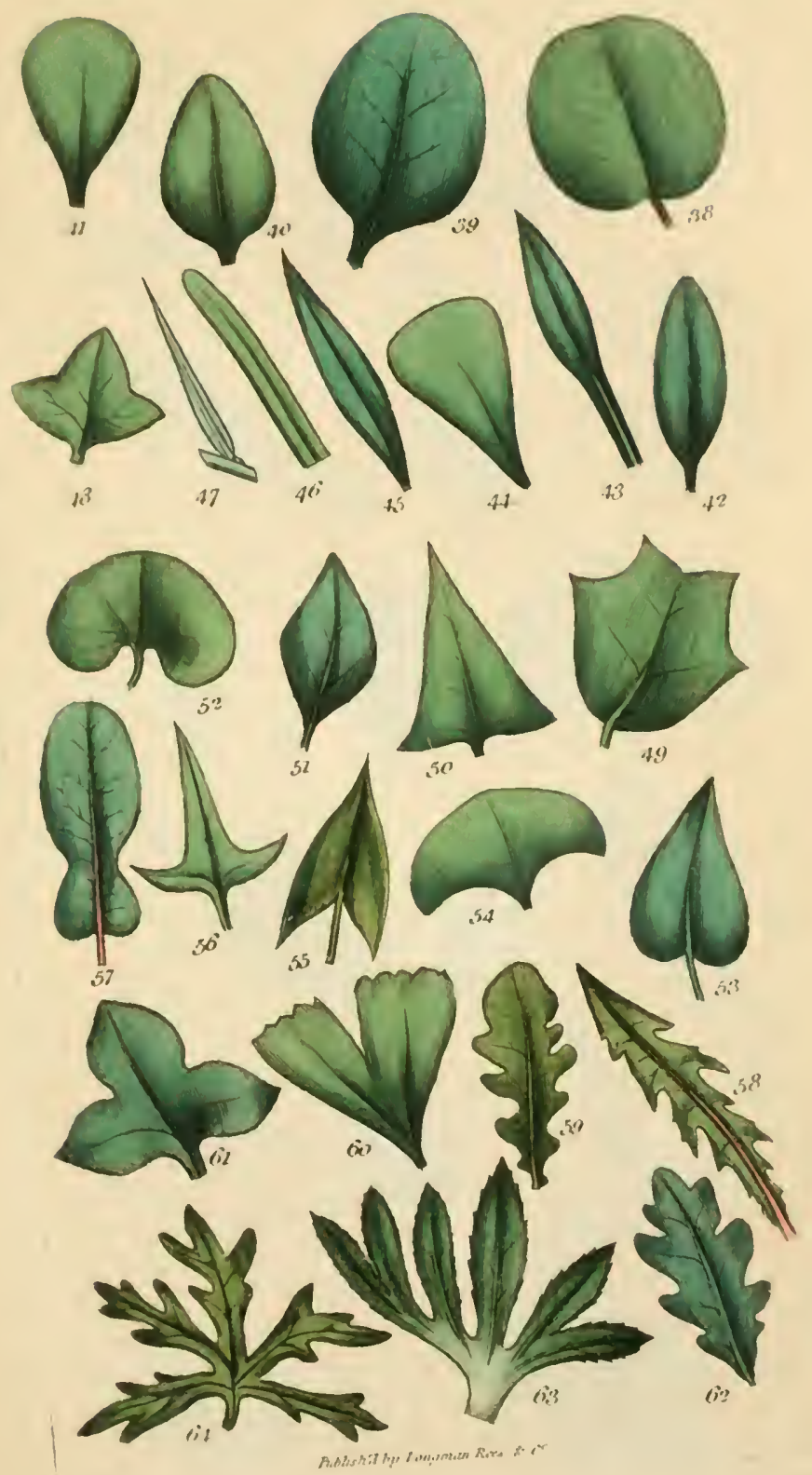

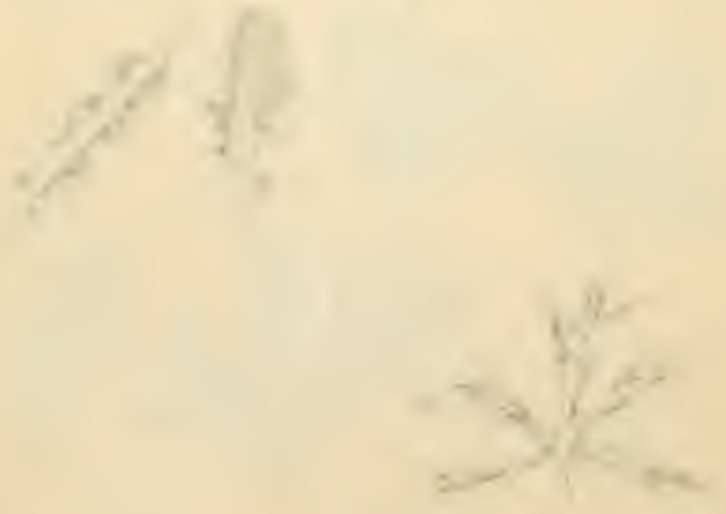

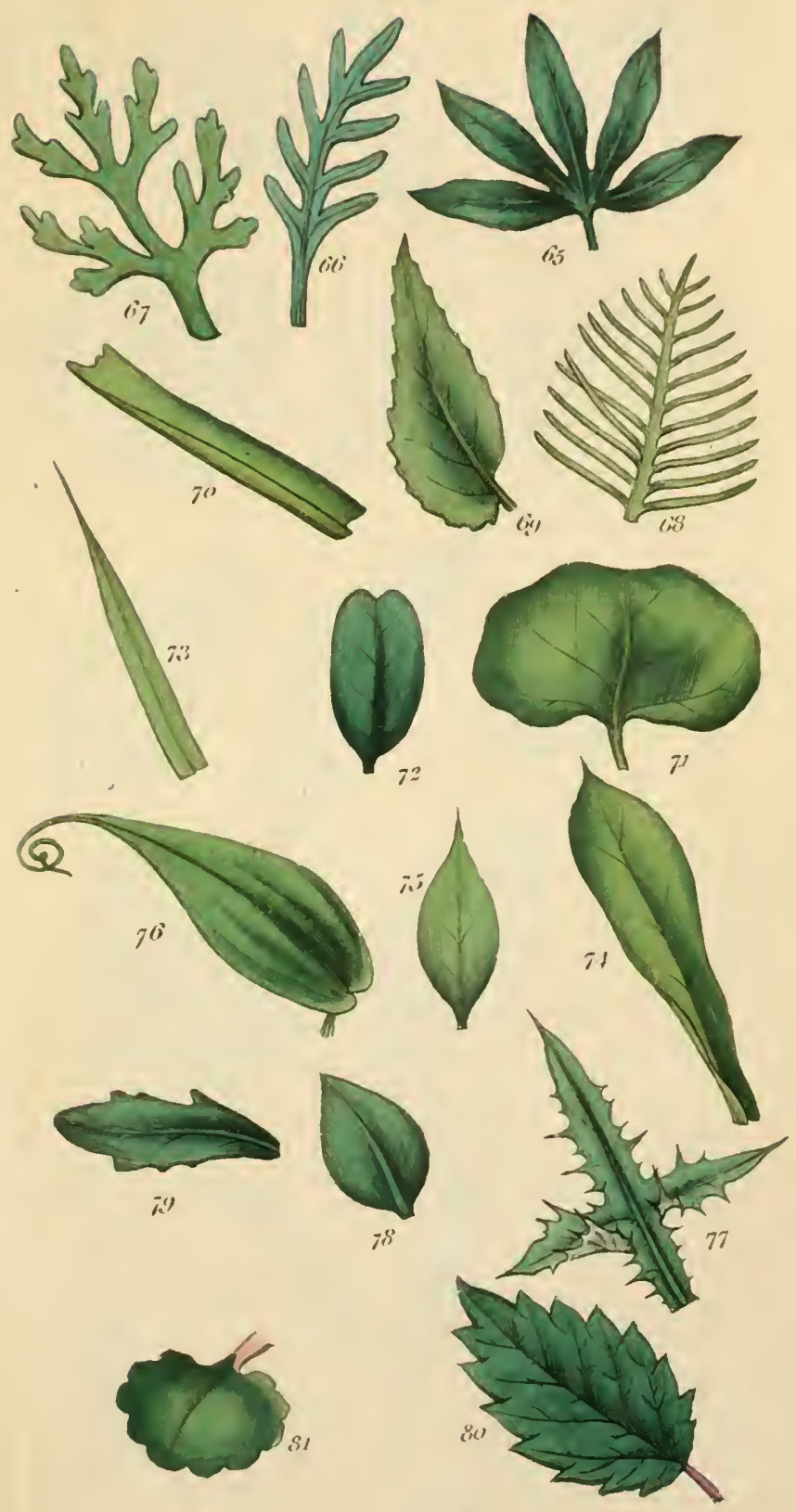



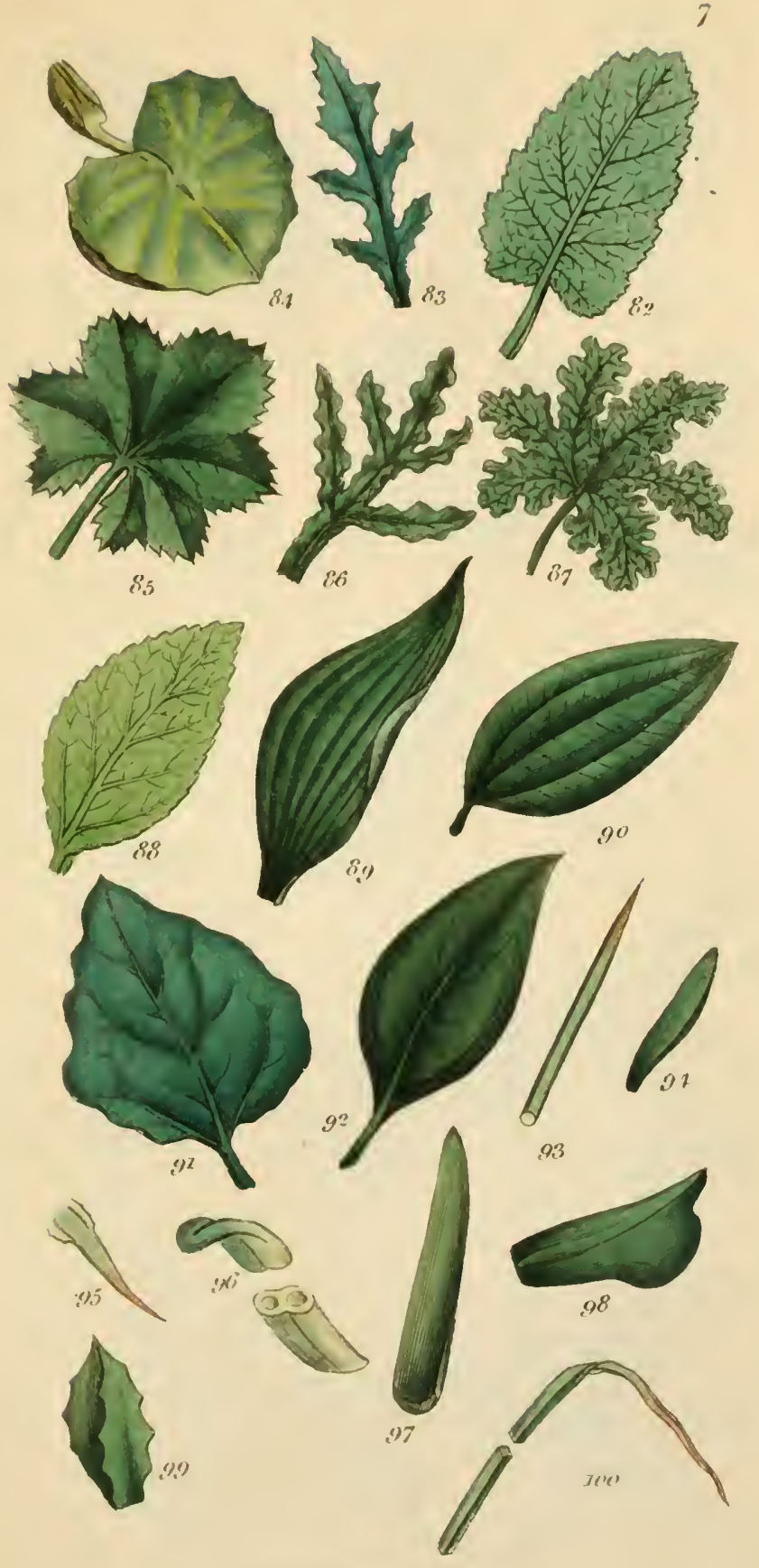





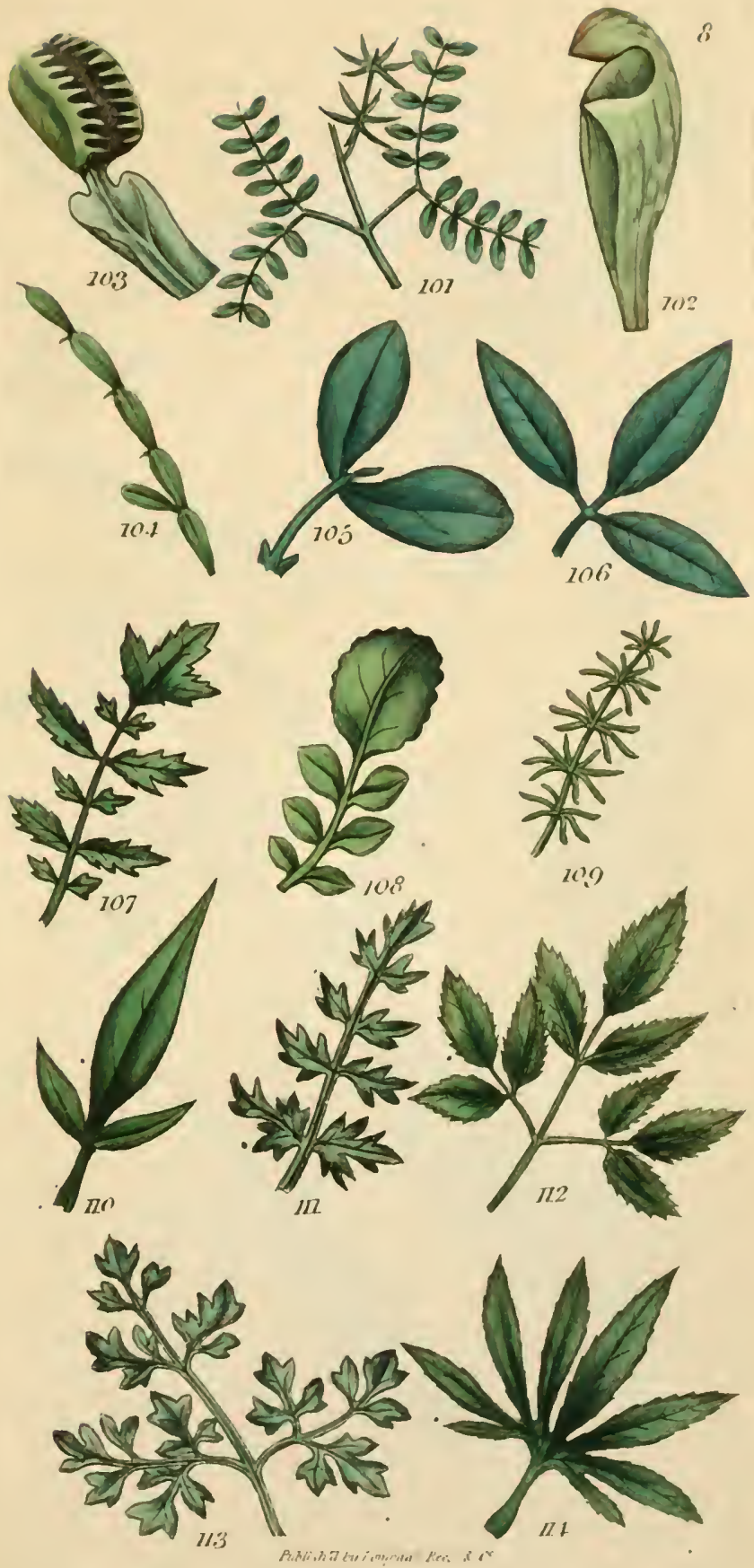





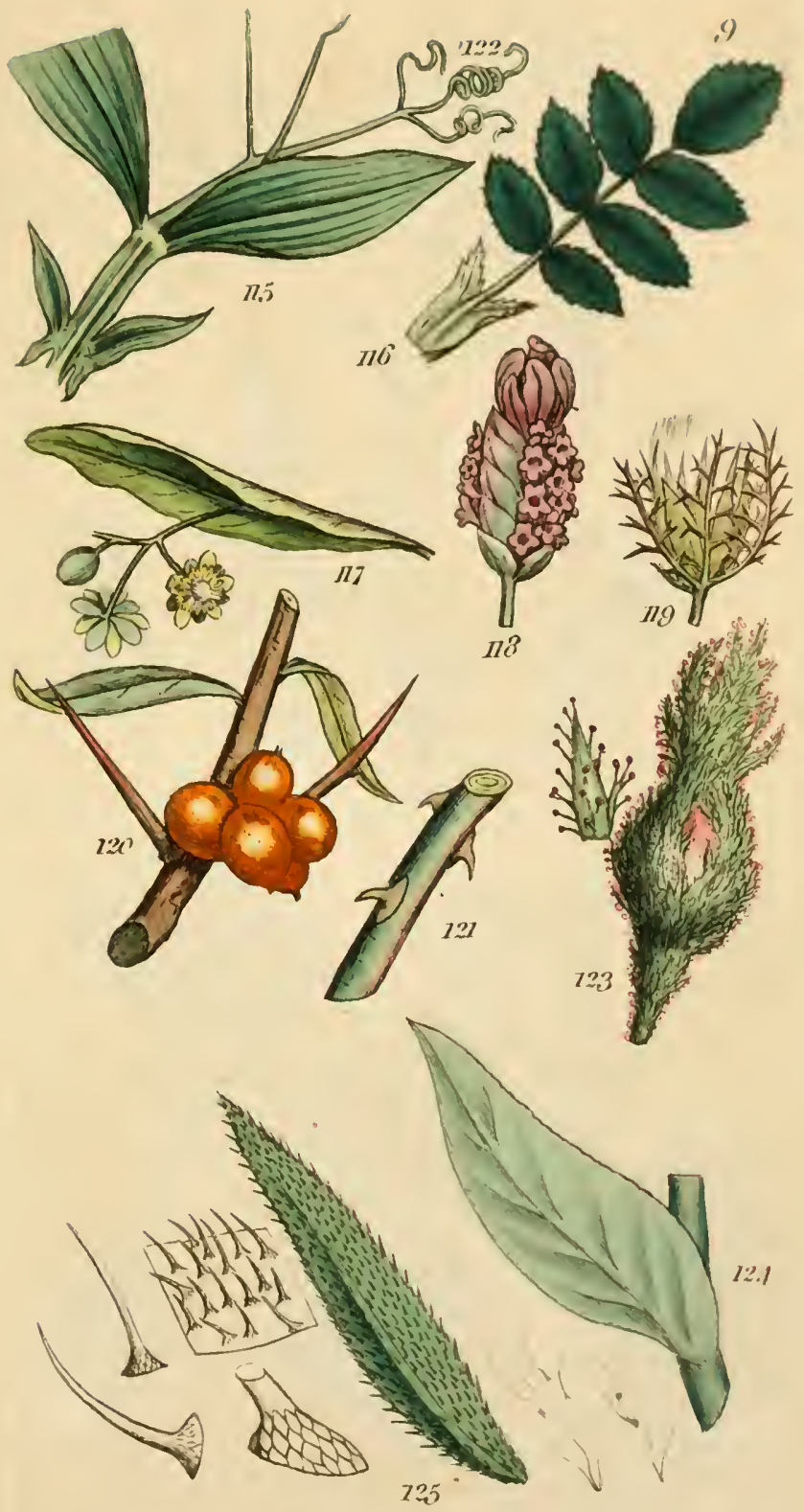




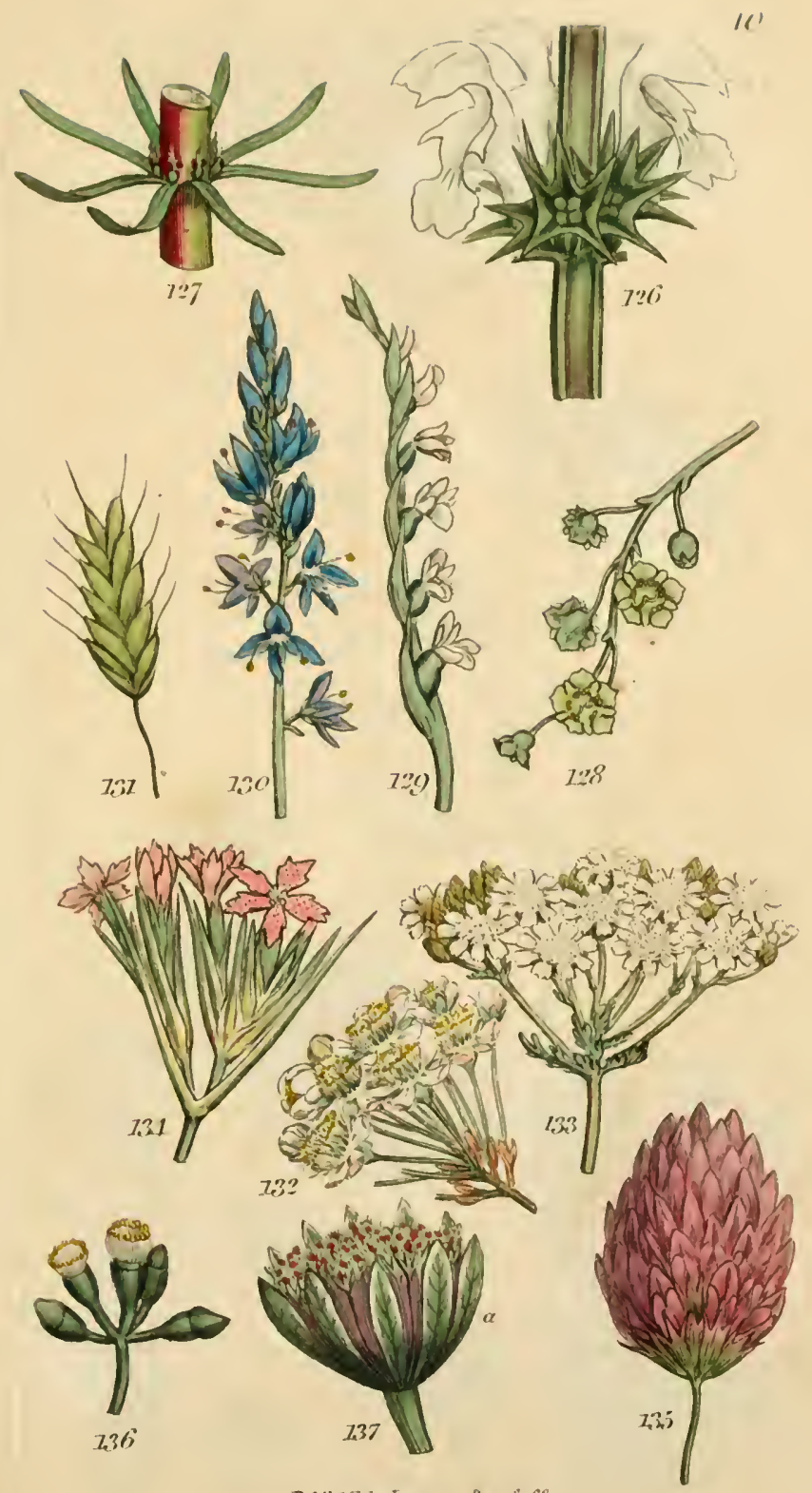

Rublisha by Lomman Rere if re 



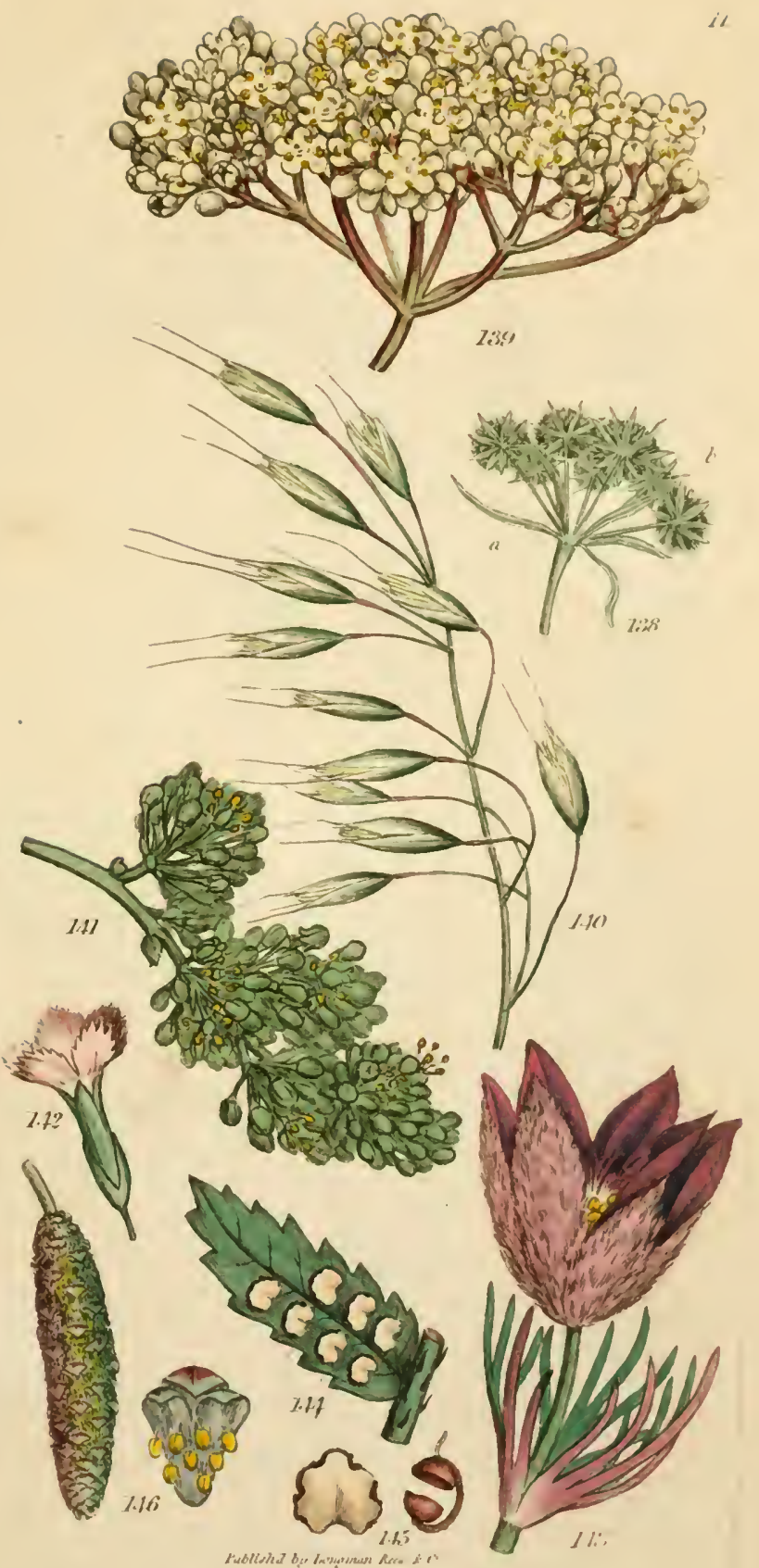




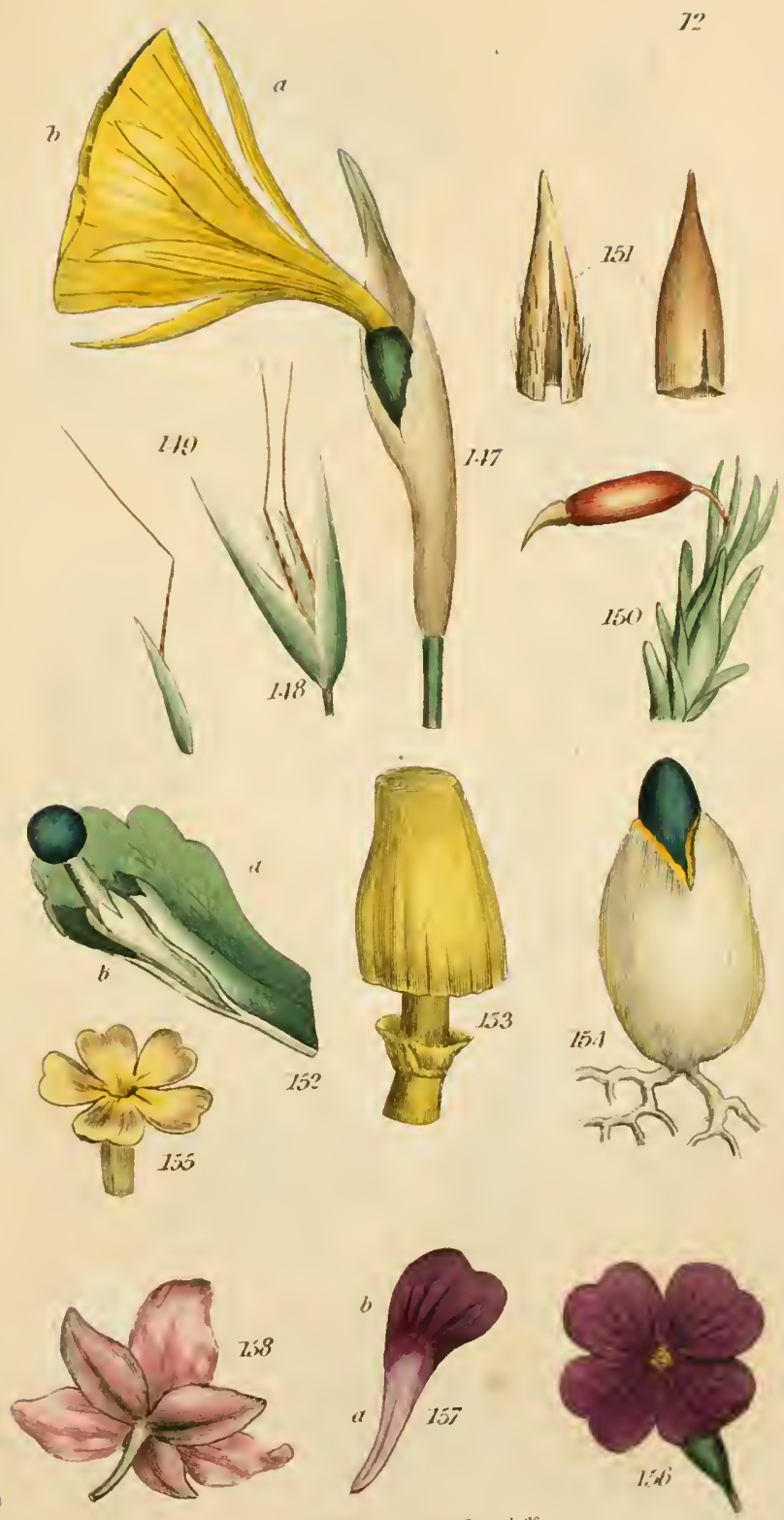

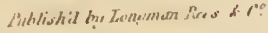




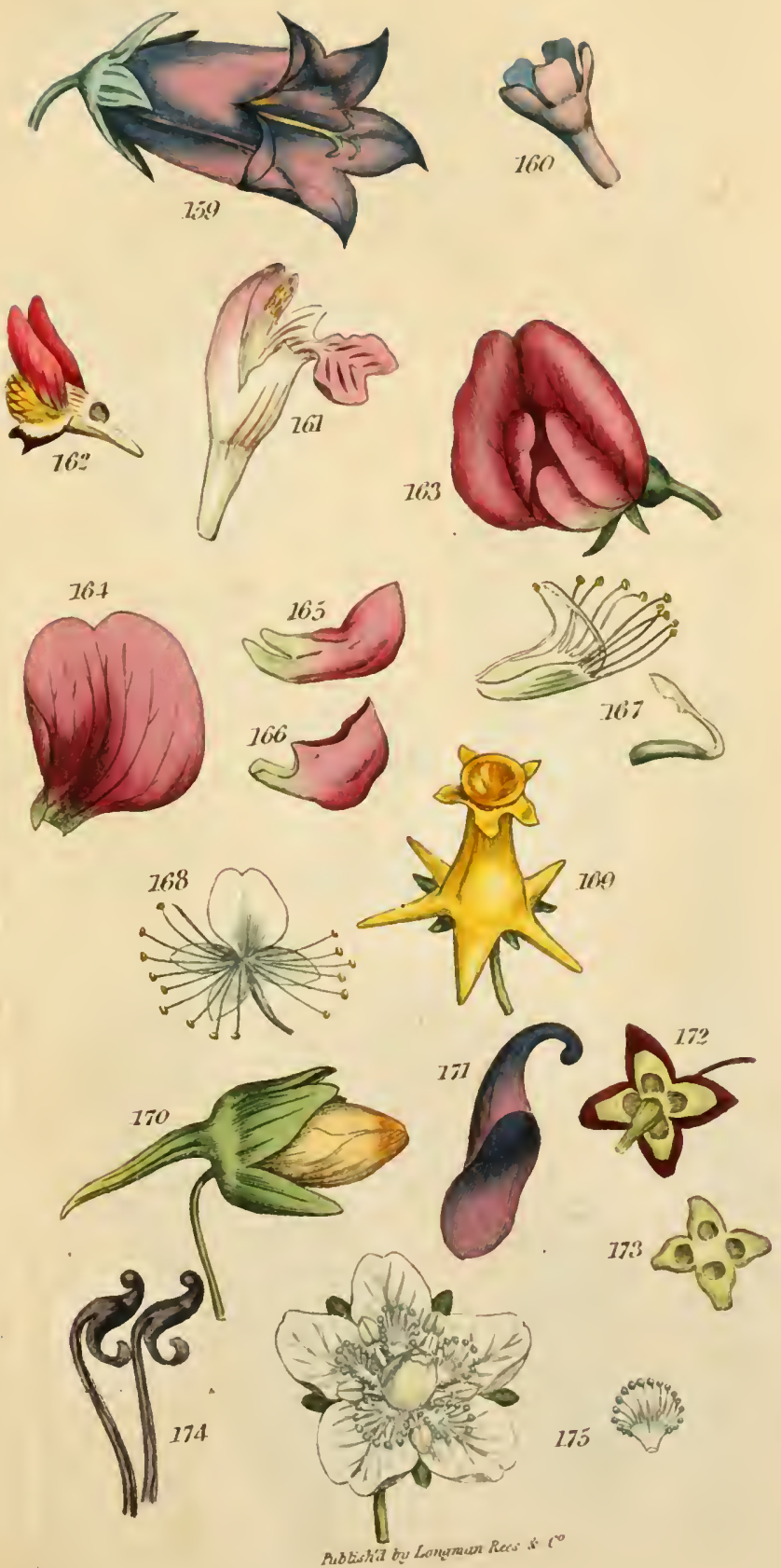



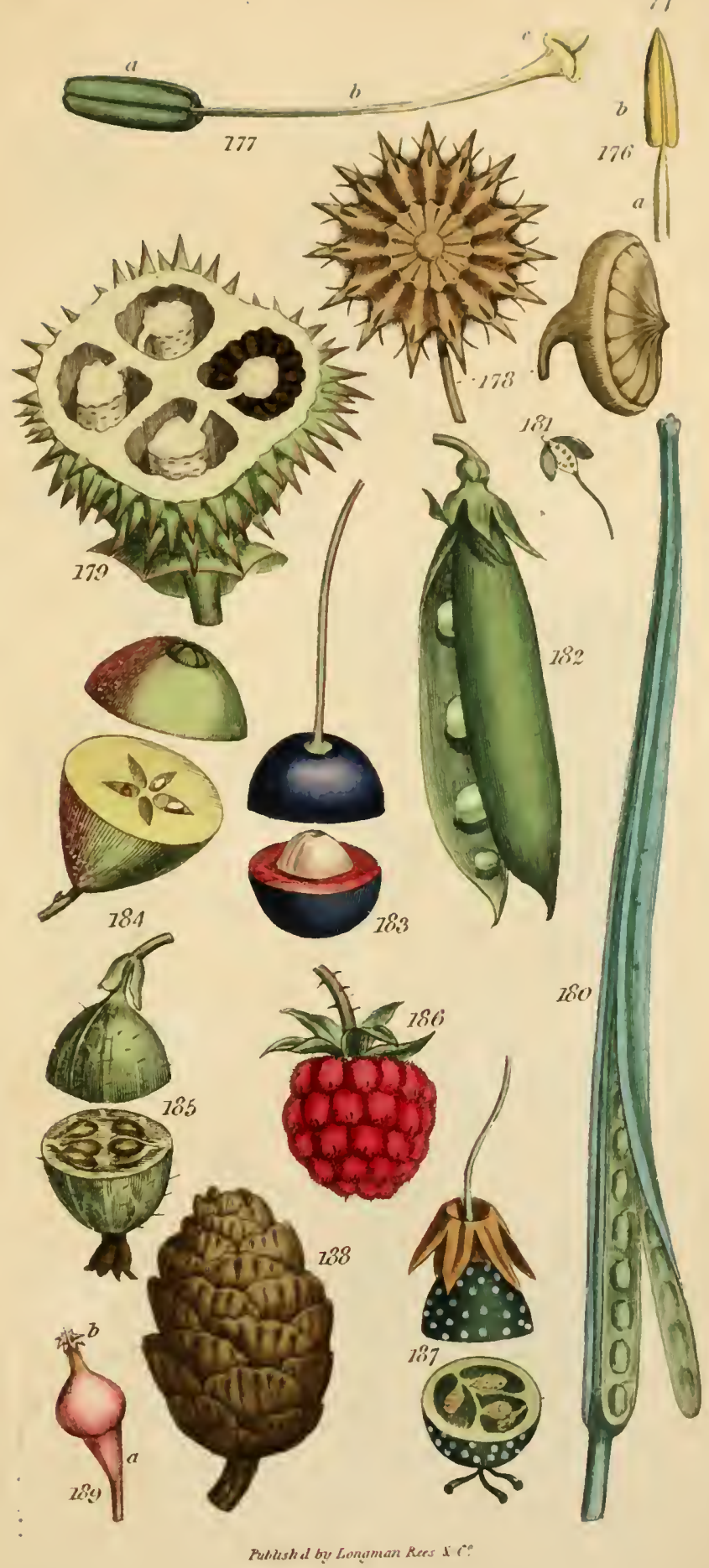




I. Index of remarkable Plants, or those of which any particular Mention, or any Change in their Classification, is mude.

Anroma, 448

Abru; precatorius, 446 Acer, 4.2

- saccharirium, 67 Assculus Hippocastanum,137 Agrimonia, 365, 425 Ailanthus, 372, 482 Alga, 495-499 Alopecurus l'ullusus, 114 Amaranthus, 373 Amaryllis formosissima, 320 Ambrosinia, 469, 476 Anagallis, 329 Angiopteris, 388 Aunona hexnpetala, உ\&6 Aponogeton, 420, 426 Aquilicia, 47.5 Arenaria, 362, 374 Aristolochia Clematitis, 337 Sipho, 337,386 Arum, 81, 91, 965, 469, 476 Ash, 61, 114, 127 Asperifolice, 414 Athrodaciylis, 373, 470 Atriplex, 484 Aucuba, 372

Bainboo, 75, 372 Barberry, 325 Bauhinia, 376 Black rose, 88 Blandfordia, 362 Bonupartea, 376
Brodica, 263

Broultia, 382

Bryonia, 475

Bubroma, 448

Bufforia, 382

Cactus coccinellifer, $33 \% \mathrm{~g}$

Canopteris, 388

Calcmagrostis, 387

Calceolaria, 374

Calla, 469, 476

Canna, 462

Cammabis, 330, 481

Capura, 419

Curpinus Betulus, $\mathbf{2 4 9}$

Caryocur, 431

Caryoplayllus, 497

Celosia, 324

Ceratonia, 185

Ceratopetalum, 374

Chara, $4 \pi 3$

Cherry, double-blossomed, 275

Chrysanthomum indicum, 80 Cistus creticus, is

Citrus, 449

C'erme, 430, 436

Climbing plauts, 110

Clunlia, 181

Cotce, 314

Coiumifere, 440

Concliam, 374

Conferra lullosa, 213 
Contrrice, 115,163

Corivaria, \& 80

Comes masuia, 60, 187

Coryintium, 157

Cncrimis, 475

Curmbita, 475

Cuscula, 95, 102

Cyamus Nelumbo, 290,291, Hastingia coccinea, 403 371,387

Cycas revoluia, 331

Cylinus, 463

Darea, 388

Devil'sthit, 107

Dicksenia, 377

Diglannms alurus, 188

Dillenia, 377

Diona'e muscipula, 173,198

Doducutheon Meadia, 01

Dog-rose, 316

Domileya, 98, 289

Dorstenia, 377

Dracontium, 469

Epimedium alpinum, 361

Erioculia, 373

Ervatm, 443

Fuclea, 183

Laphorbia, 327, 374, 177

T'erns, 486

Ficus, 336, 485

Filices, 48,

filores tristes, 78

Fontainesia, 375

Fraximus O:mws, 189

Fumgi, 499-502

Gentinna, 374

Gluncimn phenicium, 323

Glycyrrhia, 373

Gcoklenia, 375
Fourd tribe, 475, 179

Grasos, 41!, 475, 48?

Cremia, 160

Gueturda, 4;6

Gundelia, 375

Gypouphila, 374

Ileilysarmm gyrans, 211 Hetionthus anmuns, 68, 186, 203,373

- tulicrosus, 108

Irelicteres, 468

Hemerocallis, 362, 373

H(mp), 330

Hepaticce, 493

Hernandia, 377

Hillia, 383

Hippomane Manciuella, sos Hippophüe rhumnoides, 296, 481

Ilippuris, 316

Holmskioldia, 403

Hop, 189

Horse-chesnut, 136

Humea, 376

Jutropha urens, 321

Jerusalem artichoke, 108

Jungermunnice, 252, 265., 491,495

Kulmia, 325

Klcimhonia, 468

Kueppia, $3 ; 7$

Lace-bark, 26

Lachemalia tricolor, 112

Lasiopetalum, $31^{4}$

Lathyrus Apluca, 221

Lannlera arborea, 103

Leed, 475 
Iemna, $31 \%, 473$

Lichen, 195-497

Liliacee, 418

Lilium lublbifermm, 141, 273

Linnaa, 377,382

Lithospermum, 373

Liverworts, 493

Lolielia longiflora, 804

Lonicera carulea, 135

Luridce, 415

Magnolia, 377

Maltese oranges, 88

Malvacece, 410

Marchantia, 494

Meadow Saffron, 316

Melaleuca, 450

Mentha, ass

Mimosa pudica, 40, 210

- sensitiva, 210

Mirabilis, 466

Monocotyledones, 57, 59

Monsonia, 449

Mornes, 474

Mosses, 251, 261, 290, 317 ,

$$
489-493
$$

Bluricea, 382

Musa, 318

ATusci, 458-493

Musicenda, 222

Myosotis, 228

Myristice, 483

Bilyrti, 427

Nandina domestica, 507

Nastus, 379

Nelumliam, $3 ? 1$

Nepenthes distillatoria, :?3, $197,463,483$

Nopal, $3 \div 9$

Norfolk island, pine of, 35, s\$)
Nym! ikea, 101, m5, 333, $38 \mathrm{~J}$

Omphalea, 477

Orchilece, 10y, $455-402$, $46 \vec{i}$

Origumum, 373

Ornithopus perpusillus, 142

Orolins syluaricus, 177

Oxulis sensidica, 210

Pulna, 57-59, 62, 133, $313,321,50=-504$

Pandrnils, 379, 479

Papilionacece, $423,1.12--446$

Passiftora, 433

Periploca greca, $46 \overline{5}$

Phicum pratense, 41, 113

Phyllnchue, 462

Pine-a!ple, 316

Pinus, $47 j$

Pistacia Lentiscus, 316

Pistiu, 439, 468

Plane-tree, its buds, 130

Pomacece, 427

Populus dilatata, 189

Potamogeton, 194

Pothos, +369

Precice, 414

Primula marginal, 01

Pleris, 355

Rhapi, 322

Rhodioka, 395

Riv'ularia, 198

Roiacere, 118,428

fiolaceer, 114

Ruliacere 219

Rumex sanguincus, it

Rutacece, s!!

liuta graterilcus, 324 
Salix, 471

Salvia pomifera, 346

Sarracenia, 195, 363

Schenchzeria, 376

Scitaminea, 409, 462, 467

Scopolia, 468

Seriplium, 457

Silene inflata, 348

Sisyrinchium, 437

Smithia sensitiva, 210, 378, 445

Solandra grandiflora, 140

Spergula, 362

Sprengelia, 377

Sterculia, 425, 478

Stilago, 463

Strelitzia, 376

Strumpfia, 463

Stuurtia, 375

Stylidium, 462, 464

Tabasheer, 76

Tamarindus, 438

Taxus nucifera, 286

Thea, 450
Theolrome, 4.17

Tmesipteris, 388

Tournefortia, 375

Tragopogon major, 347

Tropceolum, 421

Tulbaghia, 263

Umbellifera, 416

Uredo frumenti, 348

Valisneria spiralis, $\mathbf{3 3 5}, \mathbf{4 8 0}$

Vaucheria, 498

Ventenatia, 464

Viscum album, 208

Willows, 34, 60, 188, 346, 471

Xanthe, 483

Xy'opia, 469

Yew, 285

Zostera, 469 


\section{II: INDEx to the Explanations and Illustrations of technical Terms:}

Anrevpt leaves, 159,177 Acaules, planter, 126 Acerosum, folium, 1.54 Acinaciforme, fol. 170 Acimus, 283, 295 Aculeus, 224

Acuminatum, folium, 160 Acutum, fol. 160

Adpressa, folia, 147

Adscendens, cculis, 117

Aggregate flowers, 308

Aggregati, pedunculi, 131

Ala, 258, 301

Alatus, caulis, 123

Albumen, 290-201

Alburnum, 33

Alienatum, folium, 172 Alterna, folia, 145, 177

Alternè ramosus, caulis, 121 Amentum, 248, 249, 309 Amplexicaulia, folia, 150 Ancetso, caulis, 123

- fotium, 1:0

Angiocarpi, fungi, 501

Anthera, a71

Aphyllae, planter, 144

Apophysis, 489

Apothecium, 497

Appendages, 218

of the seed, 302

Appendiculatum, fol. 1:7, 197

Apple, 282

-irillus, $\approx 96-899$
Arista, 250

Arrow-shaped leaf, 156

Articulata, radix, 113

Articulatum, folium, 175,

178

Articulatus, caulis, 122

- - , culmus, 128

Artificial systcms, $355--35 a_{2}$ 389

Auriculatum, folium, 179

Avenium, fol. $16 \pi$

Awlshaped lcaf, 169

Awn, 250

Axillaris, podunculus, 139

Bacca, 282-256

Bacillum, 497

Barren flowers, 306

Basi trinerve, folium, 16 ?

Beak, 301

Beard, 250

Berry, 282-286

Bifiori, pedunculi, 131

Bigcminatum, folinm, Iso

Bilolum, fol. 157

Bine, filu, 14.9

Bin tur, filium, 176

Bipinnatifidm, fol. 1.50

Bipinnatum, fo!. 181

Biternatum, fol. 1 so

Blistery leaf, 165

Blunt leaf, 100

Butany, 11

Brachiulur, rausli: 19: 
Bractca, 221-223, 246

Bulbosa, radix 111

Bullatum, fo!tum, 165

Bunch, 238

Calyptra, 252, 264, 488

Calyx $213-253$

Camlium, 36

Campanulaía, corolla, 257

Canaliculatum, folium, 170

Capitulum, 235

Capsua, 27s-280

Cariua, 258

Curinatum, folium, 1 70

Carnosum, fol. 109

Cartilagmeum, fol. 162

Catkin, 248, 249 , 286, 309

Catulus, 248

Cauda, 301

Candex, 102, 104

Canlina, folia, 144

Crulinus, pedunculus, 130

Caulis, 116

Cellular integument, 23

Central vessels, 50

Channelled leaf, 170

Characters of plants, 365370,434

Ciliatum, folium, 162

Circumscissa, capsula, 413

Cirrosim, folium, 161, 176

Cimus, 224-206

Climbing stems, 119

Cloren leaf, 157

Cluster, 231

Courctula, panicula, 238

Coccum, 280

Coloralum, folizm, 168

Coloured leaf, 168

Columella, 278

Comu, 301

Completus, flos, 306
Comprosita, folia, 151, 175181

Compound flowers, 307 , $450-457$

$-181$

Compressum, folium, 170

Concaurom, jol. 166

Conduplicatum, fol. 161

Cone, 286

Conferta, folia, 145

Conjugatum, foltum, 179

Connata, folia, 150

Corculum, 96, 288

Cordatum, folizm, 156

Coriaceum, fol. 172

Corolla, 243, 353

Corymlins, 233

Costatum, folium, 166

Cotylcions, 96, 289-291

Crenatum, folium, 103

Crescent-shaped leaf", 150

Crispum, folium, 166

Cruciformis, corolla, 257 , 436,437

Cuculiatum, folium, 173 , 195

Culmus, 127

Cuneiforme, folium, 154

Cup of the Flower, 243-255

Curled leaf, 166

Cuspidatum, folium, 161

Cuticle, 16

Cylindrical leaf, 169

Cyma, 237, 246, 309-311

Cyphella, 497

Decidunm, folium, 172

Dcrompositum, ficl. 180

Decurrentia, folia, 151, 178

Derussatu, fol. 146 
1)elloides, folinm, 1.5

Dencrisa. folia, 148

Denturam, filism, 163

Depressa, fullu. 1.is

Depréssum, folium, 170

De'erminatì ramusus, comlis,

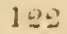

Diamond-shaped leaf, 155

Dirotyledonse's, :i

Difiusa, praniulula, 2.57

Diffusus, caulis, $1=0$

Digitum, folium, 176

Dioici, flores, 306, 395

Diséks, $30 y$

Disscatlum, folium, 158

Jisicpintertum, 275

Bssticha, folia, 110

Distichui, caulis, 121

Dolulviforme, fülium, $|\pi|$

i) own of the seed, $299-301$

Drupa, 252, 251

Dust of the anther, 268

Elliplicum, folizu, 1.53

Esnargintulum. fin!. 100

Embr:0, 96, 285-259

Emerise, fislia, lis?

Enterle, fislium, 16i

Jinodis, culmui, 12?

Eineforme, frilium, 170

Entire laat, 101

Epiclermis, io

linnitantiu. fulia, 150

Evecta, friliue 1.17

Ererlus, canlii, 117

Erosum, folium, 103

Everereen leaves, 1i2

Excitabiaity, 05

Fill of the leaf, $3 \div 1$

firciculata, foliir, 1.16

Fiscirnlatui, cunlis, 1 :?

Frasciculus, $₫ 35$

Ferile fluwers, 300
Pilrossi, raclire, 10:

Fudle-sheped leat, 1 is

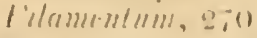

Fimgored lesing $1 ; 0$

firsum, follinm, 157

Flus rlifirmin, coulis, 11!

Flingele:al, 16:)

1\%x"erses, mulis, $1=0$

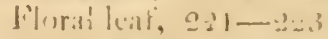

I\%turs livelus, is

Finter. 3078

I\%irifiru, folia, 151

Flexuli, 3.

fislimm, 1.13

fulliculics, -79

furcing, ? )

Frinece of musase. 10

Fringed leat, 16.

Irum, 133

fillertun, e.15

l'usijurmis, inilix, :07

Gollulus, :E.

Gali=, 314-3it

Gomman, 1:35

Gemmuncus, prelun 'u?

Gicniculalu, culmui, ing

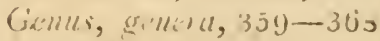

(icm), : i

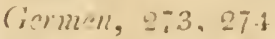

(riblum, follum, 160

Citciler, l一t

(i).ured, $\because$ : (i)

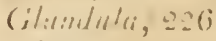

Cimmlelusmm, follimm, 161

(ilumiles, $1=5$

(illinti, 250, 300

Girlium, si

(i) malubli, rantir, 113

(y)muscilfpi, fungl, ., )

Ji. $r=$ of p'antล, $0.3 i-090$

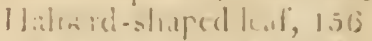

Hololum, fislinise, 156 
Hatehet-shaped leaf, 171

Heart-shaped leaf, 156

Herbarinon, 504-511

Hilum, 295

Hivus, 123

Histidus, 125

Hollow leaf, 166

Honey, 259, 206-270

Honey dew, 189

Hooded leaf, 173,195

Horizontalia, Jolia, 147

Husk, 250

Hymenium, 501

IIypocrateriformis, corol. 257

Imlricata, folia, 146

- Immersa, folia, 148

Incamns, 125

Incisum, folium, 158

Incompleta, corolla, 2.58

Incompletus, flos, 306

Incurva, folia, 1.18

Indusium, 248

Incquale, folium, 159

Inerme, folium, 162

Inflexa, folia, 148

Inflorescontia, 230

Infundilulifor mis, corol. 257

Integcrrimum, folium, 161

Integrnm, fol. 152, i61

Internodis, pedunculus, 130

Involucellum, 246,247

Involucrum, 245-248, 310

inolutum, folium, 164

Iulus, 248

Jaggred leaves, 163

Jagred-pointed leaves, 160 Jomted leafi, 175, 178

$\mathrm{Ked}, 258$

Kecled leaf, 1 70

Kidney-siapd leaf, 156

Laciniutum, folmom, 158
Lavis, 124

Lamellce, 501

Lamina, corollce, 250

Lanatus, 125

Lanceolatum, folinn, 1.54

Lateralis, pedunculus, 13 !

Laxus, canlis, 120

Leathery Ieaf, 172

Legumen, 281

Lifier, 25

Ligulati, flosculi, 307

Limbus, corollce, 256

Lineare, folinm, 151

Iingulatam, folium, 172

Lion-toothed leaf, 157

Lirella, 497

Lobatum, folium, 152, 157

Lobed leaf, 152, 157

Lunulatum, folium, 156

Lyraium, fol. 157, 178

Maculatus, 126

Medulla, 38

Memlrana, 294

Membranacersm, folizm, It:

Monocotyledones, plantee,

$5 \%, 59,97,225,289$

Monoici, flores, 300, 395

Mucronutum, fultum, 161

Minltiflori, pedunculi, 139

Mutica, gluma, 251

Naked flowers, 306

- leaf, 168

Natantia, folia, 148

Natural systems, $355-359$, 406

Nectarium, 255, 266-270

Needle-shaped leaf, 154

Nervosum, folium, 166

Nicked leat, 160

Ailuas, 124

Nomenclature, 370-388

Notched leaf, 163 
Nucamentum, 248

Nudum, folium, 168

Nurtus, flos, 300

Nut, 282

Obliqua: folia, 148

Oblique leat, at the base, 159

Oblongum, folium, 153

Obovalum, fultum, 1.53

Obtusum, folium, 160 cuin acumine,

161

Ochrea, 223

Opposita, folia, 145, 177

Opjositifolius, pedunculus, 130

Orviculatum, folium, 152

Ovale, folium, 153

Ovatum, folium, 153

Palmatum, folium, 1 ss

Panduriforme, folium, 157

Panicula, 237

Papilionacea, corolla, 258

Pupillosis, 124

Pappus, 299-301

Partitum, folium, 158

Patentia, folia, 117

Pectinut.ım, folinum, 159

Pedatum, folium, 181

Pedicellus, 129

Pedunculliss, 129

Pellicula, 296

Peltatu, folia, 149

Pentagonus, caulis, 123

Pepo, 28.t

Perfect flowers, 306

Perfoliata, folia, 150

Perianthium, 244

Pericarpium, 2.44.276-257

Periclucetium, $251-253$

Peridium, 502

Peristomium, 491

Personata, corolla, 257
Petalum, 213, 255

Peliolata, foliu, 119

Puliolus, 132

Pileus, 502

Pilusus, 125

Pilus, 226-209

Pinnalifudum, folinm, 159

Pinnatum, fol. $176-179$

Pistillum, 2.13, 273-270

Plaited leaf, 105

Plicatum, folinm, 105

Plimule, 97

Pod, eso

Pudelium, 497

P'ointed leat, 160

Pullen, 272

Pomum, 28:

Pouch, 280

Priemorsa, radix, 107

Prcemursum, folium, 160

Prickle, 224

Procumlens, cuulis, 117

Prolifer, cuul. 121

Prostratus, caul. 117

Pubes, seminis, 301

Pubescence, 226-209

Punctatum, folium, 165

Qualrangulare, folium, 1.55

Qiladrangularis, canlis, 123

Quaterna, folıu, 1.20

Ouina, folia, 146

Quinatnm, folium, $1 ; 6$

Quinquensulare, jul. 1.55

Quinquangularis, caulis, $1 \geq 3$

Racemus, 231

Radicalia, folin, 111

Radicuns, canlis, 118

Radicula, 103

Rustius, 308

Rumea, folin, 145

Ramens, pedunculus, 137

Ramosissimus, caulis, 1I

$2 \overline{4}$ 
Rays, 308

Receptaculum, 24!, 30 1, 305

Reclincta, folia, 1.17

Reclinatus, canlis, 118

Rectus, crulis, 120

Recurva, folio, $1.1 \pi$

Roflexa, jolia, 1.17

Reniforme, follimn, 156

Repanisum, foliun, 163

Repens, canlis, 117

- , redix, 106

Resupinata, folia, 148

Retusum, folium, 160

Revo'minm, folinm, 16t

Phonelezm, folium, 155

Ribbed leaf, 160

Ribless leat, 167

Pingens, coroila, 257

Rosrcen, cromolla, 257

Rostrum, seminis, 301

Rotuta, corolla, 257

Rugged leaf, 165

Rugosum, folium, i65

Rumcinatum, fultum, 157

Sngiltalum, folium, 156

Samara, 279

Sarmentosus, caulis, 120

Scaler, 125

Scaly roots, 112

Scandens, caulis, 118

Scripus, 108

Scar of the seed, 295

Scimitar-shaped icaf, 170

Siecomda, folia, 147

Seed, :4.1, $287-301$

Sced-vesscl, 244, 276-28\%

Siemen, 2.14, 287-301

Semicylinaracesm, fol. 160

Sempervirens, fotizm, 172

S parated flowers, 306

Sera+u\%, folium, 102

Semulrum, folium, 163

Sessiles, flores, 139
Sessilia, folia, 1.19

Sharp lcaf, 160

Sheath, 259, 251, 309

Shcathing lcaves, 150

Shrubs, 136

Silicula, 280

Siliqua, 280

Silver grain, 53

Simplicia, folia, 151

Simnatnm, folium, 157

Solitarius, pedunculus, 13 :

Spadix, 2.50, 265

Sparsa, folia, 14.5

Sparsi, pedunculi, 131

Spatha, 250

Spatulatum, folium, 1.54

Species of plants, 359-370

Sprica, 231-233

Spicula, 233

Spike. 231-233

Spikelet, 233

Spince, 223

Spinosum, folium, 162

Spiral vessels, 47

sporte, 497

Sforcmgium, 496

Silumen, 243, 270-273

standard, 258

Stigma, 273

Stipes, 134

Sipula, $218-221$

Stonc fruil, 282

Striatus, i 26

Strictus, caulis, 120

Sirolilus, 286

Stropitivlum, 302

Styilus, 273

Sulimersa, folia. 148

Sul rotundum, folium, 153

Sulsessile, ficlium, 174

Subulatum, folinm, 169

Sulcalus, 120

Supradecompositum, fol. 180.

Sword-shaped leat, 170 
Tail of a sced, 301

Tcndril, 224-2:0

Teres, caulis, 122

-, folium, 169

Terminalis, pedunculus, 131

Terna, folia, 145

Ternatum, folium, 176

Testa, 294

Tetragonum, folium, 171

Tetragonus, caulis, 193

Thallus, -196

Thorn, 223

Thyrsus, 238

Tomentosus, 125

Tongue-shaped leaf, 172

Toothed leaf, 162

Triangulare, folinm, 155

Triangularis, caulis, 123

Trice, 497

Trigonum, folinm, 171

Trigonus, caulis, 123

Triblotum, folium, 157

Trinerve, folium, 167

Triplinerve, folium, 167

Triqueter, cuulis, 123

Triquetrum, folium, 171

Trowel-shaped leaf", 155

Truncalnm, folium, $159^{\circ}$

Tuberosa, radix, 108

Tubular leaf, 169

Tululosi, flosculi, 303

Tubulosum, folium, 169

Tubus, 255

Tuft, 235

Tuнic, 296-200
Uniclla, 236, 246, 309-311

Undivided leaf, 152

Undulalum, folium, 165

Unequal leaf, 159

L'ngriis, 236

Uniflori, pedunculi, 151 |

United flowers, 306

Utriculus, 278

Trainantia, follia, 150

Variegatum, folium, 160

Varieties, 135, 354

Veil, 264, 158

Veinless leaf, 107

Veiny lcaf, 1 fo

Fonosum, filium, 166

Ierticalia, folsa, 1.47

Ferticillatu, folia, 145

Ferticillus, 230

Vexillum, 255

Yillosus, 125

$V$ iscidus, 124

Vitellus, -992-29?

Folubilis, caulis, 119

Folva, 253

Wravy, 103

Wherl, 230

Whorles, $110,1 \% 9$

Wing, 301

Wrapper, 253

Toked leaf, 179

Xolk, 29:- $-4 t$ 


\section{WORKS LATELY PUBLISHED}

BY THE SAME AUTHOR;

Sold by Longman and Co. Paternoster-row:

White, Fleet-street; and JAMES SOWERBY,

No. 2, Mead-place, Lambeth.

1. Flora Britannica, Vol. 1, 2, and 3, 8vo. 1800, \&c. Price 11.6s. 6d. The concluding volume of this work will be published as speedily as possible.

2. Compendum Floire Britanniciz, Pars 1, crown 8vo. 1800. Price 3s. The conclusion of this work will appear with that of the preceding.

3. Tracts relating to Naturad IIstory, with coloured plates, 8vo. 1798. Price 7s.

4. English Botany, with coloured plates, by $\mathrm{Mr}$. Sowerby, 8vo. Vol. 1-25, \&c. Published in 5s. numbers, 12 plates and deseriptions in each. A rery few volumes more will complete this work, which will then contain all the known plants of Great Britain and Ireland, Fungi excepted; the latter being published, in a separate work in folio, of 400 plates, by $\mathrm{Mr}$. Sowerby.

5. Exotic Botanr, with coloured plates, also by Mr. Sowerby. No. 1-24, at 2s. 6d. each in 8 vo. or 5s. 4 to. It will depend on the encouragement of the public whether this work should be prosecuted or not, and $\mathrm{Mr}$. Sowerby will thankfully receive any directions on the subject. Its plan, hitherto unique, is to give original coloured figures and descriptions of such exotic plants as are worthy of cultivation in the gardens of Britain, and which are not figured elsewhere, except, possibly, now and then in some rare or expensive foreign books. Its 


\section{Works pullished ly Dr. Smith.}

author will never therefore intentionally burthen the public with a fourth figure in addition to the three which sometimes appear of the same plant in our monthly writers. This he is the more desirous of attending to, as his work is not limited to plants already in culivation in England, being occasionally enriched with drawings and specimens of totally nciv productions, from Indiu more particularly, which may, when known, he procurcd from abroad.

o. A Sketcri of a Tour on the Continent, in 3 Vols. 8vo. 2 d edition, 1807. Price 11. 43.WWith severat: other botanical works.

Specdily will be pullished,

\section{A TOUR TO LAPLAND,}

Translated from the original unpublished nanuscript

Itinerary of the celebratcd LixNEUS,

$$
\text { By Dr. Smith, }
$$

Tivith above 60 wooden cuts from extcmporancous sketches of the illustrious author. 


\section{IVORKS published by JAMES SOWEREY.}

1. Bimtisin Minenalogs, in coloured figures with descriptions fiom the primitive crystals to their amorphous states, No. 1 to 52. Price 9!. 5s. to be continued in numbers published every two months, at 5s. each.

2. Tise British Misceldany, or coloured figures of new, rare, or little known aninal subjects, many not before ascertained to be inhabitants of the British Isles, and chiefly in the possession of the author, 12 numbers, price 21.7 . 6 d.

3. Crystallography, Parts 1 and 2, with models 105. 6d. each, without models is. cach, intended to txplain the nature of crvstallization of different mineral substances. The first part being on coals, the second explains the formation of that curious combustible the diamond, or pure carbon.

4. ExGlish Fungr; or coloured figures of English fungi ormushrooms, 2 - numbers, 101.35 . 6d.-Dr. Sowerey, having lately had some very curious FungI sent him, is detertuined to publish a Supplement to the English Funea early in the spring of 1809 . It will be in Tiumbers at 2s. 6d.; each number containing four plates.

5. A rew edition of the Botanical Drawing-Book, with grcat additions, corrections and improvements, price 10s. 6d. coloured, or 7 s. 6́d. uncoloured.

\section{Shortly will be published,}

6. A concise Prodromus of the British Minerals in Mr. Sowerby's Cabinet, as a sort of essay towarels a ncw, natural, and easy arrangement, with references to bis Bripisit Mineraiogy.

7. Also an Essay, for a new, nscful, and universal Chromatic Scale or List of Colours. It being a great desideratum, in the prescnt state of our knowledge, to find a means of universal agreement on this bead, the author was induced to offer this as likely to answer that end. Lectures will be given on the subject in January and Eutuary 1809. 


\section{MODERN PUBLICATIONS,}

A $\mathbb{D}$

\section{NEW EDITIONS}

OF

\section{VALUABLE STANDARD WORKS,}

LONGMAN, HURST, REES, AND ORME, PATERNOSTER-ROW.

\section{PERIODICAL PUBLICATIONS'}

Under the immenlante Putromaye of the KINI;, the QUVEN, and the rost of the JoOYA1, FAMILY

THE BRIJISH GAIALRY OF JICJURES,

under the superintemence of JHENItY THESIJAM.

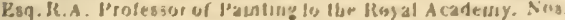

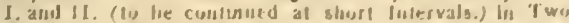

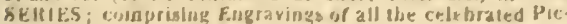

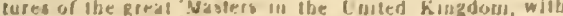
bistorical and Arscripluve Jelter l'iess.

The lisistorical l'art by Irilleam Young Ollley, R.sis.

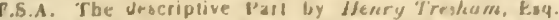

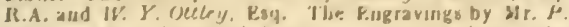
IV. Tornkins, llislurieal Yugraver lo lier Majesty, who has the Managerrent of the ox+cullye vart of the Wosh :

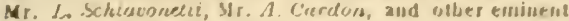
Eugravers. The Jirawiags of the First serles by Mr.

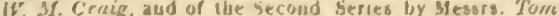
kins, Uatres, Violes, Jludisoon, Ansel, Salchuell, Le. FSRST SEMIE,S. Sinull Engruzings

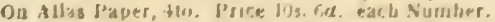

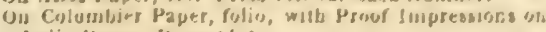
India p"alus. Pree Il. Is.

On Columbirr Paper, Jolun, wilb lue Plates alizbily con loured, l'rice 1l. lis.ed

No. 1. Contaius fen Puetures, from the Marquis of seaf. ford i Cirllectuon, viz.

Baplesin, and Cicrifiravalus, ny N. Pousuna-Tzu Cunduapes, and a Destune Vou of Jizole, by G Pousurn

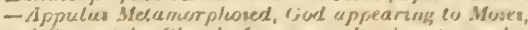
and Sun-ues, by cluude forume. - Jucul, valering hes

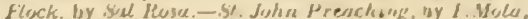

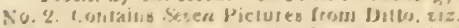

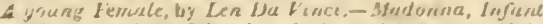

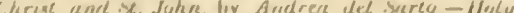

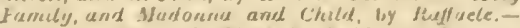

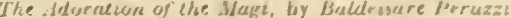
- Pennance, and The Eivcharist, liy N. Perusstre

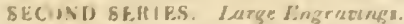

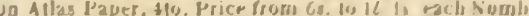

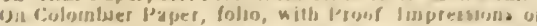

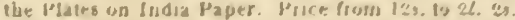

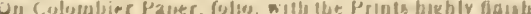
ed in Colours, in Imitation of the vrigiual pictures. Jil cuuerquence of the very kital liune and Allention

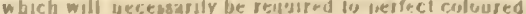

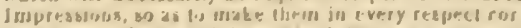

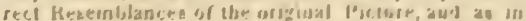
some Cage the Time and Altestivoll required will be grealer than in others, the firios of each wil be te gulated accurdiugly nbesi pulblielied.

No. 1. Containg The Iloman taten in Adultery, by Raterts. Mr. H. Hopers cillecturn.

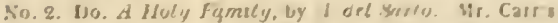
* A mixed sianner of hugraving las been cliconen for the present Wolk, as ackinwledyed tis lore the beat sieans of anulatiog accurately the whor bale of the

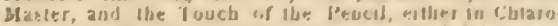

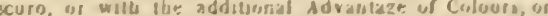

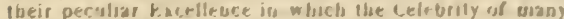
of the thest d stumgunbes Bastero ie tosuded. The olsject

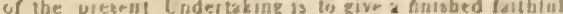
liepresentation of the origiual ficture, under all the Cornbsaatiess of atyle of brawiog, Conpusition, Lighi and shador, and rolourang.

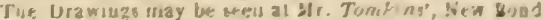
streel.-For forthes Particular, ite rrospectia
GHAERAI, COI,JECTION OF VOYICIS

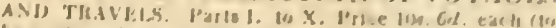

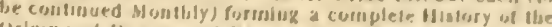

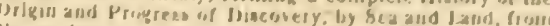

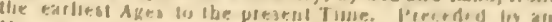

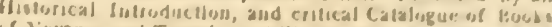

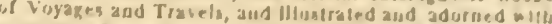

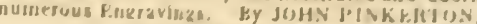
Autuor or Modens foerzrapby, \&ec.

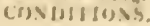

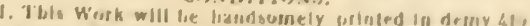
on doew Iype.-II. The Work, it is expecied, wib be

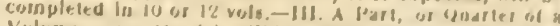

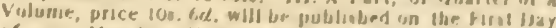

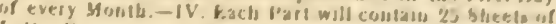

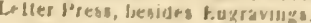

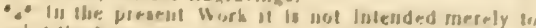
reprlat the Sarrativen which bave alseady apyeartd, nint

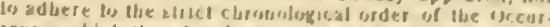

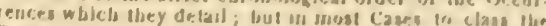

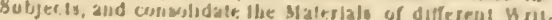
ers, ess as lis exfutul at ofie Virw all that is trateresfing of

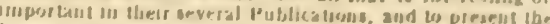

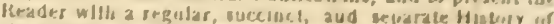

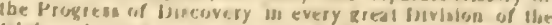

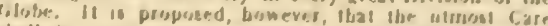
- ball loe taken uol tos destroy or weaken the Julerest

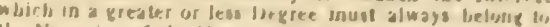
Itse Narrative of the Voyages bimaelf, by ualise wheie is call be dout with Adoantage, the Janzuage of ullasind

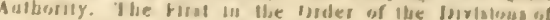

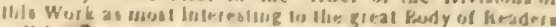

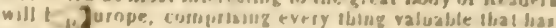

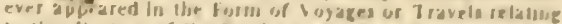
(is) this ferrsiuts of the farth, aud in the absequent Pail. the order of Arranzersielll which Mr. Pinberion bas ver aued lis bia greal groggaplacal Wiort, will be adopled.

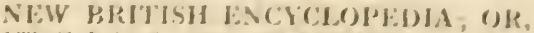

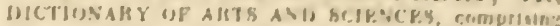
an accurate and propular view of the vrearint improveil

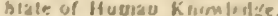

by WII.S.IA 31 Sic Ifo)I.SC)

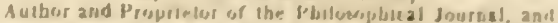

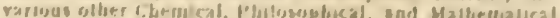

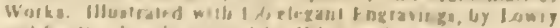

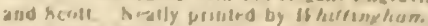

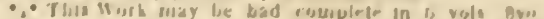

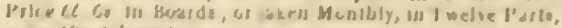
frice 109, ide each.

THE, \ЕW CYCI.PFIIIA, OR, UNI. VPRSAL MILIJINAILY UR AKIS, BCIYNCES, ASI II

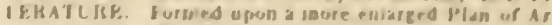

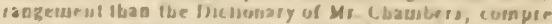

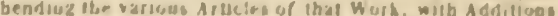

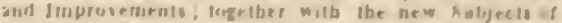

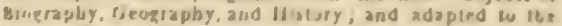
virteut blele sil Litolatuse ard srience.

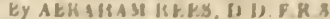

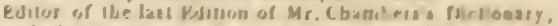

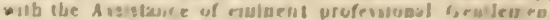

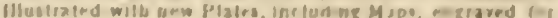

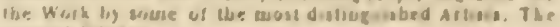
sircund tidit ing

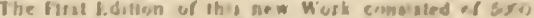

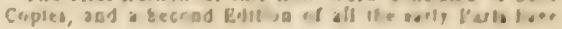


been already called for. The following are its priscipal Recon!mendations.

1. 'Th: L'lan of this Work is intended as an tmprovemeul nyou sumilar Publications, beilg a Medium befwcen the Plan of a Dictumary and that of Treatises; and $\mathbf{c o m}$. prehending the Mdvintapes of each. The History and Jullites of eitell sirnce are given moder its appropiate title; atd its rarions Divisons, which can be more satisfactorily explained in separate Articles than in the Body of a"1 realise, are introdiced mider theor sespective f'eams.

The Editor is of ackmowledged Letumug and Indins try, and of unquestlouble Esperience in this Depatment of literary Labour; the greater Part of his Life having bees cmployed in editing and inproving the last Edition of Mr. Clambers's Dictiunary, and in cullecting Materials for the present Work.

3. Anong the fientlemen who have ensaged to contrl bute llacir Assistance to this Work, are many of distin. gurblud Enanenre.

4. The imbelishments are of a vely supesior Descrip tivn, and will lorm, when completed, an monus arably more elrgaut and correct set of scientitic and wher l'littes than has ever been produced. The scientitic Subjects ale en:laved by Mr. Lowry, whose accurate Knowledge and impured Nethod of Execution, in this Branch of the sil, lavr not hees equalled. The Subjects of Naluril Ilistory, \&c. are chietly e.1graved by Mr. Mitton and Mr. Scott, witls corresponding Taste and Beanty.

Tit I rawmes art alumst wholly new. The Plates which are alleaty engraved, are frou Irawings by Messrs. Ha: man, lloward, Stubbs, Lowry, Eúwards, Uonovan, Sowerby Sirntu, Mushett, E. Aihin, F. Nicholson, Danicl, Nayler, Anderson, Kirkman, Farey, junior, \&c.

The Maps will he duible the Size usually

spmiar Publicalions, and are drawn and engraved und the Directums of Mr. Arruwsinith.

Parts 1. to XXIr, are already published, and may be gath elth: r ceriodically or together, Price 20s, each, in liwads, auid arrangements have lately been made to pul, bish the succeteding Parts every two Montlis, till the whole Wort be co:muleted.

7. A few Copies are printed off on royal paper, wi
proot impressons of the plates, pice $l l$. J6s. each Part.

THE LONDON MEDICAL REVIEW, NOS.

1 tw IV. (t) be continued Quarterly) Price $2 s .6 d$. each.

The object of olbis Publication is to analize and cri ticise Woiks of primary Imporlance in Medicine, Surgery, atid the cullateral Sciences. An ample D scussion of cou inoversial Subjects. and the riequent Intruducton of ull. ginal Maties, will form its jeculiar Charicter.

The Necessity of such a Wolk must be obvions, its Ltility must be proportioned to the Abilities af its Exe cutun-its Merits minst be determincd by Time.

Gach Number will contain a correct List of the Medical Fublications of the preceding Quarter.

THE A'THEN AUT ; a Magazine of Literary and Miscellantous Iuformation. Conducter by J. AIKIN, M. D.

Nos. I. 10 XXI]I. Price 2s. each.

( $\Gamma$ o be comtimed bisutbly.)

Conlaining Gcueral Correspondence, Classical Disqui sitions, Acconuts of and Exthacts from rare and curion Jooks, Memeirs if distinzuished Persons, Otiginal Poetry, Literary and Miscellanoous Infurmation, Lisl of new l'nb. lications, Meteotolomifal Register, biscroveries and Im-

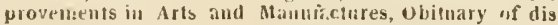
tinguished J'ersons, Donestic Coccurrences, List of lank rupts, Foreinn occurrences, Retrospect of Public Afairs, Combietcial Reports, Price of Slocks, Agricultumal Re ports, alıd prices of Graill.

"* The Albcuxum is designed essentially to be one of these popular Miscrllanies, so long known and apjroved iu Hlis Combliy. Wuder the tame of at Mergazine, and to enbrace all the usual Ohiects of such Publications: Int as its Title way be understood to inuply, it is mcant to aim at a bigher literary Chasacter than they eommonly supuort

THE HRITISH THEALRE; or, a COL LECTION GF PLAYS, which are acted at the Tlieatres Royal norry-Lane, Covent-Garden, and Haymarkel, pronter uniler the Auhority and by Pelonission of the Managers from the Prumpt Bonks, with Biographical and Critic: i

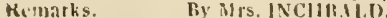

Wi:h elegant Engravings. In 25 vols. royal $18 \mathrm{mo}$. Price 6l. lis. fid. in boards : nr on fine Paper, witb Portraits and

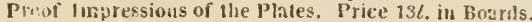

Ibe following are the llays contained in llis Work, nhiflo may he purehased ieparately, l'rice is. eard
1. Nontrineers; 2. Sperd the Plough ; 3. Wheel of Fortune; 4. Lovers Vows; 5. Inkle and Yarico; 6. Isabella; 7. Whlt Uats; 8. Donglas; 9. Stranger; 10. Country (jirl; 11. Dramatıst; 12. Hamlet; 13. Grecian Danghter; 14. Busy Budy; 15. Jolan Bull; 16. Tancred and Sigismun14; 17. All in the Wrong; 18. Macbeth; 19. Bold Stroke for a Wife; 20. Puor Gentleman; :1. Such Things Are; 28. Oruonwho; 23. Love in a Village; 24. Ruad to Ruin;
25 . Jante Stoore; ofi. Clandesine Marriage; 27. Edward the IBlack I'rince; 28. Merry IVives of Windsor; 29 . Rule a Wife and have a Wife; 30. Mourning bride; 31 . Cure for the lieart Ache; 32. All for Love; 33. Way to Keep 1im; 34. Kung John; 35 . Slie Strups to Conquer; 36 . The cinscins Lovers; 37. The lievenge; s: Love for Love; 39. Every llan in his Ilmmonr; 40. Coriolanas; 41. Jew; t2. Romfo and Juliet; 43 . The Careless Husbnad; 44 George barlawell ; 45. The beanx Stratagem; 46. Gustavis Vasa: 47. The W'st Indian; 48. Julius Cresar; 49. Evely One bas his Fan!t; 50. The Jealous Wife; 51. The Tempest; 52. The Urplatin; 53. Cato; 54. The Belles Stratagem; 55. Zara; 5to. The Fair l'euitent ; $5 \pi$. The Deserted Danghter ; 58 . First Love; 59 . Siege of Danniscus ; to. Provoked Wife; 61. Kival Qncens; 62. Lady Jane Grey; 6.3. Love makes a Man; 63. Roman Father; 65. Point o Hotlour : Gii. Isarbarossa; i. Merchant of Venice; 68. Wives as they Were; 69. King Lear; Tu. Colnstant Cou ple; 7 L. School of Reform: 72. To Marry ur not to Marry 3. King Henry VIII.; 74. Kilg Henry V.; 75. Good.NaInred Man; it. Antony and Cleoporra ; 77 . Recrniting Orticer; 78. Countess of Salisturry; 79. Winter's Tale; 80 . De Mullfont; 81. Cuunt of Narbonile; 82. Castle of Aludalusia ; 83. Suspicions Hushand; $8 \%$. A Buld Stroke for a Hus. taind; 135 . A new Way to pay old Delis ; $y($. Way to get Married; 87. Fatal Curiosity; 88. Laul of Warivick; 89. Fonntaiblean; 00. The Jloneymoon; $4 \mathrm{~J}$. The Wonder: Q2 Lionel and Clarissa; 43. Earl of Essex; 4. King Hessy the Fourth, Part i; 95 . The Erothers, a Comedy; 6. She Wourlel and she Would Not; 97. The Juconstant; 3. The livals; 99. Measure for Measure; 100 . Know your own Mind; 101. King Richard the Third; 102. Kung Henry 1l:e Fourh , 1'ant 2; 11)3. Tlie Gamester; 104. The Mall of lie World ; 105. Maid of the Mill; 106. The Dnenna; 107. The Provok d Husband; 108. The Chastces; 109. The Distressed Moth , l10. The Beggars' Opera; ill. Mahomet; 112. Tle Foulding; 113. As You Like it; 1i4. Twelftis Night; 115. Much Ado about Nothing; Vo. Cymbeline; 117. Venice Presfrved; 11\%. Comedy of Errors; 119. Tamerlane; 120. Surender of Calias; 12i. Battle of Hexham; 12\%. 1kon chest; 123. Heir at Law; 12\%. Qthello; 25. Heuress.

THE ANNUAL REVIEW, and HISTORY OF LITEKATURE. To be continut Aunually.

A. AIKIN, Ediur.

Volume I. to VI I'rice $i l$. Is. ench in Exira Boards.

"** This lieview consprises in one volume, Accoums of all the Works jublished during cacb Year, (incluting a Variety of valuable l'ublications. which never find it whace in any other Review) arianged into Chaplets, agiceably to their respective Subjucts, and preceded hy an Historical Introduction. It is paticularly suifed for the Libraty, and for Exportation.

THE ARCHITECTURAL ANTIQUITIES OF (IREAT BRITAIN, displaying a Series of Stect Filgravings, representung the most beantiful, evrous, and Interesing Aucient Editices of this Conntry; with an 11istorical and descriptive Aecount of each Subject.

By JUHN I:RITTON.

Parts I. to XIV. In Medium and Imperial s10. 10s. Gd. and 163 , earb (to be continued Quarterly.)

"The engravings are executed in a superior style; the descriptions are sulliciently ample, and appear to be accurate; and, under the superintendence of so able au antiquary as Mr. Britlon, there can be no dount (liat clie succeding yarts will display a corresponding excellence" sisti Jac. "lihe plates are ticautifully execuled, and the whole constitutes a pleasing pcrformance of a mo-

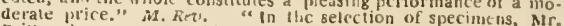
Britton has ungliestiondbly shown tis judgment: a work so executed cannot tail to metel encouragenent?" Brit. Crit,

CENSURA LITERARIA, Second Series, Nos, 1 to XXIII. Price 3s, each, (to be contuued Nomli. $1 y$ :) coutaining Opinions, Extracis, and Titles of old Eng. lisli Books, especinily those wbich are scarce; witl, Medli. lations ou Liternture and Life. To which will uow be regularly idded, NECOGKAPHIA AUTHORUM, of Me. moirs of decensed $A 1:$ thols.

\section{By SAMULL EGERTON BRYDGES, Esq.}

* " The first Series of the above Work may be had in three Vols. 8vo. Price 16. 17s. Gd, in Boards, or in Twelve Numbers, Prise is, eacll. 


\section{HISTORY AND BIOGRAIHY'.}

THE ECLECTIC REVIEW (mulliwhes)

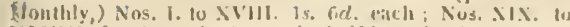
XLVIII. \&r. 2s, eacli; in bs rals, half-burmul, st i3s.

The Ectectic Review was estiblislied witl the mos! be nevolent Purposes, on the most litwera! Plan. Its Cim. dlucturs, disclatiming all p'ersolld atul P'arly Views, lahiug mos Share in the Minur Theologicall luspulns, and devoting its l'rofits to the Fuals of a Piblatuthropic Institution. Iave

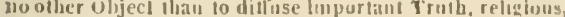
moral, and literary, hy Mleans of imparlial and enlig btomed Criticisu. Llow fir it is supurior to similar Wouhs, II Reclitude of I'riuciple and Alulity of Fasecutions, wall best be ascertained lay Refereuce to it, loiges. It includers co.

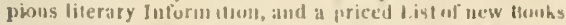

'THE GENUINE WORKS OH' HOGIR'TH.

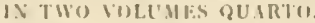

To be comprised in Sisteen Numbris; each Vumber containug seren or l:ight loints, and alumil lionly l'ages uf Leller-Press) illustrated with fingrdphieal Anecdubes, a Chronolugical Catalogue, anul Coumeutary

ay Jolls viculuLs, F S. A. Lolumb, and l'erlin: auth the

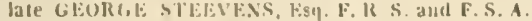
Nos. I. a YIV. Price Half a Gumeal encli, on demy pa. per; or Price One Guinea un ruyal pitper, wilh prosor impressions. The l'lates will mvarably be engraved from Original l'iclures, a hen there is a posslublity of whtainin them: when this is not the case, from l'roof Impressints.
The Wurhy of the Imumblale fluearth bave mot only

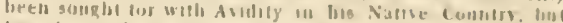

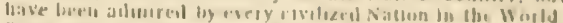

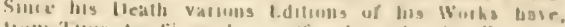
loum tume (1) rime, heell whered to the poulle. Pui

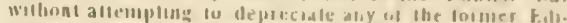

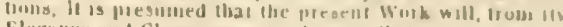
Elegance inbl Cheaponess, stamil nutivalloul

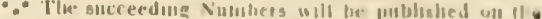
first Jay of every siccond Montl.

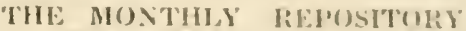

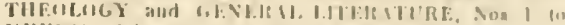

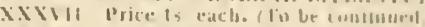

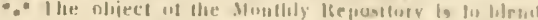

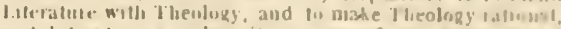

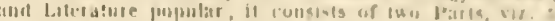

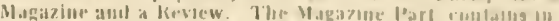

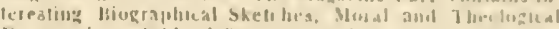

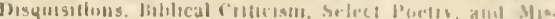
rellumenos Urleinal Communcatums. The liewen com

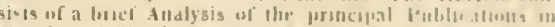

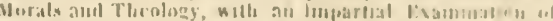

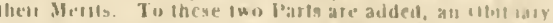

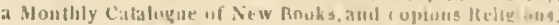

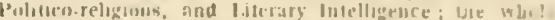
fortumg annually one latge elorgant trio. volumit.

\section{HISTORY AND BIOGR.IPHY.}

SIR JOHN FROISS.IRT'S CHHONICLES of ENGI,AVD, FRANCE, SPAIN, all the adjotning Comm-

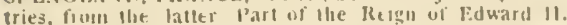
to the Coronatims of Henry [N. Newly translateal from

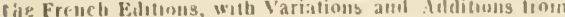

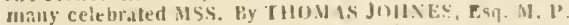
To which is pretivedl. a life of the An'thor, anl lissay (口)

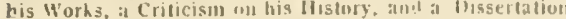
on his Poetry. The Third fidtion, Price $i l .45$. ill buarAs.

\section{" prowsart is an historian consulted and}

whose subject leads isim to tiie perio.l in whic

zessed of with reeard en
lions of our national ann

Miss.

as u ell
iram

nivis

slation

MEMOIRS OF JOHF LORI DE JOIS.

VILLE, Grand scheschal of Champigne, writell by humself, containing a Histury of Part of the Lafe uf Lnuis IX. King of France, surnamed Sı. Lonis, inchudıng all Account of that King's E.xperlition lo ligypt, ill llie year 12th. To which are added, the Notrg and II issertalums uf $\mathrm{W}$. Du Cinge on the anove, together whl the Irissprlatlums of W. Le Baron de Lil linttie on the Liti of St. Lomis. M.

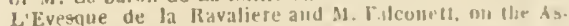
sassins of Syria; froul the "Memoirs de l'Acinlsulle de Belles Letlles pl linscriptions de France."

Translated ly rHou is JUHVE, F sq. II to

Handsomely pitinted in 2 vols. ito and illustrit d with Eingravings. Price $+l$. ts. in linarcls.

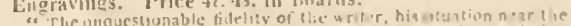
presence of tite king, the simplicity in wlt:ch he

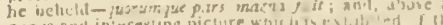

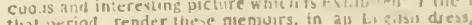
ralu.tulc." Brit. crt.

MEMOIRS OE THE LIFI: OF COI,ONFL

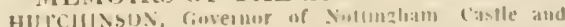
Tuwn, Representalive of the Cunney of Vullamglatum an the

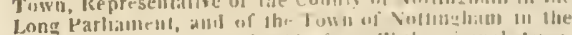

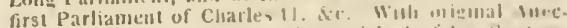
dutes of many of the mose distmenishest of lis contem-

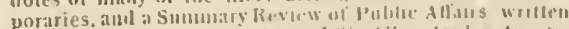

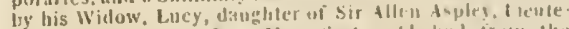

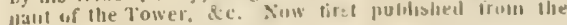
oriuinal Mamuscripl,

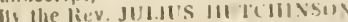

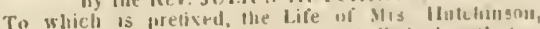
writlen ly berseli, a liagment. Finlsellishat will two clemantly engraved lourtrals. antal al View uf Nutsiaglatil Cistle. In une vol. 411 . The 21 edit. Price 1l. IIs. Od.; and Royal, price $2 l$. Its. fid in Boards.

"As a political reconil we regard this work as a valiable nddition to our stock of original documencs: hut perlin,ps 113 brealest meri to our stork of ortginal wocumenclioncy di dieralycospusion.
The story 14 interesting in the laphey? dezres exaggerifed when be recomments lie be $k$ io extert.

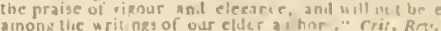
gene volume larius a valuale ai hor

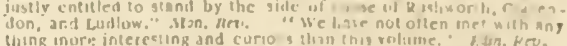

NIVIL AUI MII.ITARY MEJUIIS of GREA R BRITAIN, from 17 ร 111743.

By RUBERI UEATSUN, F.sq. I.L.D.

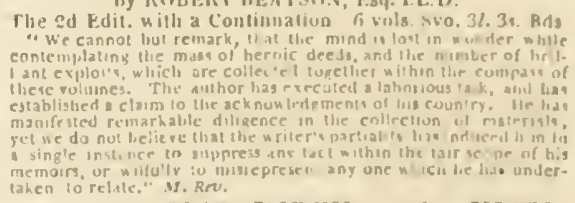

A POLITICA. INDEX to the IIISTO. RILS of GIII:IT IIRITAIN and IREI ANH: nr a Com-

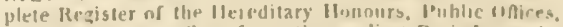

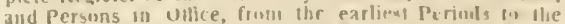

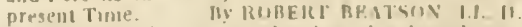

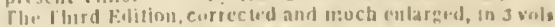

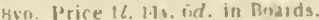

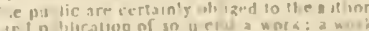
apronce of inuch

1 CHR()NOLOCIC 11 , KI:SISTER of hot

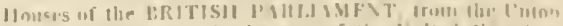

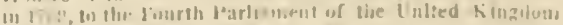
of Greal Lrstain : Ind Ire la bl, in I in.

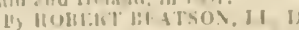

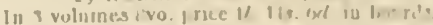

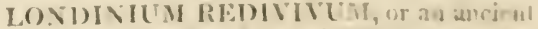

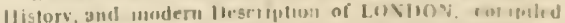

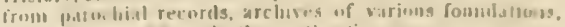
flec Ilarleiall llst and uther authentic sourees

BY JIYIS PELLIER YALCII.UI. I. \& A

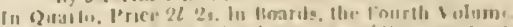

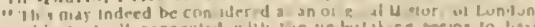

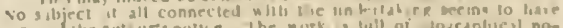
escaped lile aut ures nothe. The wurk. Iull oi todraphical no-

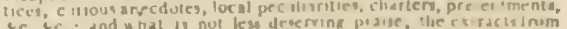

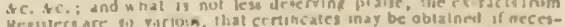
Hegisters are su' virrions, Halt crraticates inay be oblatmeal if meces-

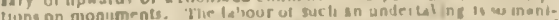

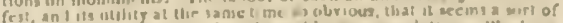
p.tblic ditr to fromote 11 by all possible a cutumatalion. We bave p.rblic d it hit when nnighed thas will be the must e empor hensuce ac-

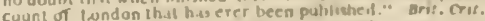

$\because$ The carrchasers of the fonturer vuluanes are requested to complcte their sets.

The three first solumes nay be bad sitber separately or logellier, price 56. 56. Iil boarda 
ANECDOTES OF THE MANNERS AND CUSTOMS of LONDON during the 18th Century, includ. ing the Charities, Depravities, Dresses, and Anusements of the Cilizens of Loudon, chring that Perton, with a Review of the State of Society in 1807 . To which is added, Sketch of the domcslic and Ecclesiastical Archilecture of the various Improvements in the Metropolis. Illus. trated by Fifty Engravings.

By JAMES PELLER MALCOLM, F.S.A.

Author of Londiuium Redivivum. In I vol. 410 . Price $2 l$. Is.

The HISTORY of the ORKNEY ISL $A N D S$. Bv the Rcy. GEORGE BARRY, D.D.

Minister of Shapenshay. The ad edit. with considerable Mdditions and Notes, ly the Rev. Mr. Headrick. In one vol. 4 to. illustrated with an accurate and extensive Map of the whole Islaud, and eleven ylates of the most interesting objects they cuntain. Price $1 l .11 s .6 d$. in Boards.

LETTERS on the STUDY and USE of ANCIENT AND MODERN HISTORY. Coutaming Observations and Reflections on the Ciuses and Consequences of those Events which have produced any con. spicuous Change in the Aspect of the World, and the general State of Hutoan Afiairs. By JOHN BIGLAND.

The Third Edition. In I vol. demy 8vo, embellished with an elegautly engraved Head of the Author. Price lis. fid. or 1 vol. $12 m$ o. Price fs. in Rotarls.

"Mr. Biglant displays in this volume a well cullivated and comprehensive mind. lis style is generally correct; his information is extensive; and the many pertinent remarks and inferences with which lie has enriched this summary of general history, meet our cordial approbation." M. Rev.

LETTERS on the MODERN HISTORY AND POLITICAL ASPECT OF EUROPE; exhibiting the Nature, Causes, and probable Consequences of the grand Contest between Great Britain and France, and the yolitical Circumstances of the different Nations which com pose the European System. Illustrated with Historical and Geographical Observatious. By JOHN BIGLAND.

The Second Edition, revised, and adapted to the prosent Slate of Europe. In $t$ vol. 8 vo. Price $8 s$. in Boards.

"These Letters discuss, in turn, almost all the great questions which can be agitated by politicians of the present hour. The knowledge is surprisngly extensive." Brit, crit.

VIEW of the RUSSIAN EMPIRE during the Reign of Catharine 1I. and to the Close of the Eigh. teenth Century, \&c. \&c. \&cc. Contajuing an accurate De scription of the Government, Manmers, Customs, Religion, Extent, Boundaries, Soil, Climate, Produce, Revenue, Trade, Manufactures, \&zc. \& c of the several Nations that compose that extensive Empire.

By WILLIAM TOOKE, F.R.S.

In 3 large vols. $8 v 0$. Price $1 t .11 s .6 d$ in Boards.

THE LIFE of CATHARINE II. EMPRESS OF RUSSIA. By IVILLINM TUOKE, F.R.S.

The Fourth Edition, with considerable Improvements, in 3 vols. 8vo. Price 1 $l .7 s$. in Boards, embellished with Eugravings.

THE HISTORY of EGYPT ; from the earliest Accnints of that Country till the Expulsion of the French from Alexandria in the Year 1801.

By JAMES IVILSON, D.D.

In 3 vols. 8vo. Price $t, 4 s$, in Boards.

"This work is composed in a clear, agreeable, and lively man ner." An. Ret. "Dr. Wilson is unquestionably a man of talents and the rapidity of his narrative, and his flow of language, give considerable animation to his pages." M. Rev.

A HISTORY of IRELAND, from the earliest Accounts to the Accoinplishment of the Union with Great Britain in 1801. By the Rev. JAMES GORDON, Rector of Killeguy in the Diocese of Ferns, and of Cannaway in the Diocese of Cork. In 2 vols. 8 vo. $1 l$. $4 \mathrm{~s}$. Bds. "The author has not derogated from the reputation which he derived frnm his prior publication; since we discover in it the same clear discernment, the same sound judginent, the same strong pood zense, the sanie manlv sentimenis, and the same fearless inlegrity, and devotion to truth." Mon. Riv.

THE LIFE and ESSAYS of BENJAMIN FRANKLIN, LL.U. A new and inmproved Edition. In 3 vols. fuolscap svo. with a l'ortrait. Price $8 s$, in Boards.

A VIEW of the PRESENT STATE of POL.AND.

By GEORGE BURNETT.

In One Volume 12mo. Price $7 s$. in Roards.

' $T$ his is an interesting and entertaining little volume. It is written in a pleasing ur.affected style, and has afforded us much entert wingent as Hell as information." Bris, cris,
THE REIGN of CHARIEMAGNE, cor; sidered chiefly witlı reference to Religion, Laws, Literxure, and Manners.

By IIENRY CARD, A. M. of Pembroke College, Oxford. In One Volume 8vo. Price 6s, in Eoards.

MIEMOIRS of the LIFE of DAVID GAR. RtCK, F.sq. interspersed with Characters and Anectoles of the Theatrical Cutemporaries, the whole forming a IHistory of the stage, which incincles a Pcriod of 36 Ytars. By THOMAS DAVIES.

A new edit. In two vols, crown Bro. wilh copious Additions and Illustrations in the form of Notes. With a Head of Garrick. Price 1 ts. in Enards.

THE ANTIQUITIES of MAGNA GRECIA, dedicated l,y Permission In the Earl of Moira.

By W. WILKINS, Jun. M.A.F.A.S.

Fellow of Gonville and Caius College, Cambridge. In 1 large vol. imperial folio, illustrated by 85 Engravings, executed by eminent Artists. Price 10 Gumeas.

MEMOIRS of the LIFE and ADMINIS. TRATION Of Sir ROBERT WALPOLE, Earl of ORFORD, with original Correspondence and anthentic Papers, never before puhlished.

By the Rev, WILLIAM COXE, M.A. F.R.S. F.A.S

Archdeacon of Wilts, and Rector of Bemerton.

In 3 vols. 4to. with a Portiaif of Sir Rubert Walpole. Price $5 l$. 5s. in Buards.

** Also sn Editinu in 3 vols. 8vo. Price 1l. 4s. in Bds.

LIFE of HORATIO LORD WALPOLE. A new Edition, in 2 vols. $8 v o$. Price 1 . 128 .

THE HISTORY of the ANGLO-SAXONS. The First Volume containing their History before their Invasion of Brtain, and their subsequent History in Eugland to the Norman Conquest, including the Life of At fred, and the Accomit of the Seakings and Pirates of the North.-The Secoud Volume, describing their Manners, Government, Laws, Poetry, Literature, Religion, and Lan gllage. By SHARON TURNER, F.A.S.

In 2 vols. 4to. Price $3 l .3 s$, in Boards, the Second Erltion, corrected and enlarged, with an Introduction, on the History of Britain before the Arrival of the Romans.

"' We ragard Mr. Turner's work as a very raluable addition to our national histories, from numerous and reconditc sources he has collected much that is interesting and curious, respecting both the manners and the events of the nerinds which he de certainly was occasicn for sucl a work, and the execution of it
leaves no room to regret tlat il devolverl on Mr. Turner." Ecl. Rov.

LIVES of ANCIENT PHILOSOPHERS, translated from the French of FENELON, wilh Notes, and a Life of the Anthor.

By the Rev. JOHN CORMACK, M.A.

In 2 vols. foolscap 8 vo. The $2 d$ Edit. printed by Ballantyne. Frice 12s, in Boards.

An ACCOUN'T of JAMAICA, and its IN. HABITANTS. By a GENTLEMAN, long resident in the West Indies. In 8 vo. Price 7 s. $6 d$ in Boards.

The present work contains a great deal of useful information respecting lamaica. We have been considerably gratified by the perusal; and more so, as the information which it contains, in stead of being copied, from other books, seems to nave been principally derired frum personal observation. The author appears to be a judicious and impartial man, ard it is with pieasure that lo be a judicious and impartial man, ard it is with pieasure that
ue bestow on his performance the praise of candour and of Monthly Rev.

MEMOIRS of an AMERICAN LADY, with sikelches of Mamuers and Sccnery in America, as the existed previous to the Revolution. By the Anthor of "Lelters from the Moustains," \&zc. \&zc. In 2 vols. I"mo. Price 10s. od. in Boards.

An ACCOUNT of the LIFE and WRITINGS of JAMES BRUCE, of Kinnard, Esq. F.R.S. Author of Travels to discover the source of the Nile, in 17nis-0.70-1. 2 and $3 . \quad B Y$ ALEXANDER MURRAY, F.A.S.E.

$A$ id Secretary for Foreign Correspondence. In I vol, 4 to. Price $2 l .12 \mathrm{~s} .6 d$. in Boards.

A BIOGRAPHICAL PEERAGE of the EMPIJE of GREAT URITAIN ; in which are Memoirs and Chasacters of the most celebrated Persons of each Fanily.

Volume I. and II. (conlaining the Peerage of England, with the Arms neatly eugraven on Wood. Price 16 s. in Bds.

In the Fress, and in a State of considerable forwardness, Volumes III. and IV. containing the Peetage of Scotland and Ireland.

** Auy Corrections direcled to the Publiohers will be thankfilly received. 


\section{VOYACES AND TRAVELS.}

TRAVTTS to DISCOVER the SOURCE. OP TIIE NILF, in the Years 1768, 1760,1771$), 171$, 1779. and 177.3 . liy JIME.S BRUCE, of Kinuairu, lis!, F.R.s Tise 21 Edit. corrected and enlitrgerl. To whlicls is pretlsed a Life of the Antling bundsomely printed in 7 vols livo. with a volume of Copper-plates in to. $4 l$. Ifis, in Buitrits.

A few Coples are prininl in royal kvo, with flat iumpres. sions of the l'iates. P'rice $7 l$. 75 . ill Boirds.

THESCENERY, ANTIQUITIES, and BIO firtl'IY OF SOUTII IVALES, from Iaterials collected during 'Twil Fucursions in the Year I803.

By BENJAMIN HEATH MALKIN, Figq. M. A F, S.

In i vol. 4to. lllustraled with V'iew's, drawn and ellgraved by Laporte, alld a Map of the Couniry. Sl. 12s. fid. Boards.

A rew Copies may be liad with the View g fincly coluntrid by Laporte. Price $+l$. 4 s. ill limarils.

Also a 2 us Edit. in ? vols. 8*o, will consulerylule Addi. tions, and I wo Engraviugs, by Landseer and Midulumsu. Price 1l. 1.9. III Boards.

"Mr. Malkin displays a masterr of atvle, and is an Instruclire companion: we have no liesitasion in agsianng him place in tire first class of Tourisis." $M$. Rri

borate, and indeed, saliafactory accounts of Weles, that has yet appeared." Bris. Crit of pature; and descrtbes, in appeopriate terme, the panes in review befure him. Cris. Reis.

THE TOPOGRAPHY of TROY, and ITS viciNITY, illustrated and explained hy luawings and llescriptiuns. Dedicated, by Permission, to her firace the Duchess uf Devolishire.

By WILLiA M G.LL, Esq. of Jesus College. M.A. F.R S. F.A.S. and late Fellow of Einmanuel College, Cambridge III Lulio, Price 10l, los, III Boards.

In lhe work are given forlv-luree colouled Plales, Iaken from arcurate lirawings, inatie on the Spot, by the futhor, and chietly eugraved by Mr. Medland. The Work is lleaigned to afforilat Upporiunity to such as hatse nol visiter che cuuntry of furming llatir own npinions of the lopography of ilnmer.

THE GEQGRIPHY and INTIQUITIES of ITIA ACA, dedicated by Permission to the King.

Hy WILLIAY GELL, Es?. B.A. F.R.S. F.S.A. And Member of the Sociely of Dilelauti. In one vol. ito. illustratpd by Eogravings. Price $气$. 12s. $6 d$. in Hoards. "We are now ollined, by the limils of our Reriew, to close Nr. Ceil's volume, which (we tske this opportunily of observing) it a spemen of very clegant typography. That wr bave perused it with un common alistaction, the reader will atready have perceived. a' in the account of Trov, he senerally reniler flomer hils un aludy, for his geographical and antiquarian researches." Bris. Crif.

\section{A DESCRIPTION of LITIUM ; or, LA} CAMPAGNA II ROMA. In I rol. demy $\$ 10$. Illustrated by Elcbings by the Author, and a Map. 1L. 11s. Gd. in Bds. "It is nnt our tortune ulteo to mect with a rolumk, where mole
information and entersainment are combined. Tlie work ss confidently, and we believe rightly, attributed to a lady already ceic. brated as a writer, the accomplisised Cornclia Knight." Bris. Cris.

IJLUSTRATIONS of the SCENERY of KILLARVEY, the surrounding Country, and 2 curnsider. able Part of the Southern Coast of Ireland.

$$
\text { ISy IS IAC KELI, Esq. M.K. T. A. }
$$

In 1 vol, 4lu, with bumerous l'lates eleganily e'namied Price $c l$. Is. and on royal l'aper, with filst Impressions of the Plates, l'rice $3 l .3 \mathrm{~s}$. In extra Boarts.

the In Mr. Weld this illastrinus and beautsful ecenery has found an accurate and able deilneator. His pen and hia pencill lase buth becn emoloyed with effecl, and we liave acldom seen a work liat been employed with eftect, and we with a ligh degree of graphic combines mo

NORTH WALES; including its Scenery, Antiquities, Custonss, and some sketclies of its Natural His. tory; delineated from Twn Excursluns throngh all the Interesling Parts of that Country. Nuring the Summer of 1798 and 1801 . By the Rev. W. BINGLEY, A. M. III \& vols. Bvo. illustrated with a new and accurate Map. Frontispieces, and several favourite Welsh Airs. 16.13. Bds,

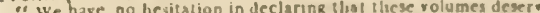
to be ranked among the beat perlurmaoces of the klad ; oor will any one hereatier act wisels, who should risis North Walez, withow one hereaiter act wisely, who should risis

GLEANINGS throughW ILFS, HOI.LAND, AND WESTPHALIA.
The sivtls Eilition. In 7 vols live $l l$ th In Foards.

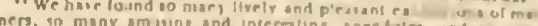

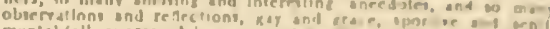

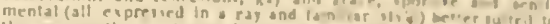

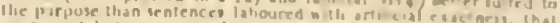

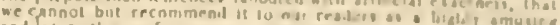

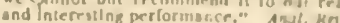

GIJANINGS in FNGIINI); recriptive of the Combenance, Mind, and Character of the Cownliy. liy Mr. I'R it'

Vol. I. II. Prlce ins, firl. earlo, III Hoarda; and Vol. III. Price 124. In Boarda.

The Seconil and Thurd Vinlumes may he had separalely "The autline continues to merit llie cliaracler lir has lara ons

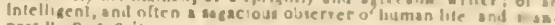
ners." ners. cris.

NOTES on the WIST INBIES, written during the Forpedutiou undes lae Comnand of the late fie. neral sir lialph Aliercromuliy. BV LEFHIGE PINCKARD, M D.

In T vols sqo. Price 1 $l$. Ills. In Howerds.

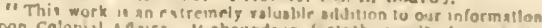
apon Calomial Adary, It abounds in facta the requilf of actual ob.

TRAVEIS in SOUTII AMEIRICA during the year 1801, 1803, 1803, and 1804; contatang a [reacrip. tron of the Captain fieneialship of (araccas, and an AC. connt of the lhiscovery, Conquest, Topogmpluy, legislatur. Commerre. Fluance, and Natural Prodnchous of tue Coun. Iry; will a View of the Maoners and Cuntouns of lbe Spa. niards and the Native Judians.

By F. IDE.I'ON'

Late deent in the French fowverument al Caraccas. $\because$ Translatel froull the Fiench.

In \& Vols. Cro, with a Slap of the Country. Price Il. Is.

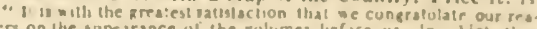
ders on the appearance of the volumes liefure us, In which ther nill find rerr wmple delaslis on the nafucal resources and pruductions accompanied hy muclic curious in formation on ilie internal s'ate aed covernment of the spsntali Colonies in Amer'Cs. Sacts s work has

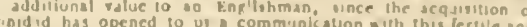

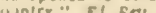

A I)ISCRII"TION of CEYLON, containin an Accomut of the Country; lubabtlauts, and liatural l'ro ductions: with Narratises of a lour round the Island in IPow, the Campleit in Candy III I803, and a Juorney is IRamisseram in Itant.

HY Hie Rev. JIMES CORDINER, A.M.

Lale Chaplain to the Garrison of Columbo. In two vols. tho. illustrated by lwenty tive lingravings from origlual Ilrawuligs. Price $\%$. 1.3s. fid in lloards.

Considered a rolumes of I rave't, Mr. Cus liner'I Lahnuri mate enjny a respectable rank amon neet il and weresble $p$ blicalume.

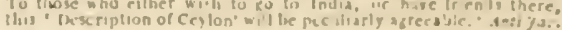

\section{A 'TOPOGR IPHICAL DICPIOSIIRY of}

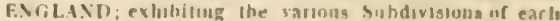
County unlo Hundreds. Lathes, Waprentakes, Nic. The Va.

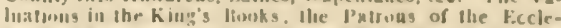
siastical Belleftres; and the Jutelary Saunt of eacb Churcb. -The Ihatance and beariug of esery l'arish. or Ilamlet,

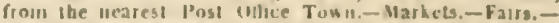
Corparalinns. - fre Schools - The Silualion and llescrip.

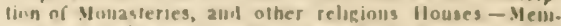
hers of Parliameni. - Iswizes aud l'elly Sessions - Cul. leclest from the most antlieutic luncumenls, and arranged

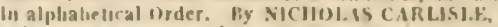
Fellow and Secretary of the Society of Antuquaries of Lon-

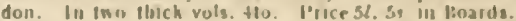

Fiols Work will be emineully useful. - To Magistrales In the Rernoval uf Paupers, \&c- II. To Conveyancers, Sollcifors, Ruyera and sellers of risiales and l'roperiy by Commissinu, (ientleusen desirous of purcbasing, anil in those who nay have uceaston in exaruine the l'uhlic Ad. verusemenls, icc-III. To all l'ervons concerbed in the Goverument, and in the varuus Public (utlices, partica. lasly the l'ost umce Departiuents, - IV. To Sludenta. Privale Genllemell, Authors, alid other Persons of Itesearch, who may require antbenlic Information reapecting the Incal, slatistical, and otber Facts and Circumatanres relatiug in the Kingdous of Pnglanil.- - Tn the Clergr, anil all Peraons in any Manner connecled wilb ficcleslastical thenellces, local Rigbts, and otber Objects apper. lainliz to the Eatablishuent. 
if If ever there was a bonk indispensable for refercnce to a vast variety of persuns it is this, which bears at the same time erery mark of the utmost accuracy or we embrice the tirst opportunity of congratulating the public in the acquisition of this useful performance, and of offering $\mathrm{Mr}$. Carliste that commendation to shich his dilizence and indelatizahle industry are emidation tontitled. A compilation of this kind, executed with palience and fidelity, lias long been a desideratum, and the lask of filliri an this liatus in our fitrartes, could not have fallen into bette hands." Mon. Rer.

\section{CHRONICLE of the CID, Rodrigo Diaz}

\section{de bivac, the Campeador.}

Corrected by ROEERT SOUTIIEY. In 1/n. Price 1l. $15 \mathrm{~s}$. in Boards.

"The Chronicle of the Cid, or the llistory of the Life and Adpentires of that justly celebrated Warrior, were at all times worthy of being tratislated into English for the enteriainment of the lovers of novelty but at the present period they are particularly valuable, as exhibiting traits of national charac'er, which may tin come real parallels in less romantic times." Ant $-J a c c$. Re?

THE TRAVEIS OF BERTRANDON DE LA BROCQUIERE, Coumsellor and First Esquire Carver to Philippe Le Bon, Dake of Burgundy, to Palestime and his Return fiom Jerusalem overland to France, snring the Years 14.32 and 1.433 , cxtracted and put inlo mostern French from a Manuscript in the National Lilirary at l'aris.
Translated by THOMAS JOHNES, Esq. M.P. In 1 vol. 8vo. illustrated with a Map of Tartary. Price liss, in Boards.

TRAVELS in ASIA and AFRIC $\Lambda$, including a Journey from scanderoon to Alepin, and over the Desert (1) Bagdad and bassora; a Voyage from Bassora to bounbay, and alung the Western Coast of Inutia; a Voyage from bombay to Mocha and Suez in line Red sea, and a Jouruey from Snez 10 Cairo and Rosetla, in E:

Fy flue late ABRAHAM PABSONS, Esy.

Consul and Partor Marine at Scandcroon.

In I vol. 4to. ensleellished with Two Engravings. Price $1 l$. 5s. in boards.

We have throughont found Mar parsons an instructive and agreeable companion, Ilis travels are nol, as usualls liappens, made agreeable companion, llis travels are nol, as usually happens, made he himself saw and heard: bis descriotions are alwass conspicuous, and 8 ?metimes exluibit specimens of elesance and taste; his remark's are sensihle, and never trifling; he exhibits the present state of the countries, through which he travelled, without encuinbering his narrative with a representation of thic past; and his work exhibits the marks of a mind which sought after knnwledse. without being impelled by vanity, which was communicative but not ostentatious, which was studious of norelty, but never negligent of truth." Ann. Rev.

\section{MEDICINE, SURGERY, AND CHEMISTRY.}

THE PRINCIPLES of Surgery; Volume the lirst; as they relate 10 Wounds, Ulcers, and Fistulas Aneurisms, and Wounded Arteries, Fractures of the Limbs, and the Duties of the Military and Hospital surgeon.

By JOIIN BELL, Surgeon.

(iI I large vol. joyal 4to. illustrated by Eighty Engravings, unany of them accurately coloured from Nature. Price $1 \ell .4 s$.

Volnme the Second; containing the Onerations of Surgery, as they relate to the Anatomy and Diseases of the Urethra and Bladder, and the Anatomy and Diseases of the Scull and Braill. In Two Parts, royal 4to. illnstrated by untmerous Engravings. ए'rice $5 l$.

Volume the Third; being Consultations and operations, on the more important Surrical Diseases, coutaining a Series of Cases, ealculated to jicat Diseches, the Docinne of Tumours, and oflser ir regular Parts of Surgery, and to instruct the young Surgeon how to form his Prognostics, and to plat lis Operageons, ln royal to. illustrated with 37 Lngravings. Price al. $2 s$. in Boards.

A SYSTEM of OPERATIVE SURGERY, founded on the BASIS of ANATOMY. By CHAKLES BELL.

Enolume the First, in royal 8 vo. Illustrated with numerous Engravings. I'rice 18s. in Boards.

* * The second Volume is in the Press, and speedily rvill he published.

THE ANATOMIY of the HUMAN BODY. By JOHN and CHARLES BELL, Snrgenns, Edinburgh. in 4 vols. royal sivo. The Two first Volumes of the above Work contain the Anatorny of the Bones, Muscles, and yoiuts, and of the Heart and Arteries: with munerons Enoravings. Price $l l$. 10 s, in Boards. The Third Volume contains the Allatomy of the Brain, and Description of he Course of the Nerves, and the Anatomy of the Eye and iar with Engravimes. Price 16s. in Boards. The Fourth ronlains the Automy of the Viscera of the Abdomen, the Parts in the Male and Female Pelvis, and the Lympliatic System, with an Appendix and lingravings, which com pletes !le Work, royal 8 vo. 'The Second Edition. Price 1.5s. in Bosids.

ENGRAVINGS of the ARTERIES, illusirating the Second Volume of the Anatomy of the Human Body, by JOHN BELL, Surgeon; and serving as an Introduction to the Surgery of the Arteries, by CHARI.ES BELL, Sumgeon. Snperinly printed in imperial svo. and benutifully cr loured. The Second Edit. Price 12 . 1 s. Bds.

- We have seen no work better calculated for giving clear ideas on this important branch of anaiomy, and we strungly recom. mend it to our medical friends, as at once a very useful and mighly ornamental addition to their libraries." M. Ret.

THE ANATOMY of the BRAIN; explained In a Series of Engravings, beautifully coloured, with a Dissertation on the Communication helweell the Veutriclas of the Brain.

by CHARLES BELL
Fellow of the Royal College of Surgeons, of Edinburgin, In royal 4to. Price $2 l$. 2s. in Bosirts.

We have here a publication, which retiecs smuch credit on the author's allatomical knowledge, and on lus skill as an artist. The plates are executed in a very superior style of correctness and elegance." M. Rer"

A SERIES of ENGRAVINGS, explaining the COURSE of the NERVES. By CHARLES BELL, Fellow of the Royal College of Surgeons. On royal 4 to. with letter-press Descriptions. Price $1 l$. Is. in Boards.

These cngravings are in the author's usual style of correctness and elegance, and they may theiefore be regarded as a valuable "cquisition to the medical library." M. Rev.

ENGRAVINGS of the BONES, MUSCEES, and JoINTs, illustrating the First Volume of the Anatomy ot the Human Body. By JOHN BELL, Surgeon. in 4to. with alrent 200 pages of explanatory Letter.press. 'rice $1 l$. 11s. fid. in Eoards.

\section{THE CHEMICAI, LECTURES of the cc.} lebrated Dr. JOSEPH BLACK,

Regins Professor of Chemistry in the University of Edin burgh ; published from the Author's Maumscripts, by JOHN ROBINSON, LL.D. Professor of Natural Philosopliy in the University of Edinlumgh. With Notes, phulosnphical and historical, by the Editor, partly for Illustration of the Text, and partly in order to ascertain the claims of $\mathrm{Dr}$. Black, and olber emincut Philosnphers of these Kingdoms, to the areat Discoveries and Improvements which have been made in this Seience, especially since the Year 1756. In 2 vols.4to. with a Head of the Author. Price $3 l .3 s$. lids.

ELEMEN'TS of CHEMISTRY and NA. I'UIRAL HISTORY. To which is prefixed, the Philosophy of Chemistry. By A. F. FOURCROY.

The 5th Edition, with Notes. By JOHN THOMSON, Surgenn, Ediuburgh. In 3 vols. royal 8 vo. Price 1i. 11 s. 6 d.

"This edition has a clijm to our attention, on account of the notes which have been added by the editor. 'The Notes on the Aninal kingduin, Part IV, are particularly instructive and Intewestig. The same may indeed be said nearly of the whole; and chemical students." NI. Rnt.

LFC'TURES on DIET and REGIMEN ; be. ing a systematic Inquiry into the most rational Means of preserving Health, and prolonging Lift; together with Pliysiological and Chentical Explanations, calculated chiefly for the Use of Families; in order to hanish the prevailing Abnses and Prejudices in Mcdicine. In I large vol. 8vo. By A. F. M. WILLICH, M. D.

The Third Edition, enlarged and improved. Price $9 s$. Bds. " We lave said erough to evince that the writer has fulfilled al his promises, and, on the whole, has given by far the fullest, mos: perfect, and comprehensive dietetic system which has ret appeared." Crit. Rev" "This work is not only a valuable accession to medical science, but must prove an inesiımable accommodation both 10 tamilies and individuals situated at a distance frook regular adrice." Now tond, Rev.

THE PHARMACOPCEIA of the ROYAL COLLEGE OF PHYSICIANS OF LONDUN, trauslated into 


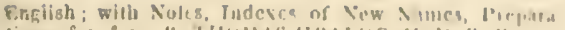

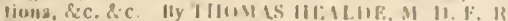

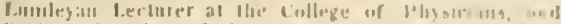

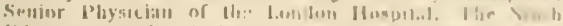

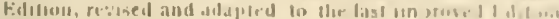

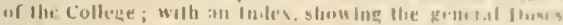

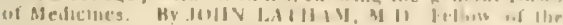

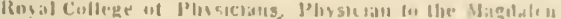

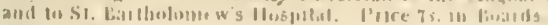

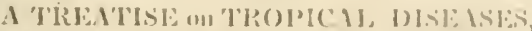

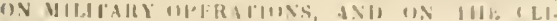

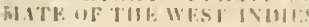

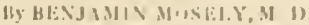

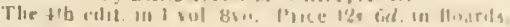

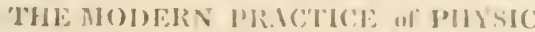

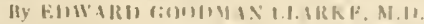

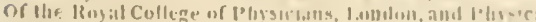

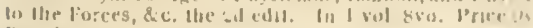
Bnarris.

This solun may lec ictuminerdod

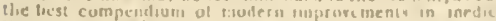

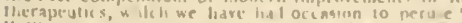

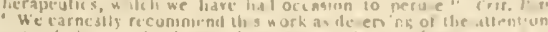
particularty of lise jun ne hianclies ol the piofersion,

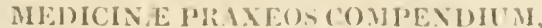

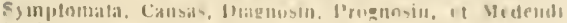

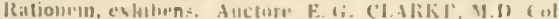

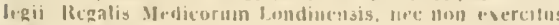

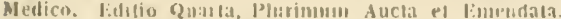
Price 5s, sewed.

PR.ICTICAL OISERTATIONS on the UTERINI, IIEVUIRHAFE; Will Remarhs nI Ihe Ma nagement of lie placeula. Hy Jullv Bt'ls vis.

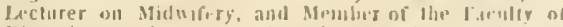
Physicians and surgcons in dilitgou. In I vol. tivin Price 5r. in livands.

OBSERVATIOAS nII ABOR'IION : rontuining all Acconut of the Malloer in which 13 lithes place. thic Causcs which produce it, ant lie Molbull ut preventung, or trealming it. By JuIIN BLIS.S. Lecluter of Nidwifers, and Meuber of the lachlly of Physicians and surgeous un (ilasgow. The :d t.milunt Frice 5s: in Eus rils.

ive have pertased this rninime w th great salisfacl An. Rni.

Au ESSAY, Mrolical, Philosophical, and Che. mical, on DKLAKF.SESS, and its I:fecls on the Ilu man hody. Ly TIIUMAS TIUIJ TEK, M. I

Late Physician to his Majesty's Fleet, Menlecr of the Reyat Medical sociely of lidsibureh. The Second Eill. toul. In I vol. 8vo. J'rice 5i H? Buards.

MEIICINA NAUTIC.I; an Fssay un thr

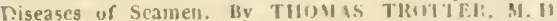
Late l'liysician to his Majesty's Fiect, \&c. In 3 vols mo. Price 1L.3s, in Boards.

A VIFW of the NERTOTS TE.MPl:R:I. MENT. Being a Practical Inquirs Into the increasing b'ro valence, Irevention, and Treatinenl of Hoase lliseases. counmonly called vervous, Billinus, Slomacli, and Liver Complaints; Indigestion, Jow spirits, Goul, dic. By TIIONAS TRUTITHII, M. I1.

Lale Physician In his Majesty's Fleet, Wormerly physician to the Royal Itrspital at Itaslar, \&ic. Aic.

The codif. in i Volume, sio. price is. fod. In Boards.

CONVERSATIONS On CHFMISTRY. In which the Elements of that Scicuce are famaliarly el plained and illustrated by lisperuatuls. III E inls. I:4n with plates by Lowry. Second lidif Pice 16s. Lt] Boards

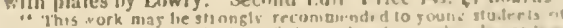

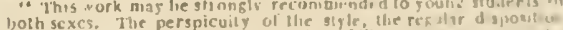
of the suliecl, the judicious selection of illuatratsre e epriments and the eligance of the plates, are 30 well astanted fo thic cavat tr

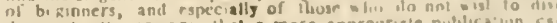
deep in:o llie sceence, lliat a more appropriste puhlication cal hardly be desired." Bril, Crrt.

THE MEIDICAL (GIII)F, for the LSe of Fanvilieg aud loung Praclikioners, or Sindonls in Medi

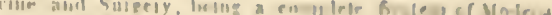

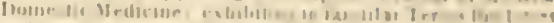

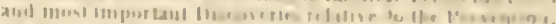

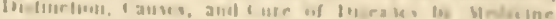

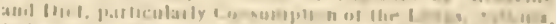

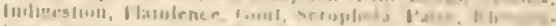

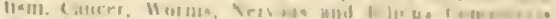

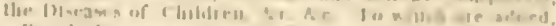

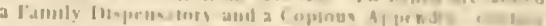

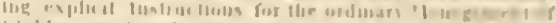

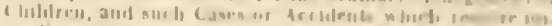

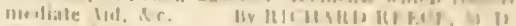

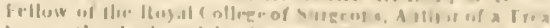

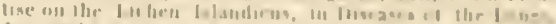

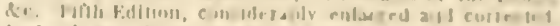

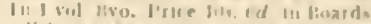

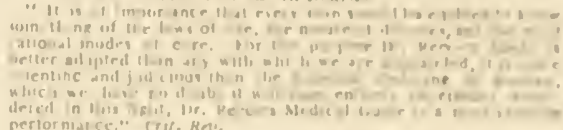

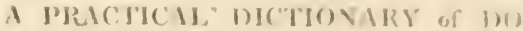

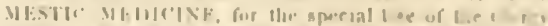

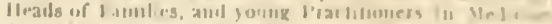

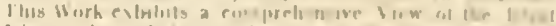
lliecoverics rolative to lle: rames, Trmatment ambl i te

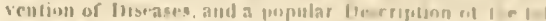

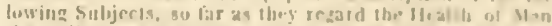

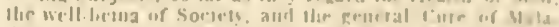

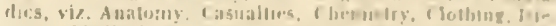

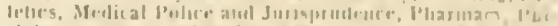

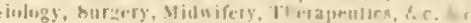

$$
\text { liy lile II II:II IIJ.J.1 k, II II }
$$

Memlore of the kusil corllege of st rgeons on Isnelon. In

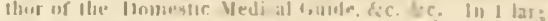
vol. ronal usa J'rue 18 s m Jiour Is.

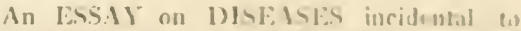

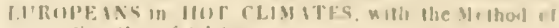
preveuting lluer falal consmurnes.

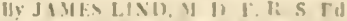

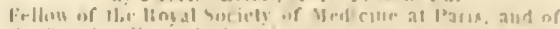

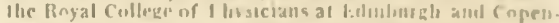

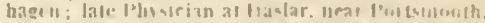

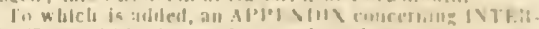

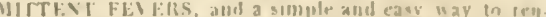

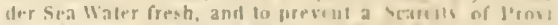

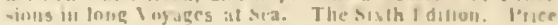
bs. in [\$oardy.

\section{A TREDTISE (NI VHTERISARY MIDI}

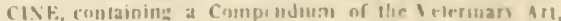

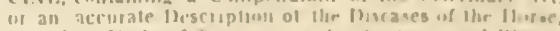

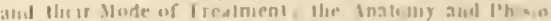
ligy of the firot, ambl the l'unciplea an I l'ractice uf shome

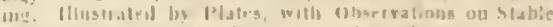

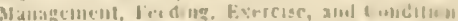

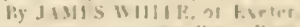

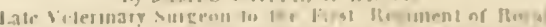

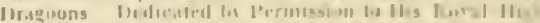

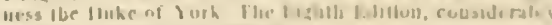
culargeis. Price is. in Buads.

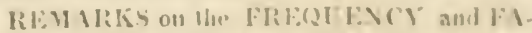

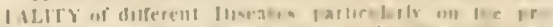

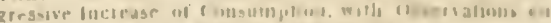

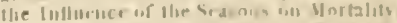

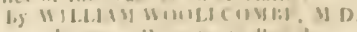

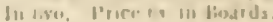

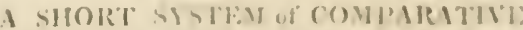

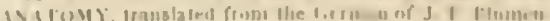

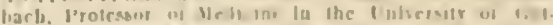

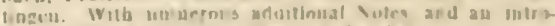

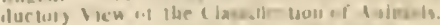

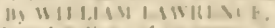

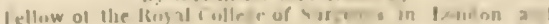

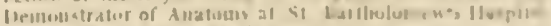

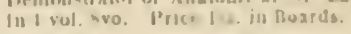

\section{DIIIVITY}

ZOLLIKOFER'S SERMUN'S on the I)I(;NIIY UF MAN, from live fierman.

By the Rev. WHLLA M TOUK F. F.R S.

(i) 2 large vols. svo. Second lidifini, lerice 1h. Is. Loards

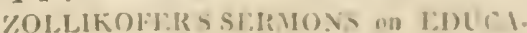

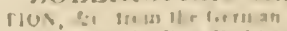

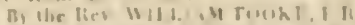

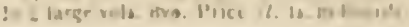


The concurreul testimony of all the periodical jouruals, butit at bome and abroid, in favour of the Sermons and devotions of this celebrated divine, not onty on account of the unaffected and captivating sirain of eloquence in which they llow, but for the benign and truly evangelical spurit with which they are animated, is sullicirusly known. 7 hat they breat be the pure and gemine spirit of cluristanity, and exhibit religion in our view in a farm the most ani. mated and alluring, is indecd their pecutiar praise, as thousands can happily testify, from their own experience of the checrinl and placid influence they have had upon their heart and life,

SERMONS on the GREAT FESTIYALS and FASTS of the CHURCH, on other Solemn Occasions, and on Various Topics.

from the German of the Rev. GEORGE JOACIIIM ZOLLIKOFER, Minister of the reformed congregation at Lcipsick. By the Rev. WILliaM TOOKE, F. K. S.

In 2 large Volumes 8 vo. price $\iota .4$. in Boards.

A New Literal TRANSLATION from the Original GRLEK of the APOSTOLICAL EPISTLES, wilh * Commentary, and Notes Philological, Critical, Expldi. uatory, and Practical: to which is added, a Hisiory of the Life of the Apostle Pant.

$$
\text { lYy JAMES MACKNIGHT, D. W. }
$$

Antior of "A Harriony of the Gospels," \&c. The ad Erlition (to whicls is prefixed an Account of the Life of the Anthor.) In 6 vols, S'o. Price $3 l .13 s, 6 d$. in Isords.

LECTURES delivered in the Parish Church of Wakcfield, in the Year 1802 , on that Part ot the Iitusgy of the Cluurch of England contained in the Morning Prayer, By TIIOMAS ROGERS, M.A.

Master of the Grammar School, Afternoon Lecturer of St. lohn's. and Sunday Evening Lecturel of the Parish Clunch 1日 Wakefield. In + vols, crown 8vo. Price $1 l$. $4 \mathrm{~s}$. in Bds

DISCOURSES on various SUBJECTS. By JEREMY TAYLOR, D.D.

Chaptain in Ordinary to King Charles the First, and late Lort Bishop of Down and Commor. A new Edition, in 3 vols. $86^{\circ}$. Price $1 l$, $7 \delta$, in Boards.

THE RULE and EXERCISES of HOLY LIVING, in which are described the Means and Iustlu. neuts of ubtaining every Virtue, and the Remedies agains every Vice, and Considerations serving to the resistiun all Temptations; logether with Prayers, containing tine Whole Duly of a Christian, and the Parts of Devolion fitted for alt Occasions, and furmislied for all Necessities. BY JEREMY TAYLOR, D. 1).

And edited by the Rev. Thomas Thirlwall, M. A. the 27lb Edition. in 1 vol. 8 vo. Price $7 s$, in Boards.

THE RULE and EXERCISES of HOLY DYING, the Seventcenth Edition.

By JER. TAYLOR, D.D. In one vol. 8vo. Price 7 s.

THE GOLDEN GROVE, a chosen Mamul, containing $w$ hat is to be believed, practiscd and desired, or prayed for. The Piayers being fitted to the several Days of the Wcek. Also Festival Hymms, atcording in the Ianner of the anrient Church. Composed for llac Use of the Devout, especially of younger Persons.

BY JEREMY TAYLOR, IT.T).

The 16 lh edit, In I vol, $12 \mathrm{mo}$. Piice s's, fid, bound.

THE POWER of RELIGION OU llı MIND, in Retirement, Afliction, and at the spproach of Death. Exemplified in the Testimonies and Experience of Persons, distingnished by their Greatness. Learumg, or Virlie. By LINDLEY MURliaY.

'l'lie 10th Edit. corrected, aud greatly enlarged. 3s. $6 \mathrm{~d}$. Bul. "It is a book which may be read with ploft, by persuns in all bituations; and, with the rising generation, it may answer the douthe purpose of improving them in blograplig and in virtue." M. Rev.

A POR'TRAITURE of AIETHODISM ; being an Impartial View of the Rise, Progress, Doctrines, Discipline and Manners of the WESLEYAN METHO. DISTS. In a Series of Lelters, addressed to a Lady. By JOSEPH NIGHTINGALE.

In 1 Volume, Oclavo, price 10s. $6 d$. in Boards.

"We have derived from his book both instruction and amuse. mient, and are the better pleased with it, not only because it appears to contain the truth but because we can discover no moture for its publication but the love of truth." Br crit.

PAROCHIAL DIVINITY ; or, SERMONS on various Subjects. By CHARLES ABBOT, D.D. F, L. S. Chaplaju to his Grace the Duke of Bedtord, Vicar of Gakley and Goldington in Ledfordshire, apd late Fellow of Now Collerge, ox:ort.
II 1 Volume sivo. price $9 s$. in Boards.

"The Sermons in this Volume, in number iwenty-seven, are on interestiog and inportant subjects, enfurced with a zeal ard eas st ness which do great credit lo the Aullor's Teelings." ox. Rez?

Ait EXPOSIIION of the HISTORICAL WRI iriNGS of lise New Testament, with Reflections "subjoined to eacls Section. Ry the late TIUOTHY KENRICK. With Menuoirs of the Author. In three vols, large bvo. Price Two Gumeas, in Boards.

JUDGMENT and MERCY for AFFLICTED SUULs; or, Atrdutions, Solıtuquies, ant Prayers. By R RANCIS QUARLES.

With a fiographical and critical Introduction. By REGINALDE WOLF, Esq.

In 1 vol. crowu bvo. A new edil, with a Head of the Autlior, by Freeman. Price is. in Borats.

A PARAPHRASE and COMMENTARY an the NEW 'liSTAMENT. By DANIEL WHITBY, D.D. in \& vols. The First Volmme contains the Gospels, with the Acts of the Aposiles.-The Serond, the Epistles, a Treatise of the Milennimm, a Chronological Index to the $N^{\top}+$ w Testamenl, and an Alphahetical Talile of Places at the End of each Volume. Tables of the Words, Pbrases, and Batters explaiued. 'I hie toth Edil.

A VIEW of the PIINCIPAL DEISTICAL. Whiters that lave appeared in England in: the last aud frrent Conlury, with Observations upon them, and some lecomnt of the Answers that have been published against them, in several Letters to a Friend.

by JOIIN LLLAND, D.D. In 2 vols. 8vo. Price 14.s. Pds,

A PRIEST to the TEMIPLE; or the Country Parson's Character and Rule of Holv Life. By Mr. GEORGE HERBERT.

In 1 vol, foolscat, :so. Frice $4 s$. oid. in Boards.

OKIENTAL CUSTOMS; or, an ILLUSTlitrion of the sacred Scriptures, by an explatuatory Apulication of the Customs and Manuers of the Eastern Nations. By SAMUEL BURDER, A.M.

III 2 vols. Price 1ss. in Boards. or on Royal Wove Paper, not pressed, $3 l$. 4 s. 'The Thirl Edition.

A PORTRAITURE of QUAKFRISM, as laken from a View of the Moral Edncation, Discipline, pcculiar Customs, Religions Principles, Political and Civil Economy, and cluaracter, of the SOCIETY of FlilENDS.

By TIIOMAS CLIRKSON, M.A.

Author of scveral Essays on the Subject of the Slave Trade. The Secoul Edition. In 3 vols. 8vo. Price $1 l .7 s$. iil Boards.

"This book is to be considered as a faithful portraiture from the life of the most remarkable people existing amnng us. Its publication will form as great an era in the histo

EIGITT SERMONS. The Nature and Guilt of Scbism, with a particnlar feference to the Principles of the Reformation. Prtached before the University of Oxford, in the Y'ar 1807, at the Leclure founded by the Rev. John Bampton. M.A. Caunn of Salisbury. JYY TIIONAS LE: MESURIER, M.A.

Reclor of Newnton Lonuville. Pncks, and late Fellow of New College, Oxford. In I vol. 8vo. Price Ins. fid. ill Bds.

ILLUSTRATIONS of the FOUR GOSPELS, foumded un Circumstances peculiar to our Lord and the Evangelists. By JOHN JONES.

This Wurk, while it contains occasional sotes for Cri. tics, is addressed to l'ersons of plain Sense, who seek re. ligious Improvement, and exhibits an amalytic Detail of the Sayiugs aud Works of Jesus Christ, togetber with the Explanations of obscure Passages, founded on Facts, as far as they conld be collected from Historical Investigalion. In I vol. Bvo. Price $15 s$. in Boards.

SERMONS on several Subjects. By the late Rev. WJLliaM PALEY, D.D. Subdean of Lincoln, Pre bendary of St. Paul's, and Kector of Bisbop Wearmouth, Author of "Natural Theology, Moral Philosophy," \&c. In 1 vol. 8vo. Thurll Edit. Price tus, $6 d$. in Boards.

INTIMATIONS AND EVIDENCES OF A FUTURE STATE. By the Rev. THOMAS IVATSON. In 1 vol. 12 mo. The Second Edition. Price $4 s$. in Boards.

POPULAR EVIDENCES of NATURAL RELIGION and CHRISTIANITY. By the Rev. THOMAS WATSON, In 1 vol. $121 n 0$. A new Edit. Price $9 s$. Boards. "The work contains multum in parvo, is singularly calculated to answer the olject which is has in riew; and as a popular and at tractive antidote $t o$ infidelity, may be recommended to the parieus. book surieties scatteral throushout the empire." VIon, $\mathrm{knn}$. 


\section{EDLCATION.}

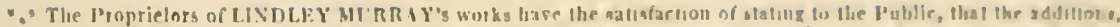

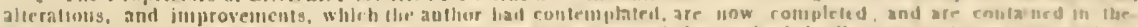

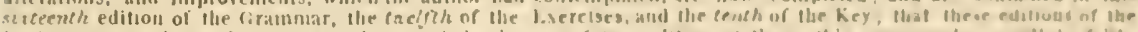

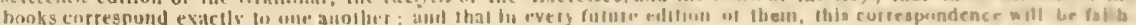

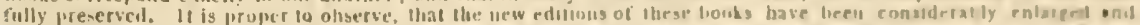

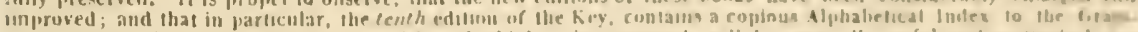

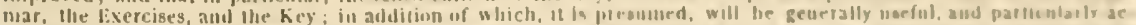

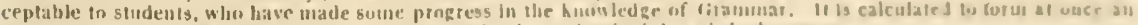

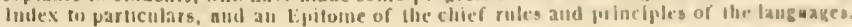

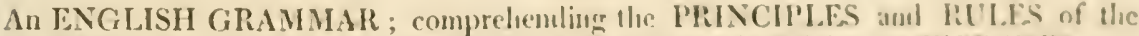 LANGUAGI, illnstrated by appropriate EXERCISES, and a KEY lo the EXRRCIsl:s.}

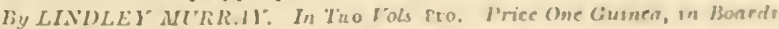

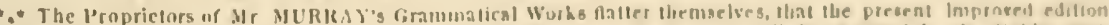

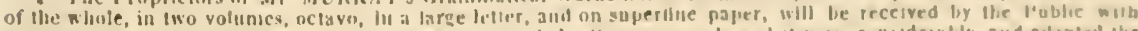

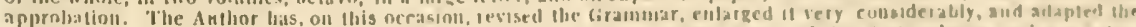

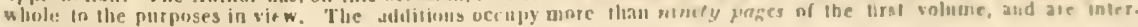
sperscil tlirolighoul tlie book.

In jts present sate, the work may be considered as aluost a new performance. Il cuntaims an ample eshil tling of

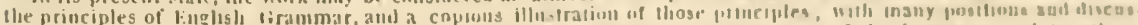

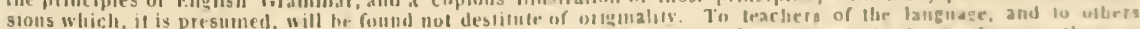

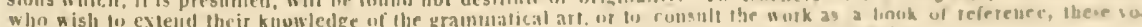

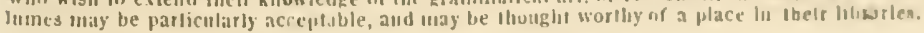

An ENGLISH SPEIIING BOOK; with Reading Lessons adapted in the capacitics of Chithen : In Fliree l'arts, calculatell in advance llie Learures ly nat tural ausl ensy Gralations; and tos teac,li Oullography and Pronmenciation tomether. $13 y^{\circ}$ LINDLEY MUMKA. Aullior of "English Grammar," Sce. The Sixfl Edullun. Ia demy ismo. l'rice is. fid. homut.

rolume recommend to the puthic this mnat anportant

rolume, as the unly work with which we

English tanauge, or leaching clithiren
loguplier and a mian of tinste." Lit, Jgarn. witich has ialely tallen under nur Inspectiun." Anti fac.

Dot cummonly tound in such works." Brif, Cris.

bouk is singularly well adapted to angwer the purpose for w bich is intended." W. Ret." "Nir. Nurray lias cumposed one of the best elementary books fur children in the englhwh language

FIRST BOOK FOK CHILDRFN.

By LINDLEY MIRRAY. VIth EAlit. Price tid. sewed - This recy improsed leritumer is Intended tn prepare the lesmer for the above mentloned spelling Booh, and is particulirly
iniended by the author to asaist motiliers in the instruction of their voung children." "s, Rov.

ENGLISH GRAMMAR, adapted to the dif ferent Classes of Learmers. With an Appendix, cnutau ing Rules and observanons, for assisling lie more ad vanced Students to write with Perspucully and Accuracy. BY LINDLEY MUIRAY

A new and improved Edition, heing the sixleenlh. In vol. Demy $12 \mathrm{mo}$. Price 45 . bound; and nn supertine royal Price 5s. in extra Boards.

An ABRIDGUENT of MURRAY'S ENG LISH GRAMMAR. Will, an Appendix, conlaining Ever clses in Parsing, il Urlhograpliy, in Sy'ntax, and in P'ulc tuation. Designed lor the younger Classes of Learners. The Twenty-first Edition, eniarged and impruved. Price 15. bound.

ENGLISH FXERCISES, adapted to MUR RAYS ENGLISH GRAMMAR, cunsisting of Fien. plificatious of the Parts of Speech, Instances of False plincations vinlations of the Rules of syular, nelects in Puncluation, and V'iolitions of the kilcs respecting l'er. spicuity and Accuracy. Jesigned for the Benelit of pill. sate iwelfih Editioli, much iniproved. Price ss. $6 d$. bound.

A KEY to the ENCLISH EXERCISES ; calculated to enable private Learners to berome their ow Iustructors in Granumar and Composition. The Tenth Edilion. Price 25 , bound. The Exercises and key uay be ball twether. Price 4s. Iinunil.

"Me. Nurray'a Engligh Grammar, F.nglied Exerelses, and Abridg. ment of the Grammar, claim our attention, on account of theit heing cumposed on the principle we lisve io frequenily recomunended, of combining religinus and moral improveinent with thie elements of scirntific knowledge. 'The sate lement Dr. Blatr gare his opinion of it in the following tering:- Mr. Lindley slurray Gramisar, with the Exereises and the key in a asparate rolume, estecin as a most excellent perlorinance. t tis Ink it supertor to anwork of that nature we have yet had; and am persuadet that it is by much, the best Grammar of the Englinls lapguage entant, On Syntax, in particular, he bassliown a woiderful déree of acutenrse Eyntax, in parting ascerlaiviog the propriety ol leaguage, and in

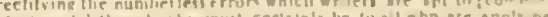

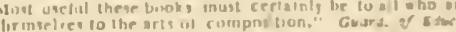

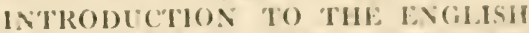

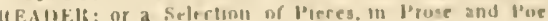

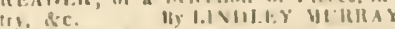

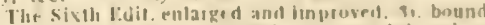

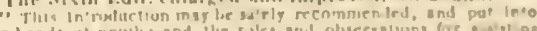

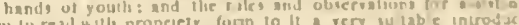
צ. $R \rightarrow$ ?

THI: ENGLISII RE.ADLR; or, l'irees in Prose and Puclry, seiecled frum the best Writers. Ile signed lo assist younk l'risous in read will l'rugutely sud Fifect: In imurave their Jauguage aud Selutumento, and tis inculcate soure of the most impottum Punriples ot

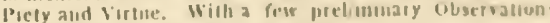
on the l'rinciples of gooul leeading.

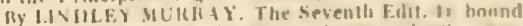

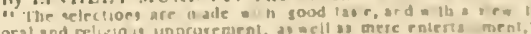

morat and relig

SEQUEI, to the EAGIISH Ri:I DER: 01, Vifegant Selcefiuns, in Prose and puetry liegloned pu improve the higlu:r Class of I.earimers on theading, in eolablisb a Taste for just and acrurale Counposition, and to promule the interests of Plety and Virlue.

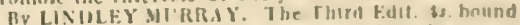

He hare no lachitation in recommend $\mathrm{n}$ g this velection as ithe leat of its hind." Cril, knt.

LECIFUR FRANCOIS; on, Rreneal ile Pleces, en Prose eten Verse, lures des Meillcurs fieruraing, pour servir a perfucllouner les jeunes Gens dans la Lec. poir servir a per leur commolsanance de la Imugne firan. cuise a a leur Juculquer dea princlipes de Vrrlo el de

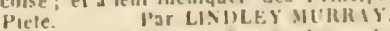

duleur d'une Grammasre Anglotse, Se. Secrnde Edit, Ismo. price \$s. Ed. boutul

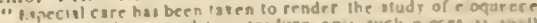

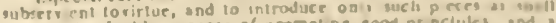
answer llie luuble plipose of promating good pr nciples, and a correct and regant laile. This mill, no dasbi, be found in "ety

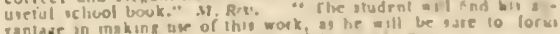

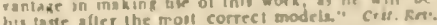

INIRODLCTION AU LECTEIR FRIN. cols : on lieenell de p'leres choices, asee l'k. plleation des Idiotismes el des l'hrases dicheules, quil sy iruuveat. Par LIVILFY MLKRAY.

Anteur diune Cramuaire Augloise, de. In I 'nu+b l'rice is, bil lloards.

- Mr. Murray hasesencived lais ugual castion and farment in

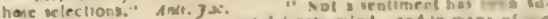
multed which can burt the mont delieate miad i sod in masp of 0

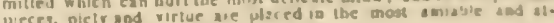
pleces, picty whd virtue are phistedso

LECTURES on BELLYS LETTRFS and LOfilC ny the late WISLIAN BARRUN, F, A ... E. And professor of Kelles leltres and Lozic in ibe tinversily of SI. Alidiess. In 2 vuls. INo. P'rice (ine livinea. IHalds. This wort is weil enteulated for lice intist on of the gourg

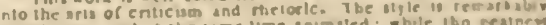

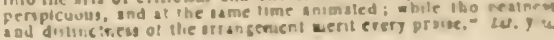


An ABRIDGMENT of Mr. PINKERTON'S MODEKN GEOgRAl'HY; and Professor VINCE'S AS. TRONOMIC.AL. INTROUUCTION. In 1 large vol. 8vo. with a Selection of the mosi uscful Maps, accurately copied from those in the larger Wolk, all which were drawn pieder the Dirction and wilh the litest Improvements of Arrowsmith. The Second Fdition. Price 12s. in Boalds.

An INTRODUCTION to Mr. PINKER TON'S IPIIDGMLN of his MOIBERN GEOGRAl'IY, for the Use of Schnols, accomsanied with Tuenty outline Maps, adapted to this introduction, ant suiled in ollie Geographical Works, forming a complete Juvenile Atlis. BY JOHN WILLIAMS.

III 1 vol. $12 \mathrm{mo}$. Price 45 . bound; and witls the Atlas, consisting of rwenty Maps, price \&s. $6 d$. The Atlas separate. price 4 s. fid.

A1] INTRODUCTION to the GEOGRA PHY OF THE NEW TESTAMEN I ; comprising a Sum hary Chronological and fengraphical View of the Events recorded respecting the Ministry of Our Siviunr; "it? Questions for Examination, and on accented ludex; principally clesigned for the lise of Young l'ersons, and for the Sunday Employneut of Schools.

$$
\text { BY LAN'T CARPENTER, LL.D. }
$$

In 1 vol. $2 \mathrm{mo}$ illustrated with Maps. Seconol Edilion. Price 5s. Ronrils.

" We recommend this book to alt such as are anxious to ubtai ccuracy and precision in their geograntical and clironological knowledge, as far as relates to the.History of the events recorded in the writings of the New Testament." fit. four

PITY'S GIFT; a Collection of interesting Tites, from the Works of Mr. Pratt. In I vol. J2mo. tmibellished with Wnod Cuts. Price 3s. bound.

THE PATERNAL, PRESENT; being a Semel to Pirys Gift. Chienty selectcd from the Wrilings of Mr. Pratt. Emhellished wilh 11 Wood Cuts. 3s. Iround.

A new TREATISE on the USE of the GLOBES; or a Pbilosophical View of the Eartb and Heaveus : comprehending an Acconnt of the Fignre, Mag nisude, and Motion of the Eartls; with the nafural Changes of its Surface, caused by lilonds, Earthquakes, \&c. de. signed for the lustruction of Youth.

By THOMAS KEITH.

III 1 vol. 1emo. wilb Copper-plates. Pric 6s. in Boards. "This volume comprehcnds a great quantity of valuable matter in a small compass, and we "Thit. Crit. "Tork is paly executed." Cen Eur.

INSTRUCTIVE RAMBLES throngh Londow and its Envirous. by Mrs. HELME. Complete in 1 vol. I'rice $4 s$. bound.

"Much topographical and historicat knowledge is contained in

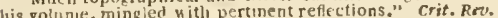

MATERNAL INSTRUCTION; or, Family Conversations, on mora! and interesting Snbiects, inlerspersed with listory, Biograpliy, and original Stories Designed for the Perisal of Youth.

By EIIZABETH IIELME

In 2 vols. 12mo. with Frontispieces. Price 6s. in Boarts. "rhere is something in the plan of the present fittle work par. ticularly pleasing. It is with great pteasure that we reconmend satistaclory." Brit. crit.

THE HISTORY of ENGLAND, related in Familiar Convelsations, by a Father to his Children. I:1tersnersed with moral and instructive Remarks and $\mathbf{O b}$. servations on the most loading and inleresting Subjecls, tesigned for the Perinsal of Yonth.

\section{By ELIZABETH HELME.}

In \& vols. 12ino. iss. Bd. witli Froutispieces by Hopwood.

"The present performance seems exccedingly well adapted to he proposed purpose, and it is worthy of a respectable place in thic jusenile ribrary." "Brit, (orit.

LE'T'TERS addressed to a YOUNG LADY, wheren rhe Duties and Characters of Women are considcred chefty with a Jeference to prevailiag Opinions. By Mrs. WEST.

The Second Edition. I 3 vols. 12mo. Price 12.1 s. Boards. We du not venture vitlinut mature deliberation to assert chat noc merely as critics, but as parents, husbands, and brothers, chat mo West"." Crit. Eev.

LETTEIS addressed to a FOUNG MAN, oll his First Entrance into Life; and aclapted to the pecnJiar Circumstances of the preselt Times.

By MIS. IVEST.

The 4th Edit. In 3 vols, 12 mo. Price $166.6 \alpha$. Boards.
"This work appears to us highiy valuable. The doctrines whics it teaches are orthodox, temperate, unilorm, and liberal ind the manners which it recommends are what erery judicious partent would wish his sou to adopt." Brit. crit. "We consider these letcers as truly valuphle, and would strongly recommend liem 0 the allemtion of our youngel friends" Cr. Ret". "We cannot withinold our tribute of praise which a work of such supcrla

LETTERS from MIS. PALMERSTONE TO IHER I)AU(iHIER; inculcatiug Morality by entertainms Narrativts $\quad$ By M.S. IIUNTER of Norwich.

1113 vols. persi $8 v 0$. Price $15 \mathrm{~s}$, in Boards.

"This is a very pleasing and well exceuted performance." $\mathrm{Rr} . \mathrm{Cr}$.

LE'TTERS ON NATURAL HISTORY, exhiliting a View of the I'uwer, llie Wisdoni, and Gundness of the Deity, sn emusently displiyed in the formation of the Univetse, and the variois Relations of Utility which inferior Belugs lave to the Human Sprcies. Calculated particulanly for the Use of Scluobls and Young Persons in general of both suses, in orter 10 impress their Mind swith a just Knowledge of the Creation, and with exalteal ldeas at its Great Anthor. Illusliated by npwards of 100 charaved Subjects, apulicible to the Wort.

By JOHN BMiLAND. In I vul. J2m\%. Price 9s. Boards. "' he hook is cleally stiperior to any thing of the same size
and extent that has lintiertu appeared." pirtit. Crit.

A GPAMIMAR of the GREEK IAN. rUAGE, on a new and improved Plan, in Euglish and Greek. By JOHN JoNES,

Menber of the Fhilological Sociely at Manchester. Neatly printer in lemo. The sd edit. Price Gs. in Buards.

"This work is in reality what in the title-page it protesses to be, a Greek Gratimmar upon an inpretict, as welt as a new plan.

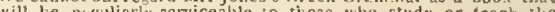
Wree pectiany scriceable to these who study or trach the creek language." Imp. Rev. "It exhibits many pronls of ingenuity and exlensive rescarch, of a mind acute and vigorous, and habiiually, and ofien suecesslully, employed in plitosophica
investigations." Ann. bev.

GREEK EXERCISES, in Syntax, Ellipses, Dialects, Prosody, and Metaphrases, (after the Manner of "Clarke"s and Mair's Introduction to the making of Latiu,") adapted to the Grammars of Eton, Wettellball, Mcore, hell, and Holmes. To which is prefixed, a concise but comprehensive Syntax.

By the Rev. WILLIAM NEILSON, D.D.

Minister of Dnndalk, I reland. Tlıe Second Edilion. In 1 vol. Bvo. Price 5s, in Boards, and with llse Key, 8s. "This work strictly fulfils the protessions of the title-page."

\section{An UNIVERSAL FRENCH GRAMMAR,} heing an accurate System of Freuch Accidence and Syntax, on an inproved Plan. By NICOLAS HAMEL. Fifill Edition. Price 3 s. 6 d. honnd.

"Of the many excelient french crammars now in use, this is among the besto" " $1 \mathrm{t}$ is both comprehensive and concise, and is as well adapted as most Granimars for the use of schools.""Ite has composen lis work on snund principles and exact definitions."- "lis book demands our comniendation."

\section{GRAMMATICAL EXERCISES UPON}

THE FRENCH LANGUAGE, compared with the Englisb. By NICHOLAS HAMEL.

The Third Edition, with great Improvements. Price $2 s .6 d$.

THE WORLD in MINIATURE; containing a curious and faithful Account of the Sitnation, ExIent, Prodictions, Gnverument, Populatiou, Diess, Manners, Conriosities, \&zc. \&zc. of the different Conntries of the world, compiled frum the hest Auflorilies; with proper References to the minst esscutial Rules of the Frellch Language, prefixed to the Work, and the Translation of the difficult Wor.Js and idiomatical Expressions: a Book particularly useful to Students in reography, History, or the Frelich Lauguage. By NICHOLAS HAMEL, The Second Edition. In 1 vol. 12mo. Price 4s, bound.

An ALPHABETIC KEY to PROPRIA QUA: MARIBUS, QUAE GFNUS, and AS IN PRESENTI, contajuing all the Exampies declined and translated, with the liulcs quoted under each, and numerical References to the contexi. By J. CARl:Y, LL.D. Ii 1 vol. 1smo. Price ss. Gd. honnd.

SCANNING EXERCISES for YOUNG PROSODIANS, confining the first Two Fpistles from the Electa es Ovidio, scanned and proved by the Rules of the Eton Grammar, and interspersed with occisional Remarks By 3. CAREX, LL. D. Price 4s. in Boards.

LATIN PROSODY MAI)E EASY. JYJ. CAREY, L.L D, privale Teacher of tha Classies, Jrench 
Language, and Sliorl lland. Besides ollier malerial Ius

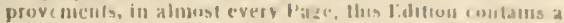

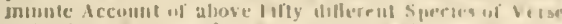

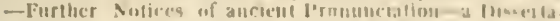

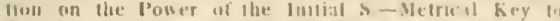

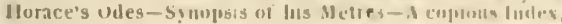

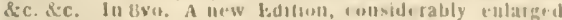

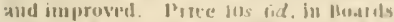

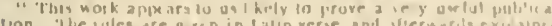

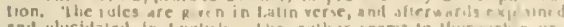

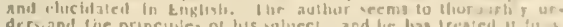

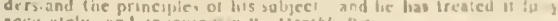

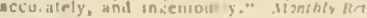

\section{A KEY to CHIMB,IUIS EXFRCISI:}

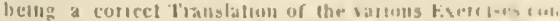

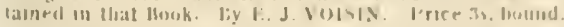

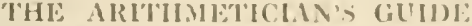

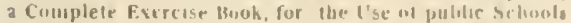
and privite T'eachels. lig WIILIAy I MI IRk. Tearlier of the Mathemalus, \&c. Kic. Sc. The bifle Edhion In 1 vol. 12ums. Price 3s. bound.

HISTORICIL aml MISCLLIANEOUS QUESTluss tos the l'se wi Young lenple; with a Selecttion of Brilssh and rienteral Bugraplis. \&ic.

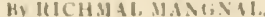

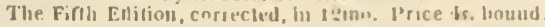

'THE SCHOLIR'S SIELLING ASSIN' ANT. Intended lin the Use of Silunols and private Tititiun. By TIIUMIS CAIRI I:.NTEI?,

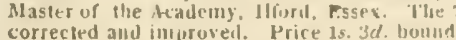

THE NEW OITHOGRIPHICIL AS-

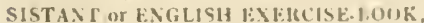

Written on au Improvet Plan, fur the mor' speedy In. Btruction of young Persons in lise Art of Spelling, ans l'ro. unuciation, infencled for flue l'se of Siliools.

By TIIOMAS CARPENTER. Prices. Bomd.

THE CHILD'S MONITOR: or, Parental Tustraction. In live Parts, tonlainiug a great Vartety of Progsessive Lessons, adapled to llue comprelacisian of Children; calculared in instruct lliem is Readuus, in the

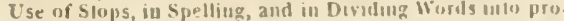
per Syllables; and al the same Time to give them some Kuowledge of Natural History, of the Scriptures, and uf several wher sublime and imporlanl Subjects.

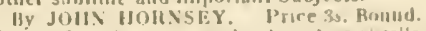

"Tlsig is one of the best conceived ard most praticalls ueclut

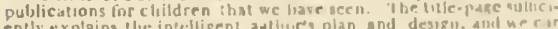

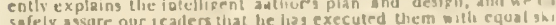
solety assure our teatrens inty

THE BOOK of MONOSVILABLES; or, an Iutroduction in the Cluld's Monitor, adaplest fut the Capacities of young Children. In two Parts, calculated ins instruct by familiar (iradations in the lirst lerinciples of Euncalion and Morality.

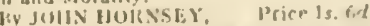

"The obrsous atilats of llus plan lg such as lo requ re ho com-

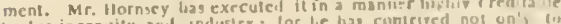

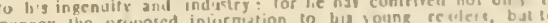

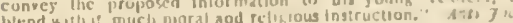

A SHORT GIRAMMAR of the liNGILISH LAGLAliE, simplited th the Caparilies of Chilurm. Lin Foir Parts. L. Urthograplyy. \&. Inalog!. 3. P'rosudy.

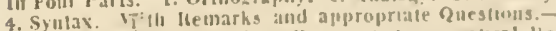

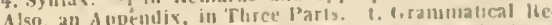

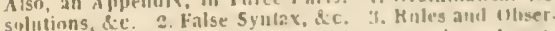

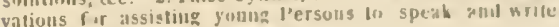
7fith perspicuits and Accuracr.

IIY JUHX HORNSEY.

A new Edit correcled and greally unproved Price 2 s. lid.
I VOC'ABVI. ARI; linglist and firch, afo

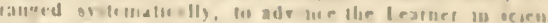

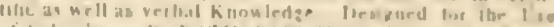

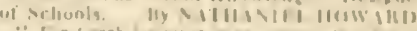

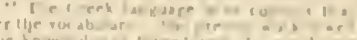

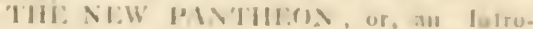

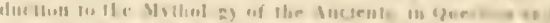

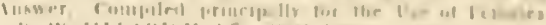

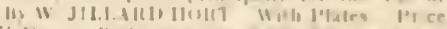

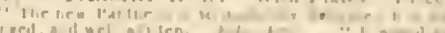

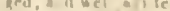

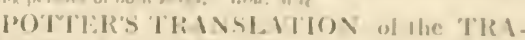

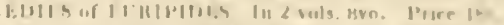

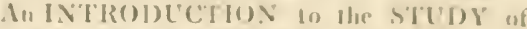

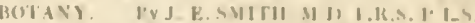

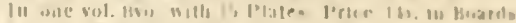

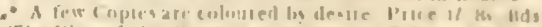

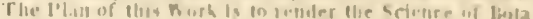
nical Arrauge lluell as wrll an lloe geocral strucluse aud

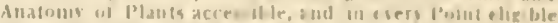

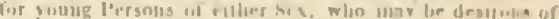

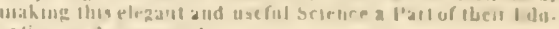
caliuns or Imusement.

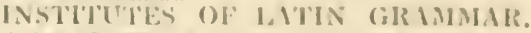

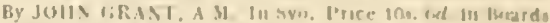

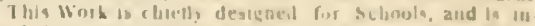
leuded not to superserte the I se of our corumon filam.

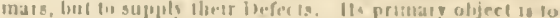
furuish tlie aculor sebolar wilh a rumplete liges of the Kules and l'tinciples of the balin langurge and to afford the Traclier a Useful Busk of me satumal Reference.

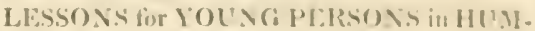

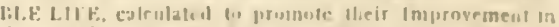
the Irt of ltesdius. III I Irtue and l'icts. and partleulaty in the knowledge of the louttes jucular lu thear statnous. price in, id. In llisitis

:. Very ica ly primted, and wel selected, con'a nina a rrea?

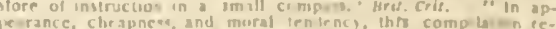

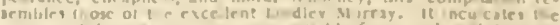
most usclul sentlgenis in a vep! pul able form, and wel dererse

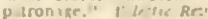

MATII:M ITICS SIMHJIFIED, amI PRAITI il.LY ILI.I STR IT E.L hy the Adaptafion of the lutiaripal l'rublems (1) the ordtuary Purposts of Life, and

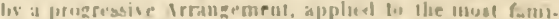

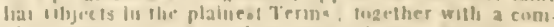
plete l.zsay an the irt of survegunz laurls. Ac. by stirlo

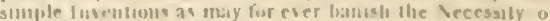
costly atui cumbles Instruskents.

liv Caplum lith is w 11.1119401

Autlaur of the Wild sparts of India. Ju 8 so. Wilb as plates. I'ricu. cha in Boards.

'TYLOR'S ISEFUT, ARITHMETIC; or, the most uece sary parts of the selelire of Nuinleris reiz.

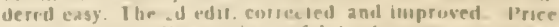

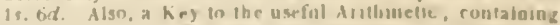

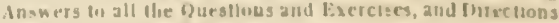
pritiu solunom l'rice: is.

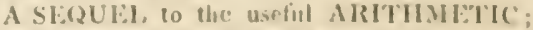
or, an IIfoupt in esplasn and exconplify the sulure, l'rincijoles, llporatiosa, autl proper Applicalson of flse bigher Branclies of the sclonce of Numbers. Inelndiue

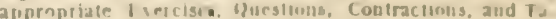
blis; dranned lusurceet the former $\mathbf{T}$ rat, and complete a bystell of Arithuetiedl listruction.

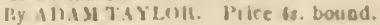

\section{POETKI.}

'THE MINSTRELSY of the SCOT'IISH BOKul: cousisting of llisterical and Romantuc Ballarts, collected in the sonthert Cenutues of Scollatad; will a collected in the simte lininded on lincal Tradtion. Wilb

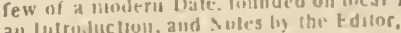

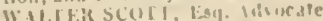

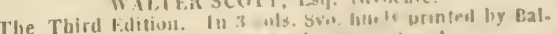

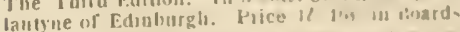

The L.' Y of tlat LI: MIASIREL a

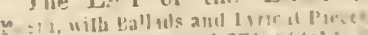
by iv.1L[EI, acul1, 21 .
Faleganlly prutcd lis Ballautym, on snperflne wove Paper, and hot-prissul. I lie I.J hith kililion. In tlo Price 2 ?

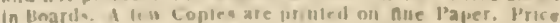
3l. I b $(1$. in lioards - This lislume. with slatuilon, foims

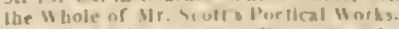

Also an I diliun in ivas. I'tue liw ad is hoards.

B.ILIAUS and J.YRKC'ML, I'IECIS.

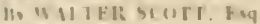

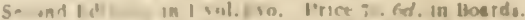
- i la liller Worle, wilh." Nermion, cublain

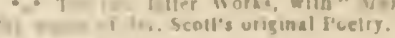


SIR TRISTREM, a Metrical Pomance of th: Thirteenth Cectury.

BF THOYAS of CRCILDULNE. called the RHYBIER. Edited from the A achialeck MS. by WALTER SCOTT, Esq. second Edition, in royal svo. Price 15s. in Boards.

THE NATURE of THINGS; a Didactic Poem. Iranslated from the Latiu of TITL's LCCRE. TIC'CARCS. accompaned with the original Text, and illastrated by Sotes. philological and explanatory. BI JOHS MASON GOUD.

In 2 vols. tin. erabellished witb elegantly enzrared Fron. tispieces. Price 4l. is. io Boards.

MADOC. A Poem. In Two Parts. BY RORERT SOLTHEY.

In a rols. foolscap, elegantly printed by Ballantrae, with Four beantiful Vianeltes. Price iss, in Boards.

A few Copies of the original Quarto Edition may be had. price $2 \%$. 2s.

For a high cheracter of ihis work, see 49. AF. 135.

JOAI OF ARC. An Epic Poem.

By RODERT SOUTHEY.

In 2 ruls. foolscap 8ro. The Secnnd Edition. 12s. Boards.

MIETRICAL T.ALEs, and other Poems. Selected from the "Ananal Antbology." BS ROBERT SGLTTHEY

In 1 rol. fólscap \&ro. Price 5s. 6d. in Boards.

POEMS, inclnding the Visiocs of the Maid if urlears. BY ROBERT SOLTHEY.

In? vols. Price 11s, in Boards.

THALABA THE DESTROYER, a Metrical Romance, witb copions Notes.

BY ROBERT SOLTHEY

Fiesantly printed in o rols. foolscap 8vo. 1ts. in Bozds.

POEMS. By WILlay WoRDsworte. Aythor of the Lrrical Ballads. In 2 rnls. fnolseap forn elezantly printed on wore Paper, azd boi-pressed. Price 11s. in extra Boards.

THE POEMS of OSSIAN; containing the Poetical Wurks oi James Macptarson, Esq. in Prnse and lingme; with Notes and lliasirations. RE M + LCOLY LAING. Esq.

In 9 large vols. 5vo. Price it. 10s, in Boards.

THE WA XDERER of SWITZERLA ND, and other Poems. By JAYES MONTGOMERY.

T bird Edit. in \& rol. fnolscap 8vo. Price 5s. in Boards. "s Mr. Nootgocery d splays a rich and foma tic iatcr, render heart, a copions and actse command of inazery and "For a very higa character of inis rolame, see Ant. keo. is is.

POEJS. Bs JAYES GRAHAME. In $\triangleq$ Vo lnmes, Foolscap 8vo. Price ies.

viol. I. containing the Sabbath (Jith Editinn); Sabbath Walk ; the rural Calendar; and smaller Poems.

Vol. II. containing the Birds of Scolland; and Mar Staris a Drmatic Poem.

THE BIRDS of SCOTLAND, BIBLICAL PICTLRES, aAd THE RLRAL CACENDAR, wish other Poems. BY JAYIES GRAHAME.

poems. "The Sabbath," a Poem. In I rol. fnolscap Svo. Price ;s. in Boards.

The SABB.ATH, a Poem. To which are arded, SABBAIH WALKS.

BV JAMIES GRAHAME.

In 1 vol. foolscap 8rn. Price Es. in Boards. The Eth edit.

POEMS. By Mrs. OpIE. The Fourth Edition, with a beantiful Frontispiece. Frice ês. in Boards.

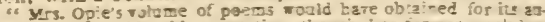
thor a rest considerable reputa"ion, "houkh ter former wort kat

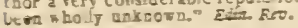

THE WARRIOR'S RETURY, and other POEVS. EY Mrs. OPIE.

In Ioolscap Swa. embellisbed with a Frotispiece. Frice 63. in extra Boards.

POEMIS and PLAY\$. Br Mrs. MEsT. Ia f vols. fnolsoap 8vo. hot.prassed. Price 12 . 3 . in Boards.

MISCELLA VEOL'S POETRY ; consisting of TRAVSLATIOSS from the Icelandic. Italian. Smanis, Purtnguse. German. dec. By the Hon. W. HER8ERT. In 9 rnts. ansl 8 ro. Price ins in reards.

For a h'gh chardeter of tis woril see Am. 8.t. 1505.

THE WORKS of THOMAS CHATtERTOS, consis: ing of all the Pieces contained in Korley's Powns. Chatterion"s Miscellanies. and the sappletitnt; with more tban an equal Portion of gew Matier. In 3 large vols. 8vo. Price $1 L$ 11s.6d, in Boards.

ALFRED, an Epic Poem, in Twenty-four Ronks. BY JOSEPH COTTLE

In 2 rols. foo'scap Yro. The Sd Edition. 10s. ed in Bracds.

POE IIS. Br S. T. Coleridge. The Third Fditinn. In ioolscap Evo. Price is ed. in Boards.

ODFS of PINDAR, translated from the Greek with lintes and Ilicstrations.

BV G. TFEST, EST. LL. D. 2nd H. PYE, ESg.

To which is prefired a Dissertatina on the Dlympic Games. By GILSEliT WEST, EST. LL. D.

A nev Edition it ? vols. 10mo. Price $\%$ s. in Boards.

CONTEMPLATION\$, a Poem, with Tales, and olber Poetical Composirions.

By JUHN PE.TW 1 HXE. Price 6s. in extra Eoards.

POEHS. By SAMtel Egerton BRYdges, Esfy. In foolcap Evo. price ;s. in exts Eoards, the Fourth Edition with considerable adcitions.

THE HIGHLANDERS, and other Poems. EY MIs. GRAST

In $t$ snl. fonlscaporn, the od edit. Price is. in extra Rds.

THE MI_STREL, Book Third, being a Continuatiun of Dr. BEiTTlE's Poems. In 1 rol. ftu. Prce in $\mathrm{Bnards}$.

A $\because$ CIEIT HISTORIC BALLADS, conraining, 1. Richard Plastazenet-2. The Cave of Mora. the Man of Sorrow. - 3. The Dattle of Florldan. $\rightarrow$. The Hecmit oi Warkworth. -5. Hardrhante. In one rol. fools. cap Evo. Price 5s. in Boards.

LETTER.S and SONIETS, on Moral and other interestinz Sabjects. Addressed to Lord John Rassel. BY EDYLND CARTWRIGHT, D.D.

Prfbendary of Lincoln, and Claplain to his Grace the Doke of Bedford. In one vol. foolscap 8vo. Price 5s.

PARTENOPEX DE BLOIS. A Romance. in Fan Cantos. Freely uanslated from the Fiencb of $\mathbf{M}$. LE GRAND, with Notes. By WILLIAM STEWART ROSE. In 1 vol. $\div$ th elegants priuted by Ballantya, with anmeronz Enaravings, from Desians by Mr. Richard Smirke, illustrative of the Scenery and Habits of the Twelfth and Thirienth Centuries. Price ol. 23. in Boards.

\section{THE RESLRRECTION. A Poem.} EV JOHY STEWART, Esq.

In I rol. foslscap svo. Price is. in extra Bnards

EDWY and ELGIVA, and Sir ETERAPD.

Two Tales. By the Ret. ROBERT BLAND.

la 1 vol. fonolsca p \&vo. Price is. in Boards.

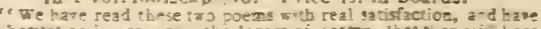
o tesitajoc in promis na he lovers of poetry, lbat ter wi there meet with some reng beazufif pasazes, and wo very interesticg aed spir.ted compositions." Eris. Cris.

MIETRICAL LEGENDS, and other POE.I5 BY CHARLES SIRKPATRICK SHARPE, ES.

In i rol svo. Price 5s, in Boards.

\section{NOVELS AND ROMANCES.}

AMADIS of GAUL, from the Spanish Version of Garcinrduaez de Montalvo, with 2 Preface, \&-c. BY ROBERT SOUTHEY.

In Four bandsome volumes, 1 smo. Price 12 . 1 s. in Boards. "We can recommend this wort' with confdesce." Bris. eris.

PALSIERIN of ENGLAND.

HY FRANCISCO DE YOREAS.
Corrected by Robert Sonthey, from the onininal Portagcese. with Amendment3. In four large vols. foolscap 8vo. Priet 1i. s. $_{5}$ in Boards.

THE KNIGHTS. TALES illustrative of the MARVELLOUS. By R. C. DALLAS, Esq.

In 3 rols. dandecimo. Price 25 s, in Boards.

THE SWISS EMIGRANTS. A Tale. In I vol. $19 \mathrm{mo}$. Price 4s. in Boards. 


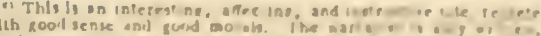

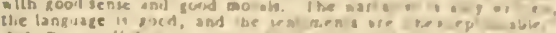

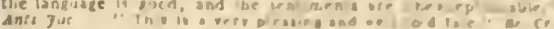

THE MORAIITY of FICIION, ur, an

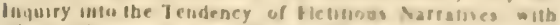
Observationg on aurne of the umal fortinent

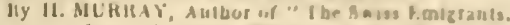
III I vol. Ismu. P'ice is in Moarmi

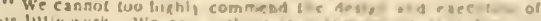

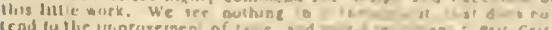

WOMEN : THEIR C'ONIJTIOS and I

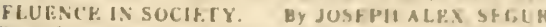
Iranglated frum the treach. in 3 sols 1. uin price tes

A GOSSIP'S STORY, and I.EGI:ND.IKY TALE. Ey Mis. Wist

In 2 vols. 1?mo. Fourth Fidition. Price is. In Roards.

A TALE of the TIMES. By Mr. WEST.

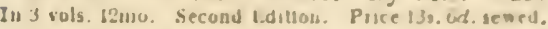

THE MDVANT:IGES of EIJUCATION nr, The Halstury of Marla Williams. A Tale, for very Young Ladies, By Mis KiE. I:

The 211 Edil. In 2 vols. IIwiu. Price 7s. III Boards.

SIMPLE TAICS. By Mrs. OfIE. Second Editinn. II t vols. 1:mu. Price 16. 19. in Boards.

"In the tales now before us we knd much of the ume merits ol in lice beastus story of Adeline Mowhrag: the same Iruth and

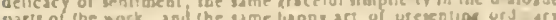

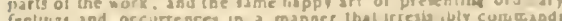
reetimps and occiarresces in a thanner

THE FATHER ANI DAUGHTER. A TALE. By Mrs. UPIE.

The Fiourth Edilunn, wilts a rontisurece. 4r. Gd. In Bmards

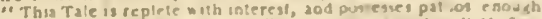
o affect the lieart al the most callous ol crituca readera." w. hro.

ADELINE MOWIBRAY; or, the Mother and I)anghier. A rale. By Mrs. OPIE

The Secrund Editiun. In 3 vols $12 \mathrm{~m} n$. 13s. Bid. in Eoards ". These volumris are, bota is the $\mathrm{r}$ desirn and execut on, wa raperiur to those which we usua ig encounter under $\&$ e l the ul ing

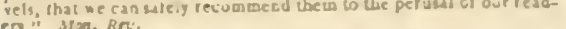

\section{"IHADDEUS of WARSAW. A Novel.} By MIIS PUKTER.

The Fifth Rdition. In \& vols. Pnce 14s. In Boards.

Triaddeus is a work of genius, and has nothing to lear at the candid bar of taste: he has 10 rece re the precious meed of ismputhy irnm erery reader of unspplasticated yenturaent and genaine fceling." imp. RT'. "Thu work has mure went iman san be ascrived in ihe croed of product ons of this class, acd loculcate risfuous and enaznsnimosisenuments:" si Rro,

THE MYSTERIES of UDOLPHO. A ROmance; interspersid wilb some Pieces of Poeiry. BY A.N RAUCLIFYE.

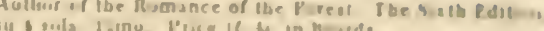

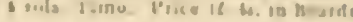

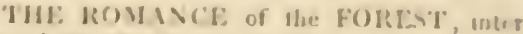
spersed with su lue linces of lnuple

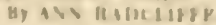

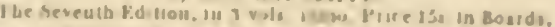

\section{A SICIJIIN K()MING:.}

by A \N kABCe it F P.

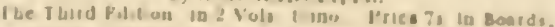

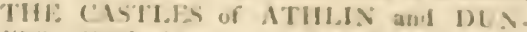

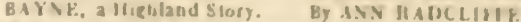

l'mo. I'rke is lat in braids.

MFM()IKS of MI KMO VTI.. Writhatsy Ifimself. Lontaraine las Literaly and Pollicat Life, and Anecdoten of the Principal Chararteis of the fichienth Century. A new ralion, corrected throughoul. It t rols. 1. mus. Prlec une Gulnea In Buards.

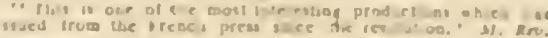

TIIE ILIKE of KILILIRNIV, A Nosel.

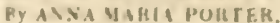

In 3 rols. Itanu. Irtice $13 \mathrm{~s}$ cd. it Hoards.

THF HUNG IKIAN HROTHFKS.

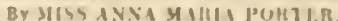

Ins iolames 120io. Second foll. Prire ISt. In Bats

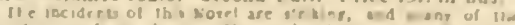

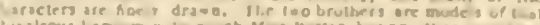

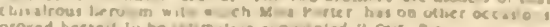

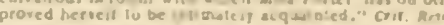

THE(O)(O)L: or, the ENTHC'SIST, In fuir Solinmes $12 \mathrm{mo}$. I'rice 36 . 18. In Boards.

THEFATAL REVI:AGF; or, the Family of NIINTURIO). I HUMAVE.

RV (H.T.IS JISPER MLRPIIY

In 3 liclumes I:mo. Price 16 . Is. In Boards.

ARTLEST TALES. In 3 vols. 1!mo.

By Mrs. HURKY. Pnce 15s. In Eoards.

THE WILI) IRISH BOY. By the Autior of MoNTuItuy. In 3 vols. Ismo. Pise leis. Ge in Boardo.

ROMA.IIC TALFS. By M. G. LI:WI: Autbor of the Monk. Adelgitba, ac. In t vals. Istuo. Prsce Il. 4., in Boards.

THE RIVG AND THE WFLL A Ro. mance. In b rols 12 mo. Price ll's. in Boards.

The HOUR of 'TRIIL, a Tale. Isy MIRI' AVNE NEHI. Aurbor of the "RTe of SaD trietro." IU3 vols 12 nis. ['rice ise Iu Boardi.

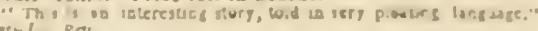

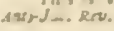

\section{AGRICULTURE, GARDENING, Sic.}

A TREATISE on the CULTURE of THF VIVE exbibitung new and advansazeuns Methods of propagating, culturatiug, and iratalag that plani, 30 as to

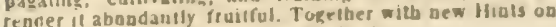
reformation of Vineyards in E.neland.

By WILLIAM SPEECHLY.

The Second Ecition, with Addilions. In I vol. poyal Bvo. Illustrated with Six Copper-plates. Price Is. Mi Boards.

A TRE.ATISE on the CULTURE of THE PINE.APPLE, and the Managemeninf the Hot-bouse. By WILLISM SPEECHLY.

The Secnud Edition. Ia Bro. Price Izs. In Boards.

ATREATISE on the CULTURE and MA. NAGEMENT of FRLIT.TREES, sn wbich a Dew Me. NAGE. Pruniug and Traiumg is fully describer. $T$, which is added, a new and unproved Elition of "ubser. wations oll the Diseases, lofects. and Iajunes, in all siuds of Frut and Forest Trees; with an Account of a kads uf Frumt dnd fore." Published by Urder of Ga. particular Sethod of eure. FuRsYTII, F A.S. and F S.A.

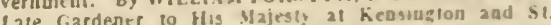
Lames. Member of the Economical Sociely al Si. PetersJames's. Nember of thew Esiliun, with is foldiog Plates. Price 12s. in Buards.

A TREATISE On FORMING, IMRROV. ING, and MANAGING COLYTIIY RESIUENCES; and un the Cholce of Situations appropriate to every Clans of Porcbasers. In all which the object in wew lo to onite tsis belier mauner than bas biluesto been lone, a Taste found. ed In Nature, with Fconomy and L IIfuly, in constructiog or improving Masions, and otber Kural Buildings, in as lo combine Architeclural Filneso with I'ietaresque Effect: and on formitus fordens. Urebards, Faruis. Pasks, Pledsure Croonds. Shrubheries, all houds of useful or decora. uve Plantations, and every libject of Couvenience, or Beauty peculias io Country Seats, according to the esteat. cbaracler, of slyle of Sliantions, and the mant. fortune. aod expenditure of Propisctors. Frum the Cnttace to the Pabce. With an APPE.NIJX, cumtaming an a nquiry InLs the aulity anil merils of Mr. Hepton's mode of shewin: Rifects by Slides and Siflebes, and atuctures on bis Upi-

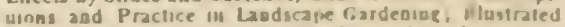
by descriptions of Sc-nery and Builings, by teferences to Country beats. and Pssares of Couoliy in mosp parts of Greal Britain; and by Thiriy two fingraving

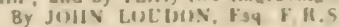

Itemher of the Sociely of Arto, Commerer. dic Londoa: of the society of Agnculinie, Pianting. Sic. Bath, Aubur of a "Treause on llot houses." and "Ubierva" thons on Landscape Gardening," \&c. In Itwo vols. Ho. l'ince $\mathrm{x}$. Is. In Koards

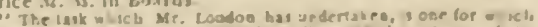
de appean to have been pec-diarly well gu led. and one of the

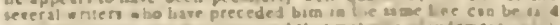

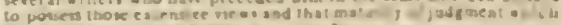

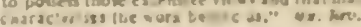


A SHORT TREATISE OU SEVERAL IMPRUVEMENTS recently made in HUT.MOUSLS.

By J. I.OUIUUN, Esy. l.R.S. In Svo. P'rice 12s. in Bds. "To all persons intcrested in possessing l: nowledge respecting the economy of thol-houses, we would recommend this petfor-

THE ENGLISH PRACTICE of AGRICULTURE, exenplified in the Batlagentemt of a Fant in I relant, belonging to llie Larl of Congugham, at Slane, in the County of Heath: with all Appendix, containing, irst, a comparative Estimate of the Irish and English Morde of Culture, as to Profit and Luss: and, secondly, a regular Rotation of Crops tor a P'eriod of Six Years. BY RICHARD PARKINSON.

In 1 vol. 8vo, illustrated with Lingravings, $9 s$, in Boards.

THE EXPERIENCED FARMER, enlarged and inproved, or COMPLETE PRACTICE OF AGRICULTURE, according to the tatest Improvernents.

The whole foumled on thr Authol's ewn Ubservations anul his actual Expernuents. By RICHARD PARKINSON.

In \& Volumes dvo Price 12.55 . in Boards.

THE CONLLETE FARMER; or, GENERAL DICTTUNARY of AGRICULTURE and HUSBANIIRY, compreliending the most improved Mcthod of Cul. tivation, the rlifferelt iiodes of rassing Timber, Fruit and other Trees, aud the moderu Management of Live
Stuck, with Descriptions of the most approved 1 mplz. menis, Machiuery, and Fanm Juildiugs.

Fifth lidition, III \& large 4to. vols, wholly ic. written and enlarged, cuntianng lixg Engravings. P'rice $f l, 6$ s, in beard?.

It has been the particular aim of the Edlitor to present thic Readel with a full Explication of the tummerois Terms of the Art, and at the same fime to affurd bim a View of moflern or impoved practical [lusbandry, sil arranged and incibodized as to be eapalile of ready referelice; a l'ollli which he conceives 10 be of the utunge Jmportance (1) oractical Farmers.

THE EXPERIENCED FARMIE'S Opinion on Gyusum or l'laster, from his owu Obscrvation aud Practice in America and England.

By RICHARD PARKINSON,

Author of the Experienccu Farmer, and nther Practical Works oll Agriculture. In olle vol. svo. Price $3 s$, in Bds.

A REVIEW of the REPOR'TS to the BOARD of AGKICULTURE, from the Northern Department of England. comprising Nortlumberland, Durham, Curnberland, Westmoreland, Lancashire, Yorkshiro, and the inountainous Parts of Derbyslite, X:c.

F, Mr. MARSIIALL,

Anthor of varions iVorks on Rural Economy, and Ho. norary Member of the Board of Agriculture. In ove. Price 12s. in Boards.

\section{MISCELLANEOUS:}

THE COMPLETE NAVIGATOR; or, an casy and familiar Ginicte to the Theory and Practice of Navigation, with all the requisite Tables, \&cc. \&cc.

By ANDREW MACKAY, LL, D. F.R.S. Ed. \&C.

Anthor of the Theuly and Practice of funding the Longitude at saa or iand, \&c. In 1 large vol. övo. illustrated with Engraviugs, \& c. Price los, tid. bound.

with Engravings, ac. Price ros, id. bound. "This is a clear, neil digested, and inasterly performance, containing besides, shat is usctul in other piblications, much and impor'ant ratter."

work of a man of scierce, uf one whu understands the subject which lie protessee tu tezch. Tu us lhere appears to be nothing wanting for the complete instruction of the young mariner in nautica! aftairs." Inip. Rev.

A COLLECTION of MATHEMATICAL TABLES, for the Use of the Practical Matbematician, Navigator, Surveyor, Students in Uuversitits, and for Men of Business.

Ly ANDREW MACKAY, LL.D. F.R.S. Ed. \&c. In 1 vol. 8io. Price $7 s$. in Boards.

RURAL PHILOSOPHY ; or, Reflections on Knowledge, Virtue, and Happiness, chietly in Reference to a Life of Relirfunent in the Country. Hritten on nc casion of the late Dr. Zinmernan's Juscourse on Sulitudt.

$$
\text { BY I:LY BATES, lisq }
$$

The Fosuth Edition. In ! vol. svo. Price 3s. in Boards. " 70 llose whu are of a serious and reiguus turn of mind thesc refectons to then all attenlive pertust of this weli-written and truly commendable volume." $M$, Rre'

THE COMILETE WORKS, in Pirilosophy, politues, and Morals, of Dr. BENJAMIN FRANKLIN aith Memoirs of his early Life. Written by HIMSELF. in 3 larue vols, 8vo, wall 16 Eugravings, and a Porlrait of the Author. Price 1l. los. in boarts.

"It is not very creditable to the liberal curiosity of the Englist public, that there sheutd !rave been no curplelc edition of the Works ut ur, roraklin fill the vear 1 g्रlfif. The public is ver 8 much indebted to the editor of the present colicctiun. It is prescnters in a cheap to the editol of the present colcction. have been cumpiled with and unostentatlous form, and seets:s to have been compiled with

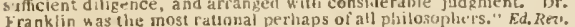

ESSAYS on the ANATOMIY of EXIRESSIUN IN PAINTING.

LY CHARLES BELL.

Containing, 1. Of the Uses of Anaiony to the Painter, Of the Study of the Autique, and of the Acadenny rigure. $\varepsilon$, of llue Shull. Of the Distinctlous of Character in dif. ferent Ages. Comparison of the Antitue will Natnral Claracter, -3 and 4 . Of the Minscies of tise Face, in Mau and Animals. - 5. Of the Exuression of Fassion as illusrated by a Comparison of the Muscles of the Face in Man and Animals. Of the Muscles veruliar to Man, amd their Etfects in hestowng IImman Expression.-6. Uf the Individual Passions. And of tlit Action of the Muscles expressive of these Passiums.-7. Geureral biew of the Economy of the Ihumat Busly as it relates to kigulession in Paint!ng.
In 1 vol. 4to. with Engravings after Drawings by the Iuthor. Price al. 2s. 11 Boards.

HINTS to YOUNG PRACTITIONERS

in the Study of Landscape Painting. Illustrated by Ten Eugravings, intendea to shew the different Stages of the Neutral Tint. To which are added, Instructions in the Art of painting on Velvet. By J. W. A LSTON, L. P.

A new Edition. Ju 1 vol. 8vo. Price 7 s. fid. in Boards. "This work contains plain and clear instructions for drawing 'andscapes; also respecling the mixing and manascment (s) cu-

LECTURES on the ART of ENGRAVING, delivered at the Royal Institution of Great britain.

By JOHN LANDSEER, Eugraver to the Kirg, and F. S. $A$. In I Volume svo. price Ins, fd. Boards.

SPECIMENS of EARLY ENGLISH METRICAL ROMANCES, chiefly written during the tarly t'art of the Funteenth Century. To swich is prefived, an Historical Introduction, intended to illustrate the Rise ann Progress of Romantic Composition in France and Englaur. By GEOliGE ELLIS, Esty.

In 3 vols, erown 8 vo. Price $1 l$. $7 s$. in Buards

SPECIMENS of the LATER ENGLISH PUETS, to the End of the last Century, with Preliminary Notices. intented as a Comtinualion of Mr. Ellis's Speciinens of the carly Euglish l'pets. By ROBERT SUUTHE. In 3 vols. crown 8vo. Price $1 l .11 s, 6 d$. in Luards.

SPECIMENS of ENGLISH PROSE WRIT ERS, irom the earliest Times to the close of the 1?1t Cellury, with sketches, Biographical and Liteıary, including an Account of looks as well as of the ir Anthors: with uccasınal Criticism, \&.c.

By GLOlifE BURNETT, late of Baliol College, Oxford.

In 3 vols. crowu 810. Price 12 . 7 s. in Bceards.

"We regard these volumes as wortby of no small comnendation, and to all who are interested it the progress of the ir innlies

\section{SPECIMENS of ENGLISH DRAMAIIC}

POETS, twlio lived about the Time of Shakspeare, with Notes. By CHAliLES LAMB.

]n crown svo. l'rice jos. Gd. in Boards.

HOUSEHOLD FURNITURE, and IN'TERIOR DECURATION, execuled from Desigus, consist. ing of perspective and Gcometrical View of Apartments, wul their Cuaios. Tables, Sophas, Candelabrie, Chandelicis, Tripods, Rc. \&c.

by THUMAS HOPE, Fis!.

Ou rusal folio. Price 5t.5s. in estra Bonds; or with l'rowt Implessions on Allas Paper, price Iil. IOs.

IIITISTRATIONS of SHAKSPEARE, and

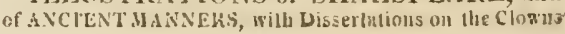


III 2 vols. duodecimo. Price 14s. iu Boards, with a Porvrait of the Autbor. 'The Secoud Edition.

"Mr. Ilarriult tas possessed vast opportunities for collecting the mosi useful, imporlant, and diversified intormation. When we add, that he has not wholly neglected these opportunitics; that to an acute and vigilant understanding he unites a restless activity, an undaunted perseverance, great quickness of feeling, and a peculiar readiness to learn; that his minor adventures, his early loves, rriendships, and quarrels, are interesting and attractive, our revived in our mind sensations which have siept almost ever since the happy days in which Rubinsou Crusoe had liee cliarm of novelty." M. Rer.

\section{A SERIES of ENGRAVINGS to illustrate} the ILIAD all ODYSSEY of HOMER.

From the Compositions of JOHN FLAXMAN, R.A. Sculptor to the King. New Editions, witb additional Plates. Piice 2l. 2s, each.

These Works altogether consist of 75 Prints (11 of which are from new Designs) representing in regular Succession the Stories of the Iliad and the Odyssey, with Descriptions of their Subjects, and Extracts from Pope's Translation upon each Plate. The Dresses, Flabits, As mour, Implements of War, Furniture, \&cc, are all of Classtcal Authority.

\section{A SERIES of ENGRAVINGS to illustrate} DANTE,

Engraved by Piroli, of Rome, from Compositions, By JOHN FLAXMAN, K.A.

in the Possession of Thonias Hope, Esq.

This Work consists of 111 Plates, illustrative of the Inferio, Purgatorio, and Paradiso of Dinte, with Descrip= tions in Italian, and the paraliel Passages from Mr. Boyd's Translatiolı. III folio, price $4 l .4 s$, in Boards.

SOME ACCOUN'T of Dr. GALL'S NEW THEORY of PHYSIOGNOMY, founded upon the Anatomy and Pliysiology of the Brain, and the Form of the Skull. With the Critical Strictures of c. W. Hufeland, M.N. Author of the Art of prolongiag Life, \&c. In 1 vol. 8vo. Price $6 s$. in Boards.

THOUGHTS on the EFFECTS of the BRITISH GOVERNMENT on the STATE OF INDIA; accompanied with Hinrs coucerning the Meals of convey. ing Civil and Religious Instruction to the Natives of that Country. By the Rev WILLIAM TENNANT, LL. D. Late Chaplain to his Majesty's 'Troops in Bengal. In I vol. Evo. Price $7 s$. in Boards.

THE MANUAL of NOBILITY, exhibiting the Distinctions of Armorial and Heraldic Bearings; the several Degrces and Rank of Nobillty; a complete LIst of the Peers of the United Kingdom; their Surnames, Titles, and Time of Creation; a Table of Precedency; an Historical Acconnt of the Great Officers of State, and of His Majesty's Household, from their first Institution of Office, with a Variety of other useful and interesting Information, \&c. \&cc. \&c.

Collected from the best Authorities. Price 2s. $6 \mathrm{~d}$.

THE GEORGiCS of Publius Virgilius MAIRO, translated in to English Blank Verse. BY JAMES R. DEARE, LL.D.

Vicar of Bures, in the County of Suffolk, and Chaplain in Ordinary to his Majesty. In post 8vo. embellished with a Hear of Virgil, and hot pressed. Price $7 s$. in extra Bds. "Mr. Deare is one of the most faithful transiators that we have giet with; he has given the genuine sense of his author almost in equivalent words, and almost in similar versification. The cursen of his translation nevertlieless is Benerally easy and clear, his words are musically arranged, and his pauses are well varied. Eclec. Rev.

A TRANSLATION of the GEORGICS of PUBLIUS VIRGILIUS MARO, with the original Text; and Notes critical, and illustrative of ancient and modern IIusbandry. BY WILLIAM STAWELL, A M.

Rector of Kilmalooda, in the Dincese of Cork.

In crown Svo. illustrated with Engravings, and hotpressed. Price 12s. iu Boards.

AN INTRODUCTION to the KNOW. LEDGE of rare and valuable Editions of the GREEK aud LATIN CLASSICS, including an Account of Polyglot Bibles; the best Greek, and Greek and Latin Ediliuns of the Septuagint and New Testiment, the Scriptones de Re IRustica, Greek Romances, and Lexicons, and Grammars. By the Rev. T. FRUGNALL DIBDIN, F.S.A and Biographical Notices (chiefly of English Anthors, price $18 s$. in Boards.

"We are decidedily of opinion tlat no bibliographical co:lection can be complete without Mr. Dibdiu's volumes, which are, independent of the solid informalion they contain, irequently enlivened by literary anecdotes, and rendered generally interest. ing by great variety of observation and aculeness of remark." srit. crit.

The NEW UNIVERSAL GAZETTEER or, GEOGRAPHICAL DICTIONARY, containing a Description of all the Empires, Kingdons, States, Provinces, Cities, Towns, rorts, Seas, Harbours, Rivers, Lakes, Mountains, and Capes, in the known World; with the Go. verument, Customs, Mauners, and Religion of the Inha bitants; the Extent, Boundailes, and natural Production of each Country; the Trade, Manufactories, aud Curio sities of the cities and Towns, collected from the bes Authors; their Longitude, Latitude, Bearings, and Dis tances, from the best and most anthentic Charts.

By the Rev. CLEMENT CRUTTWELL.

In 4 large vols. 8vo. Price $3 l$. 1:ss. ód. in Eoards, with out the Atlas; and $5 l .5 s$, with the Atlas, half-bomd. Als the Atlas separate, containing 28 whole Sheet Maps neatly coioured, and half-bonnd. Price 1l. 11 s. $6 \mathrm{~d}$.

The BRITISH CICERO; or, a selection of the most admirerl Speeches in the English Language, ar ranged under Three distinct Heads of Popular, Parliz mentary, and Judicial Oratory, with Historical IIlustri, tions. To which is pretixed, an Introduction to the Stud and Practice of Eloquence. By THOMAS BROWN, L.L.D Author of "Veridarium Peticnn," the "Union Dic tionary," \&cc. \&c. In 3 vols, Svo. Price $1 l, 11 \mathrm{~s}, 6 d$. Bds.

CATALOGUE RAISONNE of the PIC TURES belonging to the Mlost Honourable the Marqquis o STAFFORD, in the Gallery of Cleveland House, London comprising a List of the Pictures, and some illustrative Anecrotes, will critical and descriptive Accounts of the Execution, Composition, and characteristic Merits of th principal Paintings; emtellished with a V'iew of the Nev Gallery, and a Plan of the whole Suite of Apartments. By JOHN BRITTON, F.S.A.

Price $7 s$. in demy 8vo. and 10s. in royal tivo.

ILLUSTRATIDNS of the LAY of the LAST MINSTREL, consisting of Twelve Views of the tivis:Bothwick, Ettrick, Yarrow, Tiviot, and Twecd. Engrated by James Heatl, R.A. from Drawings taken on the Spot. By J. SCHETKY, Esq. of Oxford.

To which are aflixed, Descriptions and Annotations, by Mr. Walter Scott. In I vol. 4to. Price $1 l$. 11s, $6 d$.; or on Jarge Paper, and Proof Impressions, price $\& l$. $12 s, b d$. in Boards.

NEW OBSERVATIONS on the NATURAL HISTORY OF BEES. By FRANCIS HUBER. Translated from the Original. In 1 vol. $12 \mathrm{mo}$. The Se cond Edition. Price $6 s$. $6 d$. in Boards

A Genuine and corrected REPORT of the SPEECHES of the late Right Honourable WILIIAM PITT, iu the House of Commons, from his Entrance in Partia. ment in 1781 to the Close of the Session in 1805. The St. cond F.dition. Dedicaled, hy Permission, to Lord Grenville, and aided by Communications from distinguisher Members of both Jlouses of l'arliament. In 3 rots. er Price 1l. 11 s. $6 d$. in Boards.

ENQUIRIES, Historical and Moral, specting the Cliaracter of Nations, and th. Progress Society, exhibiting a View of the moral History of $M$ of the Manters and Characters of Nations, and the cumstances on which these are dependant; also a of Society as it exists itt the earlier Stages of its Progre BY HUGH MURRAY.

In 1 vol. Svo. Price 10s. Gd. in Eoards.

I.ETTERS written during a short Residen in SPAIN and PORTUGAL. By ROBERT SOUTH? In \& vols. foolscap 8vo. A new Edition, corrected amended. Price los. fid. in Boards.

'The HISTORY of the RISE, PROGRE and ACCOMPLISHMENT of the ABOLITION of SLAVE TRADE. BY T. CLARKSON, M.A

In 2 vols. 8vo. with illustrative Engraviugs. Price $1 l$ In 2 vols. cruwn 8vo. Whe $3 \mathrm{~d}$ erlit. with additional Authors, $l$ in Boards. 




\section{OK45.S5 1809 \\ Smith James Edward/An introduction to gen \\ mith James Edward An introduccion to

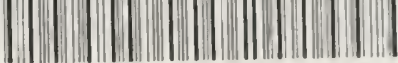 35185001039344}




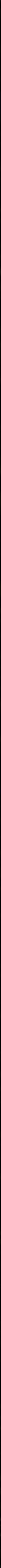

